Taís Rizzo Moreira

Alexandre Rosa dos Santos

Telma Machado de Oliveira Peluzio

Lucas Louzada Pereira

Gilson Fernandes da Silva

\title{
INTELIGÊNCIA ARTIFICIAL APLICADA ÀS CIÊNCIAS FLORESTAIS E AGRICULTURA
}




\author{
Taís Rizzo Moreira \\ Alexandre Rosa dos Santos \\ Telma Machado de Oliveira Peluzio \\ Lucas Louzada Pereira
}

Gilson Fernandes da Silva

\title{
INTELIGÊNCIA ARTIFICIAL APLICADA ÀS CIÊNCIAS FLORESTAIS E AGRICULTURA
}

\author{
ALEGRE - ES \\ CAUFES \\ 2021
}




\section{INTELIGÊNCIA ARTIFICIAL APLICADA ÀS CIÊNCIAS FLORESTAIS E \\ AGRICULTURA}

Copyright (C) 2021, Taís Rizzo Moreira

https://doi.org/10.29327/552680

Título original em português:

Inteligência artificial aplicada às ciências florestais e agricultura

Editoração e Diagramação

Taís Rizzo Moreira (E-mail: taisr.moreira@ hotmail.com)

TODOS OS DIREITOS RESERVADOS - Qualquer parte desta publicação pode ser reproduzida, desde que citada a fonte. A violação dos direitos autorais (Lei n ${ }^{\circ}$ 9.610/98) é crime (art. 184 do Código Penal). Depósito legal na Biblioteca Nacional, conforme Decreto $\mathrm{n}^{\circ} 1.825$, de 20/12/1907.

Dados Internacionais de Catalogação na publicação (CIP) (Câmara Brasileira do Livro, SP, Brasil)

Inteligência artificial aplicada às ciências florestais e agricultura [livro eletrônico] / Taís Rizzo Moreira ... [et al.]. -- Alegre, ES: CAUFES, 2021.

PDF.

Outros autores: Alexandre Rosa dos Santos, Telma Machado de Oliveira Peluzio, Lucas Louzada Pereira, Gilson Fernandes da Silva.

Bibliografia.

ISBN 978-65-86981-18-6

DOI: $10.29327 / 552680$

1. Agronegócio 2. Ciências agrárias 3. Engenharia florestal 4. Inteligência artificial - Inovações tecnológicas I. Moreira, Taís Rizzo. II. Santos, Alexandre Rosa dos. III. Peluzio, Telma Machado de Oliveira. IV. Pereira, Lucas Louzada. V. Silva, Gilson Fernandes da.

\section{Índice para catálogo sistemático:}

1. Inteligência artificial: Engenharia 621.399

Aline Graziele Benitez - Bibliotecária - CRB-1/3129 
Dedico este livro a minha família, meus pais, irmão, cunhada, sobrinhos e a todos que me auxiliam, em especial, ao meu companheiro de vida e profissão, Jeferson.

Taís Rizzo Moreira 


\section{PREFÁCIO}

Inteligência artificial (IA) está relacionado à capacidade de máquinas realizarem atividades de um modo considerado inteligente. IAs também podem "aprender por si mesmas" graças a sistemas de aprendizado que analisam grandes volumes de dados, possibilitando a elas ampliarem seus conhecimentos. O modo como um computador representa um problema, as variáveis que ele usa e os operadores aplicados a essas variáveis podem fazer a diferença entre um algoritmo eficiente e um algoritmo que não funciona. Desta forma, uma técnica de IA deve representar eficientemente o conhecimento, ser concisa, facilmente armazenável e recuperável, legível pelo especialista e passível de representação de restrições, de forma a facilitar o trabalho de inferência.

A aplicação da Inteligência Artificial no mercado florestal e agrícola ainda é bastante recente, mas já se expandiu para algumas atividades do setor e tem sido utilizada no monitoramento e no combate a incêndios, identificação de pragas, caracterização de áreas produtivas, planejamento, otimização florestal, sensoriamento remoto, cálculos de risco e de vulnerabilidade.

A interação de diferentes fatores, a otimização do tempo de resposta e a eficiência do sistema fazem com que as diferentes técnicas de inteligência artificial auxiliem na tomada de decisão. Além disso, problemas, que demonstrem maior grau de complexidade, que necessitem da interação de diferentes áreas e fatores, como a associação das condições edafoclimáticas e ambientais para o planejamento de cultivos agrícolas, têm sido solucionados por meio da associação de diferentes técnicas de IA.

As técnicas e conceitos de IA são amplos e complexos, mas tentamos neste livro abordar de forma simples algumas delas. Uma vez que você tenha compreendido a definição de IA e conhecido mais sobre a sua história, a melhor maneira de mergulhar no assunto é por meio de exemplos práticos, apresentamos nesta obra os casos de uso no campo das Ciências Florestais e da Agricultura, tais informações estão contempladas nos capítulos deste livro. 


\section{AUTORES}

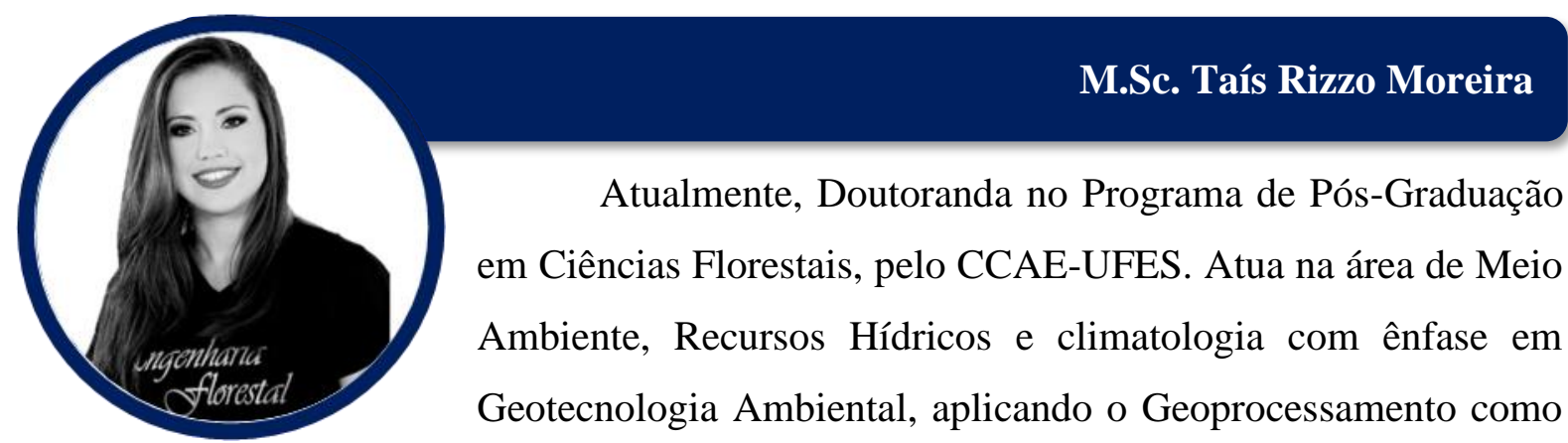

Ferramenta de Auxílio ao Desenvolvimento Científico e Tecnológico. Possui graduação em Engenharia Florestal pela Universidade Federal do Espírito Santo (2017) e mestrado em Ciências Florestais na linha de pesquisa de meio ambiente e recursos hídricos pela Universidade Federal do Espírito Santo (2019).

\section{Dr. Alexandre Rosa dos Santos}

Professor Titular da UFES. Possui Graduação em Agronomia pela Universidade Federal do Espírito Santo (1997), Licenciatura em Letras (Português) pelo Instituto Superior de Educação Elvira Dayrell (ISEED) (2017), Licenciatura em Letras

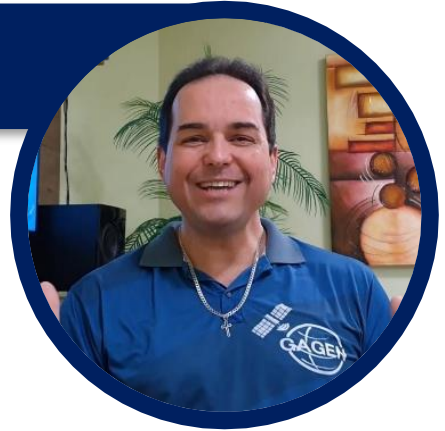
- Português e Inglês pela Universidade de Franca (UNIFRAN) (2018). Especialização em Metodologia Ensino da Língua Portuguesa e Inglesa pela Universidade Candido Mendes (UCAM) (2016), Mestrado em Meteorologia Agrícola pela Universidade Federal de Viçosa (1999), Doutorado em Engenharia Agrícola pela Universidade Federal de Viçosa (2001) e Pósdoutorado em Ciências Florestais pela Universidade Federal de Viçosa (2016).

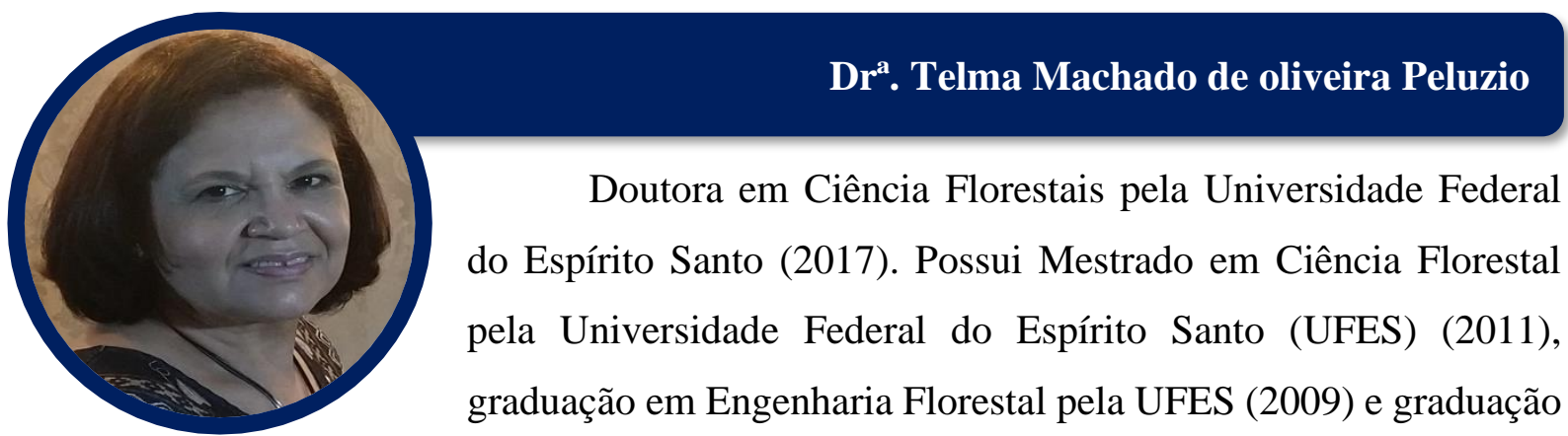
em Educação Física pela Universidade Federal de Viçosa (1988). Atualmente é professor D4 C do Instituto Federal de Educação, Ciência e Tecnologia do Espírito Santo, campus de Alegre. Tem experiência na área de Recursos Florestais e Engenharia Florestal, com ênfase em 
Geoprocessamento e Manejo de Bacias Hidrográficas, atuando principalmente nos seguintes temas: topo de morro, sistemas de informações geográficas e áreas de preservação permanentes.

\section{Dr. Lucas Louzada Pereira}

Lucas Louzada Pereira é Bolsista de Produtividade Desen. Tec. e Extensão Inovadora 2 - CNPq, Bolsista de Produtividade do Ifes - modalidade PP-1, possui Doutorado em Engenharia de Produção pela Universidade Federal do Rio Grande Sul (2017), Mestre em Engenharia de Produção pela UENF (2012). É Professor do Instituto Federal de Educação, Ciência e Tecnologia do Espírito Santo, Ifes, campus Venda Nova do Imigrante. Atua com pesquisas voltadas para o controle de qualidade em sistemas de produção, controle de processos, com enfoque especial na cafeicultura. Possui atuação nos estudos dos processos de fermentação espontânea e induzida no processamento via-úmida, desenvolve pesquisas na área de análise sensorial e torração do café. É Q-Grader licenciado pelo Coffee Quality Institute e Coordenador do Laboratório de Análise e Pesquisa em Café LAPC do Instituto Federal do Espírito Santo.

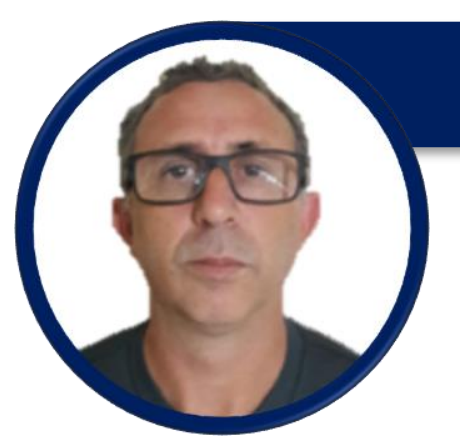

\section{Dr. Gilson Fernandes da Silva}

Possui graduação em Engenharia Florestal pela Universidade Federal de Viçosa (1992), mestrado em Ciências Florestais pela Universidade Federal de Viçosa (1995), doutorado em Ciências Florestais pela Universidade Federal de Viçosa (2001), pós-doutorado pela Universidade de Brasília-UnB (2002) e pós-doutorado pela Universidade da Flórida, Estados Unidos (2013). Bolsista de produtividade em pesquisa do CNPq, atualmente é professor Titular do Departamento de Ciências Florestais e da Madeira da Universidade Federal do Espírito Santo. Tem experiência na área de Recursos Florestais e Engenharia Florestal, com ênfase em Ordenamento Florestal, atuando principalmente nos seguintes temas: Mensuração Florestal, Manejo Florestal e Otimização. 


\section{COLABORADORES}

GAGEN - Geotechnology applied to global environment.

PPGCFL - Programa de Pós-graduação em Ciências Florestais da UFES.

UFES - Universidade Federal do Espírito Santo.

LaMFlor - Laboratório de Mensuração e Manejo Florestal.

Ifes - Instituto Federal de Educação, Ciência e Tecnologia do Espírito Santo - Campus Venda Nova do Imigrante.

Sicoob Sul-Serrano - Sistema de Cooperativas de Crédito.

FAPES - Fundação de Amparo à Pesquisa e Inovação do Espírito Santo.

CAPES - Coordenação de Aperfeiçoamento de Pessoal de Nível Superior.

CNPq - Conselho Nacional de Desenvolvimento Científico e Tecnológico

Mundo da Geomática - Portal Mundo da Geomática. 


\section{SUMÁRIO}

CAPÍTULO 01 - FUNDAMENTOS TEÓRICOS E PRÁTICOS DA INTELIGÊNCIA

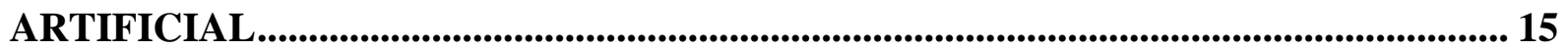

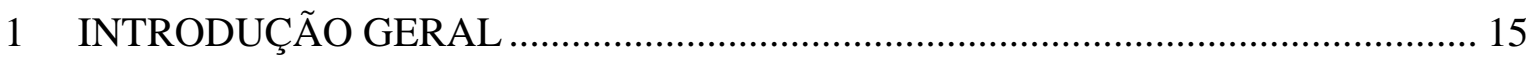

2 HISTÓRICO DA INTELIGÊNCIA ARTIFICIAL ………........................................ 17

2.1. Surgimento da Inteligência artificial.....................................................................................

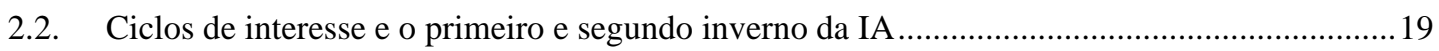

2.3. A terceira onda da Inteligência Artificial ............................................................................

3 PARADIGMAS E TIPOS DE INTELIGÊNCIA ARTIFICIAL ................................. 22

4 FUNDAMENTOS DA INTELIGÊNCIA ARTIFICIAL_............................................. 25

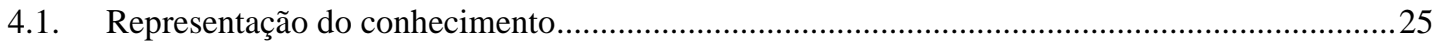

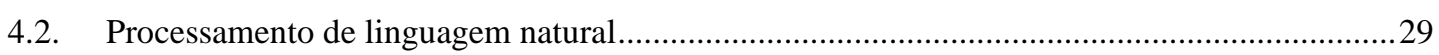

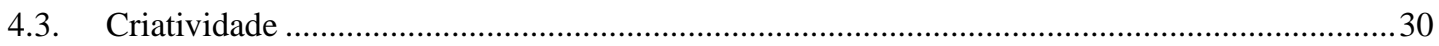

5 TÉCNICAS DE INTELIGÊNCIA ARTIFICIAL _..................................................... 31

5.1. Lógica Nebulosa ou Lógica Fuzzy …………………........................................................

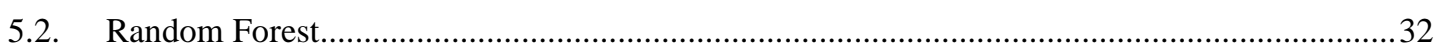

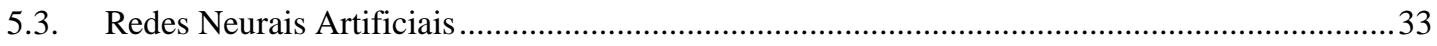

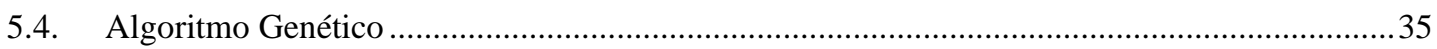

6 APLICAÇÕES DA INTELIGÊNCIA ARTIFICIAL EM CIÊNCIAS FLORESTAIS 36

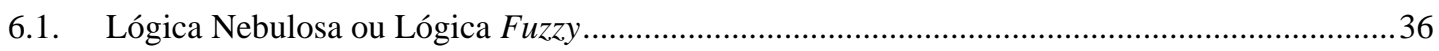

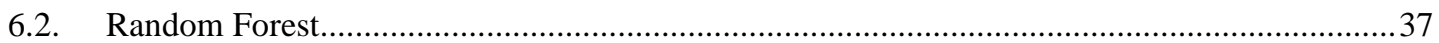

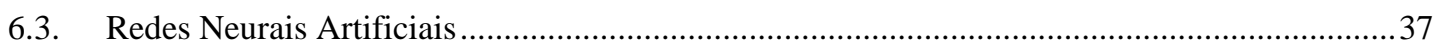

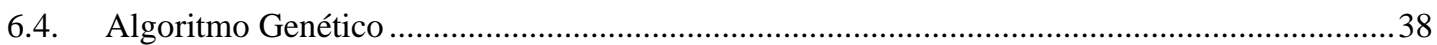

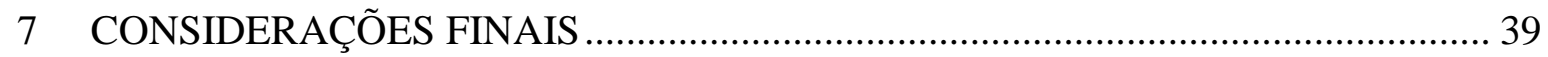

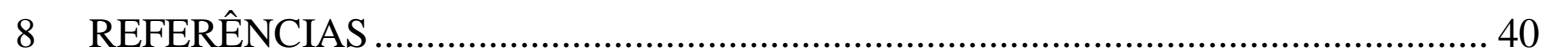

CAPÍtUlo 02 - LÓGICA FUZZY: FUNDAMENTOS TEÓRICOS E

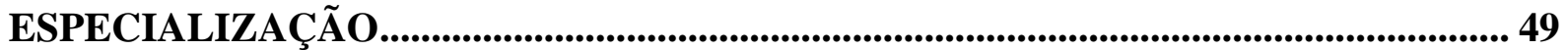

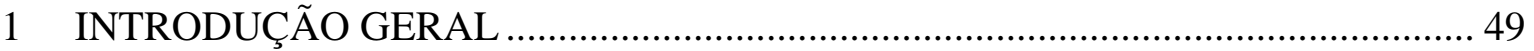

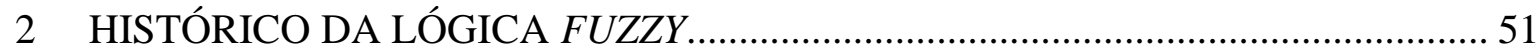

3 OBJETIVOS E METODOLOGIA GERAL DA LÓGICA FUZZY …........................ 52

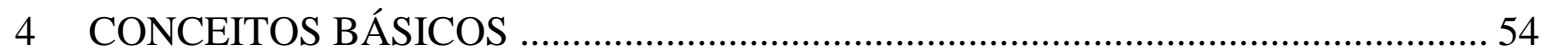

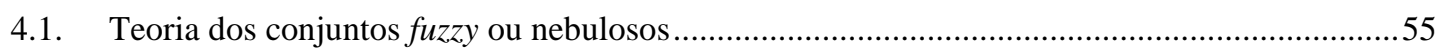

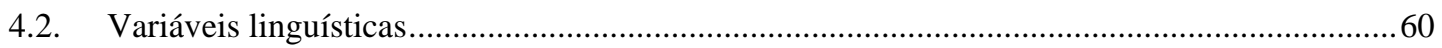


4.3. Funções de pertinência 61

4.4. Controladores fuzzy

5 APLICAÇÕES DA LÓGICA FUZZY ................................................................... 73

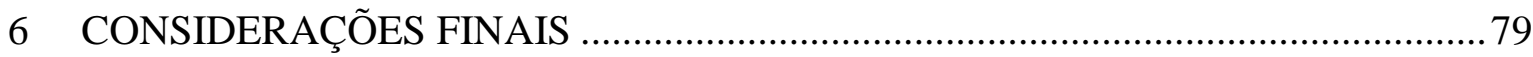

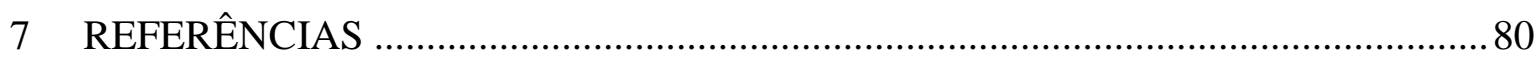

CAPÍTULO 03 - ÁRVORE DE DECISÃO E RANDOM FOREST: FUNDAMENTOS

TEÓRICOS E APLICAÇÕES ..................................................................................................8 87

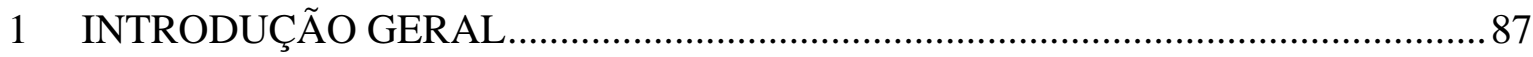

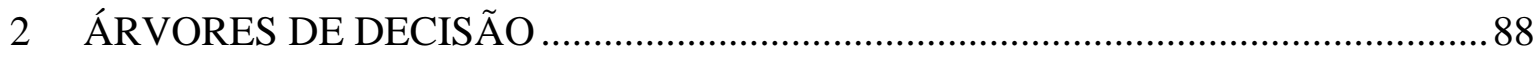

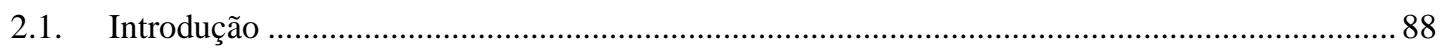

2.2. Critérios de seleção de atributos (atributos para cada nó) …............................................... 90

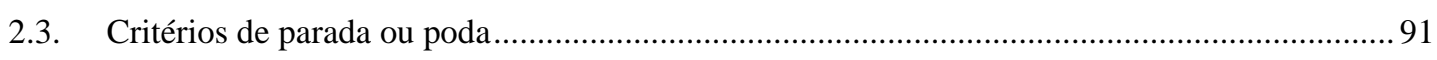

2.4. Algoritmos de indução de árvores de decisão .............................................................. 93

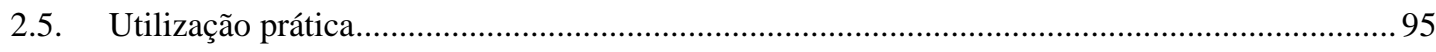

3 RANDOM FOREST .......................................................................... 104

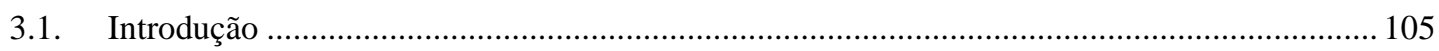

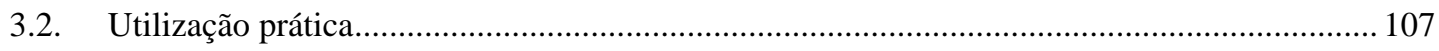

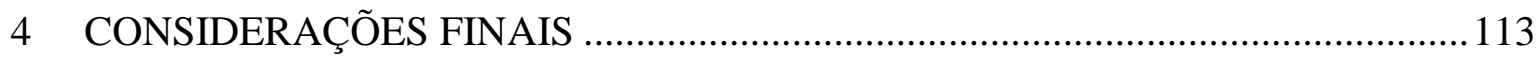

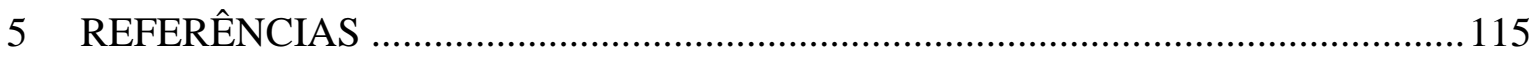

CAPÍTULO 04 - DEEP LEARNING PARA A CLASSIFICAÇÃO DE IMAGENS......121

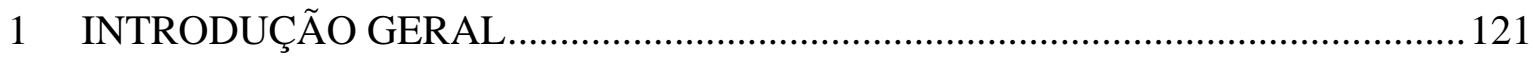

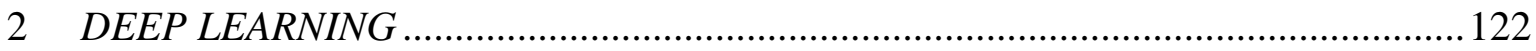

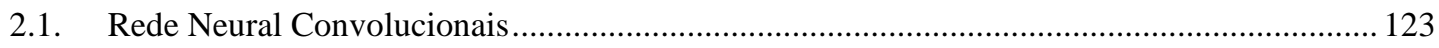

3 FERRAMENTAS E BIBLIOTECAS.............................................................. 129

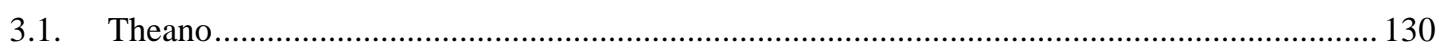

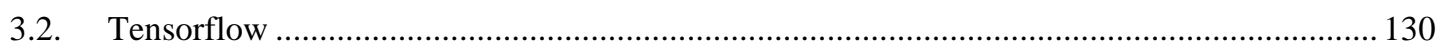

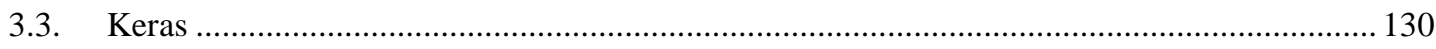

4 APLICAÇÕES DE DEEP LEARNING EM CLASSIFICAÇÃO DE IMAGENS ..... 131

4.1. Classificação de área ocupada por uma espécie de gramínea.............................................. 131

4.2. Classificação de pilhas de madeira .............................................................................. 135

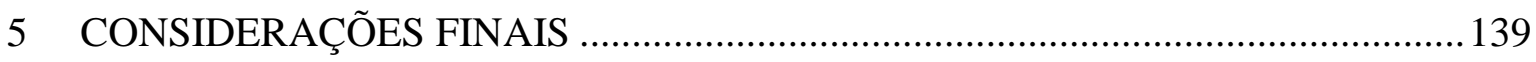

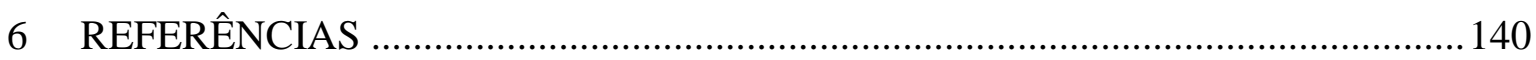


APÊNDICES

1 APÊNDICE A - Script Fuzzy C-Means (Cap. 02) .

2 APÊNDICE B - Script para obtenção da árvore de regressão (Cap. 03)................... 148

3 APÊNDICE C - Script para cálculo da random forest (Cap. 03) ............................. 150

4 APÊNDICE D - Script de classificação de área ocupada por gramínea (Cap. 04) ... 152

5 APÊNDICE E - Script de classificação de pilhas de madeira (Cap. 04) ................... 172 


\section{ÍNDICE DE FIGURAS}

Figura 1.1 - Explicação visual da relação entre IA, Machine Learning e Deep Learning. ...... 16

Figura 1.2 - Linha do tempo contendo os principais acontecimentos do surgimento da

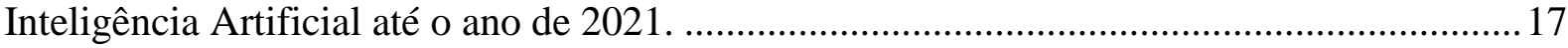

Figura 1.3 - Classificação da IA quanto ao método de solução de problemas.........................22

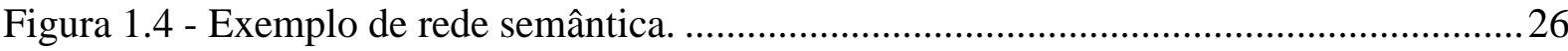

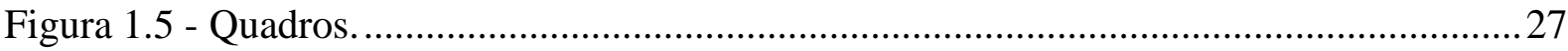

Figura 1.6 - Representação procedimental do conhecimento..................................................29

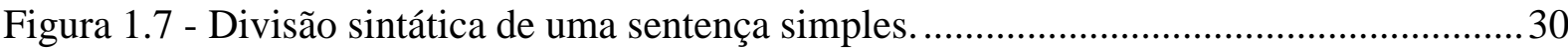

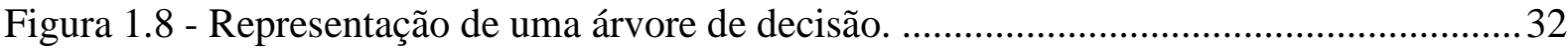

Figura 1.9 - Representação de uma Rede Neural. ................................................................... 33

Figura 2.1 - Analogia para diferenciar a lógica fuzzy da lógica clássica (booleana)...............50

Figura 2.2 - Componentes de um sistema de controle fuzzy .................................................53

Figura 2.3 - Comparação de conjunto crisp e fuzzy................................................................56

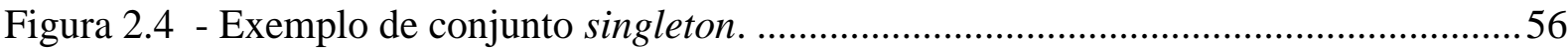

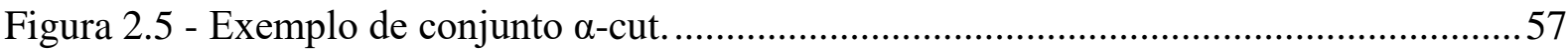

Figura 2.6 - Funções de pertinência para a variável temperatura............................................60

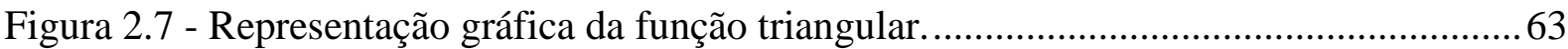

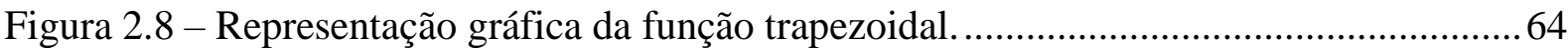

Figura 2.9 - Representação gráfica da função sigmoidal crescente......................................... 65

Figura 2.10 - Representação gráfica da função sigmoidal decrescente. ....................................66

Figura 2.11 - Representação gráfica da função gaussiana....................................................67

Figura 2.12 - Representação gráfica da função linear crescente e decrescente........................ 68

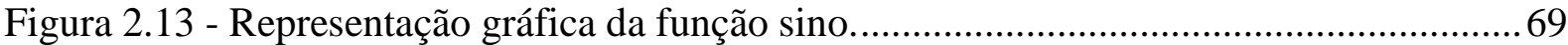

Figura 2.14 - Variáveis climáticas, altitude e pontos de análise do estado do Espírito Santo.. 75

Figura 2.15 - Agrupamento das regiões de acordo com as variáveis climáticas e altitude por meio da técnica de Fuzzy C-Means (Figura A- representa a correlação da variável com o cluster que ela pertence e com os demais clusters e a Figura B - representa os grupos formados pela técnica FCM)

Figura 2.16 - Mapa dos agrupamentos das regiões por meio das variáveis climáticas e altitude

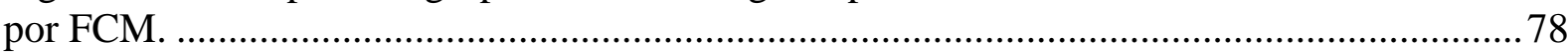

Figura 3.1 - Mapa de localização dos pontos de coleta de café...............................................96

Figura 3.2 - Resultado obtido através das variáveis de altitude (alt), precipitação (prec), temperatura (temp), umidade (umidade), radiação de onda longa (rad_long) e radiação de onda curta (rad_short).

Figura 3.3 - Resultado obtido através das variáveis de altitude (alt), precipitação (prec), temperatura (temp), umidade (umidade) e radiação de onda longa (rad_long).

Figura 3.4 - Resultado obtido através das variáveis de altitude (alt), precipitação (prec), temperatura (temp), umidade (umidade) e radiação de onda curta (rad_short).....................101 
Figura 3.5 - Resultado obtido através das variáveis de altitude (alt), precipitação (prec), temperatura (temp) e umidade (umidade).

Figura 3.6 -Resultado obtido através das variáveis de altitude (alt), precipitação (prec) e temperatura (temp). 103

Figura 3.7 - Resultado obtido através das variáveis de altitude (alt), precipitação (prec) e umidade (umidade). 104

Figura 3.8 - Estrutura do algoritmo Random forest (OOB, Out-Of-Bag, é para obter uma estimativa imparcial em execução do erro de predição conforme as RFs são construídas na fase de treinamento, que também é usada para determinar a importância da variável).

106

Figura 3.9 - Resultado obtido através das variáveis de altitude (alt), precipitação (prec), temperatura (temp), umidade (umidade), radiação de onda longa (rad_long) e radiação de onda curta (rad_short).

108

Figura 3.10 - Resultado obtido através das variáveis de altitude (alt), precipitação (prec), temperatura (temp), umidade (umidade) e radiação de onda longa (rad_long).

Figura 3.11 - Resultado obtido através das variáveis de altitude (alt), precipitação (prec), temperatura (temp), umidade (umidade) e radiação de onda curta (rad_short).

Figura 3.12 - Resultado obtido através das variáveis de altitude (alt), precipitação (prec), temperatura (temp) e umidade (umidade).

Figura 3.13 - Resultado obtido através das variáveis de altitude (alt), precipitação (prec) e temperatura (temp). 112

Figura 3.14 - Resultado obtido através das variáveis de altitude (alt), precipitação (prec) e umidade (umidade). 113

Figura 3.15 - Árvore de decisão considerando as variáveis preditoras: altitude, precipitação e umidade. Bebida estritamente mole - cafés acima de 85 pontos; Bebida mole - cafés de 80 a 84 pontos; e Bebida dura limpa - 75 a 79 pontos. 114

Figura 4.1 - Responsabilidade das camadas de um modelo de deep learning. 123

Figura 4.2 - Exemplo do funcionamento de uma camada convolucional. 125

Figura 4.3 - Esquema de rede neural convolucional. 126

Figura 4.4 - Filtro de maxpooling de tamanho 2X2. 128

Figura 4.5 - Arquitetura simplificada de uma Rede Neural Convolucional.

Figura 4.6 - Imagem da área em estudo (áreas mais claras são áreas com Elymus athericus).

Figura 4.7 - Gráficos de Perda (A) e de Acurácia (B) calculadas com base nas projeções do primeiro modelo.

Figura 4.8 - Resultado de predição sobre os dados de validação com base no primeiro modelo. 134

Figura 4.9 - Gráficos de Perda (A) e de Acurácia (B) calculadas com base nas projeções do segundo modelo.

Figura 4.10 - Resultado de predição com base no segundo modelo e comparação com a máscara. 135

Figura 4.11 - Gráficos de Perda (A) e de Acurácia (B) calculadas com base nas projeções do primeiro modelo. 136 
Figura 4.12 - Resultado de predição sobre os dados de validação com base no primeiro modelo. 137

Figura 4.13 - Gráficos de Perda (A) e de Acurácia (B) calculadas com base nas projeções do primeiro modelo. 138

Figura 4.14 - Resultado de predição com base no segundo modelo e comparação com a máscara. 138 


\section{ÍNDICE DE TABELAS}

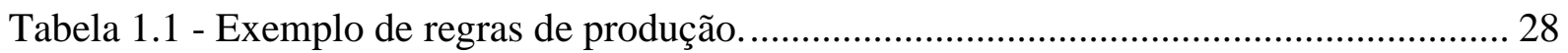

Tabela 1.2 - Analogia entre Algoritmo genético e o sistema natural...................................... 35

Tabela 2.1 - Pontos contendo as informações climatológicas analisadas. ............................... 75

Tabela 3.1 - Argumentos utilizados na função rpart.control ................................................. 97 


\section{CAPÍTULO 01 - FUNDAMENTOS TEÓRICOS E PRÁTICOS DA INTELIGÊNCIA} ARTIFICIAL

Taís Rizzo Moreira e Alexandre Rosa dos Santos

https://doi.org/10.29327/ 552680.1-1

\section{INTRODUÇÃO GERAL}

O que hoje conhecemos como Inteligência Artificial (IA) é um ramo da ciência da computação cujo o termo surgiu oficialmente em 1956, mas que possui princípios que datam de tempos mais remotos, que baseiam-se em ideias filosóficas, científicas e tecnológicas herdadas de outras ciências, entre elas a lógica, que existe há 23 séculos (FRANCO, 2014).

Não há um consenso na comunidade científica quanto a uma definição de inteligência artificial. O próprio termo inteligência possui uma série de definições e interpretações que tornam o seu entendimento mais amplo (MEDEIROS, 2018). Para melhor entendimento, podemos partir do objetivo da IA, que é o desenvolvimento de paradigmas ou algoritmos que requeiram máquinas para realizar tarefas cognitivas, as quais são executadas, normalmente, por humanos (FRANCO, 2014; MEDEIROS, 2018).

Um sistema de IA deve ser capaz de fazer três coisas (HAYKIN, 2007):

1 Armazenar conhecimento;

2 Aplicar o conhecimento armazenado para resolver problemas, e;

3 Adquirir novo conhecimento através da experiência.

A IA pode ser subdividida em camadas ou em partes que a compõe, e dessa forma é introduzido os conceitos de Machine Learning (ML) e Deep Learning (DL). Machine Learning, como o próprio nome já sugere, é o processo de aprendizado contínuo de máquina. Consiste basicamente em fornecer dados de entrada e assim a máquina pode aprender com esses dados e elaborar saídas que satisfaçam a situação problema. Algoritmos de Machine Learning são estruturados com equações pré-definidas para organizar e executar os dados conforme a demanda (SHARMA; SHARMA; JINDAL, 2021). Um exemplo do uso de Machine Learning é a identificação de spams, onde inicialmente é fornecido e-mails rotulados como spams e a partir disso o software anti-spam deverá identificar, nos próximos e-mails que forem recebidos, padrões para que possa classificá-los como spam ou não.

Um seguimento do Machine Learning é o Deep Learning que capacita a máquina a realizar tarefas mais complexas, como reconhecimento de fala, identificação de imagens e realizar previsões. O Deep Learning estabelece parâmetros básicos sobre esses dados e treina o 
algoritmo para aprender a usar várias camadas de processamento no reconhecimento de padrões (MANCO et al., 2021). Trata-se de imitar o aprendizado intuitivo humano, onde, com a experiência, tem-se a capacitação de executar uma série de atividades.

Dessa forma, interessa a máquina analisar os dados, tornando desnecessário a intervenção humana para fornecer explicitamente todo o conhecimento necessário para a execução da tarefa proposta (GOODFELLOW et al., 2016). A exemplo disso, tem o reconhecimento de fala onde a máquina deve analisar os padrões de intensidade, frequência, volumes etc. e chegar a uma aproximação quase que perfeita, capacitando-se a reconhecer quando a pessoa, cujo a voz foi analisada, falar.

Estudos na área de Inteligência Artificial, Machine Learning e Deep Learning podem ser categorizados em esferas. A Inteligência artificial surge como uma esfera global contendo o Machine Learning, que por sua vez engloba o Deep Learning (Figura 1.1). Nesse sentido, no Deep Learning as redes neurais são mais sofisticadas, de tamanho muito maior e com habilidade superior de extrair e representar informações (LEE, J.-G. et al., 2017).

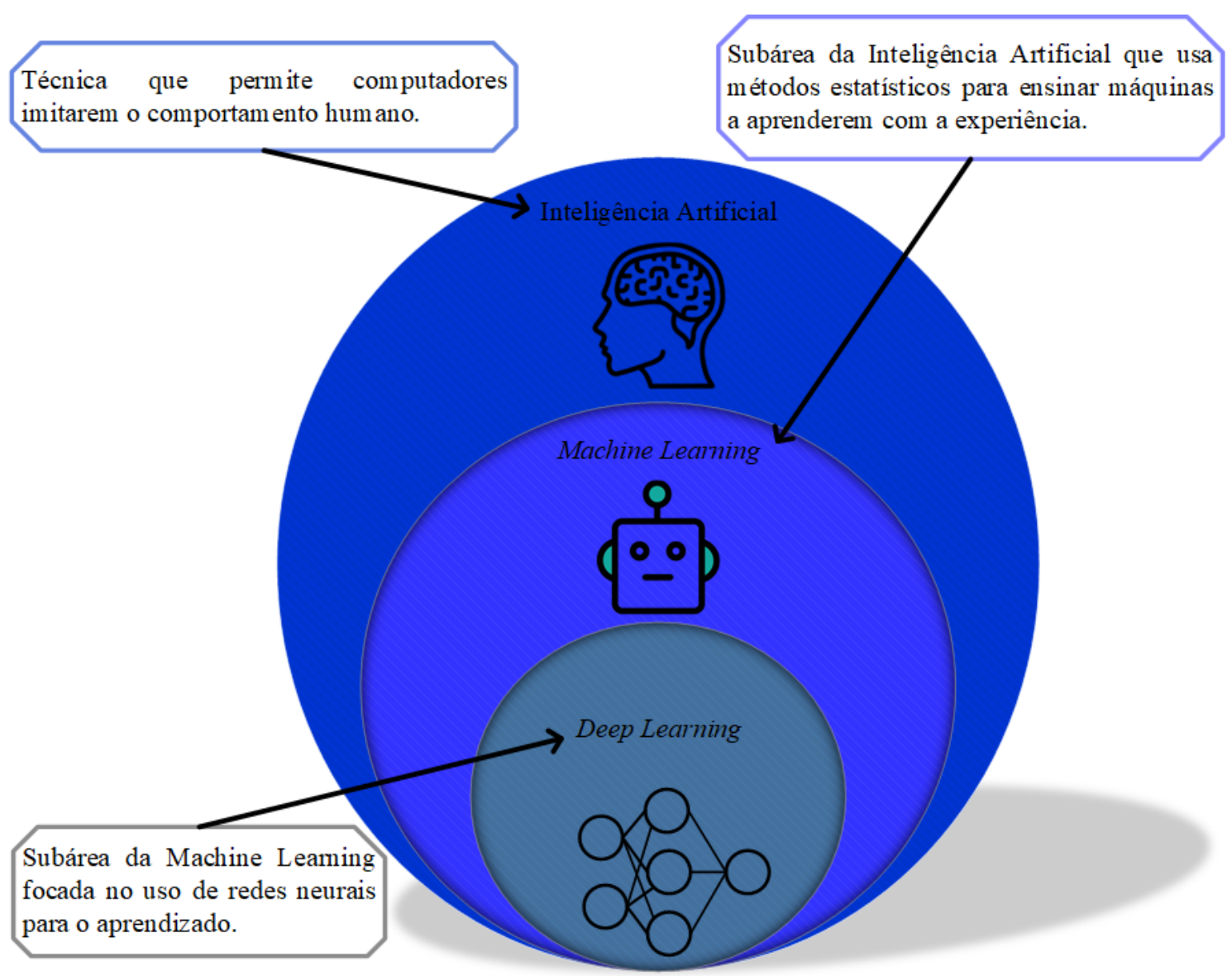

Figura 1.1 - Explicação visual da relação entre IA, Machine Learning e Deep Learning. 


\section{HISTÓRICO DA INTELIGÊNCIA ARTIFICIAL}

Como o desenvolvimento e o interesse no campo de Inteligência Artificial continuam a se expandir, é importante apreciar sua história, que será apresentada de forma resumida a seguir (Figura 1.2):

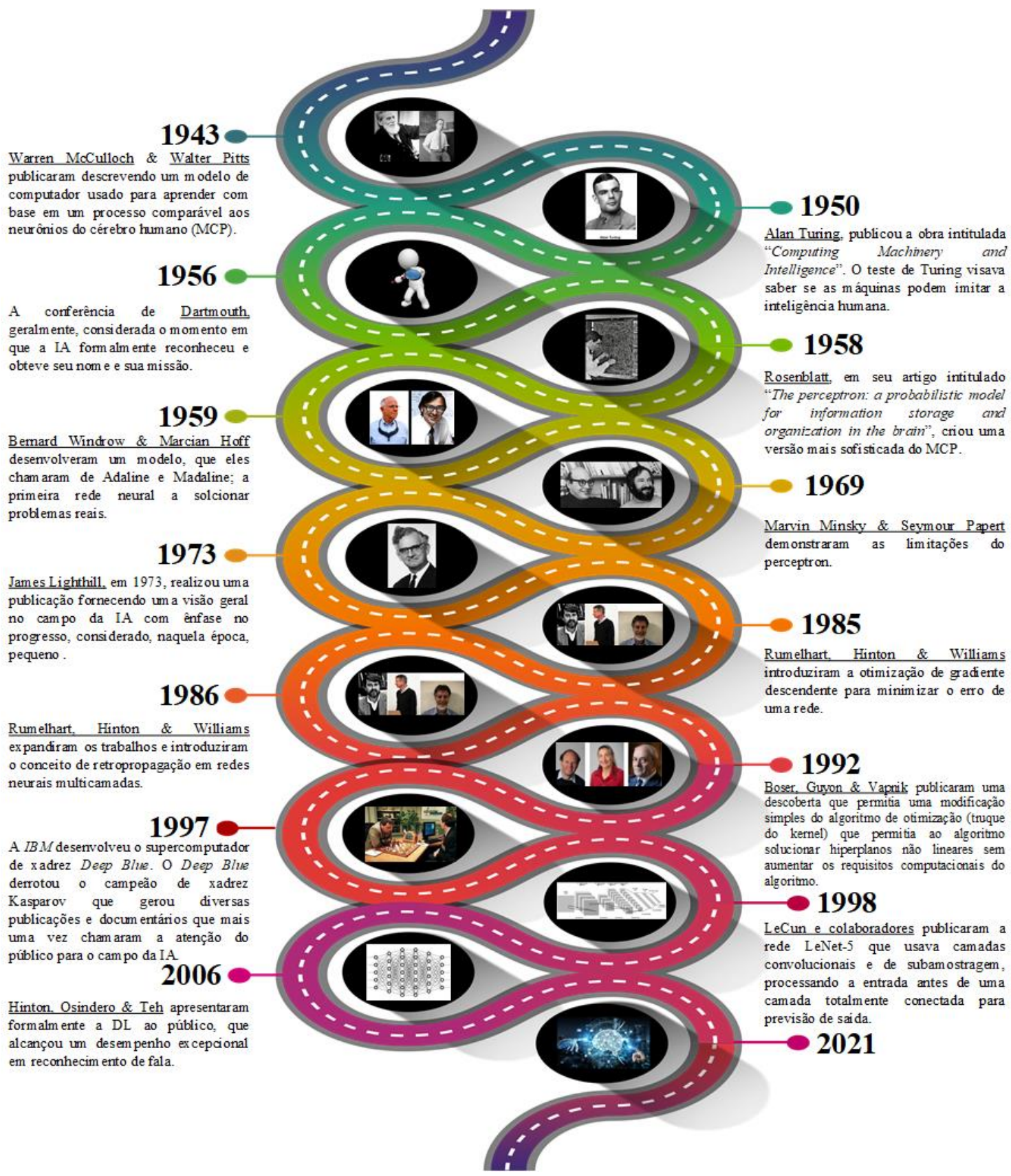

Figura 1.2 - Linha do tempo contendo os principais acontecimentos do surgimento da Inteligência Artificial até o ano de 2021.

\subsection{Surgimento da Inteligência artificial}

Os primeiros modelos de IA tentaram simular as funções de um único neurônio. Os modelos mais simples começaram como funções de entrada e saída simples (feedforward). No entanto, nas décadas seguintes, eles se tornaram mais sofisticados com a adição de funções mais 
complexas, camadas adicionadas e feedback bidirecional, eventualmente se tornando os blocos de construção das redes neurais profundas dos dias modernos ou DL (CHANG, A. C., 2020).

Uma das primeiras publicações alusivas à IA foi um trabalho de McCulloch e Pitts em 1943 (MCCULLOCH; PITTS, 1943). Esta publicação descreve um modelo de computador usado para aprender com base em um processo comparável aos neurônios do cérebro humano. O modelo descrito em sua publicação foi referido como neurônio MCP, e funcionou recebendo entradas booleanas (a lógica booleana se refere a um ramo da álgebra referente a afirmações verdadeiras/falsas), processando-as de uma maneira predefinida e se o valor processado excedeu um certo limite, o neurônio MCP produziria um valor. Ao exceder o limite, o neurônio MCP é considerado disparado ou ativado. Embora esse modelo simples fosse eficaz para tarefas de processamento simples, ele tinha muitas limitações, por exemplo, gerava uma saída binária e exigia um conjunto fixo de valores para os pesos (MUTHUKRISHNAN et al., 2020).

Com o desenvolvimento dos primeiros modelos de IA e o inevitável progresso no campo, uma metodologia sistemática para avaliar a inteligência de um modelo era necessária. Um dos primeiros trabalhos introduzindo o tópico da inteligência de um modelo foi publicado por Alan Turing, intitulado "Computing Machinery and Intelligence", em outubro de 1950 (TURING, 1950, 2009). Turing levantou a questão de saber se as máquinas podem imitar a inteligência humana e introduziu um teste para modelos de inteligência. Este teste, conhecido como Teste de Turing, envolve um interrogador humano questionando um respondente humano e um respondente de máquina. A tarefa do interrogador é identificar qual respondente é a máquina. Se o interrogador não for capaz de discernir as respostas da máquina das respostas humanas com mais frequência do que o que seria esperado ao acaso, a máquina é considerada como tendo passado no Teste de Turing (KUBASSOVA et al., 2021; MUTHUKRISHNAN et al., 2020).

A conferência de Dartmouth de 1956 é geralmente considerada o momento em que a AI formalmente reconheceu e obteve seu nome e sua missão (MCCORDUCK, 2004). Esta conferência foi organizada por Marvin Minsky, John McCarthy, Claude Shannon e Nathan Rochester e pode ser considerada o "nascimento" do campo da IA, incluindo a afirmação de que "todos os aspectos da aprendizagem ou qualquer outra característica da inteligência pode ser descrita com tanta precisão que uma máquina pode ser feita para simulála"(MUTHUKRISHNAN et al., 2020).

Em 1958 Rosenblatt, em seu artigo intitulado "The perceptron: a probabilistic model for information storage and organization in the brain", criou uma versão mais sofisticada do MCP, esta versão apresentava algumas melhorias (ROSENBLATT, 1958). Este novo modelo, perceptron, procesava entradas não-booleanas e incluía pesos $\left(\omega_{1}, \omega_{2}, \omega_{3}, \ldots \omega_{n}\right)$ no modelo para 
dimensionamento. Além disso, uma função não linear $f$ processa a soma dos produtos dos valores de entrada e seus pesos correspondentes. Isso proporcionou mais flexibilidade ao modelo e mais tarde se tornou um dos blocos de construção das redes neurais modernas (KUBASSOVA et al., 2021; MUTHUKRISHNAN et al., 2020).

Em 1959, Bernard Widrow e Marcian Hoff, de Stanford, desenvolveram modelos denominados "ADALINE" e "MADALINE". ADALINE foi desenvolvido para reconhecer padrões binários de modo que, se ele estivesse lendo bits de transmissão de uma linha telefônica, poderia prever o próximo bit. MADALINE foi a primeira rede neural aplicada a um problema do mundo real, usando um filtro adaptativo que elimina ecos nas linhas telefônicas. Embora o sistema seja tão antigo como os sistemas de controle de tráfego aéreo, ele ainda está em uso comercial (WAMBA et al., 2021).

\subsection{Ciclos de interesse e o primeiro e segundo inverno da IA}

Alguns pesquisadores afirmam que ao longo da história da IA, já houve 2 invernos de IA. O primeiro inverno de IA foi entre os anos de 1974 e 1980. Antes desses anos, o perceptron de Rosenblatt reuniu muito entusiastas e demonstrou capacidade para modelar sistemas simples. No entanto, as expectativas irrealistas iniciais da IA naquela época começaram a se tornar aparentes, conforme discutido em 2 publicações apresentadas a seguir (MUTHUKRISHNAN et al., 2020). Em 1969, Minsky e Papert demonstrou as limitações do perceptron ao identificar que uma função booleana não poderia ser modelada usando um perceptron com 2 entradas e sem manipulação significativa do usuário (MINSKY; PAPERT, 1969). A segunda publicação significativa que desempenhou um papel importante no início do primeiro inverno da IA foi por Lighthill em 1973, fornecendo uma visão geral no campo da IA com ênfase no progresso, considerado, naquela época, pequeno (LIGHTHILL, 1973).

Durante esse período, muitas organizações governamentais pararam de financiar pesquisas em IA ou diminuíram significativamente o financiamento destas pesquisas (WAMBA et al., 2021). Depois de 1980, a maioria dos pesquisadores de IA desistiram dos algoritmos que aprendem representações de dados e mudaram para sistemas especializados baseados em regras. No entanto, em meados da década de 1980, foi reconhecido que, embora os sistemas especialistas fossem capazes de realizar tarefas muito específicas, esses modelos careciam de bom senso, não podiam ser usados para realizar tarefas mais complexas e não eram generalizáveis (CHANG, A. C., 2020; MCCARTHY, 1984).

O número reduzido de trabalhos de aprendizado de representação, durante o final dos anos 1970 e início dos anos 1980 levaram ao primeiro inverno da IA. Em 1985, um trabalho de Rumelhart, Hinton e Williams encerrou este longo inverno (RUINEIHART; HINT; 
WILLIAMS, 1985). Eles abordaram as preocupações apresentadas por Minsky e Papert e introduziram a otimização de gradiente descendente para minimizar o erro de uma rede. Ao atualizar iterativamente os valores de polarização e peso por meio de um método de otimização de gradiente descendente, eles minimizaram o erro da rede e foram capazes de aprender sistematicamente os valores de polarização e peso (MUTHUKRISHNAN et al., 2020).

Em 1986, Rumelhart e colaboradores expandiram os trabalhos e introduziram o conceito de retropropagação em redes neurais multicamadas, que consistem em várias camadas de neurônios empilhados, onde os neurônios de cada camada eram conectados aos neurônios da camada seguinte (RUMELHART; HINTON; WILLIAMS, 1986). O algoritmo de retropropagação revolucionou as capacidades de aprendizagem das redes neurais (MUTHUKRISHNAN et al., 2020). Embora Rumelhart e seus colegas tenham recebido o crédito por popularizar a retropropagação, é importante observar que houve publicações anteriores sobre a introdução da retropropagação por Werbos e John em 1974, Fukushima em 1980 e Parker em 1985 (CHANG, A. C., 2020; KUBASSOVA et al., 2021). Esses conceitos e publicações começaram a atrair mais interesse e financiamento para o campo, encerrando o primeiro inverno de IA.

No início da década de 1990, percebeu-se que as redes neurais não eram escaláveis. Em grande parte, isso estava relacionado à falta de capacidade computacional, tornando aparente a inviabilidade de redes altamente complexas, levando ao segundo inverno de IA (WAMBA et al., 2021).

O segundo inverno de IA foi devido ao aumento da capacidade de processamento das redes neurais sem um avanço significativo no poder da computação. Os pesquisadores começaram a mudar seu foco para algoritmos mais práticos e simples. O algoritmo de máquina de vetor de suporte, que foi introduzido em 1963 por Vapnik e Chervonenkis, tornou-se popular novamente com a implementação de kernels não lineares em 1992 (BOSER; GUYON; VAPNIK, 1992). Antes da publicação de Boser e colaboradores, em 1992, o algoritmo da máquina de vetores de suporte tentou resolver um hiperplano maximizando as distâncias marginais entre 2 classes separadas e o hiperplano. A distância maximizada entre o hiperplano e as classes permite mais robustez porque os dados estão sempre sujeitos a ruído. A publicação de Boser permitiu uma modificação simples do algoritmo de otimização, agora conhecido como "truque do kernel", que permitiu ao algoritmo solucionar hiperplanos não lineares sem aumentar significativamente os requisitos computacionais do algoritmo. Esse truque permitiu que algoritmos de máquina de vetor de suporte capitalizassem o baixo poder computacional disponível no início da década de 1990 (MUTHUKRISHNAN et al., 2020). 


\subsection{A terceira onda da Inteligência Artificial}

Em meados de 1990, com o aumento do poder computacional, o interesse pela IA ressurgiu. A revolução do microcomputador e a lei de Moore descrevem os avanços que os computadores tiveram nesta década que permitiram a substituição das máquinas tradicionais que estavam estrangulando o desenvolvimento da IA. A capacidade da IA combinada com poder computacional suficiente foram demonstradas em 1997, quando a IBM desenvolveu o supercomputador de xadrez Deep Blue. O Deep Blue derrotou o campeão de xadrez Kasparov, o que gerou diversas publicações e documentários que mais uma vez chamaram a atenção do público para o campo (CAMPBELL; HOANE; HSU, 2002; SCHAEFFER; PLAAT, 2018).

No final de 1990 as redes neurais começaram a ressurgir com a introdução das redes neurais convolucionais. LeCun e colaboradores publicaram a rede LeNet-5 (uma rede neural convolucional de 7 níveis) em 1998 para reconhecimento de documentos, que usava camadas convolucionais e de subamostragem, processando a entrada antes de uma camada totalmente conectada para previsão de saída (LECUN et al., 1998a). Dois avanços principais, permitiram o progresso das redes neurais: armazenamento de dados e unidades de processamento gráfico. Os dados tornaram-se mais acessíveis com armazenamento eletrônico e custos mais baixos e o desempenho dos algoritmos de ML depende muito dos dados disponíveis, o que acarretou uma melhora significativa no desempenho desses algoritmos (MUTHUKRISHNAN et al., 2020). Este desenvolvimento permitiu que Hinton e colaboradores apresentassem formalmente a DL ao público em 2006 que alcançou um desempenho excepcional em reconhecimento de fala, que era tido como um problema desafiador para a IA (HINTON; OSINDERO; TEH, 2006).

Com a introdução de Unidades gráficas de processamento e a melhoria contínua dos computadores, as limitações de hardware que restringiam o desempenho das redes neurais foram superadas. O poder computacional adicional permitiu aos pesquisadores executar redes maiores com camadas mais complexas. A drástica diferença de desempenho causou uma revolução no campo da IA e o interesse voltou para o DL (CHANG, A. C., 2020; GOODFELLOW et al., 2016; KUBASSOVA et al., 2021; MUTHUKRISHNAN et al., 2020).

Mas o que a IA pode fazer hoje em dia? É difícil responder de forma concisa, porque existem atividades nas mais variadas áreas, algumas delas são (FRANCO, 2014):

$\checkmark$ Pesquisa - Máquinas de busca na Internet fazem uso de técnicas diversas de IA para aumentar sua eficiência e grau de acerto;

$\checkmark$ Jogos - Deep Blue, determinação do comportamento de avatares através de IA;

$\checkmark$ Biometria-Reconhecimento facial, impressão digital e de voz;

$\checkmark$ Fiscalização de trânsito - Reconhecimento de placas de veículos infratores; 
Diagnóstico médico - Sistemas especialistas para diagnosticar doenças com base em regras, e;

$\checkmark$ Controle autônomo - Veículos que se dirigem sem interferência humana.

\section{PARADIGMAS E TIPOS DE INTELIGÊNCIA ARTIFICIAL}

Existem várias abordagens na área de Inteligência Artificial, nas quais variam a manipulação do conhecimento, no sentido de adquiri-lo, armazena-lo e emprega-lo. Classificando a IA quanto ao método de solução de problemas, tem-se a IA Simbólica, a IA Conexionista, a IA Evolucionária e a IA Híbrida, tal classificação é abordada também como paradigma da IA (Figura 1.3).

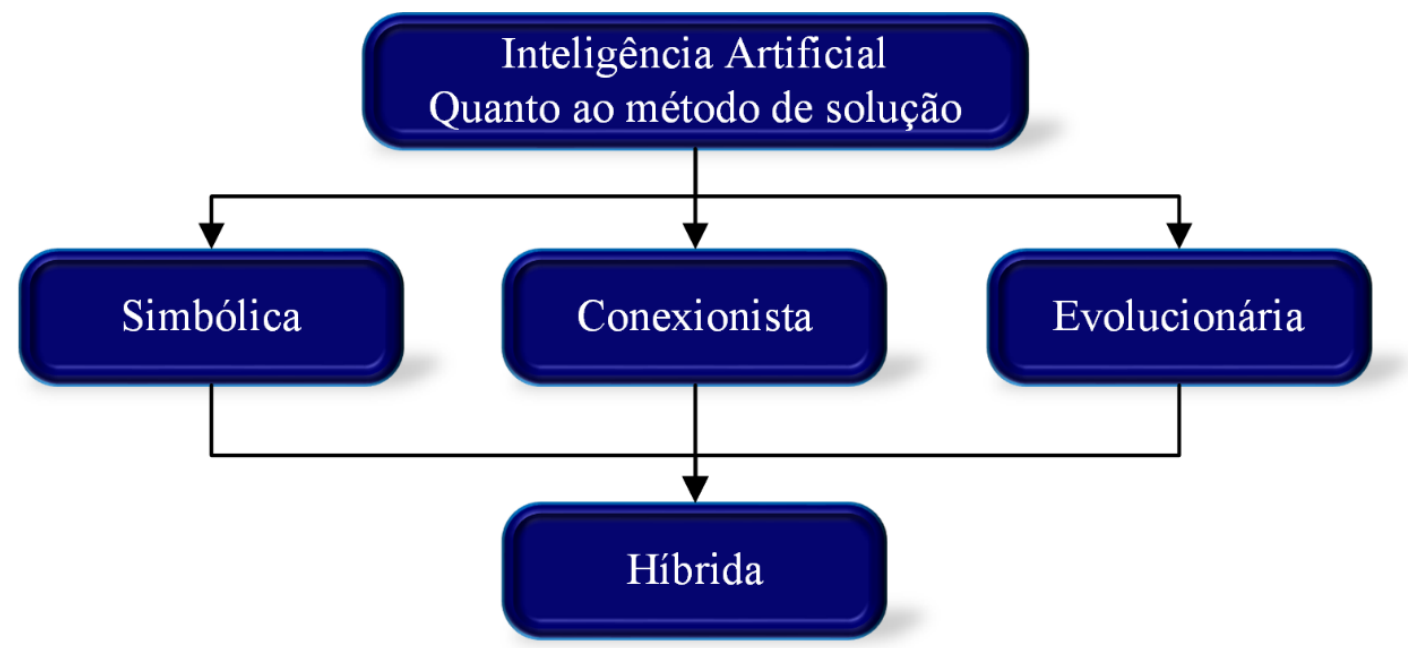

Figura 1.3 - Classificação da IA quanto ao método de solução de problemas.

Na IA Simbólica, representada, entre outros, pelos Sistemas Especialistas (SE), tenta-se reproduzir o funcionamento do raciocínio de um especialista, na solução de um problema, em uma determinada área do conhecimento. Este tipo de paradigma é interessante para resolver tarefas onde é possível articular, com relativa facilidade, o conhecimento necessário para solucioná-las. A IA Simbólica possui como ferramenta básica, para manipular o conhecimento, a lógica. Tais sistemas vêm se mostrando muito úteis em aplicações nas mais variadas áreas, entre elas: cálculo de rotas em aplicações como Google Maps, diagnóstico médico, composição de respostas a questões jurídicas (HAHNE, 2005; SUN, 2015).

Na IA Conexionista, tem-se como objetivo construir modelos que imitem o neurônio biológico e a organização neurológica do cérebro humano, simulando, desta forma, comportamentos inteligentes. Aplica-se melhor em modelos onde não se tem conhecimento explícito de como realizar determinada tarefa, ou quando os especialistas não conseguem formular regras apropriadas para a sua resolução. Existem vários tipos de sistemas 
conexionistas, tais como Redes Neurais Artificiais, Redes de Autômatos e Redes Bayesianas. Suas aplicações são variadas, indo de reconhecimento de face nos celulares, reconhecimento de voz, textos, até os complexos carros autônomos (SUN, 2015).

A abordagem conexionista encontra sua expressão mais poderosa nas chamadas redes neurais de aprendizado profundo (Deep Learning), que têm obtido resultados excelentes em áreas como visão computacional, reconhecimento de fala e processamento de linguagem natural. A DL é um modelo conexionista com número muito elevado de neurônios (às vezes, dezenas de milhões), o que a permite aprender a reconhecer padrões bastante complexos, como, por exemplo, a identificação automática de áreas de queimadas a partir de imagens de satélite em tempo real, possibilitando a ativação de alarmes para o deslocamento de equipe de combate, dispensando a presença de funcionários monitorando continuamente as imagens de satélite (CAMPOS, 2020; SUN, 2015).

O paradigma da abordagem evolutiva (IA Evolucionária) baseia-se na teoria da seleção natural e evolução das espécies de Charles Darwin. Indivíduos de uma espécie são definidos por seu código DNA (sequência de genes nos cromossomos). Os genes são transmitidos de geração em geração. Indivíduos mais aptos (dentro do contexto ambiental em que a espécie existe) tem maior chance de sobreviver e reproduzir. Reprodução sexuada (com troca de material genético entre dois indivíduos) e a mutação (alteração aleatória dos genes que comumente resultam em indivíduos não viáveis, porém que ocasionalmente propiciam uma vantagem adaptativa) promovem variabilidade genética, permitindo o surgimento de novos indivíduos mais aptos (evolução da espécie). Este processo de seleção/evolução pode ser encarado como uma forma de aprendizado coletivo, em que o DNA representa a memória do aprendizado acumulado de uma espécie, e é a essência da abordagem evolutiva, largamente aplicada a problemas de otimização em Engenharia (CAMPOS, 2020).

Em problemas de otimização, busca-se a solução que maximiza a função objetivo que descreve o problema (por exemplo, qual o sortimento florestal ótimo para se maximizar a receita?). Contudo, particularmente em problemas de otimização multivariados, o espaço de soluções possíveis é tão grande que resolver o problema por tentativa e erro (testar todas as soluções possíveis, selecionando a melhor) é computacionalmente inviável. Nestes casos, os chamados algoritmos genéticos fornecem um mecanismo para reduzir o tempo de busca dentro do espaço de soluções. A busca é guiada por uma modelagem matemática do processo de seleção natural e evolução genética, descrito no parágrafo anterior (CAMPOS, 2020; SILVA, R. F., 2018).

Algoritmos genéticos são uma meta-heurística, um procedimento que seja capaz de encontrar uma solução suficientemente boa para um problema. Tal solução é dita sub-ótima. 
De fato, como uma meta-heurística toma amostras (e as avalia) apenas de um subconjunto das soluções possíveis (em situações em que o conjunto de todas as soluções é demasiadamente grande para ser avaliado por completo), não se pode assegurar que a solução encontrada seja a melhor de todas as soluções. Essa é uma das principais críticas contra o uso da abordagem evolutiva. Todavia, é inegável que esta abordagem - particularmente através de sua principal expressão, os algoritmos genéticos - tem sido usada como sucesso em ampla variedade de problemas (CAMPOS, 2020; SUN, 2015).

Existe ainda a Inteligência Artificial Híbrida que reúne vantagens de mais de um tipo de método de abordagem para a resolução de problemas, temos como exemplo, o sistema Neuro-Fuzzy que pode ser definido como um sistema de inferência fuzzy treinado por Rede Neural Artificial (SILVA, J. P. M., 2018).

Existem algumas maneiras de se pensar sobre a utilização da IA quanto a utilização e seu poder. Assim, de forma geral, qualquer produto da Inteligência Artificial pode ser classificado em três tipos: limitada ou fraca, forte ou Geral e Superinteligência (SCERRI; GRECH, 2020).

A hipótese da IA fraca ou limitada, afirma que uma máquina executando um programa, é no máximo, apenas capaz de simular o comportamento e a consciência humano real. Esses sistemas inteligentes são capazes de lidar com uma quantidade imensa de dados e fazer cálculos complexos muito rapidamente, mas somente com um único objetivo. É o tipo de inteligência artificial que consegue vencer um campeão de xadrez, mas é a única coisa que ela faz. Se você pedir para ela fazer qualquer outra coisa, como por exemplo, filtrar spam ou jogar damas, ela não saberá (LIMA FILHO, 2010; SCERRI; GRECH, 2020).

O mesmo acontece com sistemas de IA em carros autônomos, IA de reconhecimento facial etc. que são aplicações extremamente focadas, direcionadas para terem o máximo de performance com apenas um objetivo. Esse é o tipo de inteligência artificial que temos disponível hoje (que se utiliza de diversos métodos e algoritmos, como Redes Neurais, Deep Learning etc., como veremos mais à frente). No entanto, ainda dentro dessa categoria, temos uma subdivisão importante, referente ao nível de consciência que a IA pode ter:

Máquinas Reativas: essa é a classe mais simples de sistemas de IA: são puramente reativos, e não têm habilidades para criar memórias e nem utilizar experiências passadas para fundamentar a decisão atual. Um exemplo disso é o Deep Blue da IBM, supercomputador de xadrez que derrotou um dos maiores campeões de todos os tempos, Garry Kasparov, em 1997 (GAMBUS; JARAMILLO, 2019; SCHAEFFER; PLAAT, 2018).

Memória Limitada: essa classe contém máquinas que conseguem olhar para o passado (memória) para fundamentar a decisão atual. Os carros autônomos já fazem um pouco disso 
atualmente: eles observam a velocidade e a direção dos outros carros para decidir o que fazer, e isso não pode ser feito em apenas um momento, pois requer identificação de objetos específicos e seu monitoramento ao longo do tempo (HE; HAN, 2018; LIMA FILHO, 2010).

Conhecida com IA forte ou geral, refere-se a um computador que é tão inteligente quanto um humano, em um leque enorme de habilidades (e não apenas em uma) - é uma máquina com a mesma capacidade intelectual de um ser humano, podendo realizar qualquer atividade inteligente que o homem domine. Esse é o tipo de IA que passaria facilmente no Teste de Turing, mas é muito mais difícil de criar do que as IA do tipo fraca. Já existem computadores que exibem muitas dessas capacidades (criatividade computacional, razão automatizada, sistema de suporte a decisões, robôs, computação evolucionária, agentes inteligentes), mas não ainda nos níveis humanos (SCERRI; GRECH, 2020).

O termo "superinteligência" foi definido pelo filósofo sueco Nick Bostrom como "um intelecto que é muito mais inteligente do que o melhor cérebro humano em praticamente todas as áreas, incluindo criatividade científica, conhecimentos gerais e habilidades sociais". A superinteligência artificial abrange um leque que varia desde um computador que é um pouco mais inteligente que um humano até o computador que é milhões de vezes mais inteligente em todas as capacidades intelectuais do que um humano (BOSTROM, 2003; SCERRI; GRECH, 2020).

\section{FUNDAMENTOS DA INTELIGÊNCIA ARTIFICIAL}

Existem características inerentes ao estudo da Inteligência Artificial, entre as quais podemos destacar:

\subsection{Representação do conhecimento}

Para a resolução de problemas reais, em muitos casos, um sistema de inteligência artificial necessitará de informações genéricas acerca do contexto desse problema. A representação do conhecimento é o processo de identificar informações genéricas e as representar de uma forma que o computador as reconheça e seja capaz de processa-la (HANNA; SON; DINH, 2021; TANQUE, 2021).

O modo como um computador representa um problema, as variáveis que ele usa e os operadores aplicados a essas variáveis podem fazer a diferença entre um algoritmo eficiente e um algoritmo que não funciona, especialmente para problemas que utilizam a busca. Concluindo, uma representação eficiente do conhecimento deve ser concisa, facilmente 
armazenável e recuperável, legível pelo especialista e passível de representação de restrições, de forma a facilitar o trabalho de inferência (HANNA; SON; DINH, 2021; TANQUE, 2021). A seguir apresentamos algumas das principais formas através das quais o conhecimento é representado em sistemas de IA (OLIVEIRA, 2018).

\section{$\checkmark$ Redes semânticas}

Uma representação de conhecimento bastante utilizada na IA são as redes semânticas. Uma rede semântica consiste de um conjunto de nodos conectados por arestas nas quais os nodos representam objetos e as arestas representam a relação entre eles. Uma rede semântica é um grafo.

Digamos que existe a necessidade de representar as características de um objeto árvore, indicando que esta tem raiz, é um vegetal e tronco lenhoso e realiza fotossíntese. A rede semântica para ilustrar essa situação está na Figura 1.4.

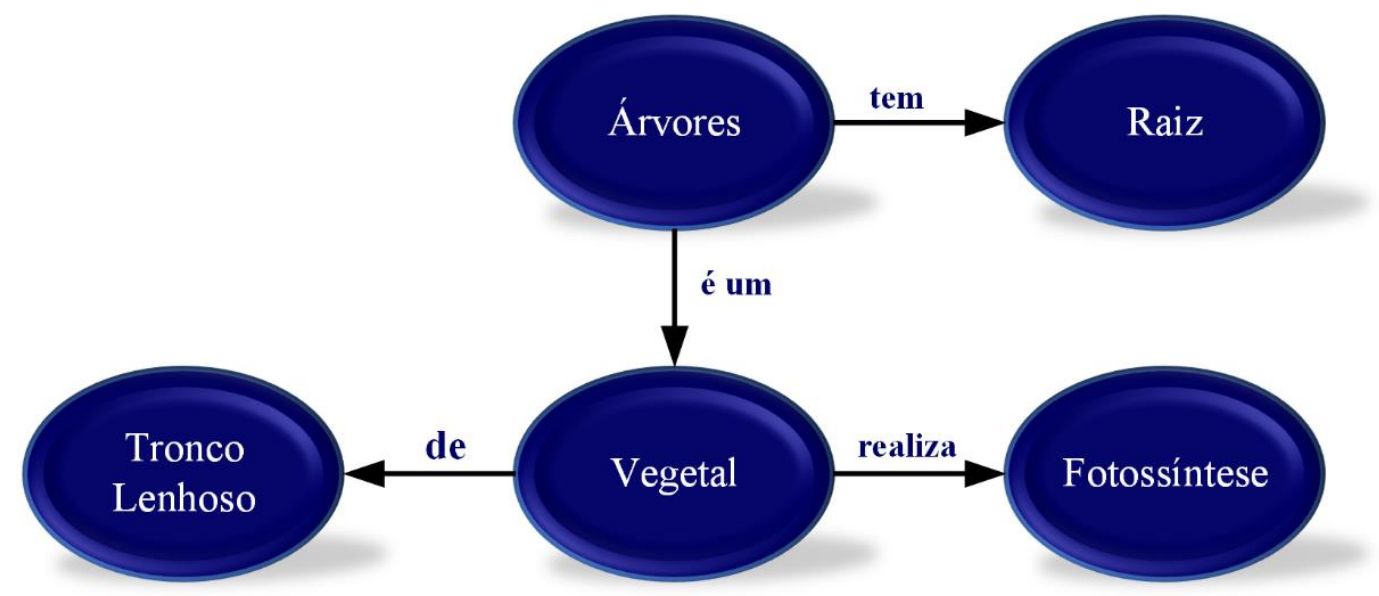

Figura 1.4 - Exemplo de rede semântica.

O círculo com a palavra Árvore é o que chamamos de nodo. O relacionamento do nodo Árvore com o nodo Raiz é representado por uma aresta com a palavra “tem”, ou seja, pode-se inferir, através da rede semântica, que a árvore tem raiz. O tipo de relacionamento pode variar, como podemos ver nas demais arestas que indicam o que a árvore é (é um), e o que ela faz (realiza). Apesar de serem de fácil compreensão, as redes semânticas apresentam algumas desvantagens: dificuldade de manutenção de consistência em domínios complexos e falta de um mecanismo de inferência naturalmente associado à representação do conhecimento.

\section{$\checkmark \underline{\text { Roteiros }}$}

É uma estrutura de dados usada como representação para uma situação que pode ser desmembrada em uma sequência de eventos. Os roteiros são bastante usados em sistemas de compreensão de linguagem natural para organizar uma base de conhecimento que possa ser compreendido pelo sistema. A utilização de roteiros em IA baseia-se na ideia de que uma dada situação usualmente possui um conjunto finito de conhecimento necessário para que se determine de que forma agir. 
Um roteiro é capaz de responder perguntas sobre determinada situação que não está explicita na sua descrição. Por exemplo: Taís foi a um talhão cortar uma árvore. A árvore não possuía diâmetro tão grande quanto o esperado, sendo necessário o corte de mais de uma árvore.

O sistema de roteiro seria capaz de identificar que Taís estava munida de uma ferramenta ou máquina de corte. Questões como “Taís possuía um instrumento de mensuração de diâmetro?" seriam respondidas por associação.

Vale ressaltar que os roteiros são bastante específicos e que seu funcionamento depende muito da criação de episódios. No caso do exemplo de corte acima, poderíamos ter episódio para ações de chegar ao talhão, escolher a árvore, fazer a mensuração de diâmetro, cortar a árvore etc.

\section{$\checkmark$ Quadros}

Os quadros (frames) foram introduzidos para permitir a expressão das estruturas internas dos objetos, mantendo a possibilidade de representar herança de propriedades. São especialmente práticos para a utilização em sistemas especialistas. Podemos dizer que essencialmente um quadro é uma estrutura que tem um nome e um conjunto de pares atributovalor. A Figura 1.5 ilustra o mesmo exemplo da árvore, visto anteriormente, mas desta vez representado por quadros.
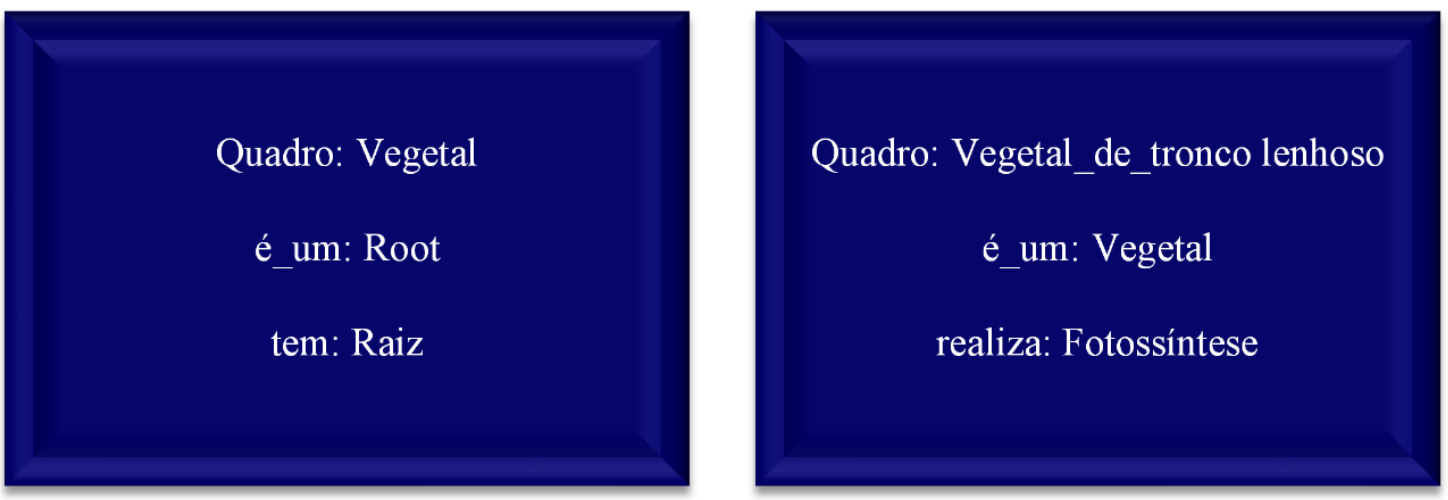

Figura 1.5 - Quadros.

O quadro à esquerda apresenta três propriedades: nome; é_um; e tem. Ele visa representar uma estrutura mais genérica para qualquer vegetal, informando que é o quadro raiz da relação e que tem raiz. A utilização da herança neste caso se dá pela propriedade raiz, uma vez que todos os vegetais têm raiz. Todas as instâncias de um quadro herdam suas propriedades, valores e restrições. O quadro a direita é uma especialização do quadro vegetal, indicando que se trata de um vegetal de tronco lenhoso que realiza fotossíntese. As propriedades de um quadro em geral têm um tipo específico (string, booleano, inteiro, real, etc) no sentido de facilitar sua representação no sistema.

Para a construção de um sistema de quadros, definem-se as propriedades que caracterizam a categoria correspondente. As propriedades definidas para os quadros são: nome; 
classe em que está contido; atributos que qualificam a categoria e todas as suas subclasses; tipos de dados e intervalos que os atributos podem assumir; relações entre os quadros e os demais do sistema.

A principal desvantagem da utilização dos quadros é que em geral as estruturas que comportam o processamento e as regras a serem aplicadas às propriedades não estão neles mesmos, aumentando a complexidade da solução.

\section{$\checkmark$ Regras de produção}

As regras de produção resultam da transformação de um problema computacional em um grafo de estados que possui um estado inicial e um ou $\mathrm{n}$ estados finais, sendo estes identificáveis quando atingidos.

Luger (2002)define as regras de produção como um sistema que fornece controle guiado por um processo de solução de problemas, consistindo de um conjunto de regras, uma memória de trabalho e um ciclo de controle.

Franco (2014) afirma que as regras representam conhecimentos heurísticos tipicamente na forma Se (condições) e Então (conclusões). Muitos sistemas especialistas utilizam regras de produção aliadas a uma máquina de inferência para realizar sua tarefa. Como exemplo de regras de produção considere a Tabela 1.1, na qual é mostrada a clássica representação de conhecimentos sobre alguns animais.

Tabela 1.1 - Exemplo de regras de produção.

\begin{tabular}{|c|l|}
\hline Número & \multicolumn{1}{c}{ Condição } \\
\hline $\mathbf{1}$ & Se (produz_leite \& tem_pelos) Então (mamífero) \\
\hline $\mathbf{2}$ & Se (mamífero \& come_carne) Então (carnívoros) \\
\hline $\mathbf{3}$ & Se (mamífero \& possui_presas \& possui_garra) Então (carnívoros) \\
\hline $\mathbf{4}$ & Se (mamíferos \& possui_casco) Então (ungulado) \\
\hline $\mathbf{5}$ & Se (carnívoros \& pardo \& possui_pintas) Então (onça) \\
\hline $\mathbf{6}$ & Se (carnívoros \& pardo \& possui_listras) Então (tigre) \\
\hline $\mathbf{7}$ & Se (ungulado \& pardo \& possui_pintas) Então (girafa) \\
\hline $\mathbf{8}$ & Se (ungulado \& branco \& possui_listras) Então (zebra)
\end{tabular}

Fonte: Adaptado de Franco (2014)

A regra Se (produz_leite \& tem_pelos) Então (mamífero), a partir de fatos conhecidos sobre um dado animal A, do tipo \{tem_pelos (A), produz_leite (A), come_carne (A), pardo (A), pintado (A) \}, pode-se concluir que A é uma (onça). Quando se busca verificar qual a conclusão a ser obtida a partir dos dados, diz-se que o encadeamento é progressivo (FRANCO, 2014).

A memória de trabalho armazena o estado atual do mundo em um processo de raciocínio. Quando o elemento da condição de uma regra encontra-se como conteúdo da 
memória de trabalho, a ação associada à condição pode ser realizada (LUGER, 2002). O ciclo de controle é definido como o agente que dispara as regras e modifica o conteúdo d memória de trabalho. Após o disparo das regras de produção, o ciclo de controle se repete, usando o conteúdo modificado da memória de trabalho até que o conteúdo da memória de trabalho não se encontre em nenhuma condição de regra.

\section{$\checkmark$ Representação procedimental}

Para esse tipo de representação é preciso estender sua funcionalidade com um interpretador que siga as instruções fornecidas no conhecimento. O conhecimento procedimental passa por um conjunto de etapas sequenciais para encontrar soluções para problemas, sendo usualmente representado através de regras encadeadas ou árvores de decisão.

Representação procedimental de conhecimento possui algumas vantagens, como, a facilidade em representar o conhecimento de como fazer as coisa; a facilidade em representar o conhecimento que não se enquadra dentro de muitos esquemas declarativos simples, como, por exemplo, o raciocínio por omissão e o raciocínio probabilístico; a facilidade em representar o conhecimento heurístico de como fazer eficientemente as coisas, e; a facilidade em representar o conhecimento heurístico de como fazer eficientemente as coisas (FRANCO, 2014).

A Figura 1.6 apresenta um exemplo de representação procedimental do conhecimento.

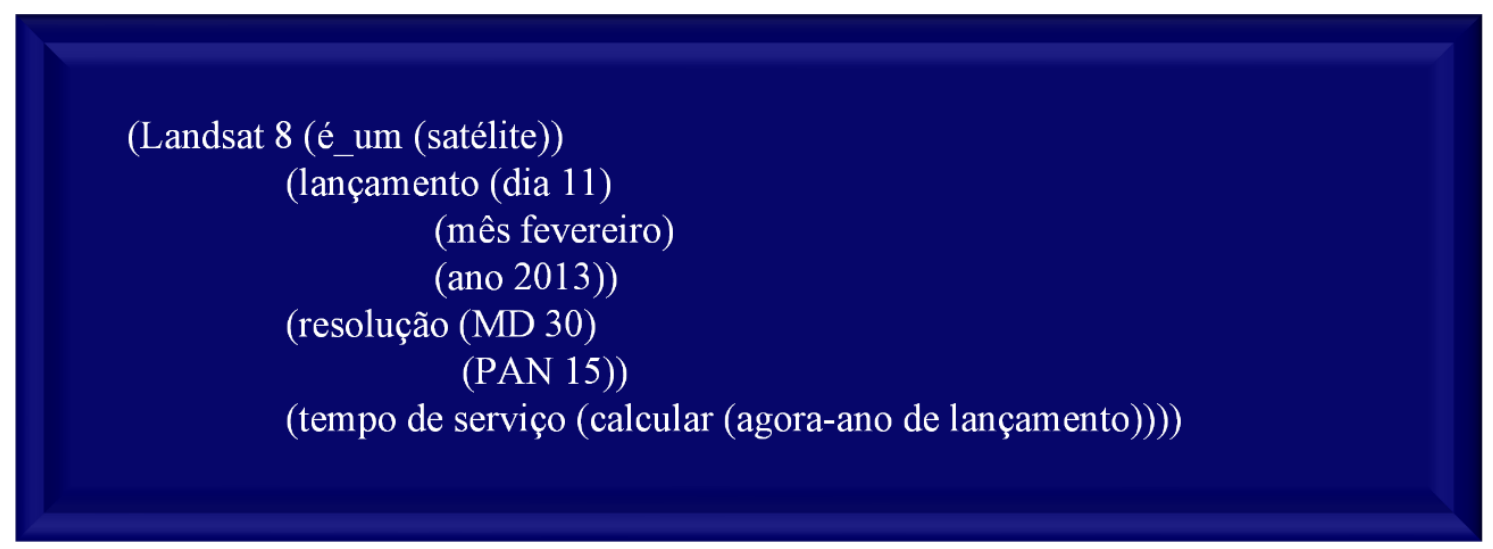

Figura 1.6 - Representação procedimental do conhecimento.

\subsection{Processamento de linguagem natural}

Um sistema de inteligência artificial precisa ter a capacidade de interagir com o mundo real, e para tanto, a capacidade de interagir com seres humanos utilizando a linguagem humana, é fundamental. Um sistema de inteligência artificial que consiga processar adequadamente a linguagem natural tem a capacidade de absorver informações diretamente de conversas com seres humanos e também de material multimídia (vídeos, textos falados), bem como da mídia escrita (livros, artigos e textos em geral). Para tanto, o processamento de linguagem natural 
deve ser capaz de dividir um texto em suas partes fundamentais sob o ponto de vista gramatical e assim identificar todos os elementos (RUSSELL; NORVIG, 2013). A Figura 1.7 a seguir mostra a divisão sintática de uma sentença simples:

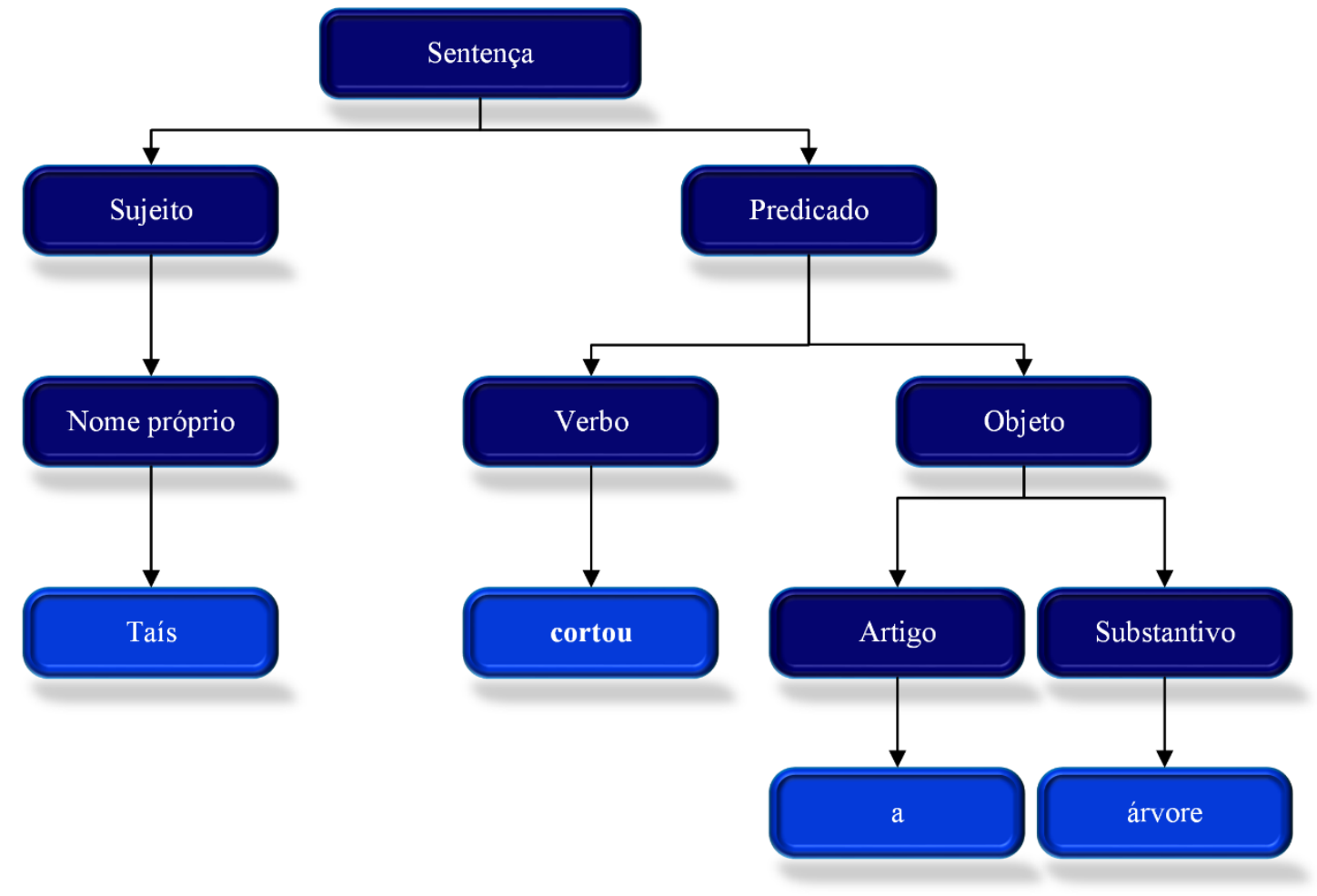

Figura 1.7 - Divisão sintática de uma sentença simples.

\subsection{Criatividade}

A questão da criatividade vem propondo desafios enormes à inteligência artificial. Podemos usar os quatro critérios a seguir para identificar traços de criatividade em um sistema de IA (OLIVEIRA, 2018):

$\checkmark$ Resposta inovadora e útil: uma resposta que utilize elementos existentes de maneira nova é inovadora, e deve, também, ter relevância dentro da questão tratada, não podendo derivar de seu propósito central.

$\checkmark$ Resposta requer que rejeitemos formas anteriores de se pensar sobre a questão: A criatividade artificial se apresenta quando um sistema de IA, livre dos hábitos e da mecânica a que nós, seres humanos, muitas vezes nos prendemos, busca maneiras diferentes de resolver determinado problema. Por não possuir familiaridade com as formas comuns de pensar dos seres humanos, o sistema de IA explora novas formas com a mesma intensidade, sem predileção.

$\checkmark$ Resposta surge de um processo intenso de motivação e persistência: Neste caso a IA não apresenta nem motivação nem persistência ativa, mas sim, cumpre com o programa a ela designado. Ocorre que a IA, uma vez tendo iniciado sua tarefa, a executará sem 
"preguiça" até que seus programadores definam que o resultado está adequado. Uma rede neural, gerará resultados cada vez melhores a cada iteração, podendo chegar a resultados surpreendentes após algumas horas ou alguns dias de treinamento.

$\checkmark$ Resposta surge do esclarecimento de uma questão que anteriormente era pouco formalizada e/ou delimitada: O sistema de IA busca identificar, à sua maneira, o ponto central de um problema e resolvê-lo. Uma formalização própria do problema acaba sendo criada, e as soluções que surgem a partir daí poderão ser encaradas como criativas sob o ponto de vista do problema inicial, mais vago e menos formalizado.

\section{TÉCNICAS DE INTELIGÊNCIA ARTIFICIAL}

Uma vez que você tenha compreendido a definição de IA e conhecido mais sobre a sua história, a melhor maneira de mergulhar no assunto é conhecer algumas técnicas de IA e, principalmente, os casos de uso no campo das Ciências Florestais e da Agricultura, tais informações estão contempladas nos subtópicos desta e da próxima seção deste capítulo.

\subsection{Lógica Nebulosa ou Lógica Fuzzy}

$\mathrm{Na}$ lógica convencional (binária), um elemento pertence ou não pertence a um determinado conjunto, e nunca se encontra entre estes dois estados possíveis. Esta é uma maneira de simplificar um mundo inerentemente complexo, mas está simplificação acaba por distorcer a realidade (SUDHA; JAYALALITHA, 2021). A lógica Fuzzy é um método que permite expressar incertezas de maneira mais consistente, através dos conjuntos nebulosos: ao invés de simplesmente pertencer ou não pertencer, um elemento poderá ter vários graus de pertinência a um conjunto (SERRANO-GUERRERO; ROMERO; OLIVAS, 2021).

Os conjuntos Fuzzy são funções que mapeiam, em uma escala de zero a um, a pertinência de um determinado elemento ao conjunto. $\mathrm{O}$ valor zero indica que o elemento não pertence ao conjunto, enquanto o valor um significa que o elemento é completamente representativo do conjunto; valores entre estes dois indicam graus intermediários de pertinência (SUDHA; JAYALALITHA, 2021; WUERGES; BORBA, 2010).

Dado que a teoria dos conjuntos Fuzzy foi desenvolvida com problemas ambientais reais, o objetivo principal é reduzir a ambiguidade e imprecisão dos multicritérios utilizados nas ferramentas de tomada de decisão. Este método, facilmente acessível com linguagem natural, tem sido usado positivamente para modelar funções não lineares e resolver problemas ambientais, como, por exemplo, realizar análises de risco, identificar fragmentos com maior 
potencial para conservação, avaliar possíveis impactos ambientais, classificação digital de objetos, dentre outros (YILMAZ et al., 2021).

\subsection{Random Forest}

A Random Forest (RF) ou Floresta Aleatórias é uma técnica de aprendizado de máquina que pode ser usada para regressão e classificação. A Random Forest gera um conjunto de árvores de decisão e o resultado predito é a média de todas as árvores, para os casos de regressão. Nos problemas de classificação, o resultado obtido é dado por um sistema de votação, em que, a nova classe predita é aquela que obteve o maior número de votos (SILVA, J. P. M., 2018).

Como já mencionado, no algoritmo RF serão criadas várias árvores de decisão, sendo este conhecimento fundamental para o entendimento do algoritmo. As árvores de decisão consistem em dividir, de forma iterativa, o banco de dados (nó raiz) em subconjuntos (nós de decisão). A divisão dos dados é calculada de acordo com algum critério, que, normalmente, é feito pelo limiar de corte das variáveis independentes, afim de diminuir a variância da variável dependente nos nós filhos formados (ANAND et al., 2021). Ou seja, o algoritmo criará uma estrutura similar a um fluxograma, se uma condição é atendida o fluxo segue por um ramo, caso contrário, por outro, sempre levando ao próximo nó, até a finalização que ocorrerá quando um critério de parada for atendido. O grupo final é chamado de folha e o valor previsto é a média dos valores pertencentes as folhas das árvores (ASADI; ROSHAN; KATTAN, 2021). A Figura 1.8 mostra um exemplo de Random Forest.

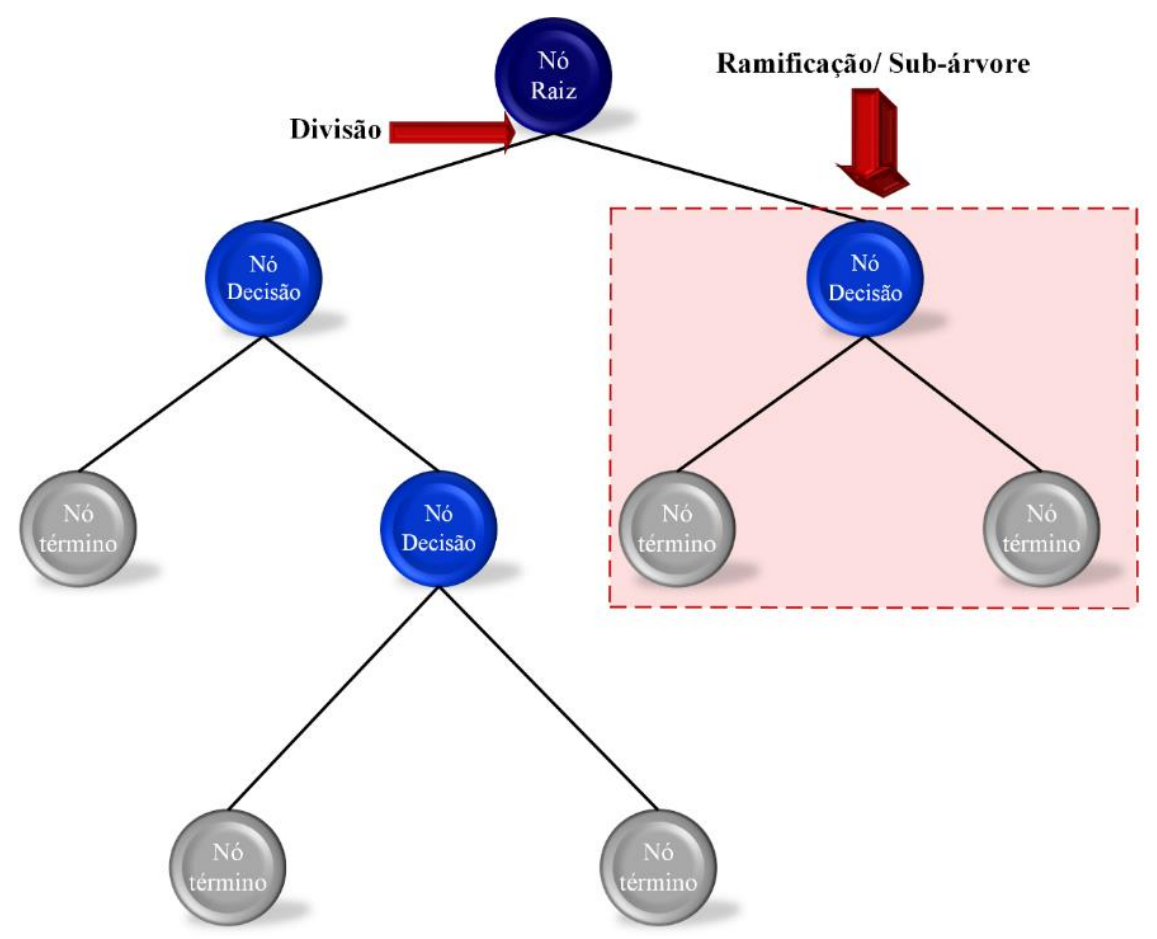

Figura 1.8 - Representação de uma árvore de decisão. 
A vantagem do uso da RF comparada aos vários métodos de aprendizagem de máquinas, como exemplo, as máquinas de vetores de suporte e as redes neurais artificiais, são as informações obtidas sobre as variáveis que melhor colaboram para previsão do modelo (ANAND et al., 2021; ASADI; ROSHAN; KATTAN, 2021).

\subsection{Redes Neurais Artificiais}

Redes neurais artificiais (Artificial Neural Networks ou RNAs) são algoritmos vagamente baseados em conceitos derivados de pesquisas sobre a natureza do cérebro, utilizados para tarefas cognitivas, tais como aprendizado e otimização (TAHERI; XIE; LEDERER, 2021). As redes neurais têm se consolidado como um dos modelos mais utilizados em aprendizado de máquina, principalmente com o desenvolvimento de redes neurais profundas e devido a sua ampla gama de aplicações (MORALA et al., 2021).

A rede é formada, segundo Van Gerven and Bohte (2017), por nós conectados em uma única direção (uma saída é sempre conectada a uma ou mais entradas de neurônios de uma camada à frente), formando uma rede, na qual sinais de entrada são processados e propagados (ou não), gerando combinações de sinais de saída. Uma rede neural genérica pode ser representada como tendo uma camada de entrada, uma ou mais camadas internas (ou escondidas) e uma camada de saída. A Figura 1.9, a seguir, representa uma rede neural com sete nós de entrada, duas camadas internas e três nós de saída

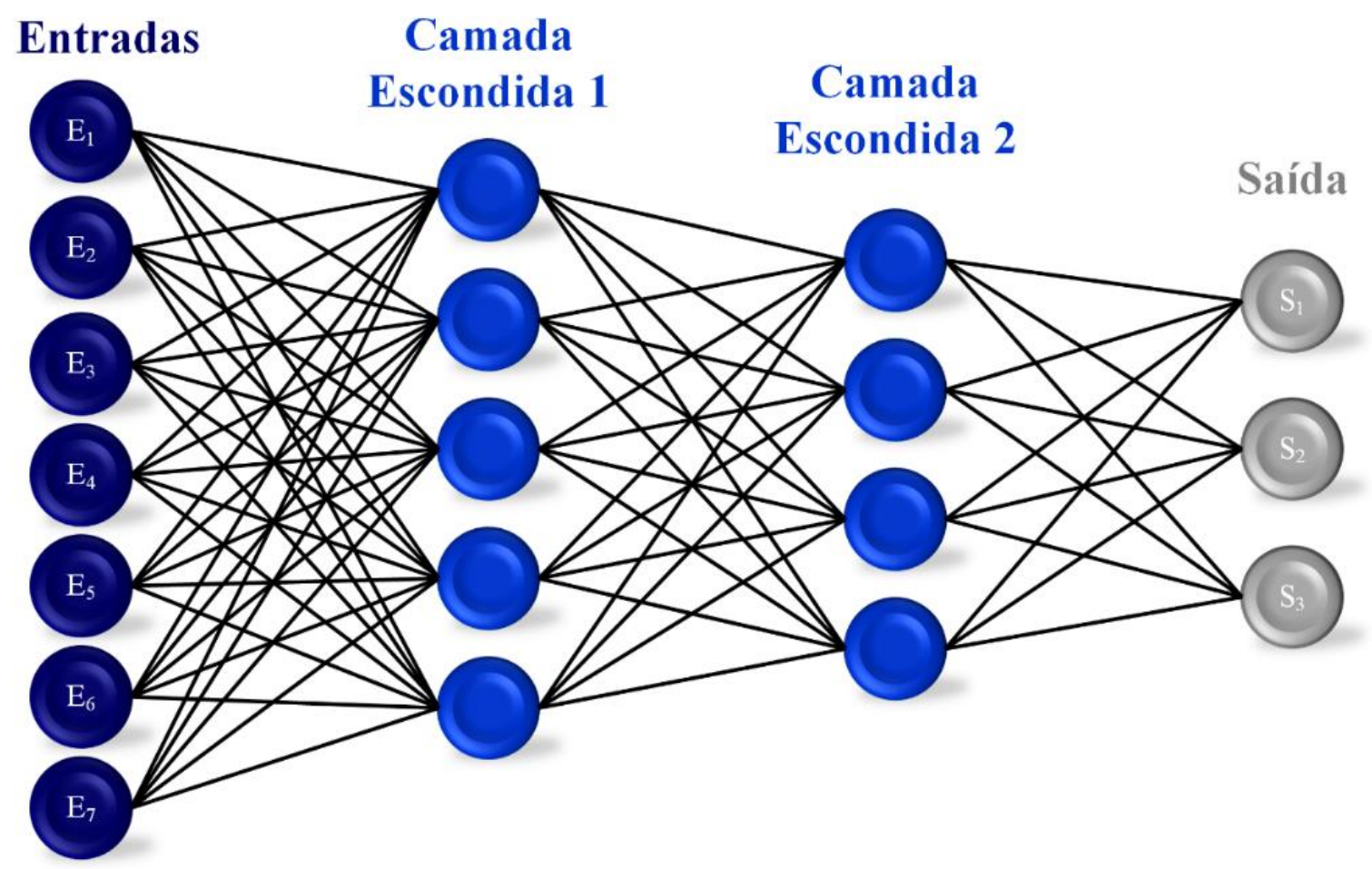

Figura 1.9 - Representação de uma Rede Neural. 
A Figura 1.9 nos mostra alguns dos elementos constitutivos das redes neurais, a saber (OLIVEIRA, 2018):

$\checkmark$ Nós de Entrada - Geralmente diferem dos nós escondidos e dos nós de saída por exibirem alguma capacidade de transformar sinais não digitais em entradas digitais. Sensores, por exemplo, são elementos que podem receber sinais luminosos e transformá-los em sinais digitais, dependendo do estímulo externo que recebem.

$\checkmark \underline{\text { Nós escondidos }}$ - São responsáveis pelo processamento interno da rede. Quanto mais nós escondidos e camadas, maior será a capacidade de processamento necessária para treinar a rede, porém, maior será a chance de obter resultados precisos após esse treinamento. Contudo, não é obrigatório que existam em uma rede neural.

$\checkmark$ Nós de saída - São a última camada de processamento, devolvendo combinações de sinais digitais booleanos (“0” ou "1") que correspondem à resposta do sistema ao problema proposto.

$\checkmark$ Conexões Saída/Entrada - Conexões entre os nós de uma camada com e os nós da camada subsequente.

$\checkmark \underline{\text { Pesos }}$ - Fatores de multiplicação para cada um dos sinais de entrada em um nó.

$\checkmark$ Função de Processamento (ou ativação) - Forma de combinar os vários binômios (sinal de entrada e peso) dentro do nó. Gera um valor que deve ser comparado com o limiar para gerar o sinal de saída.

$\checkmark$ Limiar - Valor arbitrário estabelecido para cada nó com o qual o resultado da função de processamento será comparado. Se o valor for maior que o limiar, um sinal de saída será gerado (valor do sinal de saída: “1”). Do contrário (isto é, caso o sinal seja menor ou igual ao limiar), nenhum sinal de saída será gerado (valor do sinal de saída: “0”).

Para utilização da Rede Neural Artificial são necessários ajustes dos pesos sinápticos. Essa etapa pode ser dividida em duas partes, sendo elas, treinamento ou aprendizagem e validação ou generalização. Na fase de treinamento, utiliza-se algum dos vários mecanismos de reconfiguração de pesos e limiares para reforçar os estados que geram respostas corretas, ao mesmo tempo inibindo os estados que geram respostas erradas. $\mathrm{O}$ treinamento de uma rede neural é um processo heurístico, envolvendo inúmeros passos de tentativa e erro, construindo aos poucos uma configuração que gera um patamar aceitável de acertos. Uma resposta certa gera acertos na configuração que facilitam aquela resposta no futuro, e uma resposta errada gera acertos na configuração que dificultam aquela resposta no futuro. Já a fase de validação é usada para verificar o quão bom foi o ajuste obtido na fase de treinamento. Ou seja, espera-se nesta etapa que as respostas estimadas sejam próximas as respostas observadas (reais), possibilitando 
a afirmação de que a rede possui uma generalização aceitável para seu uso no mundo real (HAYKIN, 2007; TANG, S.; YANG, 2021).

\subsection{Algoritmo Genético}

Algoritmos genéticos (AGs), por sua vez, são técnicas de busca paralela, que começam com um conjunto de soluções possíveis e, através de operações especiais (avaliação, seleção, crossover e mutação), evoluem progressivamente em direção a soluções mais promissoras. Assim como as redes neurais surgiram inspiradas no funcionamento do cérebro, os algoritmos genéticos foram inspirados na evolução, seleção natural e genética. Estes algoritmos dependem basicamente de uma função que avalie a qualidade de uma determinada solução para o problema - e esta função pode ser obtida mesmo para problemas difíceis de serem resolvidos através de técnicas convencionais (POONGOTHAI; KANNAN; GODHANDARAMAN, 2021; SO et al., 2021).

A analogia entre Algoritmos Genéticos e o sistema natural é representada através da Tabela 1.2 (WUERGES; BORBA, 2010).

Tabela 1.2 - Analogia entre Algoritmo genético e o sistema natural.

\begin{tabular}{c|l|} 
Sistema Natural & \multicolumn{1}{c|}{ Algoritmo Genético } \\
$\begin{array}{c}\text { Cromossomo } \\
\text { Gene }\end{array}$ & $\begin{array}{l}\text { Cadeia de bits que representa uma solução possível para o problema (palavra binária, } \\
\text { vetor, etc). }\end{array}$ \\
\hline Alelo & Características do problema. \\
\hline Loco & Valor da característica. \\
\hline Genótipo & Posição da palavra, vetor. \\
\hline Fenótipo & Estrutura. \\
\hline Indivíduo & Estrutura submetida ao problema. \\
\hline Geração & Solução. \\
\hline
\end{tabular}

Para efetuar a busca por soluções ótimas, os AGs primeiro geram um conjunto de soluções aleatórias para o problema para, então, calcularem (utilizando uma função de avaliação) a qualidade de cada uma destas soluções. Depois, através de mecanismos de reprodução, combinam as melhores soluções, formando novas soluções que serão, possivelmente, mais adequadas do que aquelas que lhe deram origem. O novo conjunto de soluções é novamente avaliado. A reprodução e a avaliação são repetidas até que o conjunto de soluções não possa mais ser melhorado (ERZURUM CICEK; KAMISLI OZTURK, 2021; POONGOTHAI; KANNAN; GODHANDARAMAN, 2021).

Vale lembrar que, além da reprodução, é possível trocar informações entre dois cromossomos (soluções) - técnica chamada crossover - ou alterar pedaços de uma solução, simulando as mutações genéticas encontradas em seres vivos. Seu funcionamento, como explicado, faz com que os AGs sejam adequados para analisar um amplo espaço de soluções 
(através das amostras presentes na população inicial, gerada aleatoriamente), concentrando-se posteriormente nas áreas que mostram resultados mais promissores (KLEEDTKE; HUA; POZZI, 2021).

\section{APLICAÇÕES DA INTELIGÊNCIA ARTIFICIAL EM CIÊNCIAS FLORESTAIS}

A aplicação da Inteligência Artificial no mercado florestal ainda é bastante recente, mas já se expandiu para algumas atividades do setor e tem sido utilizada no monitoramento e no combate a incêndios, identificação de pragas, caracterização de áreas produtivas, planejamento e otimização florestal. A seguir falaremos sobre alguns trabalhos e áreas de utilização das seguintes técnicas de Inteligência Artificial.

\subsection{Lógica Nebulosa ou Lógica Fuzzy}

Artigos de pesquisa são publicados todos os dias, nos quais diferentes técnicas de inteligência artificial (por exemplo, redes neurais, Lógica Fuzzy e algoritmo de agrupamento) são aplicadas a várias tarefas e aplicações relacionadas à mineração de opinião e de dados (SERRANO-GUERRERO; ROMERO; OLIVAS, 2021). Diante disso, retrataremos alguns usos de Lógica Fuzzy na Ciências Florestais.

Muitos modelos baseados em lógica fuzzy foram desenvolvidos, principalmente nas áreas de análise de adequação do uso da terra (AKBARI; NEAMATOLLAHI; NEAMATOLLAHI, 2019; BOVKIR; AYDINOGLU, 2018), aptidão agrícola (DOS SANTOS, A. R. et al., 2017; PIROVANI et al., 2018), estudo de índices ecológicos (DOS SANTOS, A. R. et al., 2020; SANTOS, J. S. et al., 2018), avaliação de impactos ambientais (MILTONTHOMPSON et al., 2021; NADIRI et al., 2017), mapeamento de risco (CABANILLAS et al., 2012; HONG; TSANGARATOS; ILIA; LIU; ZHU; CHEN, 2018; LIU, B. et al., 2020), e planejamento urbano (ARAYA-MUÑOZ et al., 2017), entre outros.

A Lógica Fuzzy oferece uma padronização flexível e direta de objetos espaciais de diferentes valores, favorecendo a comparação, permitindo a comparação de diferentes variáveis ao longo do tempo. Além disso, facilita abordar a variabilidade e imprecisão dos dados, bem como a imprecisão de interpretações. Observa-se que a análise usando lógica fuzzy em SIG, por exemplo, i) permite aos pesquisadores avaliar problemas

complexos de forma prática, ii) é compreensível, iii) permite flexibilidade na combinação de mapas e iv) é facilmente implementada. 


\subsection{Random Forest}

A modelagem de florestas, seja de suas variáveis dendrométricas ou de sua distribuição geográfica, é uma prática consolidada na Engenharia Florestal, na qual tradicionalmente são empregados modelos da estatística clássica. Entretanto, o progresso obtido pela ciência da computação nas últimas décadas tem possibilitado novos desafios e soluções, os quais podem inserir modelos de IA em suas soluções. É no contexto de relações não-lineares pouco conhecidas que os algoritmos de aprendizagem de máquina ganham sua utilidade no setor florestal. Dentre esses algoritmos, recebe destaque o random forest, por sua robustez, facilidade de parametrização e métricas internas.

A RF está se tornando uma técnica de aprendizado de máquina amplamente usada para predição espacial (FOUEDJIO, 2020), petrografia de carvão (TIWARY et al., 2020), estimativa de biomassa acima do solo (YADAV et al., 2021), mapeamento de plantações ao longo de estações de cultivo (LI, R. et al., 2021), avaliação de severidade de inundação (GHOSH; DEY, 2021), previsão de pH do solo (WANG, Z. et al., 2021) e relação entre produtividade da floresta e os fatores de povoamento e clima (WANG, Z. et al., 2021), dentre outras.

\subsection{Redes Neurais Artificiais}

Alguns estudos demonstram que a RNA é eficaz em diversos ramos das ciências florestais, discutiremos aqui e apresentaremos alguns destes trabalhos.

A primeira área abordada é a utilização de RNA na modelagem da capacidade produtiva. O trabalho intitulado "Integration of principal component analysis and artificial neural network to modeling productive capacity of eucalypt stands from biophysical attributes", concluiu que a RNA gerada é recomendada para prever o incremento médio de volume anual aos 7 anos, a partir de fatores biofísicos, com alta precisão. Esta RNA pode ser aplicada em outras áreas com povoamentos de eucalipto ou em áreas sem histórico de plantações florestais (DOLÁCIO et al., 2020).

Os modelos de rede neural artificial oferecem uma série de vantagens, incluindo a capacidade de detectar implicitamente relações não lineares complexas entre variáveis de entrada e saída, que são muito úteis na modelagem de altura de árvore. O trabalho realizado por Özçelik et al. (2013) estimou a altura da Criméia, usando modelos de regressão não linear e rede neural artificial, e obteve resultados promissores para o modelo de redes neurais artificiais de retropropagação. Reis et al. (2016) estudou a prognose de diâmetro de árvores individuais na região leste da Amazônia por meio de redes neurais, onde foi concluído que as RNAs podem ser efetivamente utilizadas para auxiliar no manejo de florestas tropicais, por meio, por exemplo, da escolha dos ciclos de corte mais adequados por espécie. 
Outra área onde as RNAs vem sendo aplicadas é em associação com técnicas e produtos de sensoriamento remoto. Esta associação de técnicas vem sendo utilizadas em trabalhos para quantificação de água em dossel de plantas (TROMBETTI et al., 2008), mapeamento de estruturas florestais (INGRAM; DAWSON; WHITTAKER, 2005), estimativa de propriedades físicas do solo (CHANG, D. H.; ISLAM, 2000), análises de variáveis climáticas (LI, X. et al., 2021), modelagem de biomassa (YANG et al., 2018) e uma série de análises de índices de reflectância associada a condição e cobertura do solo (DOBREVA; KLEIN, 2011; SANTI et al., 2014).

$\mathrm{Na}$ área de otimização vem se utilizando as RNAs para solucionar problemas reais, tem-se destacado, nesta área, a utilização de rede neural de Hopfield que vem obtendo resultados expressivos para resolução de problemas de otimização restrita (SILVA, I. N. da; AMARAL; ARRUDA, 2004).

As aplicações de técnicas de redes neurais artificiais no campo das Ciências Florestais vêm ganhando cada dia mais adeptos e demonstra ser uma área promissora para auxiliar na resolução de problemas reais, que englobam uma vasta gama de fatores.

\subsection{Algoritmo Genético}

As florestas são ecossistemas complexos que desempenham várias funções. Os gestores e planejadores florestais devem levar em consideração diversos critérios econômicos, ambientais e sociais. Usos concorrentes como colheita de madeira, recreação, abastecimento de água e conservação da biodiversidade tornam o planejamento florestal uma operação importante (FOTAKIS et al., 2012). Além disso, planejamento pré-implantação e de manutenção são de suma importância e devem levar em consideração cálculos de risco e escolhas de áreas de plantio.

O Algoritmo Genético é um dos algoritmos evolutivos mais amplamente usados para problemas de otimização (HONG; PANAHI; et al., 2018). Os AGs têm uma vantagem sobre os métodos tradicionais na solução de problemas por operarem com uma população de possíveis soluções codificadas (ADNAN; ISLAM, 2016). Desta forma têm sido empregados nas mais diversas área das Ciências Florestais, como, otimização de multiprodutos (FOTAKIS et al., 2012), otimização de estratégia de controle de poluentes (HUANG et al., 2020), simulação de fluxo de água subterrânea acoplado ao transporte (SEYEDPOUR et al., 2019), avaliação de susceptibilidade à inundação (HONG; PANAHI; et al., 2018), modelos de distribuição de espécies simulando efeitos das mudanças climáticas (SAFAEI et al., 2021) e escolha da combinação ideal de variáveis relacionadas a incêndios florestais (HONG; TSANGARATOS; ILIA; LIU; ZHU; XU, 2018), dentre outras. 
Desta forma muitos problemas da área de Ciências Florestais apresentam características próprias para solução mais eficiente por meio de algoritmos genéticos. Problemas de cunho combinatório são os que mais fazem uso de técnicas de metaheurística, com destaque para os AGs (RODRIGUES, F. L. et al., 2004).

\section{CONSIDERAÇÕES FINAIS}

A aplicação da Inteligência Artificial no mercado florestal ainda é bastante recente, mas já se expandiu para algumas atividades do setor e tem sido utilizada no monitoramento e no combate a incêndios, identificação de pragas, caracterização de áreas produtivas, planejamento, otimização florestal, sensoriamento remoto, cálculos de risco e de vulnerabilidade.

A interação de diferentes fatores, a otimização do tempo de resposta e a eficiência do sistema fazem com que as diferentes técnicas de inteligência artificial auxiliem na tomada de decisão. Além disso, problemas, que demonstrem maior grau de complexidade, que necessitem da interação de diferentes áreas e fatores, problemas esses que demonstrem o que de fato ocorre no mundo real, como a associação das condições edafoclimáticas e ambientais para o planejamento de cultivos agrícolas, têm sido solucionados por meio da associação de diferentes técnicas de IA. De tal modo este capítulo veio para introduzir os conceitos e apresentar algumas das técnicas que serão abordadas nos capítulos a seguir. 


\section{REFERÊNCIAS}

ADNAN, M. N.; ISLAM, M. Z. Optimizing the number of trees in a decision forest to discover a subforest with high ensemble accuracy using a genetic algorithm. Knowledge-Based Systems, v. 110, p. 86-97, 15 out. 2016.

AKBARI, M.; NEAMATOLLAHI, E.; NEAMATOLLAHI, P. Evaluating land suitability for spatial planning in arid regions of eastern Iran using fuzzy logic and multi-criteria analysis. Ecological Indicators, v. 98, p. 587-598, 1 mar. 2019.

ANAND, R. S. et al. Prediction of Al2O3/R134a nanorefrigerant based modified thermosyphon performance using random forest algorithm. Materials Today: Proceedings, 12 abr. 2021.

ARAYA-MUÑOZ, D. et al. A spatial fuzzy logic approach to urban multi-hazard impact assessment in Concepción, Chile. Science of the Total Environment, v. 576, p. 508-519, 15 jan. 2017.

ASADI, S.; ROSHAN, S. E.; KATTAN, M. W. Random forest swarm optimization-based for heart diseases diagnosis. Journal of Biomedical Informatics, v. 115, p. 103690, 1 mar. 2021.

BOSER, B. E.; GUYON, I. M.; VAPNIK, V. N. Training algorithm for optimal margin classifiers. 1992, New York, New York, USA: Publ by ACM, 1992. p. 144-152. Disponível em: <http://portal.acm.org/citation.cfm?doid=130385.130401〉. Acesso em: 28 abr. 2021.

BOSTROM, N. Are we living in a computer simulation? Philosophical Quarterly, v. 53, n. 211, p. 243-255, 2003. Disponível em: 〈https://philpapers.org/rec/BOSAWL>. Acesso em: 30 abr. 2021.

BOVKIR, R.; AYDINOGLU, A. C. Providing land value information from geographic data infrastructure by using fuzzy logic analysis approach. Land Use Policy, v. 78, p. 46-60, 1 nov. 2018.

CABANILLAS, J. et al. Fuzzy logic based risk assessment of effluents from waste-water treatment plants. Science of the Total Environment, v. 439, p. 202-210, 15 nov. 2012.

CAMPBELL, M.; HOANE, A. J.; HSU, F. H. Deep Blue. Artificial Intelligence, v. 134, n. 12, p. 57-83, 1 jan. 2002.

CAMPOS, R. S. Desmistificando a inteligência artificial: Uma breve introdução conceitual ao aprendizado de máquina. International Journal of Phenomenology, Hermeneutics and 
Metaphysics, v. 1, n. 3, p. 106-123, 2020.

CHANG, A. C. History of Artificial Intelligence. Intell. Med. [S.1.]: Elsevier, 2020. p. 23-27.

CHANG, D. H.; ISLAM, S. Estimation of soil physical properties using remote sensing and artificial neural network. Remote Sensing of Environment, v. 74, n. 3, p. 534-544, 1 dez. 2000.

DOBREVA, I. D.; KLEIN, A. G. Fractional snow cover mapping through artificial neural network analysis of MODIS surface reflectance. Remote Sensing of Environment, v. 115, n. 12, p. 3355-3366, 15 dez. 2011.

DOLÁCIO, C. J. F. et al. Integration of principal component analysis and artificial neural network to modeling productive capacity of eucalypt stands from biophysical attributes. Forest Ecology and Management, v. 460, p. 117862, 15 mar. 2020.

DOS SANTOS, A. R. et al. Fuzzy concept applied in determining potential forest fragments for deployment of a network of ecological corridors in the Brazilian Atlantic Forest. Ecological Indicators, v. 115, p. 106423, 1 ago. 2020.

Fuzzy logic applied to prospecting for areas for installation of wood panel industries.

Journal of Environmental Management, v. 193, p. 345-359, 15 maio 2017.

ERZURUM CICEK, Z. I.; KAMISLI OZTURK, Z. Optimizing the artificial neural network parameters using a biased random key genetic algorithm for time series forecasting. Applied Soft Computing, v. 102, p. 107091, 1 abr. 2021.

FOTAKIS, D. G. et al. Spatial genetic algorithm for multi-objective forest planning. Forest Policy and Economics, v. 21, p. 12-19, 1 ago. 2012.

FOUEDJIO, F. Exact Conditioning of Regression Random Forest for Spatial Prediction. Artificial Intelligence in Geosciences, v. 1, p. 11-23, 1 dez. 2020.

FRANCO, C. R. Inteligência artificial. Londrina: Editora e Distribuidora educacional S.A., 2014.

GAMBUS, P. L.; JARAMILLO, S. Machine learning in anaesthesia: reactive, proactive... predictive! British Journal of Anaesthesia. [S.1.]: Elsevier Ltd. , 1 out. 2019

GHOSH, A.; DEY, P. Flood Severity assessment of the coastal tract situated between 
Muriganga and Saptamukhi estuaries of Sundarban delta of India using Frequency Ratio (FR), Fuzzy Logic (FL), Logistic Regression (LR) and Random Forest (RF) models. Regional Studies in Marine Science, v. 42, p. 101624, 1 fev. 2021.

GOODFELLOW, I. et al. Deep learning. Cambridge: MIT press, 2016.

HAHNE, M. N. M. A. Metodologia de aprendizado baseado em algoritmos genéticos para modelos alternativos de redes IAC. 2005. 173 f. Tese (Doutorado em Engenharia Elétrica) Universidade Federal de Santa Catarina, Florianópolis, 2005.

HANNA, B.; SON, T. C.; DINH, N. AI-Guided Reasoning-Based Operator Support System for the Nuclear Power Plant Management. Annals of Nuclear Energy, v. 154, p. 108079, 1 maio 2021.

HAYKIN, S. Redes neurais: princípios e prática. Ontário: Bookman Editora, 2007.

HE, Q.; HAN, B. Accelerating full waveform inversion using HSS solver and limited memory conjugate gradient method. Journal of Applied Geophysics, v. 159, p. 83-92, 1 dez. 2018.

HINTON, G. E.; OSINDERO, S.; TEH, Y. W. A fast learning algorithm for deep belief nets. Neural Computation, v. 18, n. 7, p. 1527-1554, 1 jul. 2006. Disponível em: $<$ http://direct.mit.edu/neco/article-pdf/18/7/1527/816558/neco.2006.18.7.1527.pdf>. Acesso em: 28 abr. 2021.

HONG, H.; TSANGARATOS, P.; ILIA, I.; LIU, J.; ZHU, A. X.; CHEN, W. Application of fuzzy weight of evidence and data mining techniques in construction of flood susceptibility map of Poyang County, China. Science of the Total Environment, v. 625, p. 575-588, 1 jun. 2018.

HONG, H.; TSANGARATOS, P.; ILIA, I.; LIU, J.; ZHU, A. X.; XU, C. Applying genetic algorithms to set the optimal combination of forest fire related variables and model forest fire susceptibility based on data mining models. The case of Dayu County, China. Science of the Total Environment, v. 630, p. 1044-1056, 15 jul. 2018.

HONG, H.; PANAHI, M.; et al. Flood susceptibility assessment in Hengfeng area coupling adaptive neuro-fuzzy inference system with genetic algorithm and differential evolution. Science of the Total Environment, v. 621, p. 1124-1141, 15 abr. 2018.

HUANG, J. et al. Large-scale optimization of multi-pollutant control strategies in the Pearl 
River Delta region of China using a genetic algorithm in machine learning. Science of the Total Environment, v. 722, p. 137701, 20 jun. 2020.

INGRAM, J. C.; DAWSON, T. P.; WHITTAKER, R. J. Mapping tropical forest structure in southeastern Madagascar using remote sensing and artificial neural networks. Remote Sensing of Environment, v. 94, n. 4, p. 491-507, 28 fev. 2005.

KLEEDTKE, N.; HUA, M.; POZZI, S. Genetic algorithm optimization of tin-copper graded shielding for improved plutonium safeguards measurements. Nuclear Instruments and Methods in Physics Research, Section A: Accelerators, Spectrometers, Detectors and Associated Equipment, v. 988, p. 164877, 1 fev. 2021.

KUBASSOVA, O. et al. History, current status, and future directions of artificial intelligence. Precis. Med. Artif. Intell. [S.1.]: Elsevier, 2021. p. 1-38.

LECUN, Y. et al. Gradient-based learning applied to document recognition. Proceedings of the IEEE, v. 86, n. 11, p. 2278-2323, 1998.

LEE, J.-G. et al. Deep Learning in Medical Imaging: General Overview. Korean Journal of Radiology, v. 18, n. 4, p. 570, 2017. Disponível em: <https://www.kjronline.org/DOIx.php?id=10.3348/kjr.2017.18.4.570>.

LI, R. et al. Phenology-based classification of crop species and rotation types using fused MODIS and Landsat data: The comparison of a random-forest-based model and a decisionrule-based model. Soil and Tillage Research, v. 206, p. 104838, 1 fev. 2021.

LI, X. et al. Analysis of coastal wind speed retrieval from CYGNSS mission using artificial neural network. Remote Sensing of Environment, v. 260, p. 112454, 1 jul. 2021.

LIGHTHILL, J. Artificial intelligence: A general survey. 1973, London: Science Research Council, 1973. p. 1-21.

LIMA FILHO, M. M. De. A O Experimento de Pensamento do Quarto Chinês: a Crítica de John searle à Inteligência Artificial Forte. Argumentos, v. 2, n. 3, p. 8, 2010.

LIU, B. et al. Risk assessment of hybrid rain harvesting system and other small drinking water supply systems by game theory and fuzzy logic modeling. Science of the Total Environment, v. 708, p. 134436, 15 mar. 2020.

LUGER, G. F. Inteligência Artificial. 4 ed. ed. Porto Alegre: Bookman, 2002. 
MANCO, L. et al. Basic of machine learning and deep learning in imaging for medical physicists. Physica Medica, v. 83, p. 194-205, 1 mar. 2021.

MCCARTHY, J. Some Expert Systems Need Common Sense. 1984.

MCCORDUCK, P. Machines who think: A personal inquiry into the history and prospects of artificial intelligence. [S.1.]: CRC Press, 2004.

MCCULLOCH, W. S.; PITTS, W. A logical calculus of the ideas immanent in nervous activity. The Bulletin of Mathematical Biophysics, v. 5, n. 4, p. 115-133, dez. 1943. Disponível em: <https://link.springer.com/article/10.1007/BF02478259>. Acesso em: 28 abr. 2021.

MEDEIROS, L. F. de. Inteligência artificial aplicada: uma abordagem introdutória. Cutitiba: InterSaberes, 2018.

MILTON-THOMPSON, O. et al. Developing a fuzzy logic-based risk assessment for groundwater contamination from well integrity failure during hydraulic fracturing. Science of the Total Environment, v. 769, p. 145051, 15 maio 2021.

MINSKY, M.; PAPERT, S. A. Perceptrons: An introduction to computational geometry. [S.1.]: MIT press, 1969.

MORALA, P. et al. Towards a mathematical framework to inform neural network modelling via polynomial regression. Neural Networks, 30 abr. 2021. Disponível em: <https://linkinghub.elsevier.com/retrieve/pii/S0893608021001738>. Acesso em: 3 maio 2021.

MUTHUKRISHNAN, N. et al. Brief History of Artificial Intelligence. Neuroimaging Clinics of North America. [S.1.]: W.B. Saunders. , 1 nov. 2020

NADIRI, A. A. et al. Mapping vulnerability of multiple aquifers using multiple models and fuzzy logic to objectively derive model structures. Science of the Total Environment, v. 593594, p. 75-90, 1 set. 2017.

OLIVEIRA, R. F. de. Inteligência Artificial. Londrina: Editora e Distribuidora educacional S.A., 2018.

ÖZÇELIK, R. et al. Estimating Crimean juniper tree height using nonlinear regression and artificial neural network models. Forest Ecology and Management, v. 306, p. 52-60, 15 out. 2013. 
PIROVANI, D. B. et al. Climate change impacts on the aptitude area of forest species. Ecological Indicators, v. 95, p. 405-416, 1 dez. 2018.

POONGOTHAI, V.; KANNAN, M.; GODHANDARAMAN, P. Performance analysis of a single scheduling machine with cluster supply system, retardation, makespan and deterrent protection using genetic algorithm. Materials Today: Proceedings, 26 fev. 2021.

REIS, L. P. et al. Prognosis on the diameter of individual trees on the eastern region of the amazon using artificial neural networks. Forest Ecology and Management, v. 382, p. 161167, 15 dez. 2016.

RODRIGUES, F. L. et al. Metaheurística algoritmo genético para solução de problemas de planejamento florestal com restrições de integridade. Revista Árvore, v. 28, n. 2, p. 233-245, abr. 2004. Disponível em: <http://www.scielo.br/scielo.php?script=sci_arttext\&pid=S010067622004000200010\&lng=en\&nrm=iso\&tlng=pt>. Acesso em: 6 maio 2021.

ROSENBLATT, F. The perceptron: A probabilistic model for information storage and organization in the brain. Psychological Review, v. 65, n. 6, p. 386-408, nov. 1958. Disponível em: <https://psycnet.apa.org/journals/rev/65/6/386>. Acesso em: 28 abr. 2021.

RUINEIHART, D. E.; HINT, G. E.; WILLIAMS, R. J. LEARNING INTERNAL REPRESENTATIONS BERROR PROPAGATION two. . [S.l: s.n.], 1 set. 1985. Disponível em: <https://apps.dtic.mil/sti/citations/ADA164453>. Acesso em: 28 abr. 2021.

RUMELHART, D. E.; HINTON, G. E.; WILLIAMS, R. J. Learning representations by backpropagating errors. Nature, v. 323, n. 6088, p. 533-536, 1986. Disponível em: <https://www.nature.com/articles/323533a0>. Acesso em: 28 abr. 2021.

RUSSELL, S.; NORVIG, P. Inteligência Artificial. 3 ed. ed. Rio de Janeiro: Campus, 2013.

SAFAEI, M. et al. Optimization of species distribution models using a genetic algorithm for simulating climate change effects on Zagros forests in Iran. Ecological Informatics, v. 63, p. 101288, 1 jul. 2021.

SANTI, E. et al. Monitoring of Alpine snow using satellite radiometers and artificial neural networks. Remote Sensing of Environment, v. 144, p. 179-186, 25 mar. 2014.

SANTOS, J. S. et al. Delimitation of ecological corridors in the Brazilian Atlantic Forest. Ecological Indicators, v. 88, p. 414-424, 1 maio 2018. 
SCERRI, M.; GRECH, V. Artificial intelligence in medicine. Early Human Development, v. 145, p. 105017, 1 jun. 2020.

SCHAEFFER, J.; PLAAT, A. Kasparov versus Deep Blue: The Rematch. ICGA Journal, v. 20, n. 2, p. 95-101, 30 jan. 2018.

SERRANO-GUERRERO, J.; ROMERO, F. P.; OLIVAS, J. A. Fuzzy logic applied to opinion mining: A review. Knowledge-Based Systems, v. 222, p. 107018, 21 jun. 2021.

SEYEDPOUR, S. M. et al. Optimal remediation design and simulation of groundwater flow coupled to contaminant transport using genetic algorithm and radial point collocation method (RPCM). Science of the Total Environment, v. 669, p. 389-399, 15 jun. 2019.

SHARMA, N.; SHARMA, R.; JINDAL, N. Machine Learning and Deep Learning Applications-A Vision. Global Transitions Proceedings, v. 2, n. 1, p. 24-28, 1 jun. 2021.

SILVA, I. N. da; AMARAL, W. C. do; ARRUDA, L. V. R. de. Uma abordagem usando redes neurais artificiais para resolução de problemas de otimização restrita. Pesquisa Operacional, v. 24, n. 2, p. 285-302, ago. 2004. Disponível em: $<$ http://www.scielo.br/scielo.php?script=sci_arttext\&pid=S0101$74382004000200005 \& \operatorname{lng}=\mathrm{en} \& n \mathrm{~nm}=\mathrm{iso} \& \mathrm{t} \operatorname{lng}=\mathrm{pt}>$. Acesso em: 6 maio 2021.

SILVA, J. P. M. Prognose da produção florestal utilizando sistema neuro-fuzzy e random forest. 2018. 67 f. Tese (Doutorado em Ciências Florestais) - Universidade Federal do Espírito Santo, 2018.

SILVA, R. F. Modelagem e avaliação de diferentes métodos de otimização do sortimento florestal. 2018. 179 f. Tese (Doutorado em Ciências Florestais) - Universidade Federal do Espírito Santo, 2018.

SO, C. et al. PWR core loading pattern optimization with adaptive genetic algorithm. Annals of Nuclear Energy, v. 159, p. 108331, 1 set. 2021.

SUDHA, T.; JAYALALITHA, G. Analysis of fuzzy logic and fractals in DNA sequences based on human signature. Materials Today: Proceedings, 6 mar. 2021.

SUN, R. Artificial Intelligence: Connectionist and Symbolic Approaches. Int. Encycl. Soc. Behav. Sci. Second Ed. [S.1.]: Elsevier Inc., 2015. p. 35-40.

TAHERI, M.; XIE, F.; LEDERER, J. Statistical guarantees for regularized neural networks. 
Inteligência artificial aplicada às ciências florestais e agricultura

Neural Networks, 30 abr. 2021. Disponível em:

<https://linkinghub.elsevier.com/retrieve/pii/S0893608021001714>. Acesso em: 3 maio 2021.

TANG, S.; YANG, Y. Why neural networks apply to scientific computing? Theoretical and Applied Mechanics Letters, p. 100242, 3 abr. 2021.

TANQUE, M. Knowledge Representation and Reasoning in AI-Based Solutions and IoT Applications. Artif. Intell. to Solve Pervasive Internet Things Issues. [S.1.]: Elsevier, 2021. p. 13-49.

TIWARY, A. K. et al. Automated coal petrography using random forest. International Journal of Coal Geology, v. 232, p. 103629, 1 dez. 2020.

TROMBETTI, M. et al. Multi-temporal vegetation canopy water content retrieval and interpretation using artificial neural networks for the continental USA. Remote Sensing of Environment, v. 112, n. 1, p. 203-215, 15 jan. 2008.

TURING, A. M. Computing machinery and intelligence. Mind, v. 59, n. 236, p. 433-460, 1950. Computing machinery and intelligence. Parsing Turing Test Philos. Methodol. Issues Quest Think. Comput. [S.1.]: Springer Netherlands, 2009. p. 23-65. Disponível em: <https://link.springer.com/chapter/10.1007/978-1-4020-6710-5_3>. Acesso em: 28 abr. 2021.

VAN GERVEN, M.; BOHTE, S. Editorial: Artificial Neural Networks as Models of Neural Information Processing. Frontiers in Computational Neuroscience, v. 11, 19 dez. 2017. Disponível em: <http://journal.frontiersin.org/article/10.3389/fncom.2017.00114/full>.

WAMBA, S. F. et al. Are we preparing for a good AI society? A bibliometric review and research agenda. Technological Forecasting and Social Change, v. 164, p. 120482, 1 mar. 2021.

WANG, Z. et al. Disentangling the effects of stand and climatic variables on forest productivity of Chinese fir plantations in subtropical China using a random forest algorithm. Agricultural and Forest Meteorology, v. 304-305, p. 108412, 15 jul. 2021.

WUERGES, A. F. E.; BORBA, J. A. Redes neurais, lógica nebulosa e algoritmos genéticos: aplicações e possibilidades em finanças e contabilidade. JISTEM Journal of Information Systems and Technology Management, v. 7, n. 1, p. 163-182, 30 abr. 2010. Disponível em: <http://www.jistem.tecsi.org/index.php/jistem/article/view/10.4301\%252FS1807- 
$17752010000100007 / 193>$.

YADAV, S. et al. Above-ground biomass estimation of Indian tropical forests using $\mathrm{X}$ band Pol-InSAR and Random Forest. Remote Sensing Applications: Society and Environment, v. 21, p. 100462, 1 jan. 2021.

YANG, S. et al. Modeling grassland above-ground biomass based on artificial neural network and remote sensing in the Three-River Headwaters Region. Remote Sensing of Environment, v. 204, p. 448-455, 1 jan. 2018.

YILMAZ, B. M. et al. Adaptive fuzzy logic with self-tuned membership functions based repetitive learning control of robotic manipulators. Applied Soft Computing, v. 104, p. 107183, 1 jun. 2021. 


\section{CAPÍTULO 02 - LÓGICA FUZZY: FUNDAMENTOS TEÓRICOS E \\ ESPECIALIZAÇÃO \\ Taís Rizzo Moreira e Telma Machado de Oliveira Peluzio \\ https://doi.org/10.29327/ 552680.1-2}

\section{INTRODUÇÃO GERAL}

Ao nos comunicarmos e trocarmos informações sobre uma diversidade de fatores, nos embasamos em uma linguagem natural que contém ambiguidade e multiplicidade de sentidos. Em particular, os adjetivos, que utilizamos para caracterizar objetos, situações ou pessoas, não transmite clareza suficiente, sendo ambíguos em termos de amplitude de significado. Se, por exemplo, dissermos que uma árvore é alta, não podemos claramente afirmar que árvore é alta e que árvore não é. Adjetivos são usualmente qualitativos, mas alguns como alto ou antigo são percebidos em conexão com quantidades de altura ou idade. Desta forma, adjetivos que descrevem estados ou condições são, quase sempre, relacionados a quantidades e muito utilizados em diversas áreas e análises, sendo necessária a utilização de termos que se referem a níveis intermediários, como, um pouco mais alta, parcialmente, totalmente, dentre outros. Surge assim, a lógica fuzzy (LF) que consiste em modelar um problema de modo aproximado ao invés de preciso, da mesma forma que o raciocínio humano em diversas situações (JANARTHANAN et al., 2020; SERRANO-GUERRERO; ROMERO; OLIVAS, 2021).

A característica especial da lógica fuzzy (também referida como lógica nebulosa, lógica difusa e em alguns casos por teoria de possibilidades) é a de representar uma forma inovadora de manuseio de informações imprecisas. A lógica fuzzy se constitui de um método de traduzir expressões verbais, vagas, imprecisas e qualitativas, comuns na comunicação humana em valores numéricos. Isso abre as portas para se converter a experiência humana em uma forma compreendida pelos computadores. Assim, a lógica fuzzy tem um imenso valor prático, tornando possível a inclusão da experiência de operadores humanos em controladores computacionais, possibilitando estratégias de tomada de decisão em problemas complexos (SARMAH; NEMA; SARMAH, 2020; SIMÕES; SHAW, 2007).

Diante do exposto, a lógica fuzzy se apresenta como um método de análise de desenvolvido para incorporar a incerteza em um modelo de decisão. Permitindo assim, incluir informações imperfeitas, em essência, a lógica fuzzy permite considerar valores aproximados e não somente valores precisos. Existem benefícios importantes na aplicação de ferramentas da lógica fuzzy. Tais ferramentas, fornecem uma plataforma simplificada onde o desenvolvimento 
e a análise de modelos podem ser executados com tempo reduzido. Como resultado, as ferramentas difusas são fáceis de implementar e modificar (AZADEGAN et al., 2011; SERRANO-GUERRERO; ROMERO; OLIVAS, 2021).

A abordagem da lógica difusa é diferente da "lógica nítida" (lógica booleana), onde as decisões e o raciocínio são binários e baseados na lógica proposicional. Na lógica difusa, as variáveis carregam uma faixa entre 0 e 1 e não são necessariamente restritas a tais limites binários. Em vez disso, uma variável carrega um grau de pertinência em um conjunto fuzzy (AZADEGAN et al., 2011).

Uma analogia simplória a respeito da lógica fuzzy está contida na Figura 2.1, diferente de uma pesquisa binária (lógica clássica), nessa escala as respostas variam conforme o grau de concordância da pessoa respondendo a uma determinada pergunta. Enquanto que, na lógica binária (clássica) nós só temos uma resposta que pode assumir apenas dois valores (no caso do exemplo, sim ou não, zero ou um), na lógica fuzzy nós podemos obter uma resposta que está entre esses dois valores (no exemplo, você poderia não concordar 100\% com a pergunta feita, então poderia escolher a opção de concordar parcialmente).

\section{Esse capítulo foi útil em explicar sobre lógica fuzzy?}

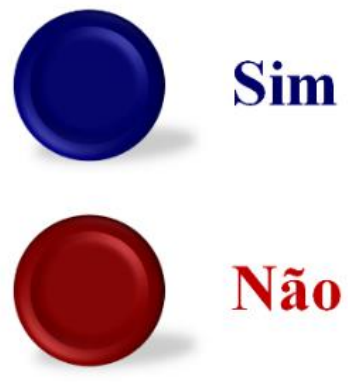

Lógica booleana

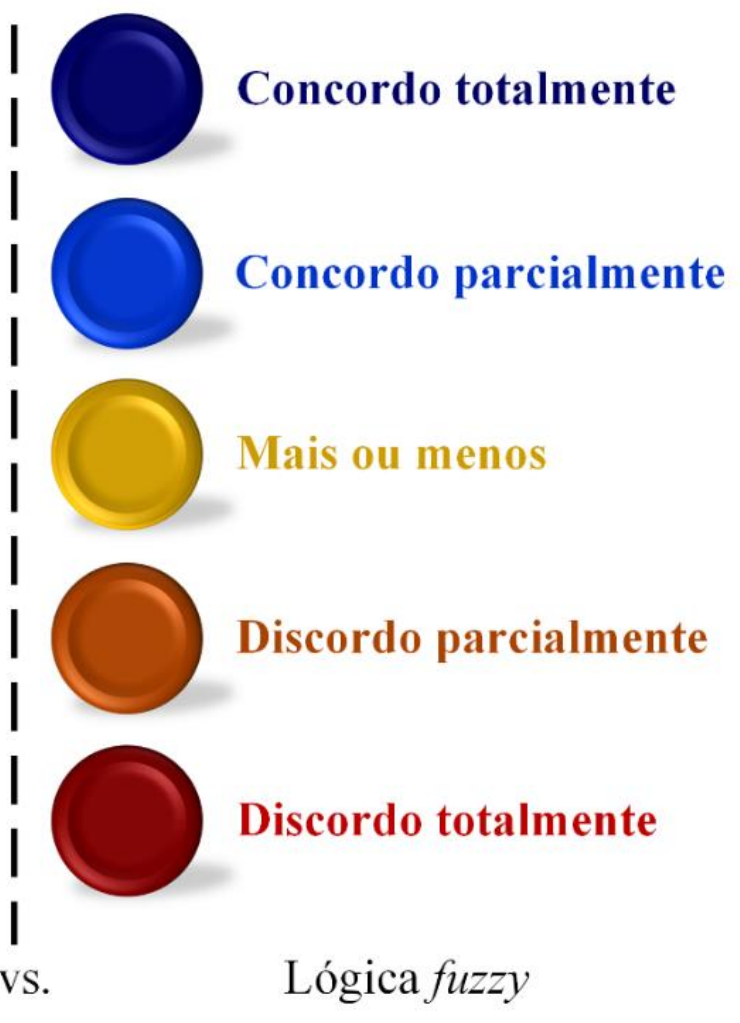

Fonte: Adaptado de Azadegan et al. (2011).

Figura 2.1 - Analogia para diferenciar a lógica fuzzy da lógica clássica (booleana). 


\section{HISTÓRICO DA LÓGICA FUZZY}

Na teoria clássica, os conjuntos são denominados "crisp", por isso, a lógica clássica, é também conhecida como lógica crisp, desenvolvida no século IV a.C. pelo filósofo grego Aristóteles, motivo pelo qual, muitas vezes, em sua homenagem, é chamada Lógica Aristotélica. Aristóteles, tirou sua ideia do trabalho de um filósofo grego que o precedeu, Pitágoras, e seus seguidores, os quais acreditavam que esse assunto era essencialmente numérico e que o universo poderia ser definido por meio de relações numéricas (QUIROGA; MORENO, 2015).

Saltando para o século XVIII, o filósofo e clérigo irlandês George Berkeley e o escocês David Hume pensavam que todo conceito tem um elemento central concreto, para o qual são atraídos todos os outros que, de alguma maneira, lhes são semelhantes. Hume, acreditava que a razão se baseava no conhecimento, que as pessoas adquiriam por senso comum, por viverem e compartilharem experiência no mesmo mundo (LIPTON, 2015). Na Alemanha, Kant considerava que somente a matemática poderia proporcionar definições nítidas e que não se poderia conciliar princípios contraditórios. Ele citava o fato de a matéria poder ser dividida infinitamente, mas ao mesmo tempo não poder ser infinitamente dividida (COOPER, 2020).

Frente a todo cenário apresentado anteriormente, a lógica Booleana, surgiu no século XIX, desenvolvida por George Boole, e possui dois estados (valores ou símbolos) permitidos. Em geral o estado zero representa não ou falso e o estado um representa sim ou verdadeiro. A maioria das pessoas, na época, julgou que isso não tinha utilidade, motivo pelo qual a lógica booleana permaneceu na obscuridade por algum tempo. Tal lógica foi "redescoberta" e, juntamente com os circuitos integrados, trouxe à luz os microprocessadores e os computadores (BALBIANI; TINCHEV, 2010; EBBING et al., 2017; SCELLS et al., 2020).

No final do século XIX, em busca de soluções não aristotélica para questões lógicas que não possuíam maneiras de solucioná-las, alguns trabalhos foram os precursores das lógicas não clássicas. Já nas primeiras décadas do século seguinte, matemáticos e filósofos criaram novos sistemas lógicos, diferente daqueles representados pela lógica de Aristóteles (SILVA, A. A. Da, 2012). A ideia de que a lógica tradicional produzia contradições, não passíveis de serem gerenciadas, surgiu e foi popularizada no princípio do século XX pelo filósofo e matemático inglês Bertrand Russel. Ele, também estudou a incerteza da linguagem, bem como sua precisão, concluindo que a incerteza é objeto de nuanças (SARAIVA, 2000).

George Kantor, matemático alemão, ainda no século XIX, criou a teoria dos conjuntos originais ( 0 ou 1), este conjunto possui as mesmas restrições que a lógica em que foi embasado. A primeira lógica de incerteza foi desenvolvida em 1920 pelo filósofo polonês Jan Lukasiewicz. 
Ele criou conjuntos com valores possíveis de pertinência $0,0,5$ e 1, que posteriormente, tornouse um conjunto infinito de números entre 0 e 1 (HARDER; BESOLD, 2018; OSORIO; CARBALLIDO, 2020; POLKOWSKI, 2019).

O passo seguinte, no contexto do histórico da lógica fuzzy, ocorreu em 1937, na Universidade de Cornell, nos Estados Unidos, quando Max Black considerou a ampliação do conceito de quais objetos poderiam pertencer a um conjunto. Ele mediu a pertinência em graus de utilização e defendeu a teoria geral de incerteza. O trabalho desses pensadores dos séculos XIX e XX propiciou o fundamento da lógica fuzzy para o seu fundador, o americano Lotfi Zadeh (SARAIVA, 2000).

Com base nos estudos apresentados por Jan Lukasiewicz, o professor Lotfi Askar Zadeh, conhecido por desenvolver estudos na área de Inteligência Artificial (IA), percebeu que os métodos matemáticos tradicionais, disponíveis naquela época, não eram capazes de formalizar algumas situações referentes a problemas que compreendessem posições ambíguas, não completamente claras ou sem um contorno nítido, introduziu assim a lógica fuzzy, por meio de seu artigo 'Conjuntos difusos' (fuzzy sets) em 1965. Para contornar os problemas de representação da lógica clássica, a alternativa proposta por Zadeh aceitava mais de dois possíveis valores de verdade. A teoria de conjuntos fuzzy, proposta pelo professor, não aplicava a bivalência como usualmente, depois, na metade da década seguinte, ele sugeriu uma lógica não clássica, estruturada com base na sua teoria de conjuntos, também não clássica (SIMIĆ et al., 2017).

\section{OBJETIVOS E METODOLOGIA GERAL DA LÓGICA FUZZY}

A lógica fuzzy e suas interfaces permitem a um especialista contornar problemas, cujo tratamento numérico é muito difícil pela quantidade de variáveis envolvidas ou por manipulação matemática complexas, cujos resultados nem sempre atendem as expectativas de soluções desejadas (KUMAR; SHARMA, 2019).

Por acreditar que nada é incondicionalmente verdadeiro existe uma oposição a toda afirmação de verdade absoluta, e, desta forma, a LF está ligada à importância relativa da precisão. Tal lógica está baseada em palavras e não em números, ou seja, através dela os valores de verdade são expressos linguisticamente. Alguns exemplos dessas expressões são: poucos, vários, em torno de, muito, mais ou menos, bastante, médio, provável, improvável. A lógica faz uso das probabilidades linguísticas que são interpretadas como números nebulosos, 
manipulados pela sua aritmética e manuseia todos os valores entre 0 e 1 , tornando-os apenas um limite (LIMA et al., 2021).

A LF é flexível ao interagir com qualquer sistema, sendo por isto indicada para se trabalhar com dados imprecisos. Utiliza-se esta lógica porque mais variáveis observáveis podem ser valoradas e o uso de variáveis linguísticas se aproxima do pensamento humano, simplificando a solução de problemas e proporcionando um rápido protótipo dos sistemas (SOUZA, 2020).

Além do dito anteriormente, a LF pode ser utilizada para modelar funções não lineares de complexidade arbitrária, possibilitando a criação de um sistema nebuloso que se combina com qualquer conjunto de dados de entrada e saída. Esse processo é feito por meio de técnicas adaptativas (ZHAO; TONG; LI, 2021). Esses sistemas nebulosos podem ser construídos com o auxílio da experiência de especialistas, o que permite uma interação com pessoas que já entendam o problema em análise. Embora esta abordagem não pretenda substituir os métodos convencionais de controle, ela simplifica a sua implementação (LAMAMRA; BATAT; MOKHTARI, 2020; ZHAO; TONG; LI, 2021).

Vale ressaltar que no caso da existência de uma solução mais simples para um problema, deve-se utilizá-la e não a lógica fuzzy. Deve-se empregar essa técnica com sabedoria, por se tratar de uma ferramenta poderosa para se lidar de forma rápida e eficiente com a imprecisão e a não linearidade dos problemas do mundo real (KUMAR; SHARMA, 2019; LAMAMRA; BATAT; MOKHTARI, 2020; LIMA et al., 2021; SOUZA, 2020; ZHAO; TONG; LI, 2021).

A fim de aplicar a técnica de LF a um problema pratico, as seguintes etapas, apresentadas na Figura 2.2, devem ser seguidas (KAMBALIMATH; DEKA, 2020):

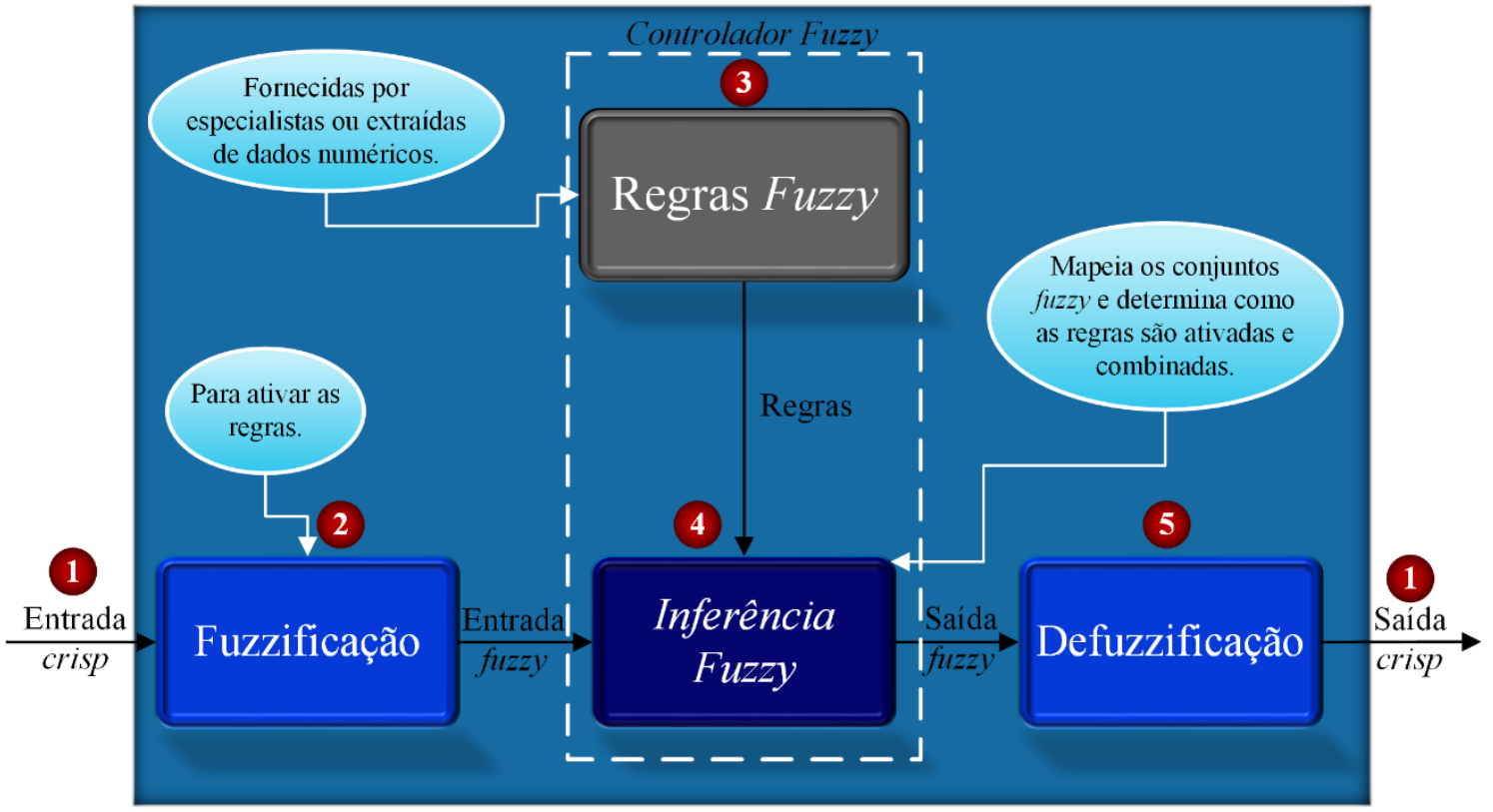

Fonte: Adaptado de Kambalimath e Deka (2020).

Figura 2.2 - Componentes de um sistema de controle fuzzy. 
1) Entrada e saída crisp - Cada variável fuzzy possui um valor chamado de valor crisp, que nada mais é do que um número dentro de um domínio pré-determinado (na LF esse domínio é chamado de universo). O universo então é a definição do intervalo dos valores no qual se encontra a variável e, por isso, precisamos definir quais são seus valores mínimo e máximo. Imagine que temos um sistema que tem uma variável fuzzy referente à altura de uma árvore. Assim, começamos definindo que o universo para essa variável terá o intervalo de $1,30 \mathrm{~m}$ a $30 \mathrm{~m}$ (limites do conjunto avaliado). Agora, vamos supor que eu fornecerei a altura de uma arvore X para esse sistema; nesse caso, a entrada terá um valor crisp de 4,54 m.

2) Fuzzificação - A primeira etapa do sistema de controle fuzzy é a aplicação da fuzzificação nas entradas crisp que foram inseridas. Essa etapa consiste em transformar o valor crisp da entrada para um valor fuzzy e, para isso, utiliza-se os termos (que compõem o conjunto fuzzy) e as funções de pertinência.

3) Regras Fuzzy - São utilizadas para ligar diferentes variáveis fuzzy, de modo que elas descrevem como uma ou mais variáveis fuzzy estão relacionadas umas com as outras. Cada uma das regras que compõem o conjunto de regras fuzzy são expressas por meio de declaração de if/then (se/então).

4) Inferência $\boldsymbol{F u z z y}$ - Este processo consiste em combinar as funções de pertinência junto com as regras de controle fuzzy para obter a saída fuzzy. Existe uma diversidade de técnicas de inferência fuzzy.

5) Defuzzificação - O componente final do nosso sistema de controle fuzzy é chamado de defuzzificação. Ela é necessária quando se espera que o sistema retorne um número e não o conjunto fuzzy, como ocorre na maioria das vezes. Nessa etapa, precisamos converter a saída da inferência fuzzy, feita com base nas funções de pertinência e nas regras, para um valor crisp. Diversos métodos podem ser utilizados para fazer essa conversão, como, por exemplo, centroide, média dos máximos, mínimo dos máximos, máximo dos máximos, dentre outros.

\section{CONCEITOS BÁSICOS}

A seguir é apresentado um resumo dos principais conceitos referentes a lógica fuzzy. Alguns desses conceitos estão diretamente relacionados a metodologia descrita anteriormente. 


\subsection{Teoria dos conjuntos fuzzy ou nebulosos}

A teoria de conjuntos fuzzy é uma extensão da teoria dos conjuntos clássicos. Na última, os conjuntos são denominados crisp e um determinado elemento do universo de discurso, ou seja, o domínio, pertence ou não pertence ao referido conjunto, isto pode ser expresso pela função $f_{A}$ (Equação 2.1). Já no conjunto fuzzy, para cada elemento existe um grau de pertinência a um dado conjunto (KABIR; PAPADOPOULOS, 2018; YUAN et al., 2021).

$$
f_{A}(x)=\left\{\begin{array}{l}
1 \text { se e somente se } x \in A \\
0 \text { se e somente se } \mathrm{x} \notin A
\end{array}\right\} \quad \text { Equação 2.1 }
$$

Em alguns casos a teoria clássica é satisfatoriamente utilizada, entretanto para outros ela pode não ser suficiente, como é o caso dos conjuntos cujo limite entre pertinência e nãopertinência não é claro, e existe uma transição gradual entre esses dois grupos (YUAN et al., 2021). Temos como exemplo:

$\checkmark$ O conjunto de árvores altas;

$\checkmark$ O conjunto de cursos hídricos com alta vasão, e;

$\checkmark$ O conjunto de áreas florestadas com maior potencial para serem preservadas.

Utilizando os conjuntos fuzzy podemos definir critérios e graus de pertinência para essas situações. A função característica é generalizada de forma a assumir um número infinito de valores dentro do intervalo [0,1] (KABIR; PAPADOPOULOS, 2018).

Um conjunto fuzzy $A$ em um universo $U$ é definido por uma função de pertinência (Equação 2.2) (KABIR; PAPADOPOULOS, 2018).

$$
\begin{array}{ll}
\mu_{A}(x): X \rightarrow[0,1] \quad \text { Equação } 2.2
\end{array}
$$

Por exemplo, na lógica exata, quando é definido o conjunto $A$ de árvores altas, este é formado por todas as árvores que medem $30 \mathrm{~m}$ ou mais. Mas, quando esse conjunto é classificado na LF, se compõe de todas as árvores que medem entre 15 e 30 m, e passa a ter mais denominações e intervalos, como, por exemplo, acima de $30 \mathrm{~m}$ árvores muito altas. Neste intervalo existe uma função que aponta o grau de verdade de uma variável, chamada de função de pertinência (Figura 2.3). 

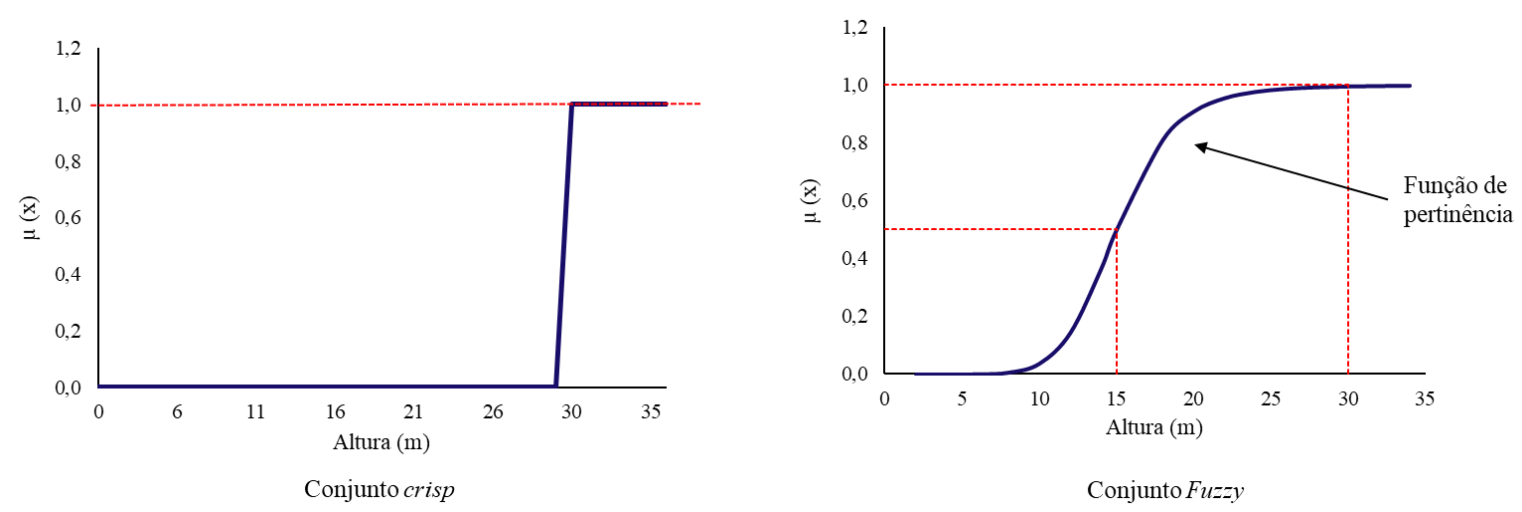

Fonte: Adaptado de Sleit; Saadeh and Mobaideen (2016).

Figura 2.3 - Comparação de conjunto crisp e fuzzy.

O conjunto suporte de um conjunto fuzzy $A$ é o conjunto de elementos no universo $X$ para os quais $\mu_{A}(x)>0$. Um conjunto fuzzy cujo suporte é um único ponto $x$ 'com $\mu_{A}(x)=1$ é chamado de conjunto unitário fuzzy ou singleton (TONG et al., 2021). A Figura 2.4 ilustra um conjunto singleton de domínio 4.

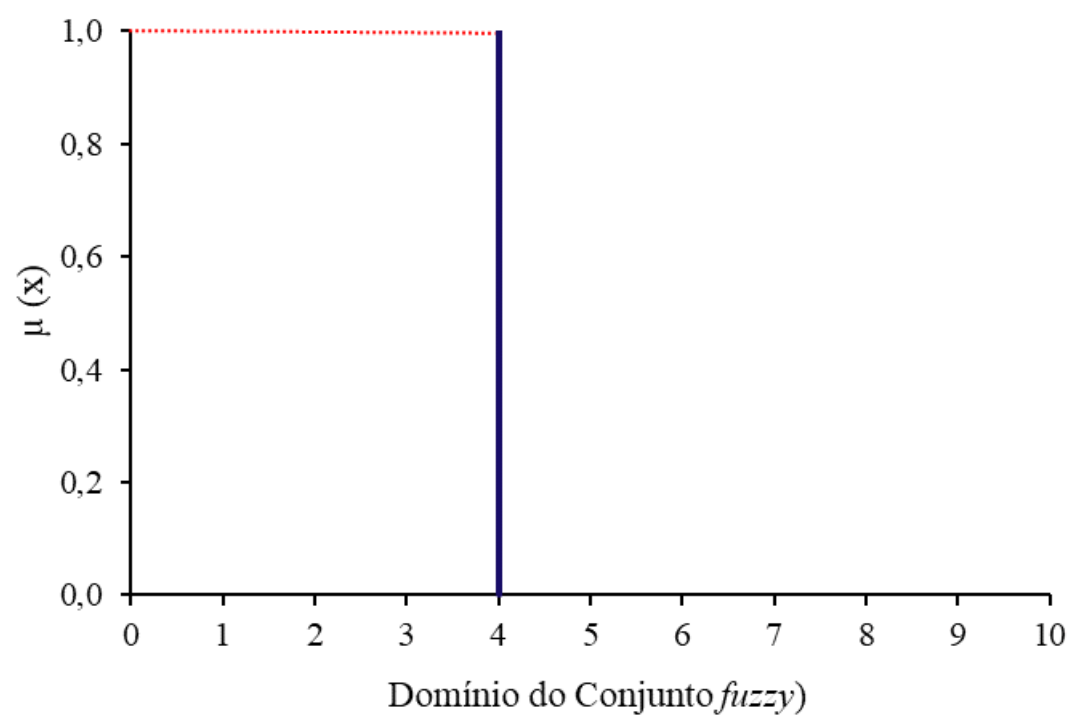

Fonte: Adaptado de Juvanhol (2014).

Figura 2.4 - Exemplo de conjunto singleton.

Além do singleton surge um outro termo ao nos referirmos ao conjunto fuzzy que é o conjunto $\alpha$-cut. $\mathrm{O} \alpha$-cut pode ser interpretado como o conjunto fuzzy que apresenta uma restrição ou um limite imposto ao domínio do conjunto baseado no valor do $\alpha$ (BAYKASOĞLU; GÖLCÜK, 2021). Assim, o conjunto resultante contém todos os elementos do domínio que possuem um grau de pertinência, $\mu(x)$ superior ou igual ao valor de $\alpha$. A Figura 2.5 ilustra um conjunto $\alpha$-cut com $\alpha=0,2$. 


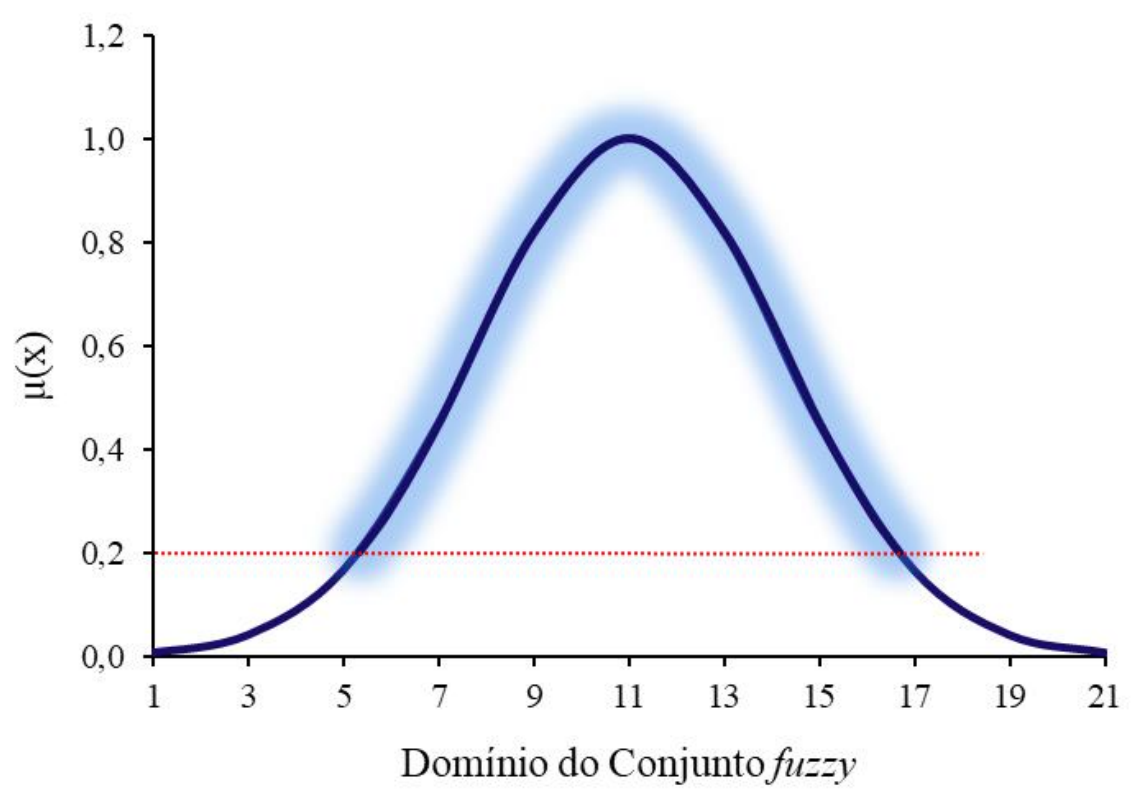

Figura 2.5 - Exemplo de conjunto $\alpha$-cut.

Desta forma, pode-se afirmar que os conjuntos fuzzy carregam algumas propriedades e conceitos que foram apresentados anteriormente e serão melhor descritos a seguir (CATTANEO, 2017; KABIR; PAPADOPOULOS, 2018; LAM; TAI, 2018; LIU, Y.; BI; FAN, 2017; SIMIĆ et al., 2017):

$\checkmark$ Altura: é o maior grau de pertinência permitido pela função de pertinência;

$\checkmark$ Normalização: um certo conjunto fuzzy é normal se sua altura for igual a 1, para obter um bom desempenho, os conjuntos fuzzy devem ser normalizados;

$\checkmark$ Domínio do conjunto fuzzy: é o universo total de valores possível para os elementos de um conjunto. Essa gama de valores é dependente do contexto;

$\checkmark$ Suporte de conjunto: é a área efetiva do domínio de um conjunto fuzzy que apresenta valores $\mu(x)>0$. Os conjuntos que apresentam um único ponto em $X$ com valor $\mu(x)=1$, é chamado de conjunto singleton, como dito anteriormente;

$\checkmark$ Conjunto $\alpha$-cut: é uma restrição imposta ao domínio, baseada no valor $\alpha$. Os elementos do domínio que possuem $\mu(x)$ acima de um certo valor de $\alpha$ estão contidos nesse conjunto. A utilização do conjunto $\alpha$-cut é útil para as funções que tendem a possuir valores muito baixos de $\mu(x)$ para um domínio extenso. Isso ajuda a reduzir o ruído, e;

$\checkmark$ Universo de discurso: é o espaço completo de variação de uma variável do modelo.

\subsubsection{Operações de conjuntos fuzzy}

Apresentaremos aqui as mais relevantes definições e operações envolvendo conjuntos fuzzy (AFONSO, 2009; WU, H. C., 2018). 
Um conjunto fuzzy $A$ em $U$ é vazio se e somente se sua função de pertinência for igual a zero sobre todo $U$ (Equação 2.3).

$$
A=\{\} \text { se e somente se } \mu_{A}(x)=0 \forall x \in U
$$

Equação 2.3

$\checkmark$ O complemento $A^{\prime}$ de um conjunto fuzzy $A$ é normalmente dado por (Equação 2.4):

$$
\mu_{A^{\prime}}(x)=1-\mu_{A}(x) \quad \forall x \in U
$$

Dois conjuntos fuzzy $A$ e $B$ em $U$ são iguais se suas funções de pertinência forem iguais sobre todo o $U$ (Equação 2.5).

$$
A=B \quad \mu_{A}(x)=\mu_{B}(x) \quad \forall x \in U
$$

Equação 2.5

Um conjunto fuzzy $A$ é um subconjunto de $B$ se sua função de pertinência for menor ou igual à de $B$ sobre todo o $U$ (Equação 2.6).

$$
A \subset B \text { se } \mu_{A}(x) \leq \mu_{B}(x) \quad \forall x \in U \quad \text { Equação } 2.6
$$

Sejam $A$ e $B$ conjuntos nebulosos definidos em $U$. Pode-se expressar a interseção destes conjuntos, como um outro conjunto $C=A \cap B$. Da mesma forma, pode-se expressar a união como um conjunto $D=A \cup B$. Embora a união e a interseção possam ser descritas também por meio de outros operadores, descreveremos por meio de operadores minimum (min) e maximum $(\max )$, representados por $(\wedge)$ e $(\vee)$, respectivamente, para a representação de interseção e união fuzzy, de modo que (Equação 2.7 e Equação 2.8):

$$
\begin{array}{ll}
\mu_{A \cap B}(x)=\mu_{A}(x) \wedge \mu_{B}(x) & \forall x \in U \\
\mu_{A \cup B}(x)=\mu_{A}(x) \vee \mu_{B}(x) & \forall x \in U
\end{array}
$$

Equação 2.8

$\mathrm{Na}$ teoria dos conjuntos fuzzy, a interseção é implementada por uma família de operadores denominados de norma-t (norma triangular), e a união é implementada por uma família de operadores denominados de co-norma-t (co-norma triangular ou norma-s). Com o objetivo de generalização, estes operadores foram definidos da seguinte forma:

Uma norma-t é uma operação binária: $[0,1]^{2} \rightarrow[0,1]$ tal que, $\forall x, y, z, w \in[0,1]$, as seguintes propriedades são satisfeitas:

Comutatividade: $x * y=y * x$

Associatividade: $(x * y) * z=x *\left(y^{*} z\right)$

Monotonicidade: se $x \leq y, w \leq z$, então $x * w \leq y * \mathrm{z}$

Condições de contorno: $x * 0=0$ e $x * 1=x$

Uma co-norma-t ou norma-s, é uma operação binária $\oplus:[0,1]^{2} \rightarrow[0,1]$, que satisfaz as seguintes propriedades: 
$\checkmark$ Comutatividade: $x \oplus y=y \oplus x$

$\checkmark$ Associatividade: $(x \oplus y) \oplus z=x \oplus(y \oplus z)$

$\checkmark$ Monotonicidade: se $x \leq y, w \leq z$, então $x \oplus w \leq y \oplus \mathrm{z}$

$\checkmark$ Condições de contorno: $x \oplus 0=x$ e $x \oplus 1=1$

\subsubsection{Propriedades dos conjuntos fuzzy}

Utilizando-se os operadores max e min para a descrição da união e interseção fuzzy, respectivamente, é fácil verificar que as seguintes propriedades algébricas de conjuntos ordinários também valem para conjuntos fuzzy (AFONSO, 2009; D’EER; CORNELIS, 2018; QIAO, 2021):

$\checkmark$ Involução: $\left(A^{\prime}\right)=A$

$\checkmark$ Idempotência: $\left\{\begin{array}{l}A \cap A=A \\ A \cup A=A\end{array}\right\}$

$\checkmark$ Comutatividade: $\left\{\begin{array}{l}A \cap B=B \cap A \\ A \cup B=B \cup A\end{array}\right\}$

$\checkmark$ Associatividade: $\left\{\begin{array}{l}(A \cap B) \cap C=A \cap(B \cap C) \\ (A \cup B) \cup C=A \cup(B \cup C)\end{array}\right\}$

$\checkmark$ Distributividade: $\left\{\begin{array}{l}A \cap(B \cup C)=(A \cap B) \cup(A \cap C) \\ A \cup(B \cap C)=(A \cup B) \cap(A \cup C)\end{array}\right\}$

$\checkmark$ Absorção: $\left\{\begin{array}{l}A \cap(A \cup B)=A \\ A \cup(A \cap B)=A\end{array}\right\}$

$\checkmark$ Lei transitiva: se $A \subset B$ e $B \subset C \Rightarrow A \subset C$

$\checkmark$ Leis de De Morgan: $\left\{\begin{array}{l}(A \cap B)^{\prime}=A^{\prime} \cup B^{\prime} \\ (A \cup B)^{\prime}=A^{\prime} \cap B^{\prime}\end{array}\right\}$

Observando que as funções de pertinência dos conjuntos vazio e universo são definidas como sendo 0 e 1 , respectivamente, verificam-se também as seguintes propriedades:

$$
\left\{\begin{array}{l}
A \cap\{\}=\{\} \\
A \cup\{\}=A
\end{array}\right\} \text { e }\left\{\begin{array}{l}
A \cap U=A \\
A \cup U=U
\end{array}\right\}
$$

As propriedades de conjuntos clássicos $A \cap A^{\prime}=\{\} e A \cup A^{\prime}=U$ não se verificam para conjuntos fuzzy quando os operadores max e min são utilizados (Equação 2.9 e Equação 2.10).

$$
\begin{aligned}
& \mu_{A \cap A^{\prime}}(x)=\mu_{A}(x) \wedge\left(1-\mu_{A}(x)\right) \neq 0 \Rightarrow A \cap A^{\prime} \neq\{\} \\
& \mu_{A \cup A^{\prime}}(x)=\mu_{A}(x) \vee\left(1-\mu_{A}(x)\right) \neq 1 \Rightarrow A \cup A^{\prime} \neq U
\end{aligned}
$$

Equação 2.10 


\subsection{Variáveis linguísticas}

Uma variável linguística é uma variável cujos valores são nomes de conjuntos fuzzy (DING; LIU; SHI, 2019; HOLT; LEACH, 2019). Por exemplo, a temperatura de um determinado processo pode ser uma variável linguística (expressa qualitativamente) assumindo valores baixa, média e alta. Estes valores são descritos por intermédio de conjuntos fuzzy, representados por funções de pertinência (representação quantitativa), conforme mostrado na Figura 2.6.

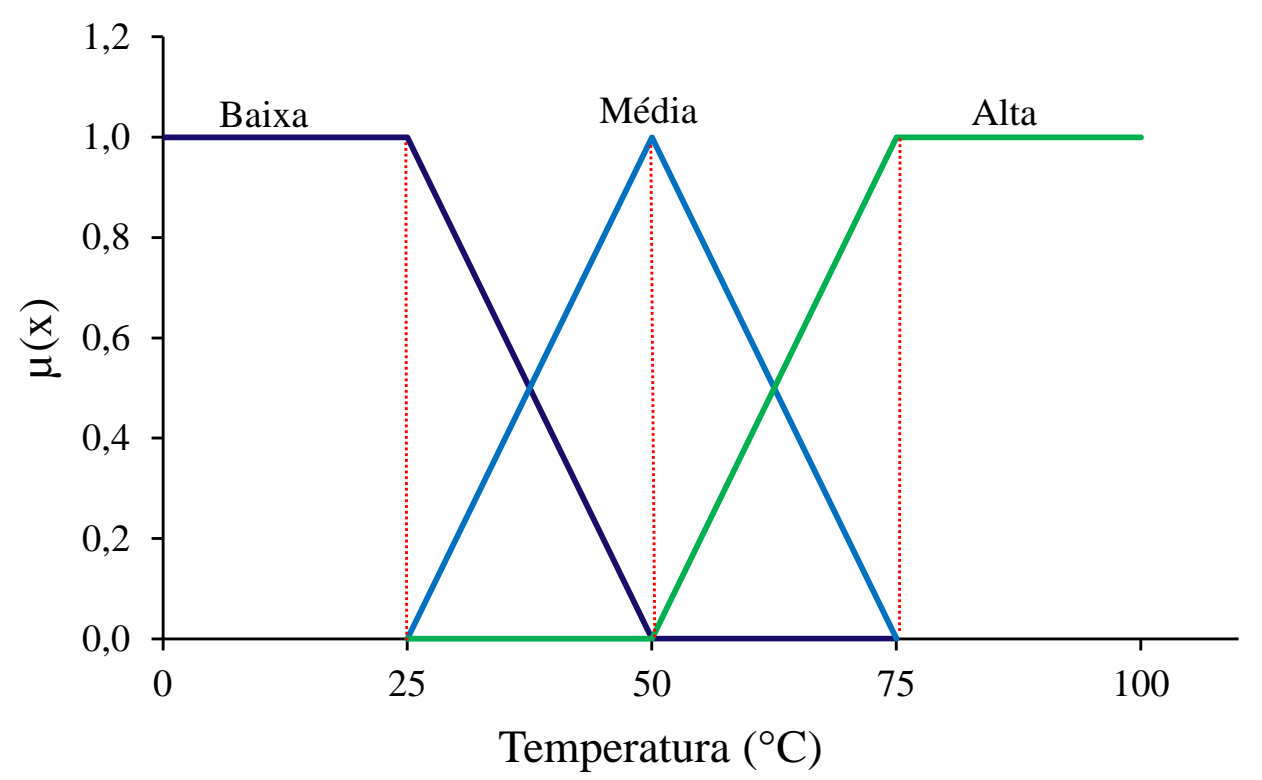

Fonte: Adaptado de Lam e Tai (2018).

Figura 2.6 - Funções de pertinência para a variável temperatura.

Generalizando, os valores de uma variável linguística são sentenças construídas a partir de termos primários (alto, baixo, pequeno, médio, grande, por exemplo), de conectivos lógicos (negação - não, conectivos - e/ou), de modificadores (muito, pouco, levemente, extremamente) e de delimitadores (como parênteses) (DING; LIU; SHI, 2019; HOLT; LEACH, 2019; ZHANG; GOU; XU, 2021).

Os termos linguísticos são usados para expressar conceitos e conhecimentos na comunicação humana, e em muitas áreas eles são a forma mais importante (quando não a única) de quantificar os dados/informações (ZHANG; GOU; XU, 2021). O uso de termos linguísticos é frequente no nosso cotidiano, dizemos que "O dia está muito quente", "O ônibus estava lotado", "A árvore é alta", "A chuva está muito intensa", dentre outros. Todos estes termos possuem um significado e transmitem informações.

Desta forma, a principal função das variáveis linguísticas é fornecer uma maneira sistemática para uma caracterização aproximada de fenômenos complexos ou mal definidos. Em essência, a utilização do tipo de descrição linguística empregada por seres humanos, e não 
de variáveis quantificadas, permite o tratamento de sistemas que são muito complexos para serem analisados através de termos matemáticos convencionais. Formalmente, uma variável linguística é caracterizada por $N, T(N), X, G, M$, onde (ALCALDE et al., 2011):

$N$ : nome da variável;

$T(N)$ : conjunto de termos de $N$, ou seja, o conjunto de nomes dos valores linguísticos de $N$;

$X$ : universo de discurso;

$G$ : regra sintática para gerar os valores de $N$ como uma composição de $T(N)$, conectivos lógicos, modificadores e delimitadores, e;

$M$ : regra semântica, para associar a cada valor gerado por $G$ um conjunto fuzzy em $X$.

No caso do exemplo apresentado na Figura 2.6, teríamos:

$N$ : temperatura;

$T(N)$ : $\{$ baixa, média, alta $\}$

$X: 0$ a $100{ }^{\circ} \mathrm{C}$ (por exemplo)

$G$ : temperatura não baixa e não muito alta, por exemplo, e;

$M$ : associa o valor $G$ a um conjunto fuzzy cuja função de pertinência exprime o seu significado.

\subsection{Funções de pertinência}

As funções de pertinência são funções que mapeiam valores do universo de discurso de uma dada variável aos graus de pertinência correspondentes, com o objetivo de representar uma classe, conceito ou característica da variável (RIGNEL; CHENCI; LUCAS, 2011).

A função que associa cada elemento de um conjunto fuzzy $A$ a medida de sua pertinência a esse conjunto é denominada função de pertinência. Nesse tópico apresentaremos os principais tipos de funções de pertinência que podem ser empregadas para a caracterização dos conjuntos fuzzy, juntamente com algumas características dessas funções (YAZDANBAKHSH; DICK, 2018).

\subsubsection{Características gerais}

A função de pertinência $\mu_{A}(x)$, é a responsável por associar os números reais contidos no intervalo $0 \leq x \leq 1$ aos elementos $x \in A$, dando assim, o grau de pertinência do elemento $x$ no conjunto $A$. A pertinência de um elemento em relação a determinado conjunto deve ser 
entendida como a "intensidade" com que este elemento está relacionado a tal conjunto (VAZ, 2006).

A definição da função de pertinência é bastante subjetiva, pois uma função específica para um mesmo conceito pode apresentar resultados variados se for definida por diferentes pessoas. Além de definir o quanto certo elemento pertence a determinado conjunto, a função de pertinência também serve para representar os limites de um conjunto fuzzy. A função de pertinência deve ser definida de forma adequada para representar a variação e os limites de cada conjunto fuzzy.

As funções de pertinência dos conjuntos fuzzy podem assumir diversas formas, sendo as funções triangular, trapezoidal, sigmoidal crescente (fuzzy large), sigmoidal decrescente (fuzzy small), gaussiana, linear e em forma de sino as mais utilizadas (JUVANHOL, 2014).

Outras funções podem ser utilizadas, e estão disponibilizadas em aplicativos que processam a lógica fuzzy, como é o caso do MATLAB, RStudio, ArcGIS, QGIS, dentre outros.

\subsubsection{Tipos de funções de pertinência}

As funções, que associam cada elemento de um conjunto fuzzy a sua pertinência, podem assumir diferentes formas. A seguir apresentaremos as funções de pertinência do tipo triangular, trapezoidal, sigmoidal crescente (fuzzy large), sigmoidal decrescente (fuzzy small), gaussiana, linear e em forma de sino (JUVANHOL, 2014; NGUYEN; WALKER; WALKER, 2019; RIGNEL; CHENCI; LUCAS, 2011; SANTOS, G. R. dos, 2014; VAZ, 2006; YAZDANBAKHSH; DICK, 2018):

\section{Função triangular}

Para a representação da função de pertinência triangular são necessários três pontos ( $a, b, c)$. Esses valores devem atender a regra $a<b<c$. Deve existir um ponto onde um valor possa ter pertinência igual a 1. A Equação 2.11 e a Figura 2.7 mostram a função triangular e sua representação gráfica, respectivamente.

$$
\operatorname{trimf}(x: a, b, c)=\max \left(\min \left(\frac{x-a}{b-a}, \frac{c-x}{c-b}\right), 0\right)
$$

Outra forma de representar a função triangular seria Equação 2.12: 


$$
f(x: a, b, c)=\left\{\begin{array}{lr}
0, & x \leq a \\
\frac{x-a}{b-a}, & a<x \leq b \\
\frac{c-x}{c-b}, & b<x \leq c \\
0, & x>c
\end{array}\right\}
$$

Equação 2.12

Para as Equação 2.11 e Equação 2.12 os parâmetros $a$ e $c$ correspondem aos valores de $x$ localizados nos vértices da base do triângulo, que possuem pertinência igual a zero. $\mathrm{O}$ parâmetro $b$ é o valor de $x$ localizado no vértice com pertinência igual a 1 .

\section{Função Triangular}

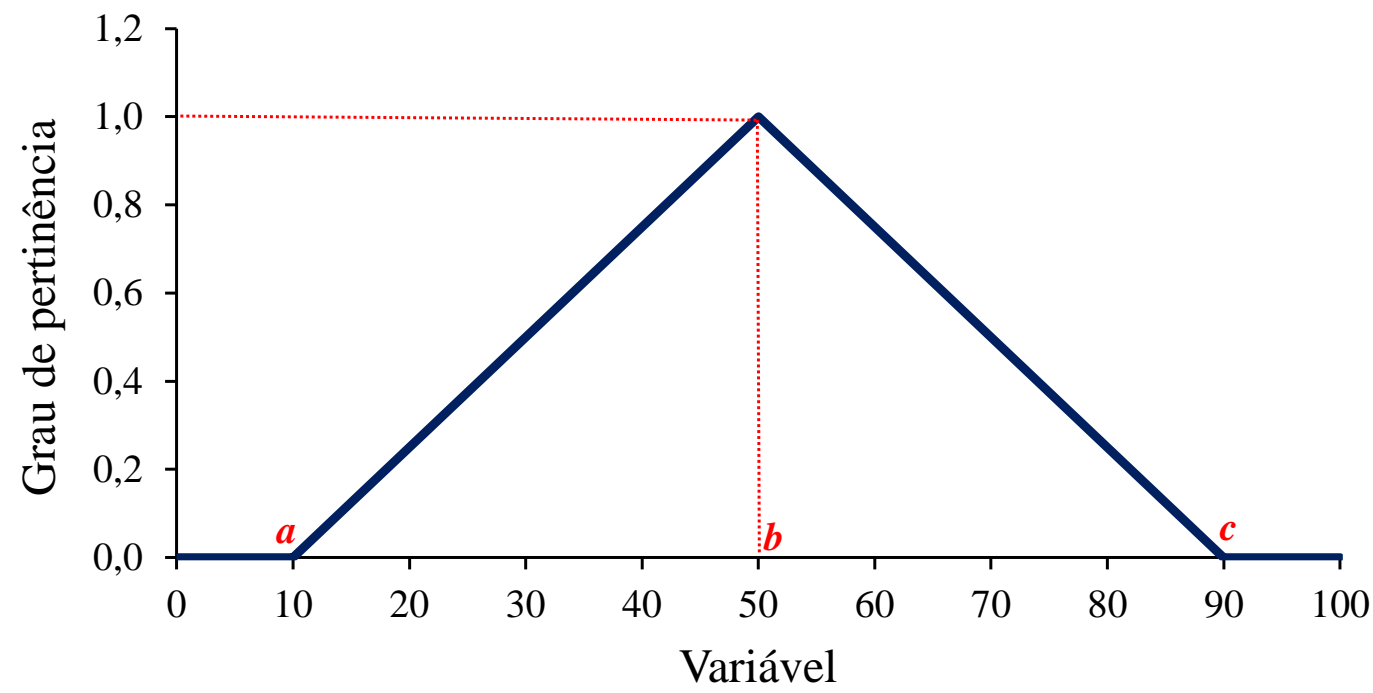

Fonte: Adaptado de Juvanhol (2014).

Figura 2.7 - Representação gráfica da função triangular.

\section{Função trapezoidal}

Para a representação da função de pertinência trapezoidal são necessários quatro pontos, onde os mesmos obedecem a regra $a<b<c<d$. Uma característica marcante é que essa função permite um intervalo com pertinência 100\%. A Equação 2.13 e a Figura 2.8 mostram a função trapezoidal e sua representação gráfica, respectivamente.

$$
\operatorname{trapmf}(x, a, b, c, d)=\max \left(\min \left(\frac{x-a}{b-a}, 1, \frac{d-x}{d-c}\right), 0\right)
$$

Outra forma de representar a função triangular está representado na Equação 2.14: 


$$
f(x: a, b, c, d)=\left\{\begin{array}{lr}
0, & x \leq a \\
\frac{x-a}{b-a}, & a<x<b \\
1, & b \leq x \leq c \\
\frac{d-x}{d-c}, & c<x<d \\
0, & x \geq d
\end{array}\right\}
$$

Equação 2.14

Os parâmetros $a$ e $d$ correspondem aos valores de $x$ cuja pertinência é igual a zero, enquanto que os parâmetros $b$ e $c$ correspondem a valores de $x$ com pertinência igual a 1 .

\section{Função Trapezoidal}

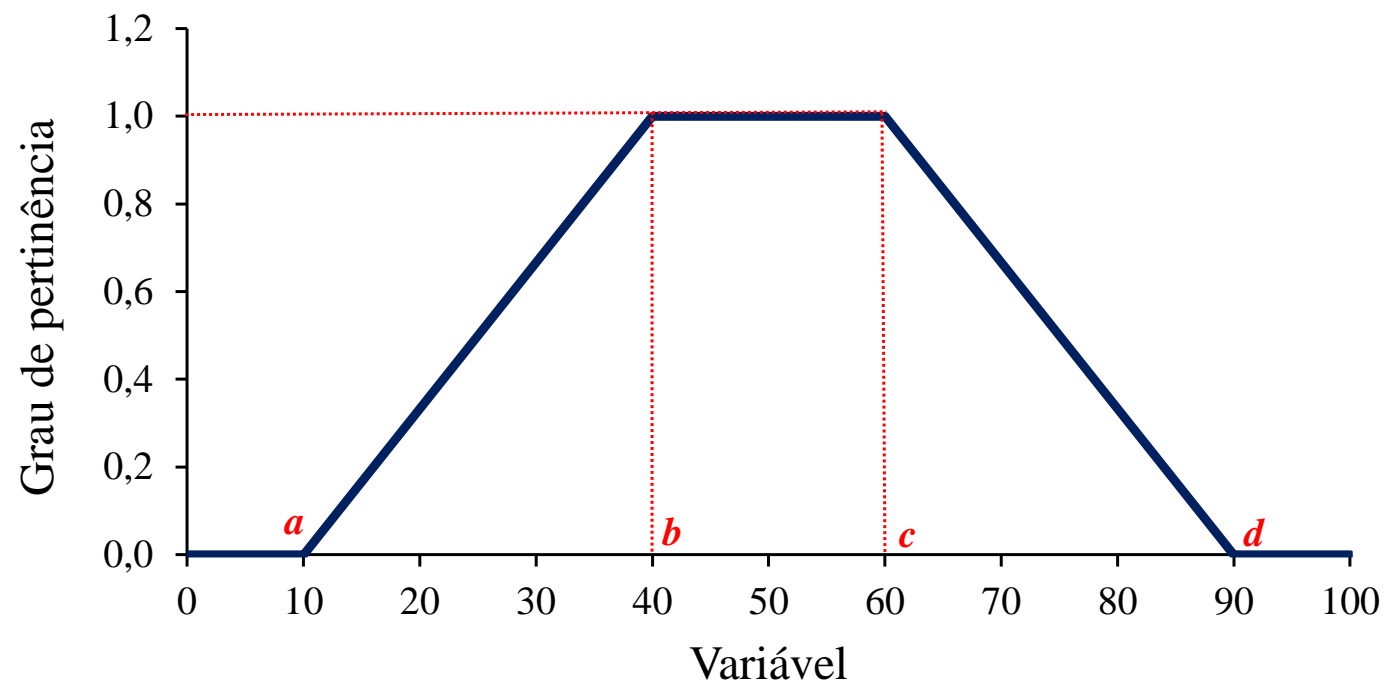

Fonte: Adaptado de Juvanhol (2014).

Figura 2.8 - Representação gráfica da função trapezoidal.

\section{$\checkmark$ Função sigmoidal crescente (fuzzy large)}

A função de pertinência fuzzy large ou sigmoidal crescente é usada para indicar que valores mais elevados do conjunto crisp são membros que assumem maior grau de pertinência no conjunto fuzzy. Tal função não funciona com valores negativos ou valores zero, desta forma, o usuário deve transformar os dados em valores positivos antes da fuzzificação.

A Equação 2.15 e a Figura 2.9 mostram a função sigmoidal crescente e sua representação gráfica, respectivamente. 


$$
\mu(x)=\frac{1}{1+\left(\frac{x}{a}\right)^{-b}}
$$

O parâmetro $a$ é o ponto médio que define o ponto central para a função em que $\mu(x)$ adquiri 0,5 e o parâmetro $b$ corresponde ao valor que determina a inclinação ou propagação da curva.

\section{Função Sigmoidal Crescente}

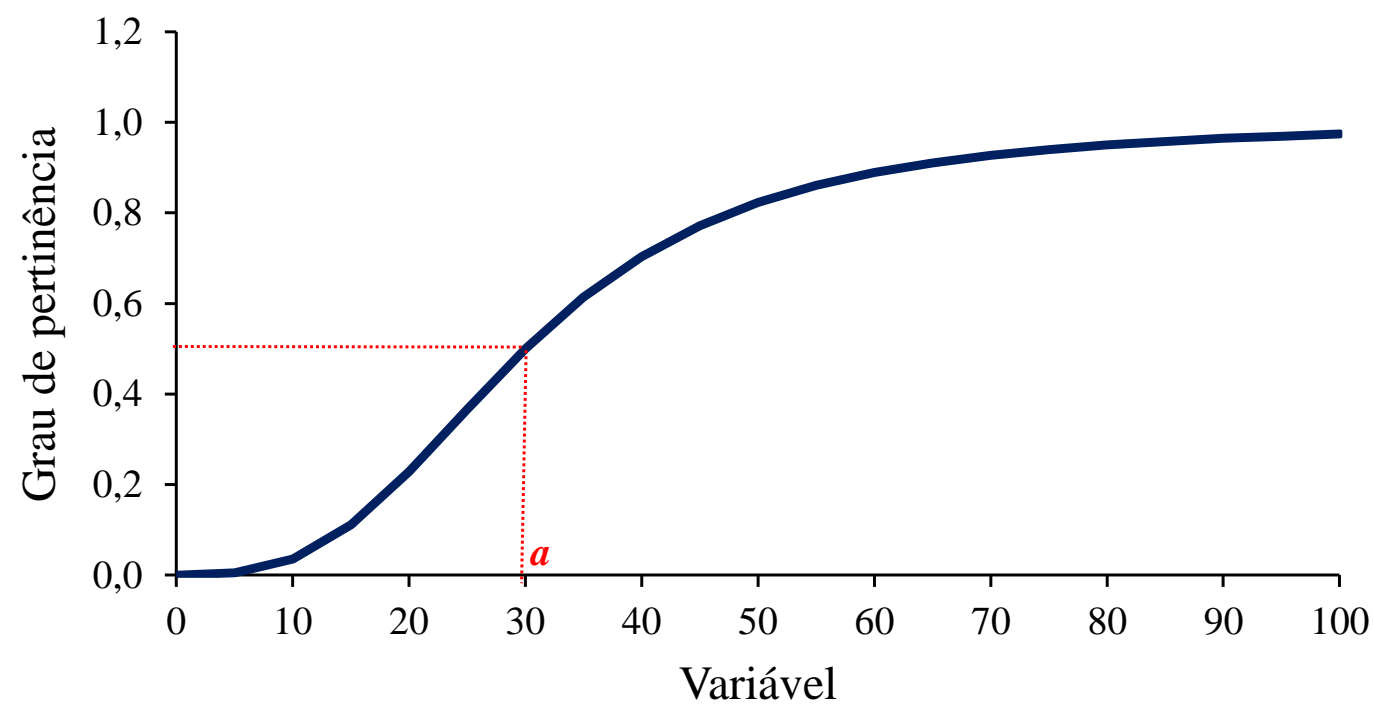

Fonte: Adaptado de Juvanhol (2014).

Figura 2.9 - Representação gráfica da função sigmoidal crescente.

\section{$\checkmark$ Função sigmoidal decrescente (fuzzy small)}

A função de transformação sigmoidal decrescente ou fuzzy small é usada quando os valores de entrada menores têm maior probabilidade de ser um membro do conjunto. O ponto médio definido identifica o ponto de cruzamento (atribuído a uma adesão de 0,5) com valores maiores que o ponto médio tendo uma menor possibilidade de ser membro do conjunto e valores abaixo do ponto médio tendo uma maior possibilidade de adesão. Tal função não funcionam com valores negativos ou valores zero, desta forma, o usuário deve transformar os dados em valores positivos antes da fuzzificação.

A Equação 2.16 e a Figura 2.10 mostram a função sigmoidal decrescente e sua representação gráfica, respectivamente.

$$
\mu(x)=\frac{1}{1+\left(\frac{x}{a}\right)^{b}}
$$


O parâmetro $a$ é o ponto médio que define o ponto central para a função em que $\mu(x)$ adquiri 0,5 e o parâmetro $b$ corresponde ao valor que determina a inclinação ou propagação da curva.

\section{Função Sigmoidal Decrescente}

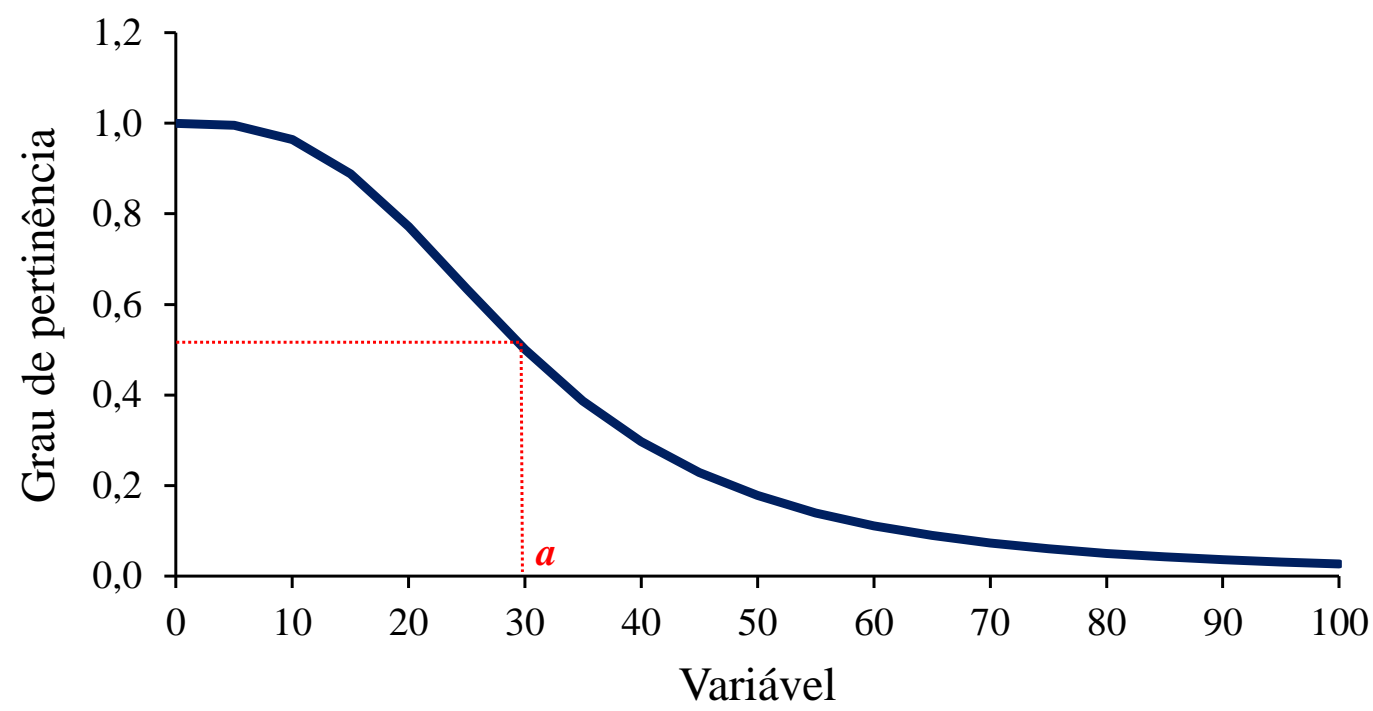

Fonte: Adaptado de Juvanhol (2014).

Figura 2.10 - Representação gráfica da função sigmoidal decrescente.

\section{$\checkmark$ Função gaussiana}

A função gaussiana transforma os valores originais em uma distribuição normal. $\mathrm{O}$ ponto médio da distribuição normal, definido pelo usuário, recebe grau de pertinência igual a 1, os valores de entrada restantes diminuem à medida que se afasta do ponto médio nas direções positiva e negativa. Os valores de entrada diminuem em associação do ponto médio até atingirem um ponto onde os valores se movem muito para longe da definição ideal e definitivamente não estão no conjunto e, portanto, são atribuídos a eles valor igual a zero.

A Equação 2.17 e a Figura 2.11 mostram a função gaussiana e sua representação gráfica, respectivamente.

$$
\mu(x)=\exp ^{-\sigma^{*}(x-a)^{2}}
$$

O parâmetro $\sigma$ é o valor que determina a inclinação ou propagação da curva e o parâmetro $a$ corresponde ao valor no ponto médio que define o ponto central para a função em que $\mu(x)$ adquiri 1 . 


\section{Função Gaussiana}

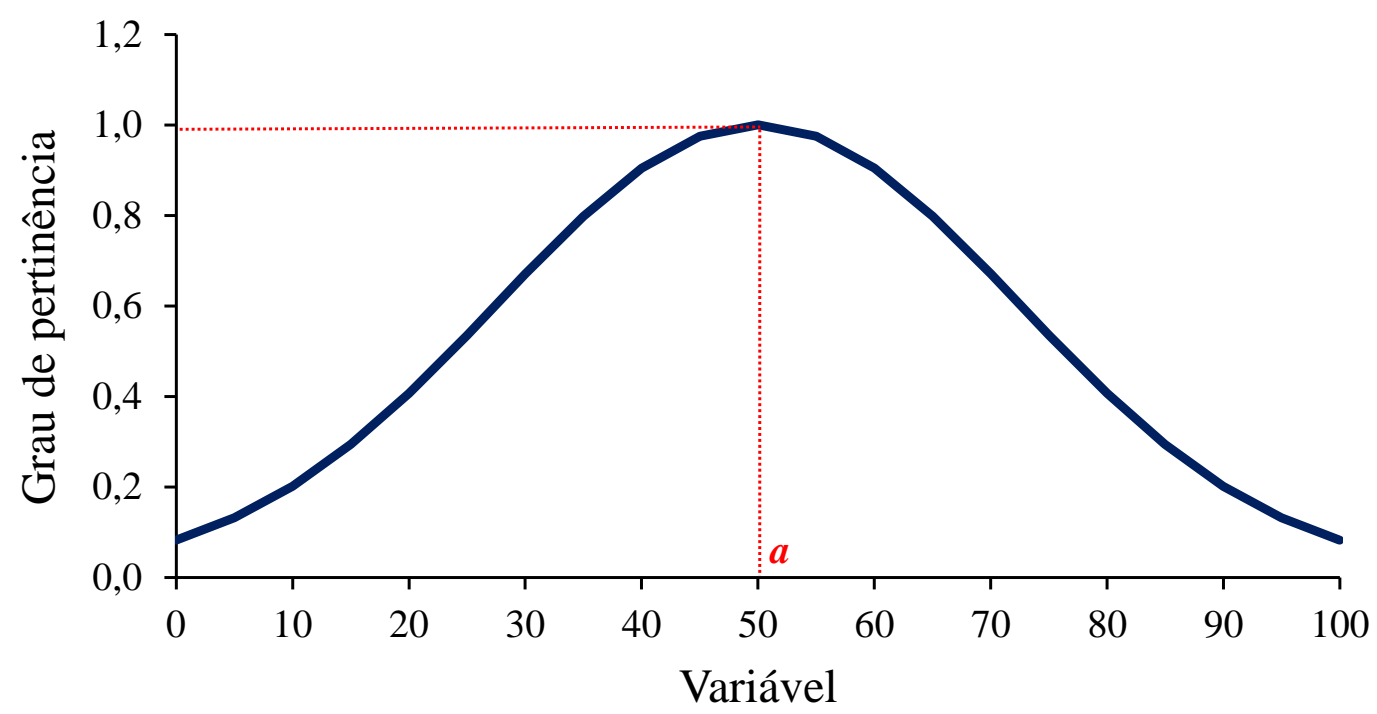

Fonte: Adaptado de Juvanhol (2014).

Figura 2.11 - Representação gráfica da função gaussiana.

\section{$\checkmark$ Função linear}

A função de transformação fuzzy linear aplica uma função linear entre os valores mínimo e máximo especificados pelo usuário. Para qualquer valor abaixo do mínimo será atribuído grau de pertinência igual a 0 (definitivamente não é um membro) e para qualquer valor acima do máximo o grau de pertinência será 1 (definitivamente um membro). A linha azul na Figura 2.12 representa uma transformação linear inclinada positiva (crescente) com um mínimo de 30 e um máximo de 80 . Qualquer valor abaixo de 30 será atribuído a zero e qualquer valor acima de 80 a 1.

Se o mínimo for maior que o máximo, uma relação linear negativa (decrescente) é estabelecida. A linha vermelha na Figura 2.12 representa uma transformação linear de inclinação negativa (decrescente). Qualquer valor menor que 30 será atribuído a 1 e qualquer valor acima de 80 a 0. 


\section{Função Linear}

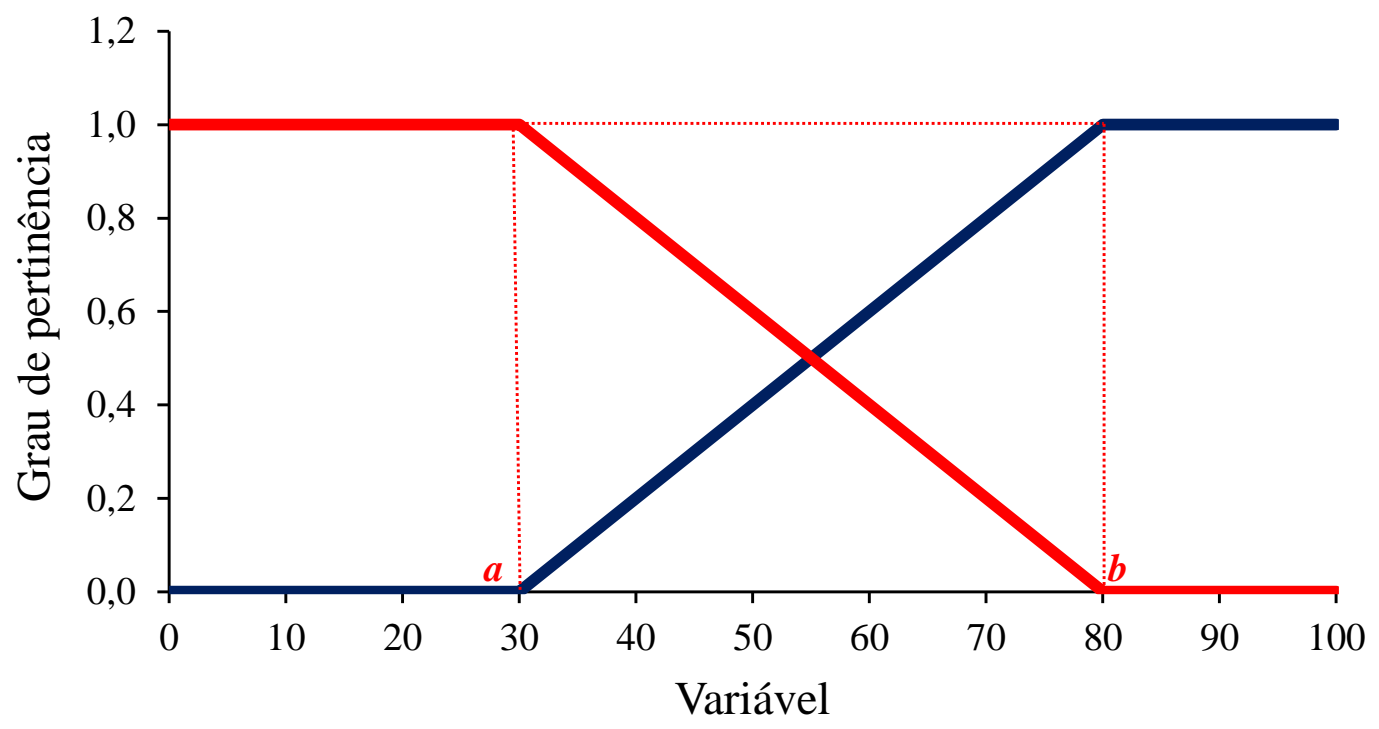

Fonte: Adaptado de Juvanhol (2014).

Figura 2.12 - Representação gráfica da função linear crescente e decrescente.

A Equação 2.18 mostra a função linear crescente (linha azul da Figura 2.12) e a Equação 2.19 mostra uma função linear decrescente (linha vermelha da Figura 2.12).

$$
\begin{gathered}
f(x)=\left\{\begin{array}{lr}
0, & x \leq a \\
\alpha \cdot x+\beta, & a<x<b \\
1, & x \geq b
\end{array}\right\} \\
f(x)=\left\{\begin{array}{ll}
1, & x \leq a \\
\alpha \cdot x+\beta, & a<x<b \\
0, & x \geq b
\end{array}\right\}
\end{gathered}
$$

O parâmetro $\alpha$ é o valor que determina a inclinação ou propagação da curva e o parâmetro $\beta$ corresponde ao valor de interceptação no eixo $Y$.

\section{$\checkmark$ Função sino generalizada}

A função sino generalizada define uma distribuição em forma de sino em torno de um ponto central indicado com um valor de propagação na função e um valor na função e um valor para controlar a amplitude no ponto central. $\mathrm{O}$ valor definido no ponto central do conjunto 
assume um grau de pertinência igual a 1. Os valores que se situam entre os dois limites se encontram na zona de transição do conjunto e, assume um grau de pertinência de mesmo valor.

A função de pertinência sino ou Bell e sua representação gráfica são apresentadas na Equação 2.20 e na Figura 2.13, respectivamente.

$$
\mu(x)=\frac{1}{1+\left|\frac{x-a}{b}\right|^{2 c}}
$$

O parâmetro $a$ corresponde ao valor no ponto médio que define o ponto central para a função em que $\mu(x)$ adquiri 1, o parâmetro $b$ é o valor que determina a inclinação ou propagação da curva, e o parâmetro $c$ corresponde ao valor que corresponde a amplitude no ponto central.

\section{Função Sino}

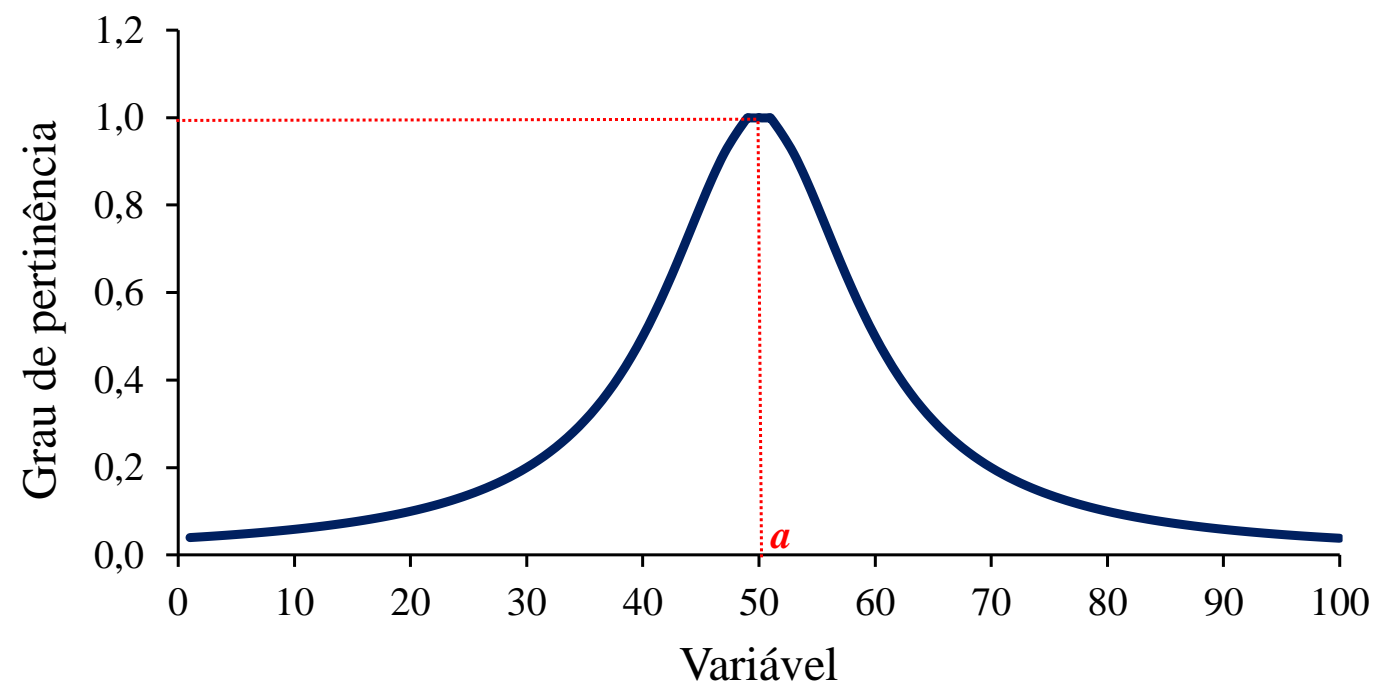

Fonte: Adaptado de Juvanhol (2014).

Figura 2.13 - Representação gráfica da função sino.

\subsection{Controladores fuzzy}

As técnicas de controle fuzzy originaram-se com as pesquisas e projetos de Mamdani and Assilian (1975) e ganharam espaço como área de estudo em diversas instituições de ensino, pesquisa e desenvolvimento do mundo, sendo até hoje uma importante aplicação da teoria dos conjuntos fuzzy.

Nos controladores convencionais os algoritmos de controle são descritos analiticamente por equações algébricas ou diferenciais, através de um modelo matemático. Nos controladores fuzzy utilizam-se regras lógicas no algoritmo de controle, com a intenção de descrever numa 
rotina a experiência humana, intuição e heurística para controlar um processo (AFONSO, 2009). O processo segue os seguintes passos:

$\checkmark$ Especificam-se as variáveis de entrada e saída utilizadas;

$\checkmark$ Define-se o conjunto de regras;

$\checkmark$ Determina-se o método de defuzzificação

$\checkmark$ Realiza-se testes para a verificação do sistema, ajustando os detalhes conforme o propósito inicial.

Controladores fuzzy (Figura 2.2) são robustos e de grande adaptabilidade, incorporando conhecimento que outros sistemas nem sempre conseguem acomodar. Também são versáteis, principalmente quando o modelo físico é complexo e de difícil representação matemática. Além disso, mesmo em sistemas onde a incerteza se faz presente de maneira intrínseca, agregam uma robustez característica (AFONSO, 2009; CARNEIRO, 2016).

No sistema de inferência fuzzy, consideram-se entradas não-fuzzy, ou precisas, que é o caso da grande maioria das aplicações práticas. Em virtude disto, é necessário efetuar um mapeamento destes dados precisos para os conjuntos fuzzy (de entrada) relevantes, o que é realizado no estágio de fuzzificação. Nesta etapa ocorre também a ativação das regras relevantes para uma dada situação (CARNEIRO, 2016).

A interface de fuzzificação faz a identificação dos valores das variáveis de entrada, as quais caracterizam o estado do sistema (variáveis de estado), e as normaliza em um universo de discurso padronizado. Estes valores crisp são fuzzificados e transformados em conjunto fuzzy para que possam se tornar instâncias de variáveis linguística. No estágio de inferência, ocorrem as operações com os conjuntos fuzzy, o desempenho do controlador fuzzy dependerá do número de conjuntos e de suas formas. Os conjuntos fuzzy de entrada, relativos aos antecedentes das regras, e o de saída, referente ao consequente, podem ser definidos previamente ou, alternativamente, gerados automaticamente a partir dos dados (AFONSO, 2009; ANTUNES, 2005; CARNEIRO, 2016).

A base de conhecimento consiste em uma base de dados e uma base de regras, de maneira a caracterizar a estratégia de controle e as suas metas. As regras podem ser fornecidas por especialistas, em forma de sentença linguística, e se constituem em um aspecto fundamental no desempenho de um sistema de inferência fuzzy. A base de regras é formada por estruturas do tipo:

$$
\text { Se }<\text { premissa }>\text { Então }<\text { conclusão }>
$$

Como por exemplo:

$S e<$ Altura é grande e Diâmero é grande $>$ Então $<$ Volume é grande $>$ 
Para um bom controlador fuzzy, é importante que existam tantas regras quanto for necessário para mapear totalmente as combinações dos termos das variáveis, isto é, que a base seja completa, garantindo que exista sempre ao menos uma regra a ser disparada para qualquer entrada. Como dito anteriormente, as premissas são relacionadas pelos conectivos lógicos, dados pelo operador de conjunção (e) e pelo operador de disjunção (ou) (AFONSO, 2009; ANTUNES, 2005; CARNEIRO, 2016). Em geral, as regras têm a forma de um sistema de múltiplas entradas e múltiplas saídas ((Multiple Input e Multiple Output - MIMO),), mas podem ser transformadas em vários sistemas com múltiplas entradas e uma saída (Multiple Input e Single output - MISO) (AFONSO, 2009). Para exemplificarmos, temos uma regra MIMO: Se $x_{1}$ é $A_{1}$ e $\ldots x_{n}$ é $A_{n}$ Então $y_{1}$ é $C_{1}$ e $\ldots y_{m}$ é $C_{m}$, que é equivalente a $m$ regras MISO: Se $x_{1}$ é $A_{1}$ e .... $x_{n}$ é $A_{n}$ Então $y_{j}$ é $C_{j}$. Em geral não se aceitam conceitos "ou" na conclusão destas regras.

As regras de controle precisam ser consistentes para que um controle fuzzy tenha um bom desempenho. No entanto, a definição de uma regra por um especialista não é uma tarefa fácil, por mais que possamos ser conhecedores de determinada área podemos cometer erros e interpretar dados de forma equivocada. Para solucionar este tipo de problema, pode-se utilizar métodos de extração de regras de dados numéricos. Estes métodos são particularmente úteis em problemas de classificação e previsão de séries temporais (KABIR; PAPADOPOULOS, 2018; SARAIVA, 2000; SERRANO-GUERRERO; ROMERO; OLIVAS, 2021).

Os tipos de controladores fuzzy encontrados na literatura são os modelos clássicos, compreendendo o modelo de Mamdani e o de Larsen, e os modelos de interpolação, compreendendo o modelo de Takagi-Sugeno e o de Tsukamoto. Existe algumas diferenças entre esses modelos que são: a forma de representar os termos da premissa; a representação das ações de controle e quanto aos operadores utilizados para implementação do sistema (AFONSO, 2009).

O método de Mamdani, proposto em 1970, foi por muitos anos um padrão para utilização dos conceitos da lógica fuzzy em processamento de conhecimento. As regras de produção de modelo de Mamdani possuem relações fuzzy tanto em seus antecedentes (entradas) como em seus consequentes (saída). Denomina-se inferência máximo-mínimo a regra semântica tradicionalmente utilizada para o processamento de inferência no modelo Mamdani.

Na base de regras de Mamdani and Assilian (1975) foi proposto uma relação fuzzy binária $M$ entre as entradas $x$ e as saídas $u$, cuja função de pertinência está descrita como segue: em cada uma das regras da base de regras fuzzy, adota-se o operador matemático mínimo 
para o conectivo lógico "e" e para o operador máximo, o conectivo logico "ou". Sendo que as sentenças "Se ... Então...” são modeladas pela aplicação do operador mínimo.

Formalmente, a relação fuzzy $M$ é o subconjunto fuzzy $x \in U$ cuja função de pertinência é dada por (Equação 2.21):

$$
\mu_{M}(x, u)=\text { máximo }_{1 \leq j \leq n}\left\{\operatorname{mínimo}\left[\mu_{A_{j}}(x), \mu_{B_{j}}(u)\right]\right\}
$$

Equação 2.21

Na qual $n$ é o número de regras que compõem a base de regra $\mu_{A_{j}}(x)$ e $\mu_{B_{j}}(u)$ são os graus com que $x$ e $u$ pertencem aos conjuntos fuzzy $A_{j}$ e $B_{j}$, respectivamente.

Desta forma para um conjunto de $n$ regras, o modelo de Mamdani é representado pela Equação 2.22.

$$
\begin{aligned}
& R_{j}: \text { Se } x_{1} \text { é } A_{1 j} \text { e } x_{2} \text { é } A_{2 j} \text { e } \ldots \text { e } x_{k} \text { é } A_{k j} \text { Então } u \text { é } B_{j} \\
& j=1,2, \ldots, n
\end{aligned}
$$

Onde $R_{j}$ é a j-ésima regra, $x_{1}, x_{2}, \ldots, x_{k}$ são as variáveis de entrada, $A_{1 j}, A_{2 j}, \ldots, A_{k j}$ são os conjuntos fuzzy correspondentes às variáveis de entrada, $u$ é a variável de saída e $B_{j}$ é o conjunto fuzzy correspondente à variável de saída.

A saída do controlador fuzzy, dada pelo método de inferência de Mamdani, é um conjunto fuzzy até para casos de entrada crisp. Esse fato é que sugere a defuzzificação do conjunto fuzzy de saída para se obter um valor crisp. As regras para esse processo dão inseridas por especialista e constituem uma etapa muito importante para o desempenho do sistema(AFONSO, 2009; NGUYEN; WALKER; WALKER, 2019).

Ao se obter o conjunto fuzzy de saída inicia a etapa de interpretação dos resultados. Isto se faz necessário para a verificação da precisão das saídas. Dentre os métodos de defuzzificação destacam-se, quanto a utilização, o método de centro de gravidade e a média dos máximos. O centro de gravidade possui como saída o valor no universo que divide a área sob a curva da função de pertinência em duas partes iguais. Enquanto que o método de média dos máximos obtém o valor por meio da média entre os dois elementos extremos no universo que correspondem aos maiores valores da função de pertinência do consequente. A escolha do método está relacionada com os dados analisados e com as características do processo (AFONSO, 2009; NGUYEN; WALKER; WALKER, 2019). 


\section{APLICAÇÕES DA LÓGICA FUZZY}

Dado todos os conceitos e definições, citados anteriormente, nota-se que a LF pode ser utilizada numa diversidade de problemas nos quais a modelagem convencional não consegue otimizar a resposta. Em razão das propriedades citadas e da capacidade de realizar inferências, a LF tem encontrado grandes aplicações em várias áreas das ciências florestais, a seguir citaremos alguma dessas aplicações:

O reconhecimento de padrões, muito utilizado na área de geotecnologia, é a técnica que tem por objetivo procurar, detectar e explicitar estruturas associadas às regularidades ou propriedades presentes em um conjunto de dados, por meio de análise de classes. Esta definição de reconhecimento de padrão demonstra o potencial da associação das técnicas de LF e de geotecnologias para solucionar problemas em diversas áreas das ciências florestais, tal associação será destaque neste tópico.

A associação de técnicas da LF com geotecnologia tem ganhado destaque na gestão de ecossistemas (ADRIAENSSENS et al., 2004), na determinação de fragmentos potenciais para implantação de corredores ecológicos (DOS SANTOS, A. R. et al., 2020), na análise dos efeitos do fogo no habitat das espécies (ANDRUS et al., 2021), na conservação dos remanescentes florestais (OCHOA-GAONA et al., 2010), no cálculo de risco de inundação, incêndios e demais cálculos de risco e de vulnerabilidade (CABANILLAS et al., 2012; DANISH; ONDER, 2020; GHOSH; DEY, 2021; HONG; TSANGARATOS; ILIA; LIU; ZHU; CHEN, 2018), na avaliação da qualidade do ar e da água (ASSIMAKOPOULOS et al., 2013; OLADIPO et al., 2021), na solução de problemas de sustentabilidade do manejo florestal (DUCEY; LARSON, 1999) e na área de levantamento de variáveis para auxiliar o processo de manejo, otimização e escolhas de sítios de produção (DOS SANTOS, A. R. et al., 2017; JUSTMAN et al., 2020; KANGAS et al., 2018; REYNOLDS; HESSBURG, 2005), dentre outras. Além das utilizações citadas a lógica fuzzy pode ser utilizada na associação de fatores edafoclimáticos para definição de unidades que possuam semelhanças (FERREIRA, C. de C. M., 2012).

Daremos destaque a metodologia utilizada para a classificação de grupos climáticos com uso de classificador multivariada baseado em lógica fuzzy visando identificar classes similares, além de avaliar a variabilidade espacial dos agrupamentos.

O conhecimento das condições climáticas de uma determinada localidade, como um dos elementos a ser considerado nas tomadas de decisões, seja a nível econômico, de planejamento territorial ou para fins de manejo dos recursos terrestres é de extrema importância, pois propicia um melhor ordenamento do território, podendo desta forma, incentivar o cultivo agrícola e 
florestal em áreas mais aptas ao desenvolvimento de determinada espécie e podendo explicar a correlação de produção em áreas com características que se assemelham.

Assim sendo, haveria a necessidade crescente de busca, evolução e adaptação de métodos de classificação, capazes de sintetizar e agrupar características similares, através de critérios próprios. Para isso utilizaremos técnicas de agrupamento fuzzy ("Fuzzy Clustering"), os agrupamentos fuzzy oferecem melhores descrições dos dados quando a sobreposição de classes é possível, ou seja, quando os elementos pertencem a todos os grupos, mas em diferentes graus, e isto pode ser quantificado por uma função de pertinência, com vimos nas seções anteriores.

O agrupamento fuzzy C-Means (FCM) é considerado suave por seus elementos possuírem probabilidade de pertencer a cada grupo com certo grau de pertinência. Em outras palavras, cada elemento possui um conjunto de coeficientes que correspondem ao grau de estar em um determinado cluster. Isso é diferente do agrupamento de k-médias e k-medóide, onde cada objeto deve pertencer exatamente a um agrupamento, por isso esses agrupamentos são conhecidos como agrupamentos rígidos.

No agrupamento FCM, os pontos próximos ao centro estão contidos no cluster com grau mais alto de pertinência que os pontos na borda. $\mathrm{O}$ grau ao qual um elemento pertence a um determinado cluster é um valor numérico que varia de 0 a 1.

No exemplo descrito a seguir utilizamos informações de temperatura média anual, precipitação média anual e déficit hídrico médio anual provenientes do banco de dados e da metodologia desenvolvida por Santos et al. (2015) e para obtenção de altitude foi utilizado o modelo digital de elevação para o estado do Espírito Santo disponibilizado pela Embrapa (MIRANDA, 2005) (Figura 2.14). Após a aquisição, em ambiente SIG, os dados foram extraídos por meio das coordenadas dos 20 pontos a serem analisados e em exportados para planilha do Excel (Tabela 2.1). 


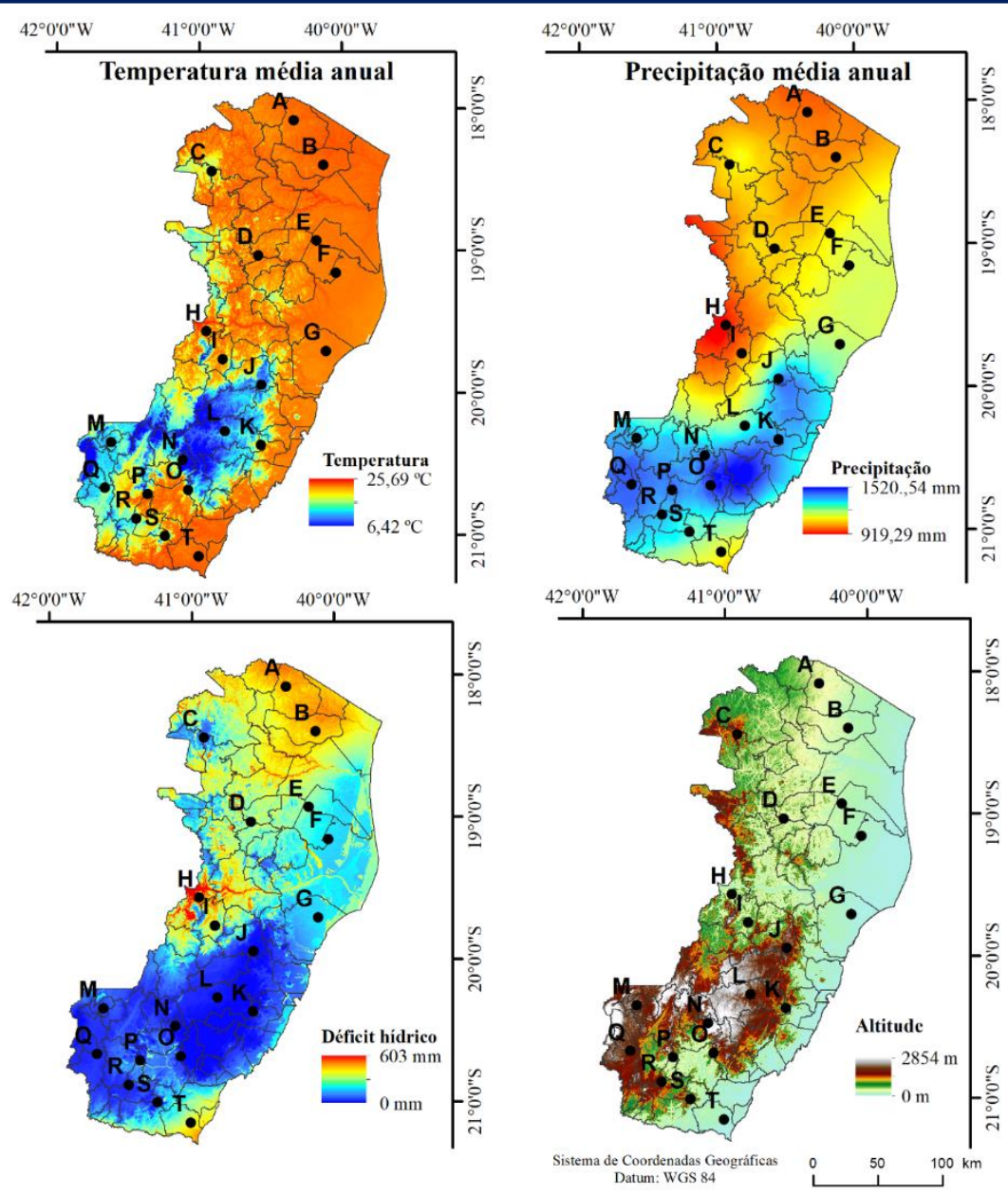

Figura 2.14 - Variáveis climáticas, altitude e pontos de análise do estado do Espírito Santo.

Tabela 2.1 - Pontos contendo as informações climatológicas analisadas.

\begin{tabular}{ccccc}
\hline $\begin{array}{c}\text { Identificador } \\
\text { do ponto }\end{array}$ & $\begin{array}{c}\text { Temperatura média } \\
\text { anual }\left({ }^{\circ} \mathbf{C}\right)\end{array}$ & $\begin{array}{c}\text { Precipitação média } \\
\text { anual }(\mathbf{m m})\end{array}$ & $\begin{array}{c}\text { Déficit hídrico médio } \\
\text { anual }(\mathbf{m m})\end{array}$ & $\begin{array}{c}\text { Altitude } \\
(\mathbf{m})\end{array}$ \\
\hline A & 24,91 & 1005,06 & 333 & 156 \\
B & 24,92 & 1040,25 & 316 & 85 \\
C & 22,51 & 1111,59 & 59 & 598 \\
D & 24,54 & 1089,15 & 228 & 176 \\
E & 24,69 & 1124,87 & 176 & 92 \\
F & 24,62 & 1171,46 & 120 & 57 \\
G & 24,77 & 1205,65 & 138 & 12 \\
H & 23,86 & 945,22 & 282 & 240 \\
I & 23,37 & 1017,03 & 175 & 308 \\
J & 20,37 & 1396,11 & 2 & 719 \\
K & 22,50 & 1387,74 & 3 & 395 \\
L & 20,80 & 1284,80 & 14 & 640 \\
M & 19,74 & 1354,65 & 27 & 977 \\
N & 20,36 & 1403,36 & 11 & 755 \\
O & 22,06 & 1456,55 & 8 & 514 \\
P & 24,63 & 1412,78 & 66 & 168 \\
Q & 20,26 & 1433,67 & 14 & 844 \\
R & 22,49 & 1354,51 & 29 & 435 \\
S & 20,16 & 1281,62 & 8 & 715 \\
T & 24,76 & 1150,87 & 244 & 46 \\
\hline
\end{tabular}


Para agrupamento fuzzy (fuzzy clustering) dos dados mencionados foi utilizado o algoritmo Fuzzy C-Means, no programa R com o toolbox e1071 (THERNEAU; ATKINSON; RIPLEY, 2019), que visou agrupa-los com base nas semelhanças e dissimilaridades dos pontos de dados (ASKARI, 2021). Este algoritmo aplica a distância Euclidiana, procurando por grupos esféricos de aproximadamente mesmo tamanho. O coeficiente da distância está baseado no conceito de que a medida quantificada do grau de similaridade entre duas ou mais variáveis, pode ser demonstrado pela distância que separa uma variável da outra, portanto quanto maior for o grau de similaridade entre dois ou mais pontos, menor será a distância entre eles.

O FCM encontra os centros dos clusters, minimizando a distância de $x_{k}$ e $v_{i}$, com a função objetivo representada pelas Equação 2.23, as variáveis para cálculo desta função podem ser observadas nas Equação 2.24 eEquação 2.25.

$$
\begin{gathered}
j=\sum_{k=1}^{n} \sum_{i=1}^{c} \mu_{i k}^{m}\left\|x_{k}-v_{i}\right\|^{2} \\
v_{i}=\frac{\sum_{k=1}^{n}\left[\mu_{i}\left(x_{k}\right)\right]^{2} x_{k}}{\sum_{k=1}^{n}\left[\mu_{i}\left(x_{k}\right)\right]^{m}} \\
\mu_{i k}=\frac{1}{\sum_{i=1}^{c}\left(\frac{\left\|x_{k}-v_{i}\right\|}{\left\|x_{k}-v_{J}\right\|}\right)^{1 / m-1}}
\end{gathered}
$$

Em que: $\mathrm{n}=$ número de observações; $\mathrm{c}=$ número de clusters; $x_{k}=$ k-ésima observação; $v_{i}=\mathrm{i}$-ésimo centro do cluster; $\mathrm{m}=$ constante exponencial com valor maior que $1 ; \mu_{i k}=$ grau da função de associação e inicialmente ocorre de forma aleatória.

O algoritmo FCM precisa de três parâmetros: o número de clusters, valor do expoente e o número de iterações. Neste trabalho foram analisados o número de 4 clusters, expoente de 2 e com o número de iterações igual a 100. O script utilizado nesta etapa pode ser visualizado no Apêndice A.

Os resultados obtidos deste processamento podem ser visualizados na Figura 2.15. 
A)

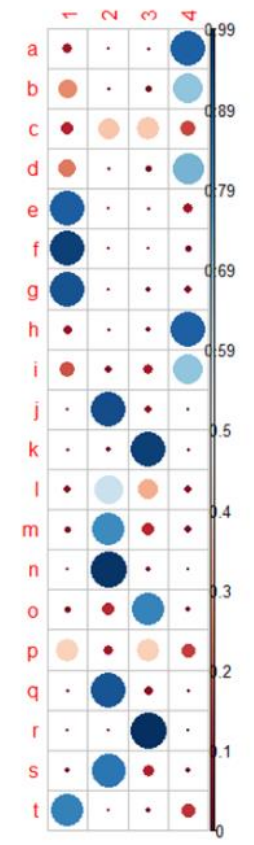

B)

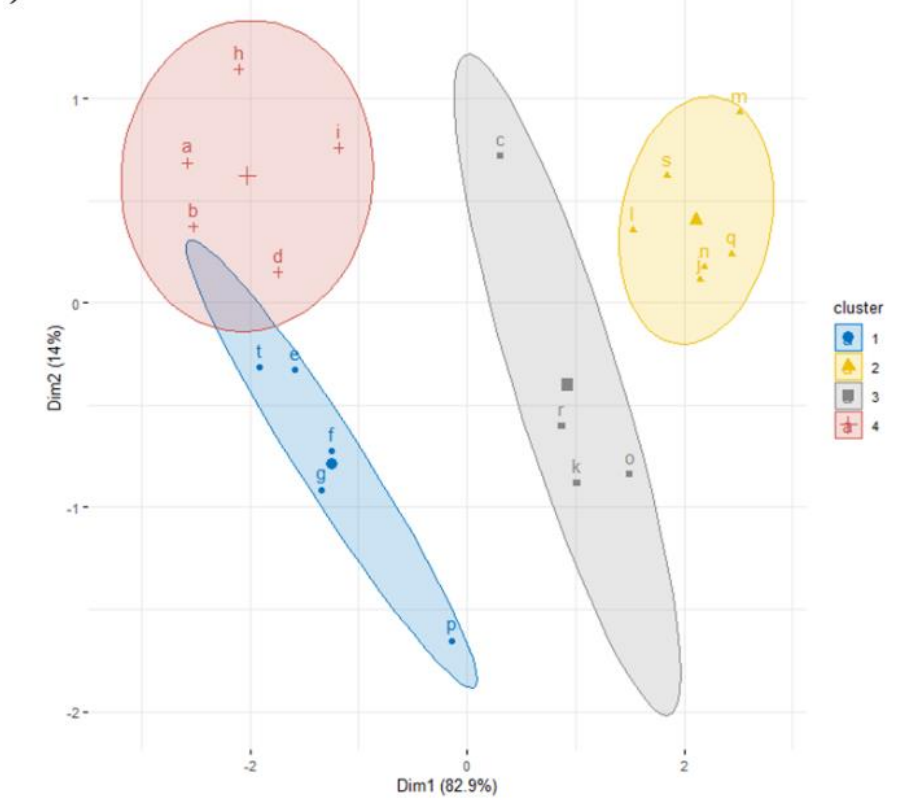

Figura 2.15 - Agrupamento das regiões de acordo com as variáveis climáticas e altitude por meio da técnica de Fuzzy C-Means (A- representa a correlação da variável com o cluster que ela pertence e com os demais clusters e a $\mathrm{B}$ - representa os grupos formados pela técnica FCM).

Com base nesses resultados aferimos que, com os parâmetros utilizados, os dados se agruparam conforme apresentado na Figura 2.16. Podemos observar por meio desta análise que embora o ponto "P" apresente maior proximidade geográfica com o ponto "R" (Figura 2.16) ele foi inserido num cluster diferente deste. Notamos que na Figura 2.15-A, na linha referente ao ponto "P", que ele possui grau de pertinência baixo (coloração rosa do círculo) para o cluster 1 no qual foi inserido e com o cluster 3 no qual o " $\mathrm{R}$ " foi inserido. Isso ocorre porque embora os dois pontos sejam próximos geograficamente, a similaridade dos dados referentes ao ponto "P" são maiores para os pontos "E"; "F"; "G" e "T", mesmo que este ponto apresente menor pertinência, para o cluster 1, que os pontos "F" e "G" (na linha referente a esses pontos na Figura 2.15-A podemos observar círculos maiores de coloração azul), por exemplo, que estão mais próximos ao centro do cluster 1 (Figura 2.15-B).

Uma outra observação importante em relação aos dados ocorre ao analisarmos o cluster 2 (coloração amarela na Figura 2.15). Os dados dos pontos “J”, "L", "M", "N", "Q" e "S" foram agrupados nesse conjunto, mas possuem diferentes graus de pertinência que pode ser notado pela maior distância dos pontos "L" e "M" do centro do cluster (Figura 2.15-B) ou pela coloração do círculo referente a esses pontos na Figura 2.15-A (coloração azul mais claro quando comparado aos demais pontos desse cluster). 


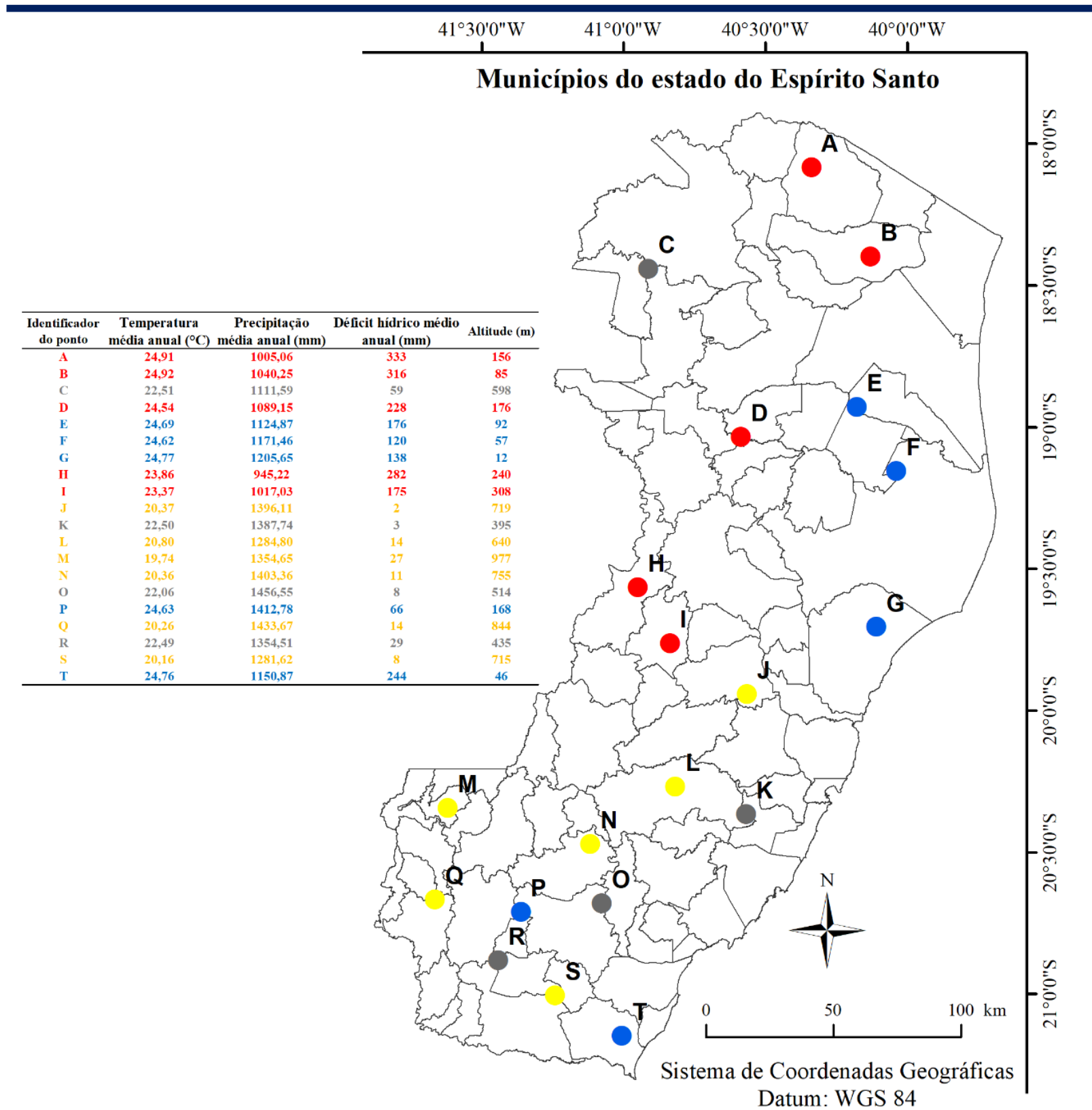

Figura 2.16 - Mapa dos agrupamentos das regiões por meio das variáveis climáticas e altitude por FCM.

Podemos fazer uma diversidade de comparações entre os resultados encontrados, demonstrando a importância e o potência de utilização, mas queremos destacar que a estatística espacial (SIG), e o próprio modelo utilizado, possibilitam uma visão de que dados climáticos e de relevo podem ser analisados, interpretados, classificados, utilizando modelos que permitam não só a descrição do fenômeno, mas que também trabalhem nos fornecendo uma maior interligação, conexão, similaridade e pertinência entre dados que quando agrupados nos fornecem grandes informações sobre determinada região, por exemplo. 


\section{CONSIDERAÇÕES FINAIS}

Diversos problemas na atualidade precisam ser solucionados com sistemas complexos, que necessitam tratar de imprecisões e dualidades. Seguindo essa linha de pensamento, Lofti Asker Zadeh, professor de ciência da computação da Universidade da Califórnia embasado na lógica clássica, desenvolveu a lógica nebulosa, mais conhecida com lógica fuzzy.

Essa lógica permite que variáveis assumam valores com graus de pertinência entre os elementos, 0 e 1 . Possibilita ainda a construção de várias regras, que facilitam a modelagem dos problemas, tornando-os assim, menos complexos. Tal lógica atrai pesquisadores das mais diversas áreas e possui uma flexibilidade muito ampla de utilizações. Vimos no tópico anterior algumas de suas aplicações nas Ciências Florestais e na Agricultura. 


\section{REFERÊNCIAS}

ADRIAENSSENS, V. et al. Fuzzy rule-based models for decision support in ecosystem management. Science of the Total Environment. [S.1.]: Elsevier. , 5 fev. 2004

AFONSO, A. C. M. Lógica fuzzy aplicada à modelagem da transferência de água em solos. 2009. 89 f. Dissertação (Mestrado em tecnologias energéticas e nucleares) - Universidade Federal de Pernambuco, 2009.

ALCALDE, C. et al. The use of linguistic variables and fuzzy propositions in the L-Fuzzy concept theory. Computers and Mathematics with Applications, v. 62, n. 8, p. 3111-3122, 1 out. 2011.

ANDRUS, R. A. et al. Assessing the quality of fire refugia for wildlife habitat. Forest Ecology and Management, v. 482, p. 118868, 15 fev. 2021.

ANTUNES, J. F. G. Aplicação de lógica fuzzy para estimativa de área plantada da cultura de soja utilizando imagens AVHRR-NOAA. 2005. 105 f. Dissertação (Mestrado em Engenharia Agrícola) - Universidade Estadual de Campinas, 2005.

ASKARI, S. Fuzzy C-Means clustering algorithm for data with unequal cluster sizes and contaminated with noise and outliers: Review and development. Expert Systems with Applications, v. 165, p. 113856, 1 mar. 2021.

ASSIMAKOPOULOS, M. N. et al. Indoor air quality in a metropolitan area metro using fuzzy logic assessment system. Science of the Total Environment, v. 449, p. 461-469, 1 abr. 2013.

AZADEGAN, A. et al. Fuzzy logic in manufacturing: A review of literature and a specialized application. International Journal of Production Economics, v. 132, n. 2, p. 258-270, 1 ago. 2011.

BALBIANI, P.; TINCHEV, T. Boolean logics with relations. 1 nov. 2010, [S.l.]: NorthHolland, 1 nov. 2010. p. 707-721.

BAYKASOĞLU, A.; GÖLCÜK, İ. Alpha-cut based fuzzy cognitive maps with applications in decision-making. Computers and Industrial Engineering, v. 152, p. 107007, 1 fev. 2021.

CABANILLAS, J. et al. Fuzzy logic based risk assessment of effluents from waste-water treatment plants. Science of the Total Environment, v. 439, p. 202-210, 15 nov. 2012. 
CARNEIRO, A. R. T. Lógica fuzzy na recomendação de cultivares de feijoeiro comum quanto à adaptabilidade e estabilidade. 2016. 125 f. Dissertação (Mestrado em Produção Vegetal) - Universidade Federal de Minas Gerais., 2016.

CATTANEO, M. E. G. V. The likelihood interpretation as the foundation of fuzzy set theory. International Journal of Approximate Reasoning, v. 90, p. 333-340, 1 nov. 2017.

COOPER, A. Kant's universal conception of natural history. Studies in History and Philosophy of Science Part A, v. 79, p. 77-86, 1 fev. 2020.

D'EER, L.; CORNELIS, C. A comprehensive study of fuzzy covering-based rough set models: Definitions, properties and interrelationships. Fuzzy Sets and Systems, v. 336, p. 1-26, 1 abr. 2018.

DANISH, E.; ONDER, M. Application of Fuzzy Logic for Predicting of Mine Fire in Underground Coal Mine. Safety and Health at Work, v. 11, n. 3, p. 322-334, 1 set. 2020.

DING, X. F.; LIU, H. C.; SHI, H. A dynamic approach for emergency decision making based on prospect theory with interval-valued Pythagorean fuzzy linguistic variables. Computers and Industrial Engineering, v. 131, p. 57-65, 1 maio 2019.

DOS SANTOS, A. R. et al. Fuzzy concept applied in determining potential forest fragments for deployment of a network of ecological corridors in the Brazilian Atlantic Forest. Ecological Indicators, v. 115, p. 106423, 1 ago. 2020.

Fuzzy logic applied to prospecting for areas for installation of wood panel industries.

Journal of Environmental Management, v. 193, p. 345-359, 15 maio 2017.

DUCEY, M. J.; LARSON, B. C. A fuzzy set approach to the problem of sustainability. Forest Ecology and Management, v. 115, n. 1, p. 29-40, 8 mar. 1999.

EBBING, J. et al. Boolean dependence logic and partially-ordered connectives. Journal of Computer and System Sciences, v. 88, p. 103-125, 1 set. 2017.

FERREIRA, C. de C. M. Aplicação da lógica nebulosa (fuzzy cluster) na definição de unidades climáticas: estudo de caso na Bacia do Rio Paraibuna - MG/RJ. Eletrônica) Ano, v. 10, n. 1, p. 1-13, 2012. Disponível em: <https://revistas.ufpr.br/revistaabclima/article/view/30589>. Acesso em: 22 maio 2021.

GHOSH, A.; DEY, P. Flood Severity assessment of the coastal tract situated between 
Muriganga and Saptamukhi estuaries of Sundarban delta of India using Frequency Ratio (FR), Fuzzy Logic (FL), Logistic Regression (LR) and Random Forest (RF) models. Regional Studies in Marine Science, v. 42, p. 101624, 1 fev. 2021.

HARDER, F.; BESOLD, T. R. Learning Łukasiewicz logic. Cognitive Systems Research, v. 47, p. 42-67, 1 jan. 2018.

HOLT, J.; LEACH, A. W. Linguistic variables as fuzzy sets to model uncertainty in the combined efficacy of multiple phytosanitary measures in pest risk analysis. Ecological Modelling, v. 406, p. 73-79, 24 ago. 2019.

HONG, H. et al. Application of fuzzy weight of evidence and data mining techniques in construction of flood susceptibility map of Poyang County, China. Science of the Total Environment, v. 625, p. 575-588, 1 jun. 2018.

JANARTHANAN, R. et al. Prediction of rainfall using fuzzy logic. 1 jan. 2020, [S.1.]: Elsevier Ltd, 1 jan. 2020. p. 959-963.

JUSTMAN, D. et al. A knowledge-data framework and geospatial fuzzy logic-based approach to model and predict structural complexity. Journal of Structural Geology, v. 141, p. 104153, 1 dez. 2020.

JUVANHOL, R. S. Modelagem da vulnerabilidade à ocorrência e propagação de incêndios florestais. 2014. 77 f. Dissertação (Mestrado em Ciências Florestais) - Universidade Federal do Espírito Santo, 2014.

KABIR, S.; PAPADOPOULOS, Y. A review of applications of fuzzy sets to safety and reliability engineering. International Journal of Approximate Reasoning, v. 100, p. 29-55, 1 set. 2018.

KAMBALIMATH, S.; DEKA, P. C. A basic review of fuzzy logic applications in hydrology and water resources. Applied Water Science, v. 10, n. 8, p. 191, 13 ago. 2020. Disponível em: <https://doi.org/10.1007/s13201-020-01276-2>. Acesso em: 11 maio 2021.

KANGAS, A. et al. Sources and types of uncertainties in the information on forest-related ecosystem services. Forest Ecology and Management. [S.1.]: Elsevier B.V. , 1 nov. 2018

KUMAR, A.; SHARMA, A. Systematic literature review of fuzzy logic based text summarization. Iranian Journal of Fuzzy Systems, v. 16, n. 5, p. 45-59, 1 out. 2019. 
Disponível em: <https://ijfs.usb.ac.ir/article_4906.html>. Acesso em: 11 maio 2021.

LAM, C. Y.; TAI, K. Modeling infrastructure interdependencies by integrating network and fuzzy set theory. International Journal of Critical Infrastructure Protection, v. 22, p. 5161, 1 set. 2018.

LAMAMRA, K.; BATAT, F.; MOKHTARI, F. A new technique with improved control quality of nonlinear systems using an optimized fuzzy logic controller. Expert Systems with Applications, v. 145, p. 113148, 1 maio 2020.

LIMA, B. N. et al. Artificial intelligence based on fuzzy logic for the analysis of human movement in healthy people: a systematic review. Artificial Intelligence Review, v. 54, n. 2, p. 1507-1523, 1 fev. 2021. Disponível em: 〈https://doi.org/10.1007/s10462-020-09885-8>. Acesso em: 11 maio 2021.

LIPTON, P. Empiricism, History of. Int. Encycl. Soc. Behav. Sci. Second Ed. [S.l.]: Elsevier Inc., 2015. p. 567-570.

LIU, Y.; BI, J. W.; FAN, Z. P. Ranking products through online reviews: A method based on sentiment analysis technique and intuitionistic fuzzy set theory. Information Fusion, v. 36, p. 149-161, 1 jul. 2017.

MAMDANI, E. H.; ASSILIAN, S. An experiment in linguistic synthesis with a fuzzy logic controller. International Journal of Man-Machine Studies, v. 7, n. 1, p. 1-13, 1 jan. 1975.

MIRANDA, E. E. de;(Coord. ). Brasil em Relevo. Disponível em: $<$ http://www.relevobr.cnpm.embrapa.br>.

NGUYEN, H. T.; WALKER, C. L.; WALKER, E. A. A first course in Fuzzy Logic. Fourth Edi ed. Florida: Boca Raton: Taylor \& Francis, CRC Press, 2019.

OCHOA-GAONA, S. et al. A multi-criterion index for the evaluation of local tropical forest conditions in Mexico. Forest Ecology and Management, v. 260, n. 5, p. 618-627, 30 jul. 2010.

OLADIPO, J. O. et al. Comparison between fuzzy logic and water quality index methods: A case of water quality assessment in Ikare community, Southwestern Nigeria. Environmental Challenges, v. 3, p. 100038, 1 abr. 2021.

OSORIO, M.; CARBALLIDO, J. L. An extension of the stable semantics via Lukasiewicz logic. 1 dez. 2020, [S.1.]: CEUR-WS, 1 dez. 2020. p. 73-83. 
POLKOWSKI, L. Jan Łukasiewicz Life, Work, Legacy. Trans. Rough Sets XXI. Berlin,

Heidelberg: Springer Verlag, 2019. v. 10810. p. 1-47. Disponível em: <https://link.springer.com/chapter/10.1007/978-3-662-58768-3_1>. Acesso em: 10 maio 2021.

QIAO, J. On (IO,O)-fuzzy rough sets based on overlap functions. International Journal of Approximate Reasoning, v. 132, p. 26-48, 1 maio 2021.

QUIROGA, L. F. C.; MORENO, W. A. Classic Formal Logic and Nonclassical Logics: Basis of Research on Neural Networks. Artif. Neural Netw. Drug Des. Deliv. Dispos. [S.1.]: Elsevier Inc., 2015. p. 297-317.

REYNOLDS, K. M.; HESSBURG, P. F. Decision support for integrated landscape evaluation and restoration planning. 7 mar. 2005, [S.1.]: Elsevier, 7 mar. 2005. p. 263-278.

RIGNEL, D. G. de S.; CHENCI, G. P.; LUCAS, C. A. Uma introdução a lógica fuzzy. Revista Eletrônica de Sistemas de Informações e Gestão Tecnológica, v. 01, n. 01, p. 17-28, 2011. Disponível em: <www.facef.br/resiget>. Acesso em: 13 maio 2021.

SANTOS, A. R. dos et al. Espacialização de Dados Meteorológicos no ArcGIS 10 . 3 Passo a Passo Alegre - ES. Alegre, ES: CAUFES, 2015.

SANTOS, G. R. dos. Lógica Fuzzy: uma aplicação na área na saúde. 2014 . 64 f. Monografia (Ciências da Computação) - Instituto Municipal do Ensino Superior., 2014.

SARAIVA, G. J. de P. Lógica Fuzzy. Pesquisa, v. 17, n. 3, p. 43-66, 2000.

SARMAH, P.; NEMA, A. K.; SARMAH, R. An approach to determine the quality of EIA reports of hydropower plants using analytic network process and fuzzy logic toolbox. Environmental Impact Assessment Review, v. 85, p. 106462, 1 nov. 2020.

SCELLS, H. et al. Automatic Boolean Query Formulation for Systematic Review Literature Search. 20 abr. 2020, [S.1.]: Association for Computing Machinery, Inc, 20 abr. 2020. p. 10711081.

SERRANO-GUERRERO, J.; ROMERO, F. P.; OLIVAS, J. A. Fuzzy logic applied to opinion mining: A review. Knowledge-Based Systems, v. 222, p. 107018, 21 jun. 2021.

SILVA, A. A. Da. Sobre raciocínios aproximados: o cas "Fuzzy”. Kinesis, v. 4, n. 7, p. 35-49, 2012. 
SIMIĆ, D. et al. 50 years of fuzzy set theory and models for supplier assessment and selection: A literature review. Journal of Applied Logic, v. 24, p. 85-96, 1 nov. 2017.

SIMÕES, M. G.; SHAW, I. S. Controle e modelagem Fuzzy. 2. ed. São Paulo: Edgard Blucher, 2007.

SLEIT, A.; SAADEH, M.; MOBAIDEEN, W. An Edge Detection Technique for Grayscale Images Based on Fuzzy Logic. British Journal of Applied Science \& Technology, v. 17, n. 6, p. 1-13, 10 jan. 2016. Disponível em: 〈http://www.sciencedomain.org/abstract/16751〉.

SOUZA, P. V. de C. Fuzzy neural networks and neuro-fuzzy networks: A review the main techniques and applications used in the literature. Applied Soft Computing Journal, v. 92, p. 106275, 1 jul. 2020.

TherneAU, T.; ATKInSON, B.; RIPLEY, B. Recursive Partitioning and Regression Trees (rpart). . [S.1.]: CRAN. , 2019

TONG, W. et al. Non-singleton interval type-2 fuzzy PID control for high precision electrooptical tracking system. ISA Transactions, 12 mar. 2021.

VAZ, A. M. Estudo das funções de pertinência para conjuntos fuzzy utilizados em controladores semafóricos fuzzy. 2006. 170 f. Dissertação (Mestrado em Engenharia Civil e Ambiental) - Universidade de Brasília, Faculdaade de tecnologia, Brasília, 2006.

WU, H. C. Compatibility between fuzzy set operations and level set operations: Applications to fuzzy difference. Fuzzy Sets and Systems, v. 353, p. 1-43, 15 dez. 2018.

YAZDANBAKHSH, O.; DICK, S. A systematic review of complex fuzzy sets and logic. Fuzzy Sets and Systems. [S.1.]: Elsevier B.V. , 1 maio 2018

YUAN, Z. et al. Attribute reduction methods in fuzzy rough set theory: An overview, comparative experiments, and new directions. Applied Soft Computing, v. 107, p. 107353, 1 ago. 2021.

ZHANG, R.; GOU, X.; XU, Z. A multi-attribute decision-making framework for Chinese medicine medical diagnosis with correlation measures under double hierarchy hesitant fuzzy linguistic environment. Computers \& Industrial Engineering, v. 156, p. 107243, 1 jun. 2021. 
Capítulo 02 - Lógica Fuzzy: Fundamentos teóricos e especialização

ZHAO, J.; TONG, S.; LI, Y. Fuzzy adaptive output feedback control for uncertain nonlinear systems with unknown control gain functions and unmodeled dynamics. Information

Sciences, v. 558, p. 140-156, 1 maio 2021. 


\section{CAPÍTULO 03 - ÁRVORE DE DECISÃO E RANDOM FOREST: FUNDAMENTOS TEÓRICOS E APLICAÇÕES \\ Taís Rizzo Moreira e Lucas Louzada Pereira \\ https://doi.org/10.29327/ 552680.1-3}

\section{INTRODUÇÃO GERAL}

A capacidade de modelar interações complexas fez com que o aprendizado de máquina (machine learning) se tornasse uma ferramenta difundida em áreas como agricultura, bioinformática, biologia computacional, ciências florestais, dentre outras. Algumas das técnicas de machine learning, como a árvore de decisão e a Random forest (florestas aleatórias) têm sido usadas no campo para várias aplicações bem-sucedidas, alcançando altos níveis de desempenho. Além disso, árvores de decisão e florestas aleatórias oferecem a possibilidade de inspecionar as regras de decisão e investigar a relevância de cada variável, bem como, as dependências entre elas (FRATELLO; TAGLIAFERRI, 2018). Aqui, revisamos os fundamentos teóricos das árvores de decisão e da Random forest e ilustramos estudos de caso com aplicações na literatura recente.

Já introduzimos anteriormente algumas definições a respeito de aprendizado de máquina, aqui abordaremos mais definições e exemplos. O aprendizado de máquina, também é o ramo da ciência da computação que permite que os computadores aprendam a encontrar soluções para os problemas por conta própria. Em outras palavras, o aprendizado de máquina torna o computador capaz de encontrar soluções sem ser explicitamente programado. Um programa de computador geralmente visa pegar a entrada, processá-la sobre as instruções fornecidas e fornecer a saída. O Aprendizado de Máquina, por outro lado, foca nos dados fornecidos e na solução do problema para encontrar o algoritmo mais adequado que conduza à solução. Os algoritmos de aprendizado de máquina têm três categorias - aprendizado supervisionado, aprendizado não supervisionado e aprendizado por reforço (FRATELLO; TAGLIAFERRI, 2018; LAN et al., 2020; RAKHRA et al., 2021).

A característica básica de sistemas de aprendizado supervisionado é que os dados que utilizamos para treiná-los contém a resposta desejada, isto é, contém a variável dependente resultante das variáveis independentes observadas. Nesse caso, dizemos que os dados são anotados com as respostas ou classes a serem previstas. $\mathrm{O}$ algoritmo de aprendizado não supervisionado aprende prevendo o valor de saída e minimizando o erro entre o valor previsto e o real em várias iterações. Algoritmos de aprendizagem não supervisionados fazem suas 
próprias regras para fornecer relações lógicas e padrões nos dados, sendo mais dependentes da máquina do que de humanos. $\mathrm{O}$ algoritmo de aprendizagem por reforço funciona para recompensar e punir a lógica, ele descobre aquela lógica que dá recompensa máxima ou menos punição para encontrar a solução. Falaremos neste capítulo sobre duas técnicas de aprendizado de máquina que utilizam algoritmos supervisionado, a árvore de decisão e a Random forest (FRATELLO; TAGLIAFERRI, 2018; LAN et al., 2020; RAKHRA et al., 2021).

Árvores de decisão têm sido amplamente aplicadas para resolver problemas nas áreas de representação de conhecimento, classificação, otimização combinatória, geometria computacional e assim por diante (MOSHKOV, M., 2021; MOSHKOV, M. J., 2005). Este método utiliza uma representação gráfica baseada em árvores, cujo objetivo é identificar grupos de indivíduos com características de interesse em comum. Para tal, é utilizado uma metodologia recursiva que divide a amostra inicial em subamostras, baseando-se em resultados observados da variável explicativa e em suas interações. Formam-se, assim, grupos para os quais a variável resposta apresenta comportamento homogêneo dentro dos grupos e heterogênea entre os grupos (DANTAS; DONADIA, 2013; HU et al., 2020; OSMANI; ZIAEE, 2021).

Random forest, por sua vez, é um modelo baseado em árvores de decisão, que lida bem com conjunto e dados de alta dimensão, e com presença de multicolinearidade. Este tipo de modelo é usualmente utilizado para executar tarefas de regressão e de classificação. Ele também aplica métodos de redução dimensional, trata valores faltantes, valores anómalos (outliers) e outras etapas essenciais da exploração de dados. É um tipo de método de aprendizado de ensemble, onde um grupo de modelos fracos são combinados para formar um modelo mais forte (BIEWEN; KUGLER, 2021; DANTAS; DONADIA, 2013).

Convidamos vocês a aprendermos um pouco mais sobre esses duas técnicas e suas aplicações.

\section{2 ÁRVORES DE DECISÃO}

Falaremos a seguir sobre o método de árvore de decisão, os critérios de seleção de cada nó, os métodos para se determinar a classe que deve ser associada a uma folha ou nó externo da árvore, e as técnicas de poda.

\subsection{Introdução}

Árvores de decisão são uma forma simples e eficaz de representar o conhecimento (DORGO; PALAZOGLU; ABONYI, 2021). Elas baseiam-se na abordagem de dividir para 
conquistar, ou seja, na sucessiva divisão do conjunto de exemplos utilizado para o treino, em vários subconjuntos, até cada um destes subconjuntos pertencer a uma mesma classe, ou até uma das classes ser majoritária, não havendo necessidade de novas divisões. A estrutura da árvore é organizada da seguinte forma (CARVALHO, 2005; OYA, 2016):

$\checkmark$ Nó interno (nó raiz, nó de probabilidade e nó de decisão): Rotulado com o nome de um dos atributos previsores;

$\checkmark$ Ramos ou arestas: saindo de um nó interno são rotulados com valores do atributo naquele nó. Normalmente, os ramos da esquerda referem-se aos dados que atenderam ao critério do nó e os da direita que não atenderam;

$\checkmark$ Nó final, terminal ou folha: Representa um resultado final ou uma consequência, e;

$\checkmark$ Ramificação negada: Representa um direcionamento existente, porém que não pode ser seguido.

De maneira geral, uma árvore de decisão se inicia com um único nó que se ramifica em outros nós, no caso das árvores de decisão binária, cada nó intermediário divide-se exatamente em dois nós descendentes, contendo possíveis opções ou resultados. Cada um desses ramos leva a outros nós que se subdivide em outros sub nós. Esse comportamento é repetido até que todas as possibilidades sejam mapeadas, resultando numa estrutura de árvore, conforme apresentado no capítulo 1. O caminho a ser seguido depende dos dados satisfazerem ou não o teste lógico (KAPPELHOF et al., 2021; MOSHKOV, M., 2021).

A árvore de decisão objetiva, por meio das divisões dos subconjuntos, criar um modelo viável que preveja o valor de uma variável de destino com base no conjunto de variáveis de entrada (preditoras). As árvores de decisão podem ser aplicadas a problemas de regressão e de classificação (CARVALHO, 2005; KAPPELHOF et al., 2021; OYA, 2016).

A árvore de classificação é muito semelhante a uma árvore de regressão, exceto que ela é usada para prever uma resposta qualitativa e não quantitativa. Para usar árvores de classificação, a resposta da variável de destino precisa ser um valor categórico, como sim/não ou verdadeiro/falso. Por outro lado, as árvores de regressão são usadas para atender aos requisitos de previsão e são sempre usadas quando a variável alvo ou resposta é um valor numérico ou discreto (CARVALHO, 2005; FARKAS; LOPEZ; THOMAS, 2021; OYA, 2016).

As árvores de decisão possuem características relevantes que viabilizam o método, tais como as seguintes (BORGES, 2013):

$\checkmark$ Escalabilidade: capacidade de construir modelos eficientemente a partir de grandes volumes de dados;

$\checkmark$ Precisão: habilidade do modelo para avaliar ou prever corretamente classes, agrupamentos e regras; 
Robustez: habilidade do modelo para avaliar ou prever corretamente, utilizando dados ruidosos ou com valores ausentes;

$\checkmark$ Velocidade: uma vez construída uma árvore de decisão, seu uso é imediato e sua execução é computacionalmente muito rápida.

$\checkmark$ Interpretabilidade: alto nível de compreensão fornecido pelo modelo, e;

$\checkmark$ Flexibilidade: o espaço das instancias é particionado em subespaços e cada subespaço á adaptado a diferentes modelos.

A árvore de decisão requer em seu processo de indução uma alta demanda computacional, pois envolve uma análise detalhada dos dados, que dependendo da dimensão e do tamanho destes torna a indução trabalhosa. O processo de indução de uma árvore de decisão pode ser realizado de forma manual; no entanto, como já foi previamente mencionado, quando existe uma grande quantidade de dados este processo de criação torna-se complicado para ser realizado de forma manual. Assim sendo, recorre-se para uma abordagem automática de indução, baseada em aprendizado supervisionado, ou seja, o algoritmo constrói a árvore a partir de um conjunto de dados de treinamento com seus respectivos valores desejados (BORGES, 2013; FRATELLO; TAGLIAFERRI, 2018).

O algoritmo constrói árvores de decisão a partir do processo conhecido como particionamento, adicionando em cada nó um teste baseado em um atributo, responsável por dividir o conjunto, adicionando-se ainda ligações para cada um dos possíveis valores resultantes. Em seguida, cada novo nó criado é novamente selecionado e um novo atributo de particionamento é atribuído ao nó para a criação de um novo subconjunto. Existem diversos tipos de algoritmo para indução de uma árvore de decisão, os quais são desenvolvidos utilizando algumas heurísticas que são apresentadas a seguir:

\subsection{Critérios de seleção de atributos (atributos para cada nó)}

A escolha de um atributo que melhor divide o conjunto de treinamento é fundamental para a construção de uma árvore de decisão. Os critérios para a seleção de atributos são utilizados para determinar qual atributo pertence a construção da árvore de decisão. Deste modo avalia-se a melhor partição a ser realizada, de acordo com a capacidade informativa do atributo. Existem diferentes tipos de métodos para escolher o melhor atributo para cada nó, entre eles destacam-se os seguintes (BORGES, 2013; GARCIA, 2003; OYA, 2016):

Ganho de Informação: Um dos mais antigos e conhecido critérios de seleção de atributos é o ganho de informação (Gain), utilizado pelos algoritmos ID3 e C45. Ele mede a redução da entropia causada pela partição do conjunto; assim, para medir esta redução, compara-se o grau de entropia do nó raiz (antes da divisão), e o atributo que gera uma 
maior diferença é escolhido como condição teste. O ganho de entropia é definido pela Equação 3.1:

$$
\text { ganho }=\text { entropia }(\text { pai })-\sum_{j=1}^{n} \frac{N\left(V_{j}\right)}{N} * \operatorname{entropia}\left(V_{j}\right) \quad \text { Equação } 3.1
$$

Onde n é o número de atributos, $N$ é o número total de objetos do nó-pai e $N\left(V_{j}\right)$ é o número de exemplos associados ao nó-filho $V_{j}$.

A partir deste cálculo é possível escolher a partição que permite obter um maior ganho de informação.

$\checkmark$ Gini: Mede a impuridade de um nó, a qual é máxima quando todas as classes possuem igual distribuição, e mínima quando existe apenas uma classe. O índice de Gini é definido por meio da Equação 3.2.

$$
\text { índice_gini }(n o ́)=1-\sum_{i=1}^{k} p\left(C_{i} \mid n o ́\right)^{2}
$$

Onde $p$ corresponde à probabilidade relativa da classe $i$ em relação ao nó pai, e $k$ corresponde ao número de classes.

$\checkmark$ Qui-quadrado: O qui-quadrado $\left(\chi^{2}\right)$ é um teste estatístico comumente usado para comparar dados observados com dados esperados, sendo o resultado obtido de acordo com uma hipótese específica.

Para o desenvolvimento do cálculo do $\chi^{2}$ é necessário, primeiramente, criar uma tabela de frequência para o atributo. Com base na tabela é calculada a frequência esperada para cada célula por meio da Equação 3.3. Com as frequências estabelecidas pode-se então aplicar a Equação 3.4 e obter $\chi^{2}$.

$$
\begin{aligned}
& E_{i j}=\frac{S_{i} * S_{j}}{|S|} \\
& \chi^{2}=\sum_{i=1}^{n} \sum_{j=1}^{m} \frac{\left(S_{i j}-E_{i j}\right)^{2}}{E_{i j}}
\end{aligned}
$$

Onde $E_{i j}$ é a frequência esperada na célula $S_{i j}$ da matriz.

\subsection{Critérios de parada ou poda}

Os métodos utilizados para a construção de árvores de decisão, geralmente, resultam em árvores de grandes dimensões, com isso tornando-as complexas e, muitas vezes, comprometendo o seu desempenho. Frente a isso, faz se necessário a definição de critérios de parada, já que as árvores estão propensas a overfitting, que ocorre quando a árvore tem um 
crescimento exagerado, onde novos nós dividem uma partição pequena dos dados em partições menores, tornando a árvore mais específica, tal que consegue memorizar os dados de treinamento, porém, não é capaz de generalizar suas soluções para novas situações (WANG, T. et al., 2010).

De forma a contornar o problema da dimensão demasiada e da precisão da classificação, as técnicas de poda podem ser aplicadas de duas formas: a primeira interrompe a construção da árvore quando algum critério de parada é satisfeito e é conhecida como pré-poda. A segunda, a pós-poda, é aplicada somente após a conclusão da árvore, ou seja, quando todos os exemplos do conjunto de exemplos tenham sido distribuídos ao longo da árvore e visa a reduzir as dimensões da árvore até serem consideradas ideais (BORGES, 2013; OSEI-BRYSON, 2007).

As podas buscam remover partes da árvore que não contribuam para o rigor da classificação, produzindo estruturas menos complexas. A pós-poda é mais confiável que a prépoda, devido ao fato de utilizar todos os exemplos na construção da árvore, enquanto, a prépoda evita a construção de partes da árvore que poderão ser descartadas a posteriori (CHEN, W. et al., 2019; OSEI-BRYSON, 2007).

Na pré-poda, a subdivisão da árvore de decisão pode chegar ao fim durante a fase de construção. O critério de parada é calculado para dar uma estimativa do ganho esperado na continuação da construção da árvore, um dos testes mais utilizados para este critério é o teste do $\chi^{2}$. Nesta técnica a poda é realizada concomitantemente com a construção da árvore. Isso evita a construção de sub-árvores que venham a ser podadas posteriormente à sua constituição. Como inconveniência da pré-poda tem-se o fato de as decisões de poda serem tomadas ao mesmo tempo que a construção da árvore é realizada, decisões estas que podem ser muito complexas, o que torna o algoritmo mais oneroso, anulando, em alguns casos, a vantagem da poda antecipada (FRATELLO; TAGLIAFERRI, 2018; GARCIA, 2003).

Por outro lado, a pós-poda é efetuada nos nodos não terminais, a partir do cálculo do erro de uma árvore e de todas as suas sub-árvores, onde são examinados cada um dos nós não terminais, começando por baixo, ou seja, pelos nodos mais próximos aos nós terminais ou folhas. Se a sua substituição por uma folha ou pelo seu ramo conduzir a um menor erro, este é substituído. Para se verificar a necessidade de uma árvore de decisão ser podada, é preciso estimar a taxa de erro apresentada pala árvore e também a taxa de erro introduzida pela poda nos testes ao longo da árvore, assim como nos nós terminais (FRATELLO; TAGLIAFERRI, 2018). 


\subsection{Algoritmos de indução de árvores de decisão}

Um algoritmo para indução de árvores de decisão trata-se de um exemplo de estrutura TDIDT (Top-Down Induction of Decision Trees), que faz uso da estratégia de decompor um problema complexo em subproblemas mais simples (BROWN; MYLES, 2020).

Falaremos aqui de alguns dos algoritmos mais utilizados (CALDAS; PITOMBO; ASSIRATI, 2021; DANTAS; DONADIA, 2013; ZOUNEMAT-KERMANI et al., 2020):

\subsubsection{CART (Classification and Regression Trees)}

$\checkmark \quad$ Método de partição: Divide as variáveis de forma binária, ou seja, sempre em dois nós, com base em alguma medida de impureza, como, por exemplo, o índice de Gini, Entropia, etc., para tornar os subconjuntos de dados cada vez mais homogêneos em relação a variável resposta.

$\checkmark$ Critério de parada: Enquanto as divisões trouxerem ganhos em relação à medida de impureza, o algoritmo continua. $\mathrm{O}$ usuário pode inserir outros critérios de parada.

$\checkmark$ Vantagens: Não precisa realizar qualquer tipo de categorização, pois o algoritmo não faz restrições quanto às escalas das variáveis explicativas, podendo estas serem numéricas (discretas ou contínuas), ordinais e nominais. Por utilizar partições binárias, as variáveis podem aparecer em diferentes níveis do modelo, permitindo reconhecer diversas interações com outras variáveis.

$\checkmark$ Desvantagens: Por fazer uso de partições binárias, pode aumentar a complexidade da árvore (muitos níveis, sub-árvores), o que pode dificultar a apresentação e interpretação dos resultados.

\subsubsection{CHAID (Chi-square Automatic Interaction Detection)}

$\checkmark \quad$ Método de partição: Constrói-se uma tabela de contingência com $r$ linhas por c colunas entre variável dependente e variáveis independentes, categorizando em classes as variáveis contínuas. Em seguida, realiza-se um conjunto de testes estatísticos, que variam de acordo com o tipo da variável resposta, agregando as classes de cada variável explicativa até restarem apenas duas, de modo a descobrir o melhor agrupamento de classes. Repete-se para todas as variáveis e a que apresenta a menor probabilidade de significância ( $\rho-$ valor $)$, é então escolhida.

$\checkmark$ Critério de parada: Investiga todas as variáveis até ser encontrada uma partição significativa em cada nó. Portanto, o algoritmo não continua a agrupar as demais categorias, o que pode impedir que uma divisão melhor seja encontrada para aquela variável. 
Vantagens: Interrompe o crescimento da árvore antes do problema de overfitting ocorrer, ou seja, não há tratamento de poda, ganhando tempo de processamento.

$\checkmark$ Desvantagem: Necessita de grandes quantidades de dados para assegurar que a quantidade de observações dos nós folhas seja representativa. É possível que o algoritmo não encontre a melhor divisão de nó, pois ele interrompe a busca de partições quando encontra a primeira partição significativa.

\subsubsection{ID3 (Iteractive Dichotomizer 3)}

Método de partição: A escolha da variável a ser particionada é feita utilizando o método de Ganho de informação, descrito na seção 2.2 deste capítulo, que busca maximizar a medida de impureza dos nós filhos relativos ao nó pai.

$\checkmark$ Critério de parada: A construção da árvore parará quando as divisões não aumentam o Ganho de Informação.

$\checkmark$ Vantagens: Demonstra simplicidade e fácil compreensão do processo de construção e funcionamento.

$\checkmark$ Desvantagens: Imutável, uma vez construída a árvore, não se pode eficientemente reutilizar a árvore sem a reconstruir. Não lida com variáveis contínuas, a não ser que sejam discretizadas e não inclui nenhum método de poda.

\subsection{4. $\mathbf{C} 4.5$}

Método de partição: Procura sobre um conjunto de variáveis, aquela que "melhor" divide os dados em relação à variável resposta, guiado pela medida estatística de razão do ganho de informação.

$\checkmark$ Critério de parada: Enquanto as divisões aumentarem a razão de ganho de informação, o algoritmo continua.

$\checkmark$ Vantagens: Lida com variáveis categóricas (nominais ou ordinais) e numéricas (discretas ou contínuas). Trata valores desconhecidos, mas não os usa para o cálculo de entropia e de ganho. Por usar a medida de razão do ganho de informação, gera árvores mais precisas e menos complexas. Combate o problema de overfitting, ou seja, possui método de poda que faz uma busca na árvore, de baixo para cima, e transforma em nó folha aqueles ramos que não apresentam nenhum ganho significativo. Realiza validação cruzada com dois ou mais grupos diminuindo a estimativa do erro cometido pelo classificador.

$\checkmark$ Desvantagens: Não considera valores faltantes para o cálculo da razão de ganho de informação. 


\subsection{Utilização prática}

Dado todos os conceitos e definições, citados anteriormente, nota-se que a árvore de decisão pode ser utilizada numa diversidade de problemas ajudando a criar modelos preditivos automatizados, que têm aplicações em aprendizado de máquina, pesquisa de dados e estatística. A árvore de decisão considera as observações de um item permitindo a previsão deste item (variável dependente) por meio do uso das variáveis independentes (preditoras). Desta forma, sua aplicação é amplamente difundida em diversas áreas das ciências florestais e da agricultura.

A utilização das árvores de decisão vem ganhando destaque no mapeamento de riscos (CHEN, J.; HUANG; CHEN, 2021; LEE, S.; PARK, 2013), na gestão de bacias hidrográficas (COLLINS et al., 2017), na gestão ambiental (ILYAS; MASIH; VAN HULLEBUSCH, 2021), no planejamento e controle de adubação (KONG et al., 2021), no mapeamento e monitoramento de degradação (VIEIRA et al., 2021), na suscetibilidade a inundação e ao deslizamento (CHEN, W. et al., 2020; HONG; LIU; ZHU, 2020), na associação com o SIG para estudos de variáveis climáticas e seus efeitos na agricultura (KOURGIALAS; KARATZAS, 2016), dentre outras.

Para exemplificação da aplicação da árvore de decisão utilizaremos dados climáticos, topográficos e a nota da qualidade sensorial do café arábica. A qualidade natural de uma bebida de café é definida como aquela que é obtida no ano de produção, variando de acordo com as condições climáticas, topográficas, genéticas, ambientais e com os fatores pré-colheita e póscolheita (CHENG et al., 2016; DE SOUZA ROLIM et al., 2020). Coletamos café em 33 propriedades (Figura 3.1), em estados produtores ao longo do Brasil, após coleta, o café foi conduzido ao laboratório recebendo o mesmo processamento pós-colheita.

No exemplo descrito a seguir utilizamos informações, de agosto de 2019 a setembro de 2020 (período de formação e colheita do café), de temperatura média mensal, umidade média mensal, precipitação acumulada mensal, radiação de ondas curtas acumulada mensal e radiação de ondas longas acumulada mensal provenientes do banco de dados da Earth Data (https://giovanni.gsfc.nasa.gov/giovanni/) e para obtenção da altitude foi utilizado o modelo digital de elevação disponibilizado pela Embrapa (MIRANDA, 2005). Após a aquisição, em ambiente SIG, os dados foram extraídos para tabela do Excel, por meio das coordenadas geográficas dos 33 pontos.

A qualidade sensorial do café, coletado nas 33 localidades, foi avaliada por meio do Protocolo para análise sensorial proposto pela Associação Americana de Cafés Especiais, SCAA (2015), com 6 Q-Graders. O número de Q-Graders em um painel sensorial foi inicialmente proposto por Pereira et al. (2018). A qualidade de um café, uma vez avaliada através do protocolo SCAA (2015), é expressa por uma escala numérica centesimal. 


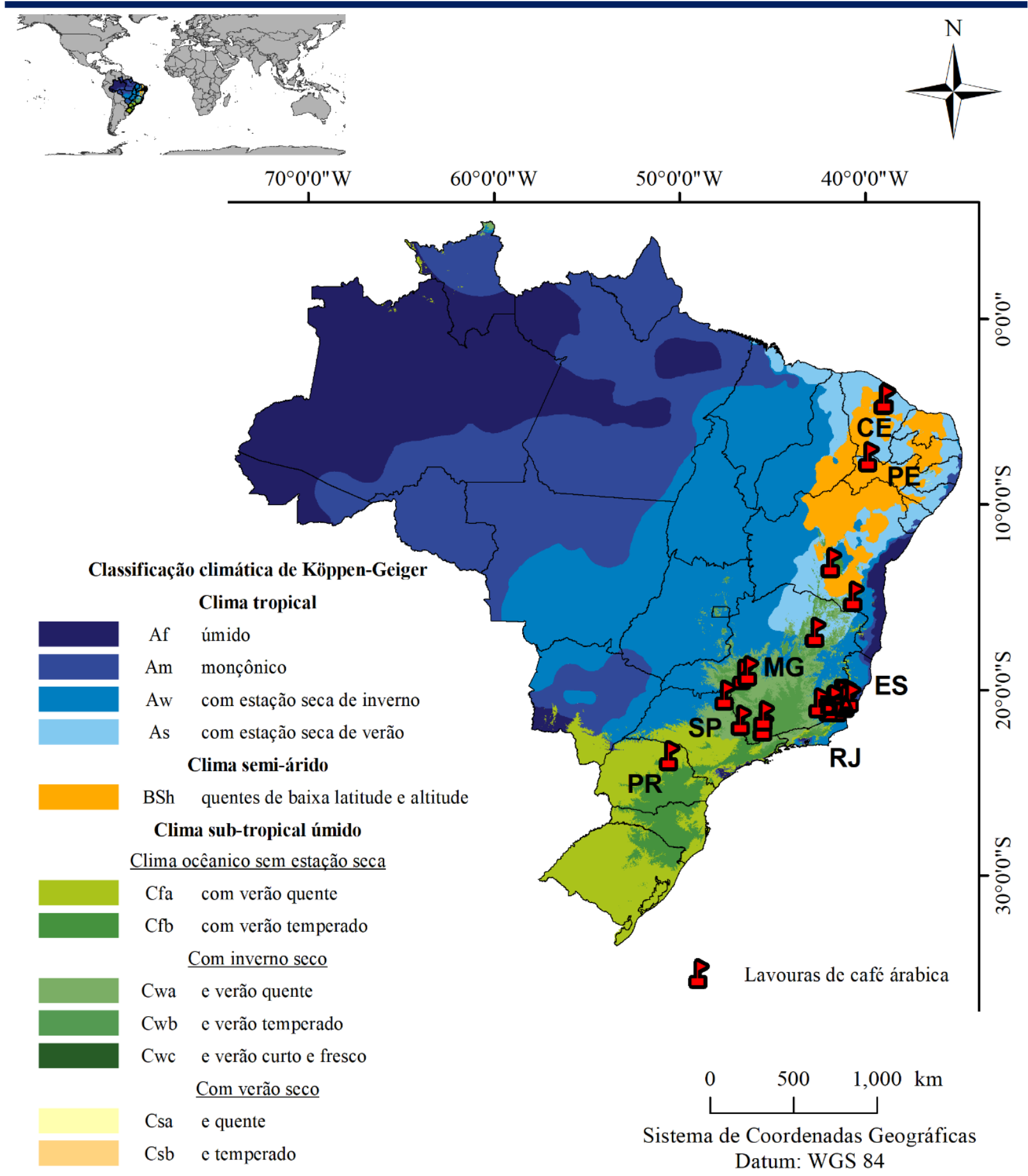

Figura 3.1 - Mapa de localização dos pontos de coleta de café.

Utilizamos para realização deste exemplo, três software: R; QGIS, e Microsoft Excel 2016. O software QGIS foi utilizado para plotagem e padronização do sistema de coordenadas geográficas, bem como para a extração da altitude. No software Microsoft Excel 2016 os dados climáticos, altitude, notas sensoriais e códigos de identificação foram organizados e checados.

Para cálculo e confecção da árvore de decisão, com os dados mencionados, no programa R foi utilizado o toolbox rpart (THERNEAU; ATKINSON; RIPLEY, 2019), que tem dois argumentos principais um indica a forma do modelo a obter, e o outro os dados a usar para o obter (ŻABIŃSKI et al., 2020). A função rpart obtém árvores de regressão ou de decisão 
consoante ao tipo de variável objetivo. Neste exemplo, temos uma variável quantitativa (nota sensorial), teremos assim uma árvore de regressão. O algoritmo utilizado por essa função para confecção da árvore de decisão é o CART. Essa escolha foi motivada pelo fato de o algoritmo não fazer restrição quanto à natureza das variáveis explicativas, por gerar resultados de fácil interpretação e ter facilidade em encontrar interações entre as variáveis (GHIASI; ZENDEHBOUDI; MOHSENIPOUR, 2020). O script utilizado para obtenção da árvore de regressão pode ser visualizado no Apêndice B.

Para calibração utilizamos a função rpart.control, na Tabela 3.1 apresentamos uma descrição dos argumentos da função e os valores adotados.

Tabela 3.1 - Argumentos utilizados na função rpart.control.

\begin{tabular}{|c|c|c|}
\hline Argumento & Descrição & Valor utilizado \\
\hline Minplit & $\begin{array}{l}\text { Número mínimo de observações que devem existir em } \\
\text { um nó para que uma divisão seja testada. }\end{array}$ & 15 \\
\hline $\mathrm{cp}$ & $\begin{array}{l}\text { Parâmetro de complexidade. Essencialmente, o } \\
\text { usuário informa ao programa que qualquer divisão que } \\
\text { não melhore o ajuste por cp provavelmente será } \\
\text { eliminada por validação cruzada e que, portanto, o } \\
\text { programa não precisa persegui-la. }\end{array}$ & 0,01 \\
\hline maxcompete & $\begin{array}{l}\text { Número de divisões concorrentes retidas na saída. É } \\
\text { útil saber não apenas qual divisão foi escolhida, mas } \\
\text { qual variável veio em segundo, terceiro, etc. }\end{array}$ & 4 \\
\hline maxsurrogate & $\begin{array}{l}\text { Número de divisões substitutas retidas na saída. Se for } \\
\text { definido como zero, o tempo de cálculo será reduzido, } \\
\text { uma vez que aproximadamente metade do tempo de } \\
\text { cálculo (além da configuração) é usado na pesquisa de } \\
\text { divisões substitutas. }\end{array}$ & 5 \\
\hline usesurrogate & $\begin{array}{l}\text { Como usar substitutos no processo de divisão. O valor } \\
2 \text {, significa que se todos os substitutos estiverem } \\
\text { faltando, envie a observação na direção da maioria, } 2 \\
\text { é o valor mais recomendado. }\end{array}$ & 2 \\
\hline xval & Número de validações cruzadas. & 8 \\
\hline surrogatestyle & $\begin{array}{l}\text { Controla a seleção do melhor substituto. Se definido } \\
\text { como } 0 \text { (padrão), o programa usa o número total de } \\
\text { classificações corretas para uma variável substituta } \\
\text { potencial. }\end{array}$ & 0 \\
\hline maxdepth & $\begin{array}{l}\text { Defina a profundidade máxima de qualquer nó da } \\
\text { árvore final, com o nó raiz contado como } \\
\text { profundidade } 0 \text {. }\end{array}$ & 20 \\
\hline
\end{tabular}

Os resultados obtidos deste processamento podem ser visualizados nas Figura 3.2, Figura 3.3, Figura 3.4, Figura 3.5, Figura 3.6 e Figura 3.7. 
Na Figura 3.2 podemos observar que ao inserirmos as variáveis altitude, precipitação, temperatura, umidade, radiação de onda longa e radiação de onda curta temos uma correlação de 0,855 com a nota sensorial em relação aos dados de treinamento e de 0,646 em relação aos de teste, visando uma melhora nestes resultados testamos alguns modelos que mesclam estas variáveis independentes.

Vale ressaltar que a árvore de decisão representada na Figura 3.2 demonstra em seus nós a média das notas sensoriais dos dados daquele nó e a porcentagem de dados pertencentes. Por exemplo, o nó raiz possui uma nota média de 83 pontos e compreende $100 \%$ dos dados. Partindo do nó raiz temos duas opções de caminho (árvore binária), o caminho da esquerda para a instância com altitude maior ou igual a 1250 metros e o da direita para instância que não atende esse requisito (valores de altitude inferior a 1250 metros). Cada nó da árvore especifica o teste de algum atributo da instância, e cada ramo que desce daquele nó corresponde a um dos possíveis valores deste atributo, ramos da esquerda representam que a condição proposta foi atendida e ramos da direita quando os dados não satisfazem o teste lógico do nó.

Desta forma, temos a seguinte interpretação proveniente da árvore de decisão da Figura 3.2:

$\checkmark$ A árvore de decisão possui 9 níveis, 17 nós internos (incluindo o nó raiz) e 18 nós terminais ou folhas;

$\checkmark$ Podemos notar que os atributos escolhidos, dentre os testados, para definição de cada nó foram altitude (13 nós), radiação de onda curta (2 nós) e umidade (2 nós). Isso ocorre porque o algoritmo busca o melhor atributo para realização da divisão, considerando uma maior homogeneidade dos dados dos nós filhos em relação ao nó pai;

$\checkmark$ Os métodos utilizados pelos algoritmos buscam as variáveis dentre todas as preditoras, identificando aquelas que possuem maior relação com a variável target, que no exemplo é a nota sensorial, e a coloca no topo da árvore, no nosso exemplo esta variável é a altitude, e;

$\checkmark$ As variáveis utilizadas no modelo (altitude, precipitação, temperatura, umidade, radiação de onda longa e radiação de onda curta) conseguem explicar 85,5\% da variabilidade da nota sensorial dos dados de treinamento e $64,6 \%$ dos dados de teste. 

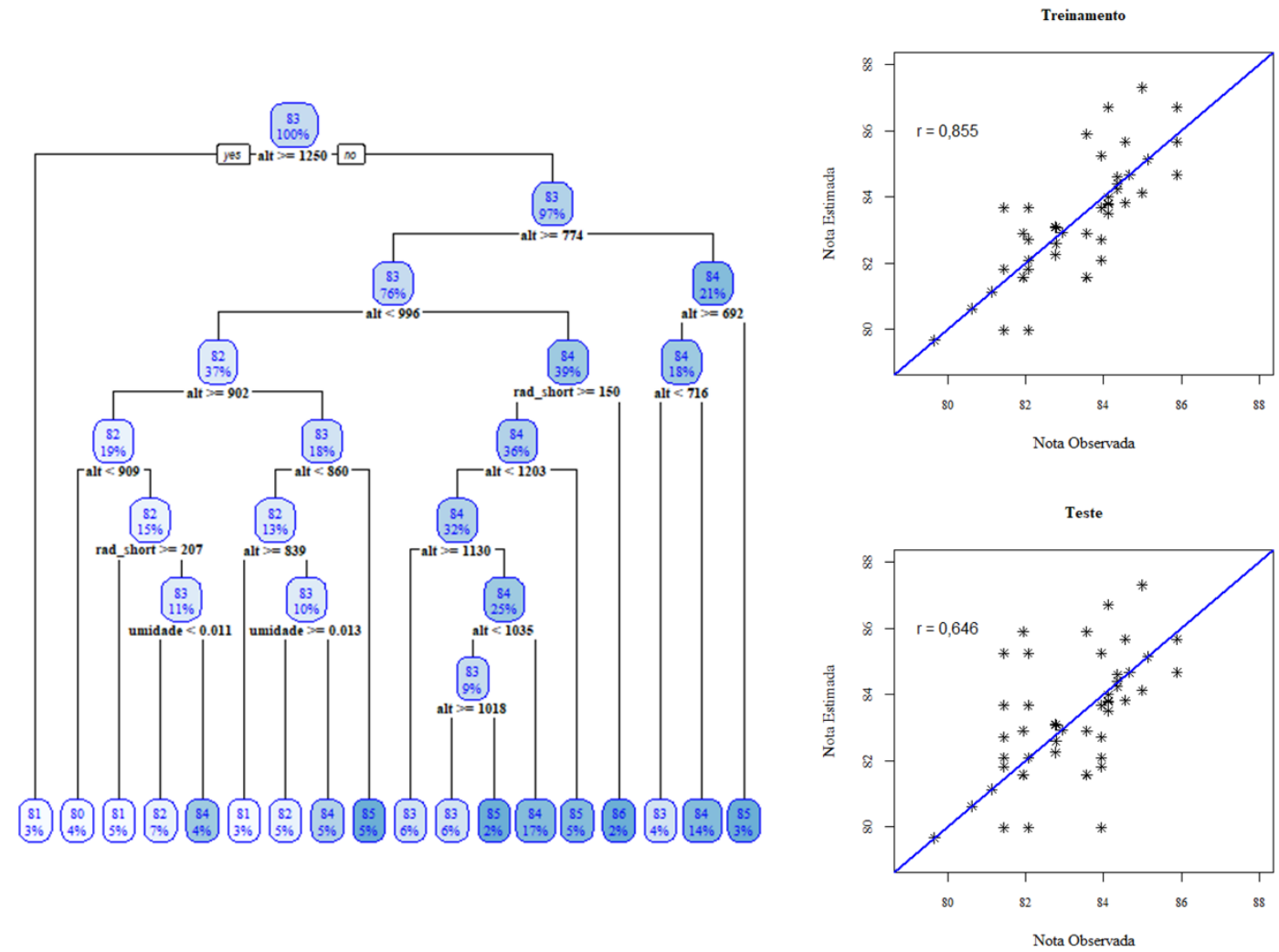

Figura 3.2 - Resultado obtido através das variáveis de altitude (alt), precipitação (prec), temperatura (temp), umidade (umidade), radiação de onda longa (rad_long) e radiação de onda curta (rad_short).

Na Figura 3.3 podemos observar que as variáveis altitude, precipitação, temperatura, umidade e radiação de onda longa conseguem explicar $89,5 \%$ da variabilidade da nota sensorial dos dados de treinamento e 70,6\% da variabilidade da nota sensorial dos dados de teste. Os 5 atributos testados foram utilizados na definição dos nós internos, com destaque para o atributo de altitude (14 nós). Podemos notar que alguns dos atributos que definiram os nós da árvore da Figura 3.2 também confeccionaram os nós da Figura 3.3. 

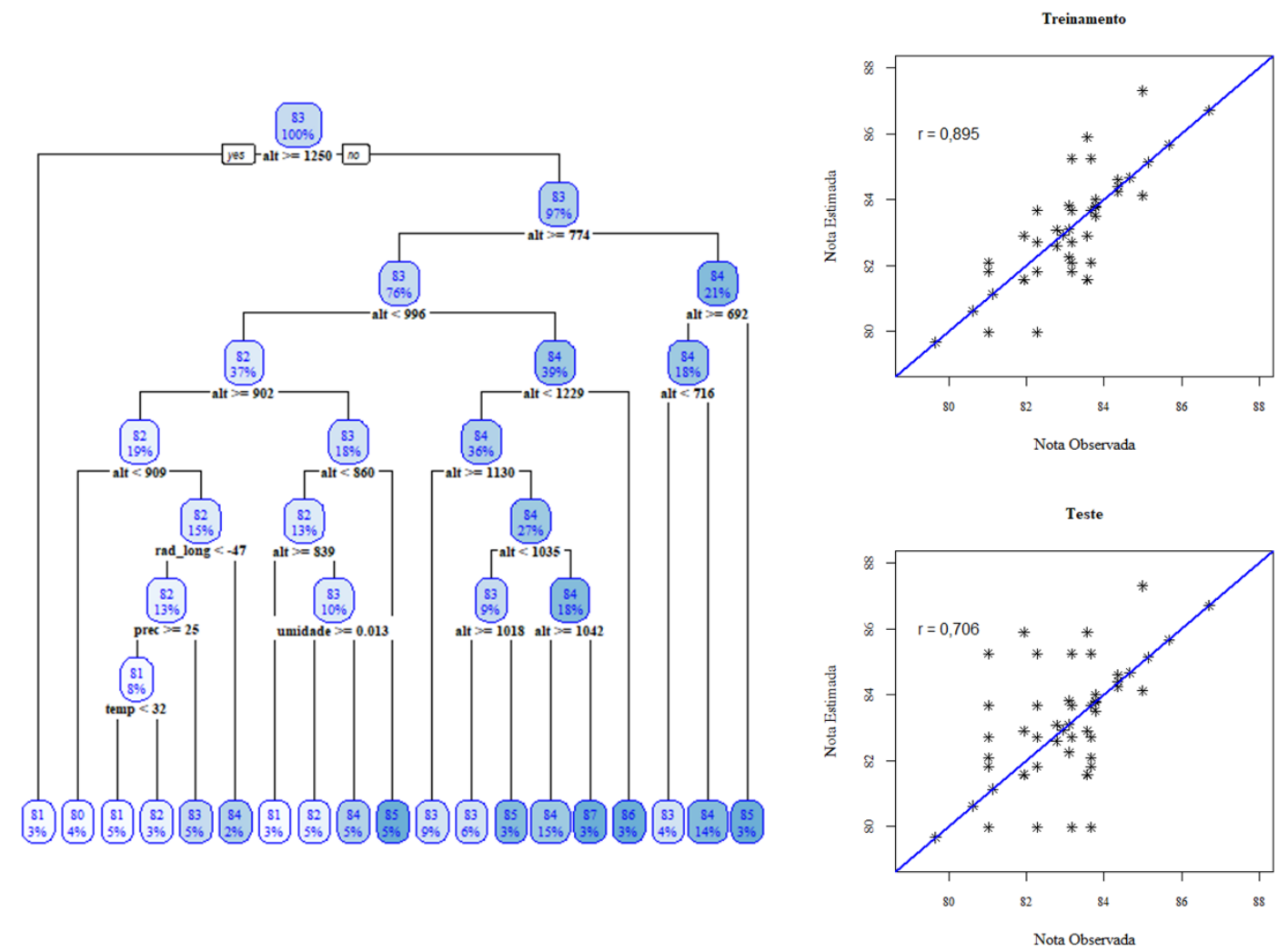

Figura 3.3 - Resultado obtido através das variáveis de altitude (alt), precipitação (prec), temperatura (temp), umidade (umidade) e radiação de onda longa (rad_long).

Na Figura 3.4 podemos observar que as variáveis altitude, precipitação, temperatura, umidade e radiação de onda curta conseguem explicar $85,5 \%$ da variabilidade da nota sensorial dos dados de treinamento e $64,7 \%$ da variabilidade da nota sensorial dos dados de teste. Dos 5 atributos testados 3 foram utilizados na definição dos nós internos (altitude, umidade e radiação de onda curta), com destaque para o atributo de altitude (13 nós). Podemos notar que alguns dos atributos que definiram os nós da árvore da Figura 3.2 e da Figura 3.3 também confeccionaram os nós da Figura 3.4. No entanto, podemos notar que a correlação reduziu quando comparada a árvore da Figura 3.3, isso ocorre possivelmente porque a variável radiação de onda longa tem maior correlação com a nota sensorial que a variável radiação de onda curta. 

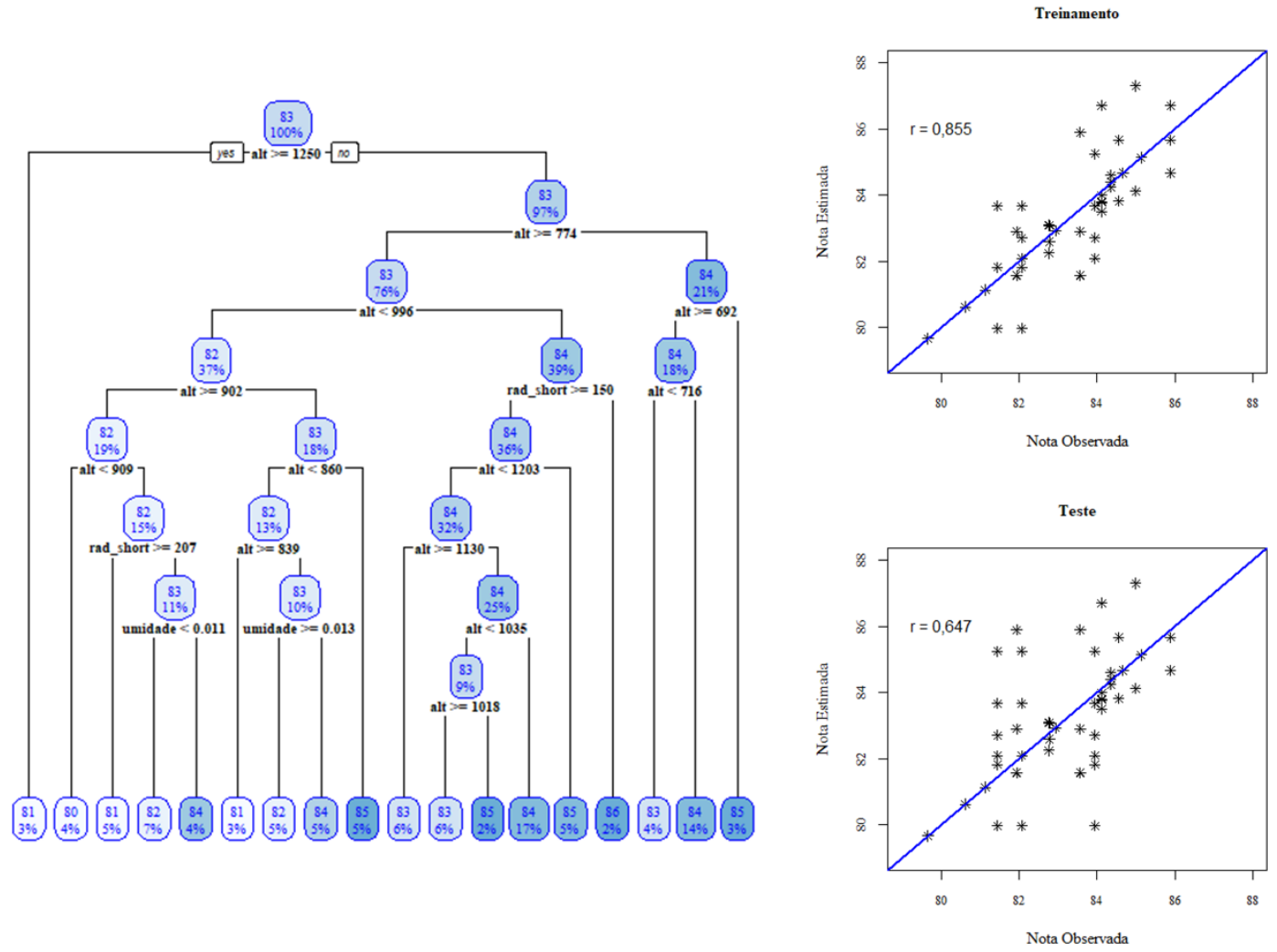

Figura 3.4 - Resultado obtido através das variáveis de altitude (alt), precipitação (prec), temperatura (temp), umidade (umidade) e radiação de onda curta (rad_short).

As variáveis altitude, precipitação, temperatura e umidade foram testadas como podemos observar na Figura 3.5 conseguem explicar 90,9\% da variabilidade da nota sensorial dos dados de treinamento e $80,6 \%$ da variabilidade da nota sensorial dos dados de teste. Dos 4 atributos testados 2 foram utilizados na definição dos nós internos (altitude e umidade). Podemos notar que a correlação entre os dados de treinamento e de teste com a nota sensorial melhorou, isso ocorre possivelmente porque dentre as variáveis preditoras da Figura 3.4 e da Figura 3.5, as da Figura 3.5 possuem maior relação com a variável target (nota sensorial). 

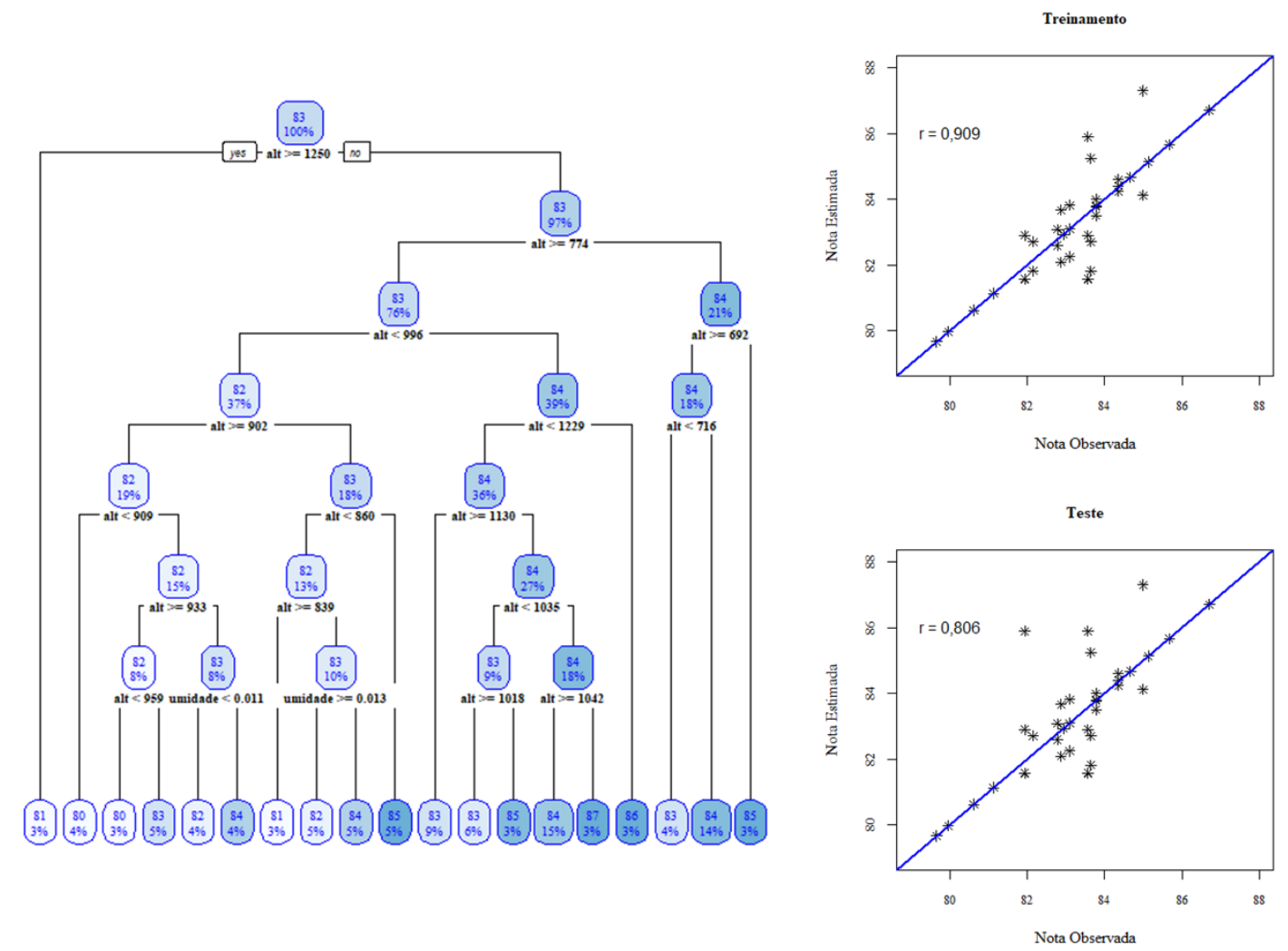

Figura 3.5 - Resultado obtido através das variáveis de altitude (alt), precipitação (prec), temperatura (temp) e umidade (umidade).

As variáveis altitude, precipitação e temperatura foram testadas como podemos observar na Figura 3.6 conseguem explicar 90,9\% da variabilidade da nota sensorial dos dados de treinamento e 76,9\% da variabilidade da nota sensorial dos dados de teste. Os 3 atributos testados foram utilizados na definição dos nós internos (altitude, precipitação e temperatura). Podemos notar que a correlação entre os dados de teste e a nota sensorial piorou em relação a Figura 3.5, isso ocorre possivelmente porque retiramos a variável preditora umidade que possuí relação com a variável target (nota sensorial).

Testaremos na Figura 3.7 alterações nas variáveis preditoras da Figura 3.5 que apresentou a melhor correlação entre os dados de treinamento e teste e a nota sensorial. 

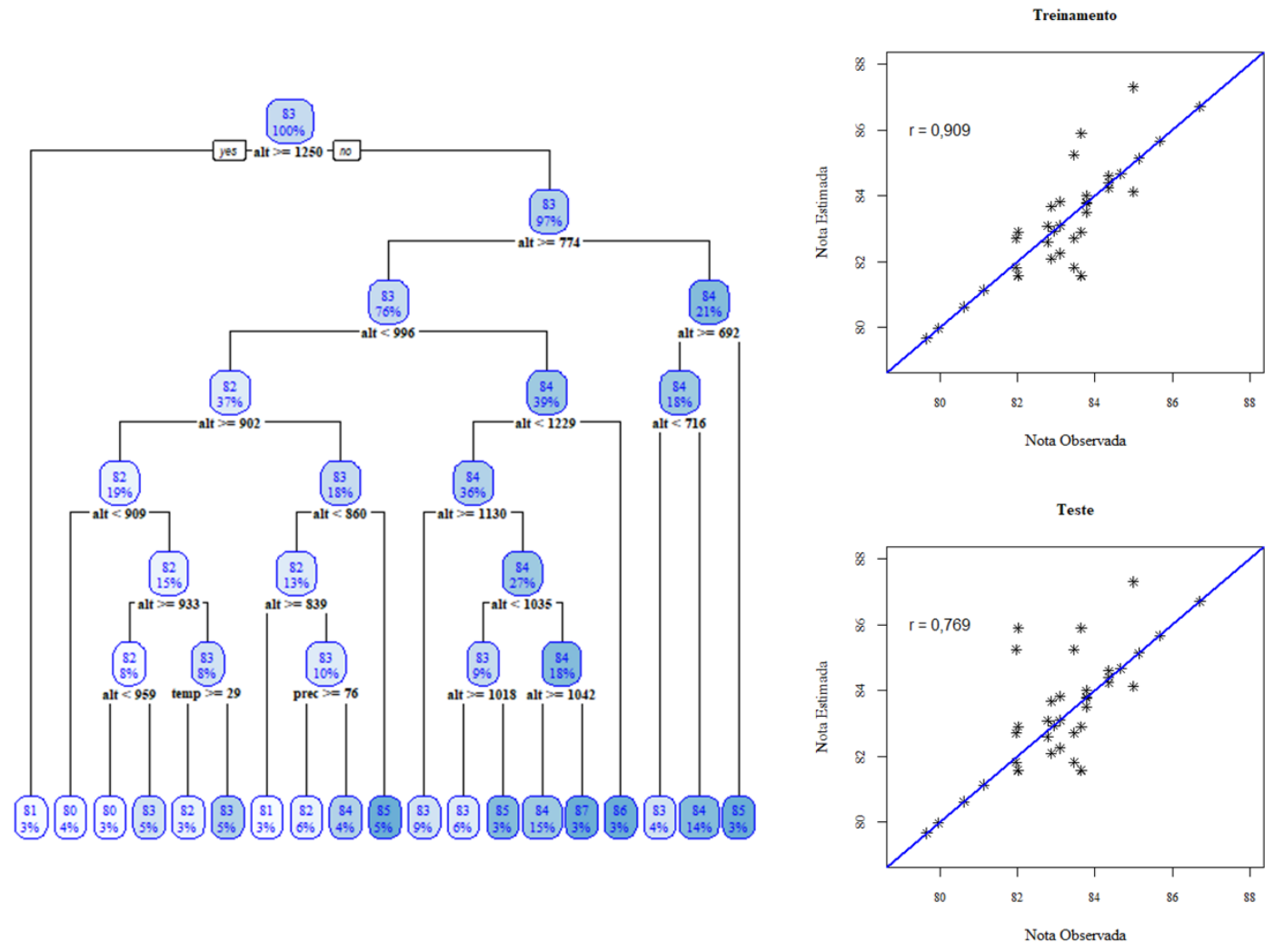

Figura 3.6 -Resultado obtido através das variáveis de altitude (alt), precipitação (prec) e temperatura (temp).

Como dito, testamos na Figura 3.7 as variáveis preditoras altitude, precipitação e umidade e encontramos valores de correlação semelhantes aos da Figura 3.5, 90,9\% para os dados de treinamento e $80,6 \%$ para os dados de teste. Podemos notar que os atributos escolhidos, dentre os testados, para definição de cada nó, se assemelham aos da Figura 3.5. A semelhança entre essas árvores pode ser explicada possivelmente porque as variáveis preditoras selecionadas são aquelas que possuem maior correlação com a variável target. 

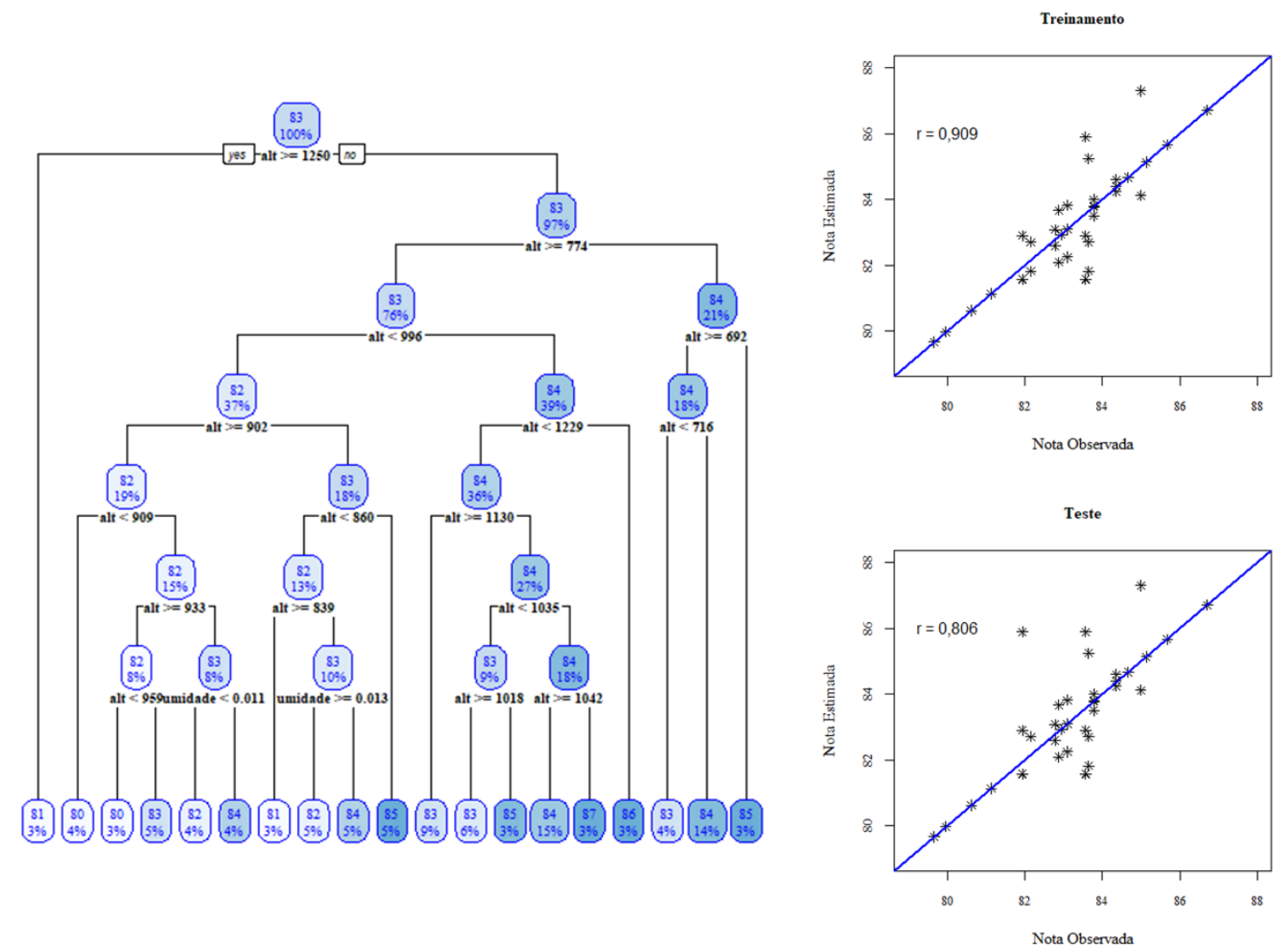

Figura 3.7 - Resultado obtido através das variáveis de altitude (alt), precipitação (prec) e umidade (umidade).

Utilizamos nesta seção apenas a correlação (r) para verificação das árvores de decisão formadas, isso foi feito porque temos como objetivo a apresentação do método utilizado. Exploramos a ideia central de demonstrar que a árvore de decisão consegue separar por meio das variáveis preditoras utilizadas a variável target, nota sensorial. Notamos, no decorrer do exemplo por meio da análise dos dados inseridos que a árvore de decisão conseguiu agrupar, em uma mesma folha, pontos com a nota sensorial semelhante. Observamos assim que a metodologia demonstrou capacidade de uso para mapear os possíveis resultados sensoriais com base nas características climáticas e de altitude. Além da aplicação, demonstrada no exemplo, a árvore de decisão tem potencial de uso em outras áreas das ciências florestais e da agricultura, permitindo uma maximização de alcance dos resultados esperados com base no comportamento das variáveis preditoras.

\section{RANDOM FOREST}

Falaremos a seguir sobre os o método de random forest (floresta aleatória) e demonstraremos um exemplo prático. 


\subsection{Introdução}

Muitos cenários da vida real lidam com a geração de uma grande quantidade de conjuntos de dados, que possui classes de tamanho heterogêneo. Alguns trabalhos necessitam que as amostras sejam agrupadas e para tanto necessita-se de um ajuste de qualidade. A random forest demonstra eficiência em grandes bases de dados e possibilita o processamento de milhares de variáveis, remove aquelas redundantes ou indesejáveis sem que haja prejuízo no desempenho do classificador (MORE; RANA, 2017).

Random forest (RF) é um modelo baseado em árvores de decisão, que lida bem com conjuntos de alta dimensão, e com presença de multicolinearidade. Esta técnica de aprendizagem de máquina pode ser usada para regressão e classificação, estudo de importância, seleção de variáveis, e detecção de outliers (ALVARENGA JÚNIOR, 2018). A RF é um algoritmo flexível e fácil de usar que produz, mesmo sem ajuste de hiperparâmetros, um ótimo resultado na maioria das vezes. O algoritmo coleta a decisão obtida a partir da análise experimental conduzida com as entradas (ANAND et al., 2021).

A RF gera um conjunto de árvores de decisão e o resultado predito é a média de todas as árvores, para os casos de regressão. Nos problemas de classificação, o resultado obtido é dado por um sistema de votação, em que, a nova classe predita é aquela que obteve o maior número de votos (TOOKE; COOPS; WEBSTER, 2014).

O algoritmo para induzir uma RF foi desenvolvido por Leo Breiman e Adele Cutler. O método utiliza a ideia do bagging, que combina várias árvores de decisão usando a amostragem bootstrap, e a seleção randômica de variáveis explicativas no processo de indução da árvore. Essa seleção trata-se de um sorteio feito a cada nó da árvore, selecionando aleatoriamente algumas variáveis candidatas para dividir este nó, ao contrário do bagging que considera todos os preditores para a divisão do nó. Desta forma, diferentes conjuntos de variáveis poderão aparecer em níveis distintos em cada uma das árvores. Com isso, a técnica se torna mais sensível a interações entre as variáveis devido ao sorteio aleatório das variáveis candidatas a dividir o nó feito a cada partição (KULKARNI; SINHA, 2012; RESENDE; DRUMMOND, 2018).

Mecanismos de funcionamento do algoritmo random forest são apresentados a seguir (DANTAS; DONADIA, 2013) e na Figura 3.8 adaptada de Ibrahim; Khatib (2017):

$\checkmark$ Gerar B amostras bootstrap a partir dos dados originais;

$\checkmark$ Para cada uma das amostras bootstrap, induzir uma árvore se poda com a seguinte modificação: em cada nó, selecionar aleatoriamente um número $m$ das variáveis explicativas a serem candidatas para dividir o nó e, dentre estas, escolher a que melhor particiona. 
Predizer novos dados agregando as predições de todos os B modelos, o que pode ser feito com base na média das possibilidades estimadas fornecidas por cada modelo. Em caso de respostas qualitativas, também é usual a utilização da classificação por proporção de votos. Neste caso, conta-se quantas vezes o indivíduo foi classificado em cada classe. Se a proporção de vezes o indivíduo foi classificado em uma classe for maior que um valor preestabelecido, então será classificado nela.

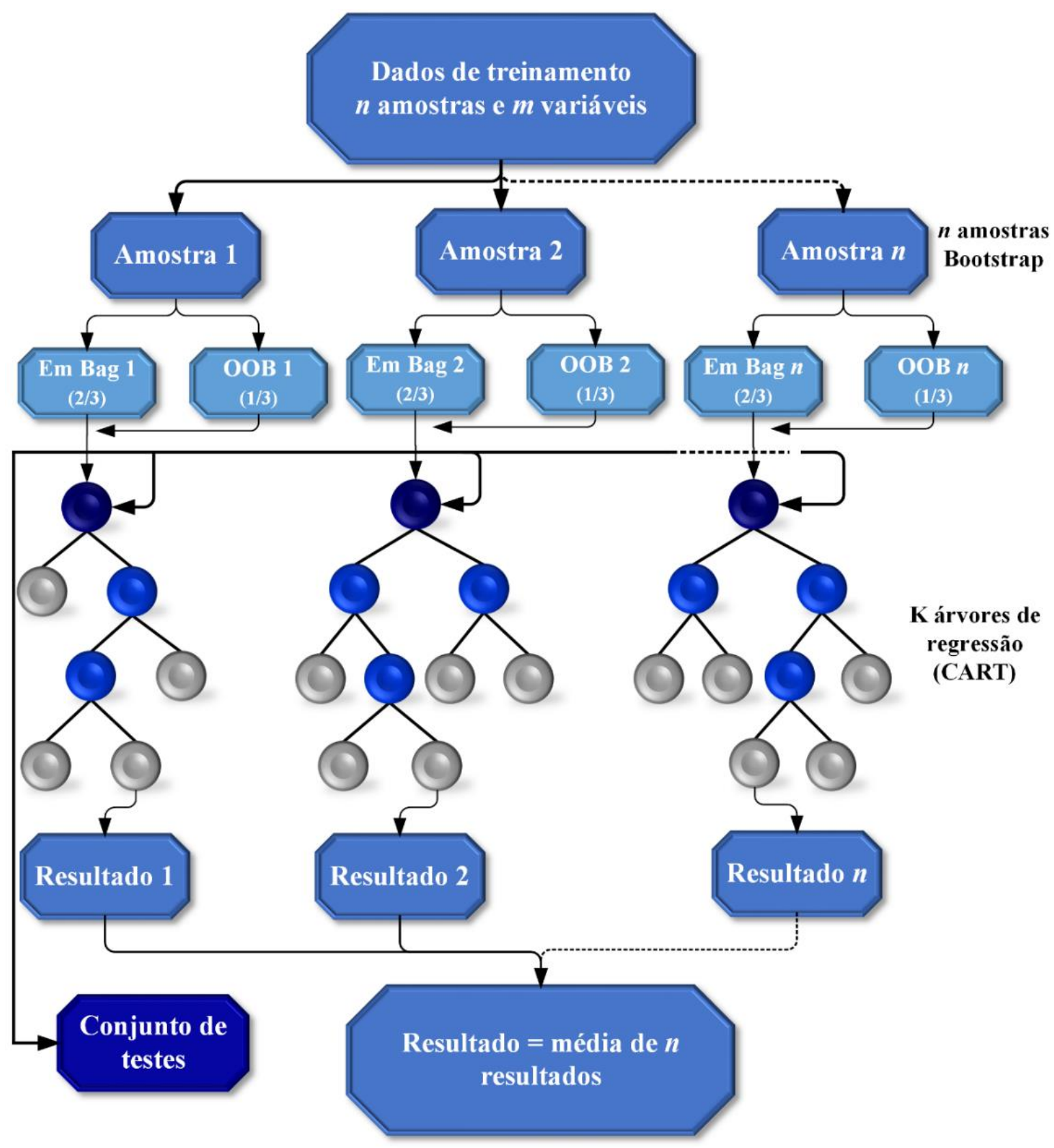

Fonte: Adaptado de Ibrahim; Khatib (2017).

Figura 3.8 - Estrutura do algoritmo Random forest (OOB, Out-Of-Bag, é para obter uma estimativa imparcial em execução do erro de predição conforme as RFs são construídas na fase de treinamento, que também é usada para determinar a importância da variável).

A seguir demonstramos um exemplo prático de random forest utilizando os mesmos dados do exemplo de árvore de decisão deste capítulo. 


\subsection{Utilização prática}

A random forest é uma técnica que tem potencial para ampla aplicação nas Ciências florestais. Alguns trabalhos vem utilizando esta técnica para estimativa de evapotranspiração (DOUNA et al., 2021), estimativa de horas de radiação global (IBRAHIM; KHATIB, 2017), previsão espacial do pH do solo (MAKUNGWE et al., 2021), análise de produtividade florestal de acordo com variáveis climáticas (WANG, Z. et al., 2021), predições espaciais (FOUEDJIO, 2020), avaliação de suscetibilidade (TANG, X. et al., 2020), na modelagem dos efeitos de poluentes (KAMIŃSKA, 2018), mapeamento e zoneamento de risco (ARABAMERI; PRADHAN; REZAEI, 2019), dentre outras.

Para exemplificação da aplicação de random forest utilizaremos os mesmos dados do exemplo de árvore de decisão, ou seja, dados climáticos, topográficos e a nota da qualidade sensorial do café arábica coletado em 33 propriedades localizadas em diferentes estados brasileiros. Para execução da random forest, no programa R, foi utilizado o toolbox randomForest (BREIMAN; CUTLER, 2018).

O script para cálculo da random forest pode ser visualizado no Apêndice C. Os resultados obtidos deste processamento podem ser visualizados nas Figura 3.9, Figura 3.10, Figura 3.11, Figura 3.12, Figura 3.13 e Figura 3.14.

Na Figura 3.9 podemos observar que ao inserirmos as variáveis altitude, precipitação, temperatura, umidade, radiação de onda longa e radiação de onda curta temos uma correlação de $96,1 \%$ com a nota sensorial em relação aos dados de treinamento e de 58,5\% em relação aos de treino, visando uma melhora nestes resultados testamos algumas combinações de variáveis. Podemos notar que a altitude foi a variável com maior grau de importância 

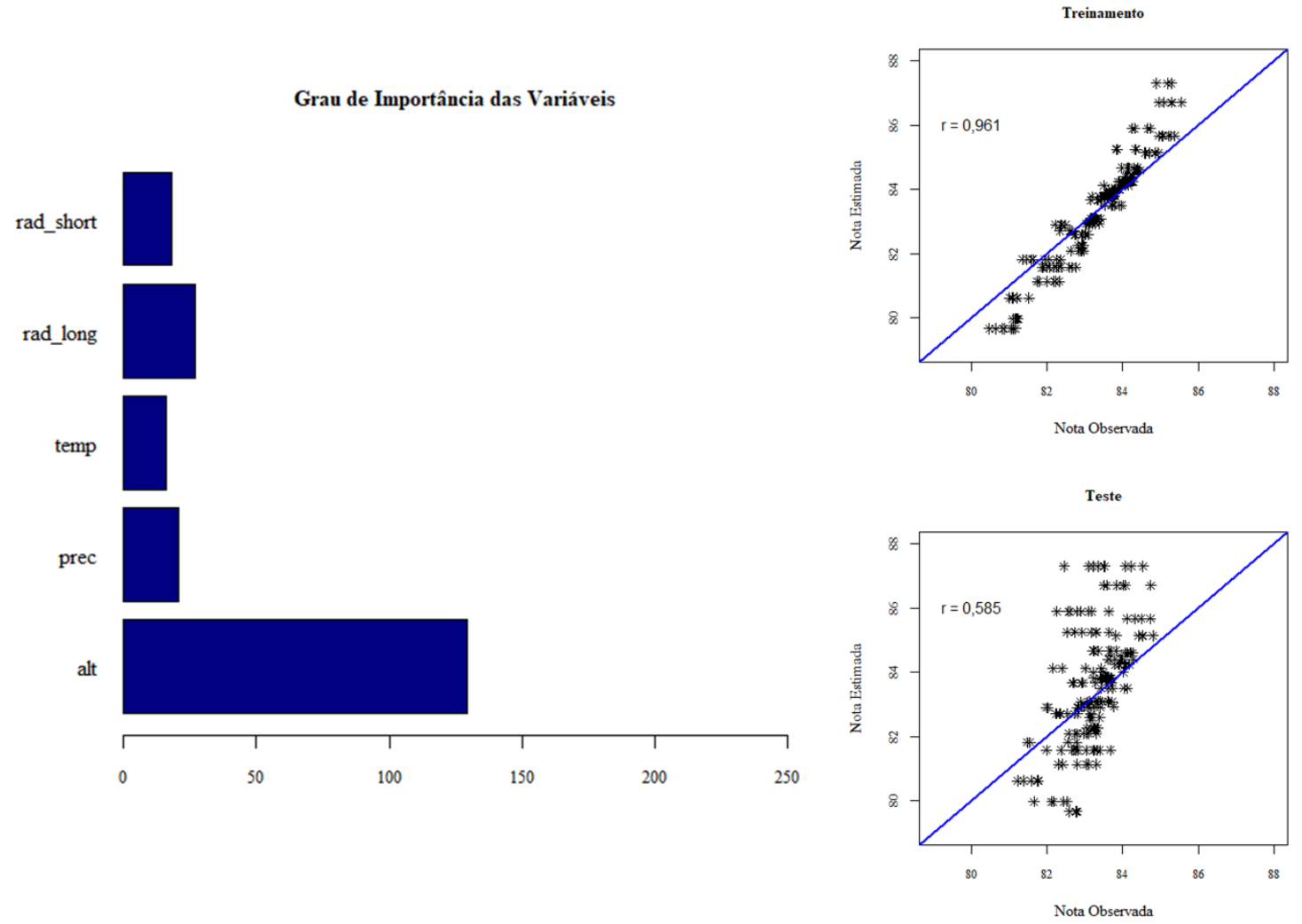

Figura 3.9 - Resultado obtido através das variáveis de altitude (alt), precipitação (prec), temperatura (temp), umidade (umidade), radiação de onda longa (rad_long) e radiação de onda curta (rad_short).

Ao utilizarmos as variáveis preditoras de altitude, precipitação, temperatura, umidade e radiação de onda longa (Figura 3.10) observamos uma correlação de 96,5\% em relação aos dados utilizados para o treino e de $66,6 \%$ para os dados de teste, notamos mais uma vez uma maior importância da variável altitude. 

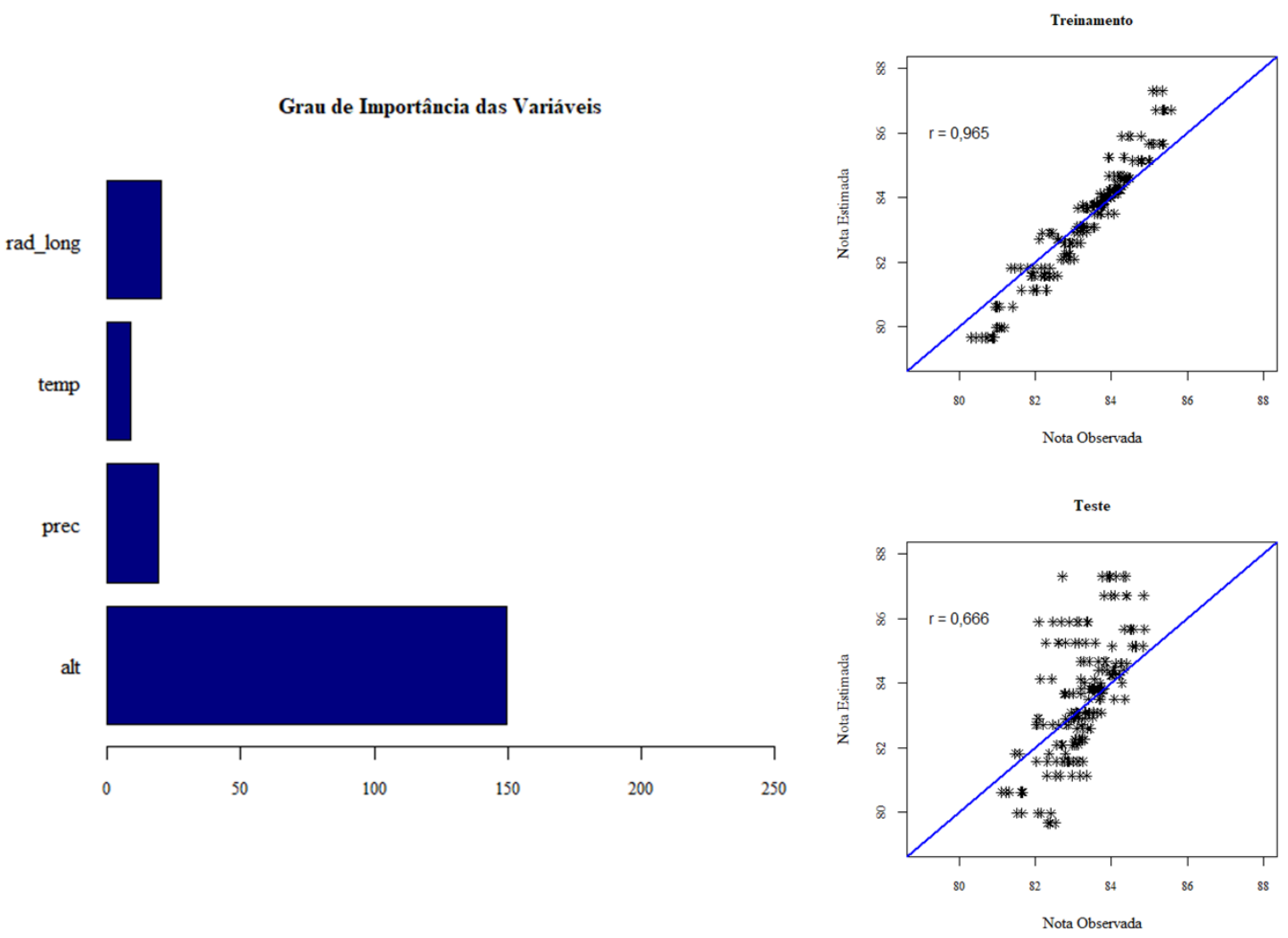

Figura 3.10 - Resultado obtido através das variáveis de altitude (alt), precipitação (prec), temperatura (temp), umidade (umidade) e radiação de onda longa (rad_long).

As variáveis altitude, precipitação, temperatura, umidade e radiação de onda curta foram testadas como podemos observar na Figura 3.11 conseguem explicar 96,4\% da variabilidade da nota sensorial dos dados de treinamento e $70,3 \%$ da variabilidade da nota sensorial dos dados de teste. Dentre os atributos testados a altitude apresentou maior grau de importância. 

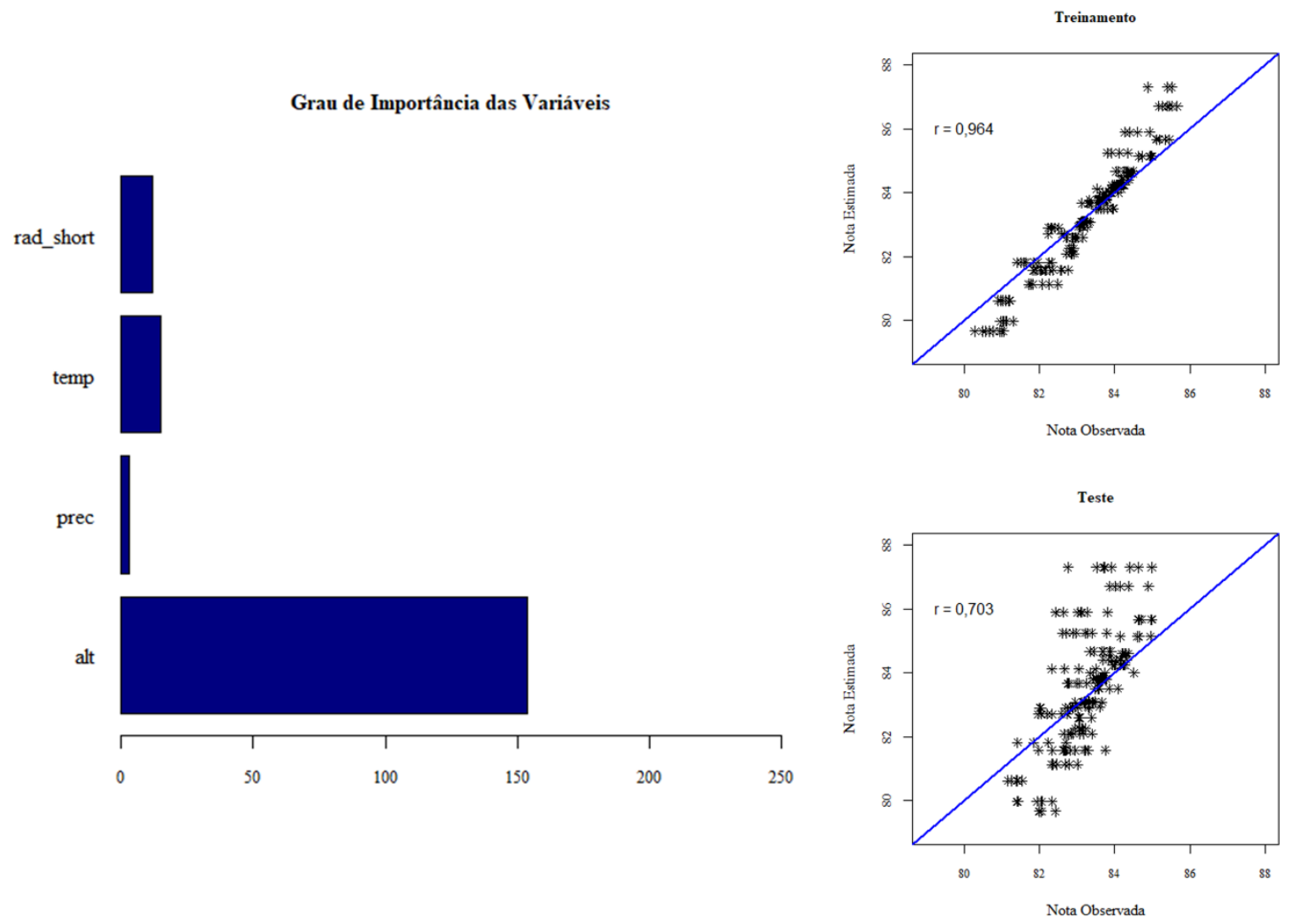

Figura 3.11 - Resultado obtido através das variáveis de altitude (alt), precipitação (prec), temperatura (temp), umidade (umidade) e radiação de onda curta (rad_short).

Na Figura 3.12 testamos as variáveis preditoras altitude, precipitação, temperatura e umidade. Tais variáveis conseguem explicar $97,0 \%$ da variabilidade da nota sensorial dos dados de treinamento e $80,4 \%$ da variabilidade da nota sensorial dos dados de teste, notamos um melhor resultado que os apresentados anteriormente. 

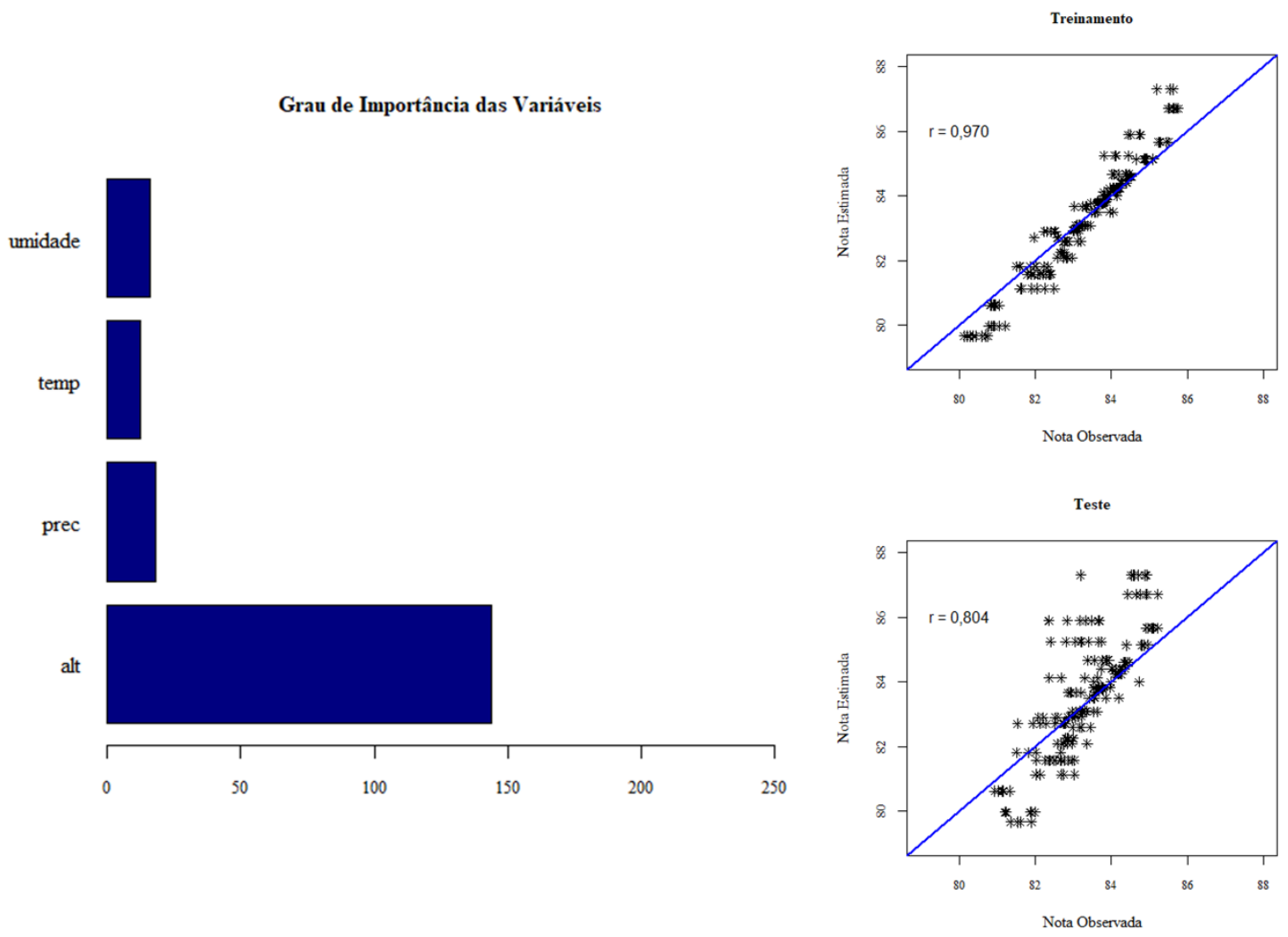

Figura 3.12 - Resultado obtido através das variáveis de altitude (alt), precipitação (prec), temperatura (temp) e umidade (umidade).

Ao utilizarmos na Random forest as variáveis preditoras, altitude, precipitação e temperatura, obtivemos os resultados apresentados na Figura 3.13. Podemos notar que 98,4\% da variabilidade na nota sensorial dos dados de treinamento podem ser explicados pelas variáveis utilizadas e $91,9 \%$ da variabilidade na nota sensorial dos dados de teste. 
Grau de Importância das Variáveis
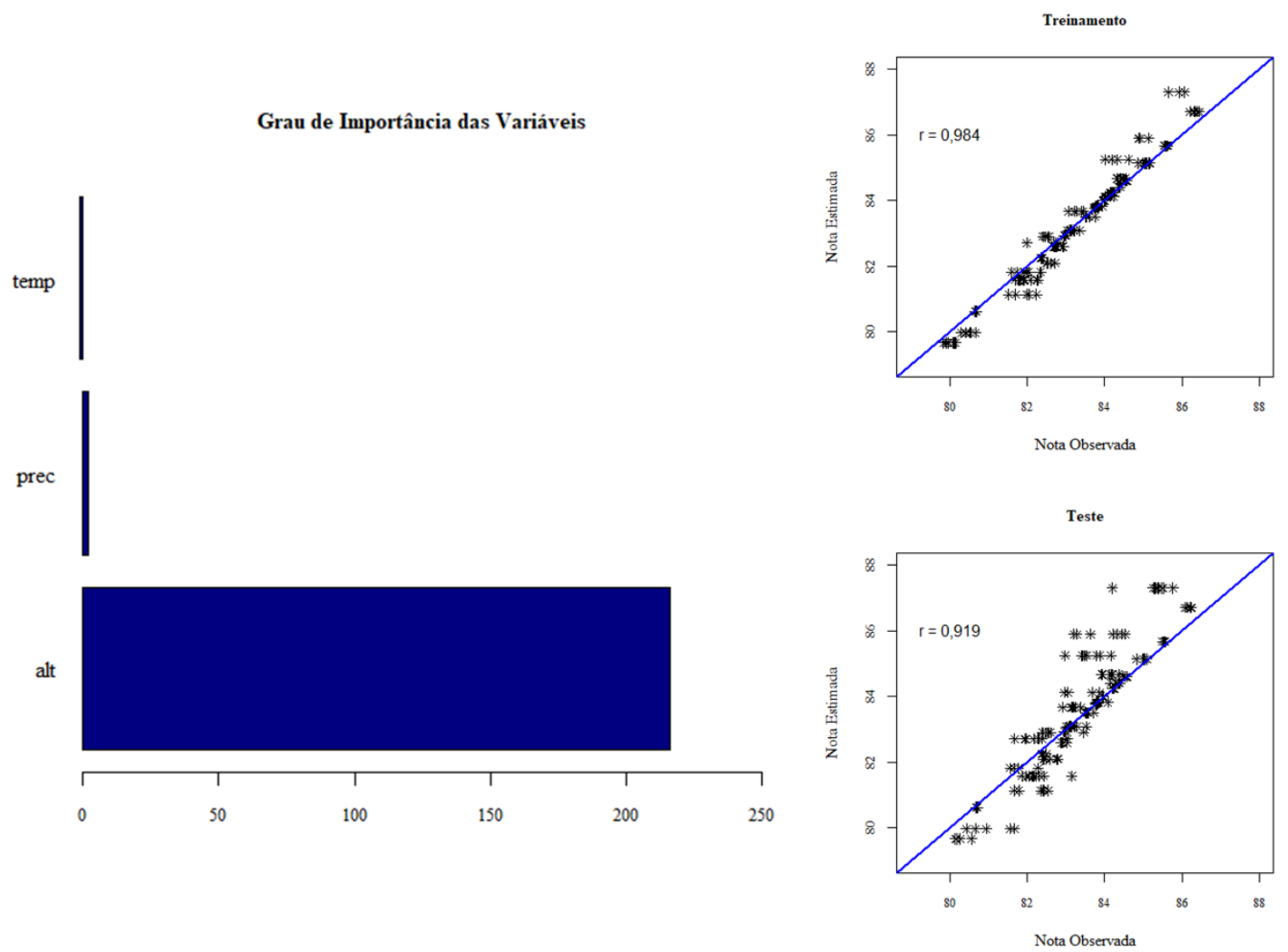

Figura 3.13 - Resultado obtido através das variáveis de altitude (alt), precipitação (prec) e temperatura (temp).

Testamos também na random forest as variáveis preditoras, altitude, precipitação e umidade e obtivemos os resultados apresentados na Figura 3.14. Podemos notar que houve uma melhora nos resultados dos dados de teste, estas variáveis preditoras explicam 98,3\% da variabilidade na nota sensorial dos dados de treinamento e $92,5 \%$ da variabilidade na nota sensorial dos dados de teste. Notamos uma alta correlação entre as variáveis preditoras e a nota sensorial.

Podemos observar que em todos os conjuntos de variáveis preditoras testadas a altitude foi a que apresentou maior importância na predição. 

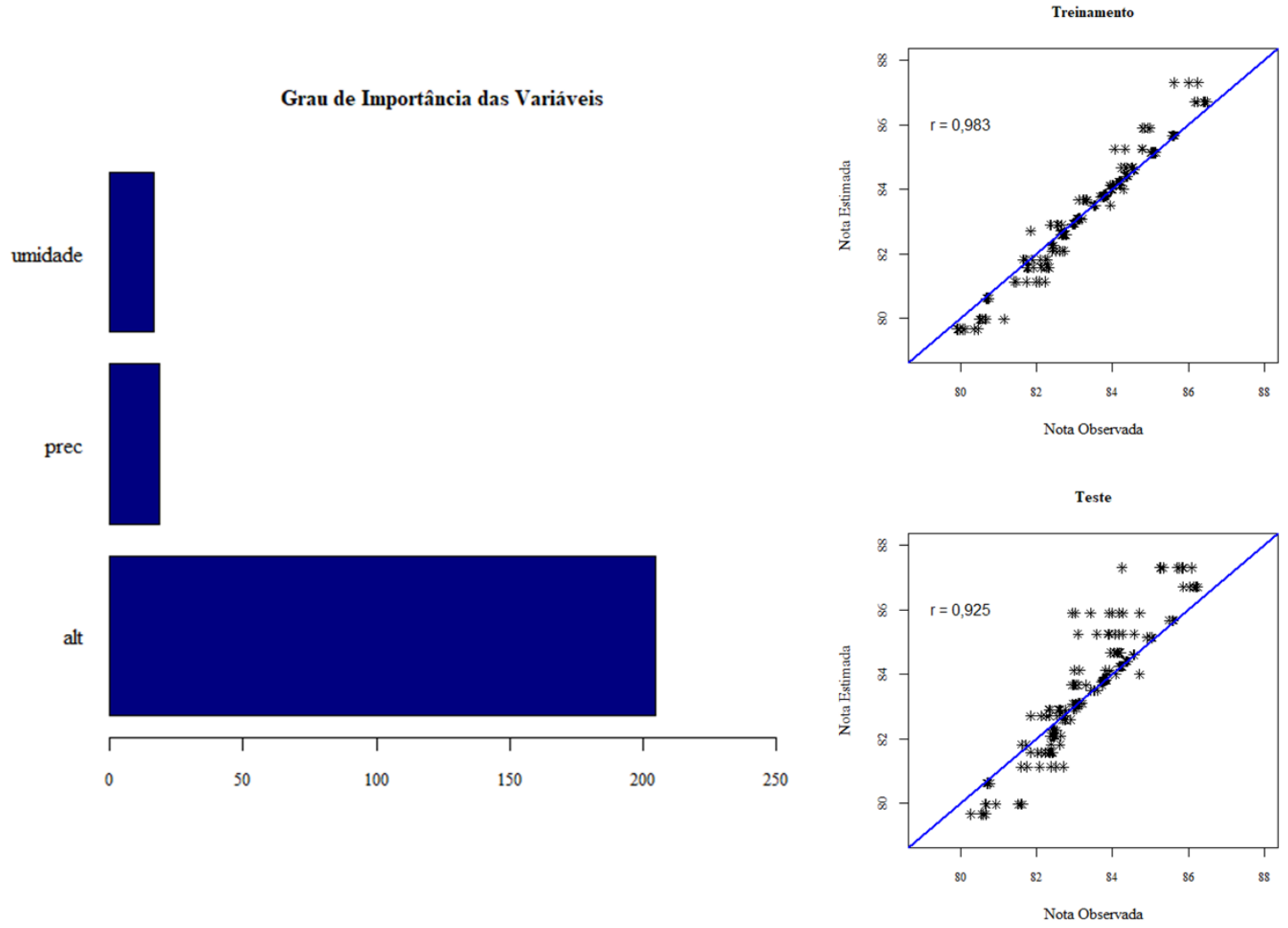

Figura 3.14 - Resultado obtido através das variáveis de altitude (alt), precipitação (prec) e umidade (umidade).

Como random forest baseia-se em um conjunto de árvores de decisão, utilizando apenas uma parte das variáveis independentes disponíveis no conjunto de dados, os resultados demonstram uma melhor correlação entre as variáveis preditoras e a nota sensorial ao se comparar com os resultados gerados pelos modelos de árvores de decisão citados previamente neste capítulo.

\section{CONSIDERAÇÕES FINAIS}

Como podemos observar no decorrer do capítulo a árvore de decisão é um método relativamente simples, porém poderosas. A árvore de decisão por seguirem a abordagem de “dividir-para-conquistar" torna um problema complexo em problema mais simples e de fácil solução. A random forest apresentou melhores resultados, para os dados utilizados nos exemplos, possivelmente, por se tratar de uma combinação de árvores de decisão potencializando a técnica.

Podemos observar o potencial de uso desses algoritmos para diferentes áreas e podemos inferir sobre o exemplo utilizado neste capítulo que existe a possibilidade de identificação de áreas produtoras de cafés de qualidade com base nas variáveis preditoras (altitude e climáticas). 
Capítulo 03 - Árvore de decisão e random forest: fundamentos teóricos e aplicações

No entanto, outras variáveis devem ser levadas em consideração e mais análises estatísticas devem ser analisadas, mas já temos um indicativo desta capacidade de predição, com base na correlação apresentada neste capítulo e no erro (RMSE) calculado.

Outra forma de apresentação e análise de dados para mapeamento agrícola e ambiental seria a categorização das variáveis de saída (target). Com base no exemplo utilizado neste capítulo teríamos o resultado apresentado na Figura 3.15 que possibilita uma compreensão mais simples dos resultados encontrados, podendo analisar as variáveis preditoras da qualidade sensorial do café por um outro ângulo.

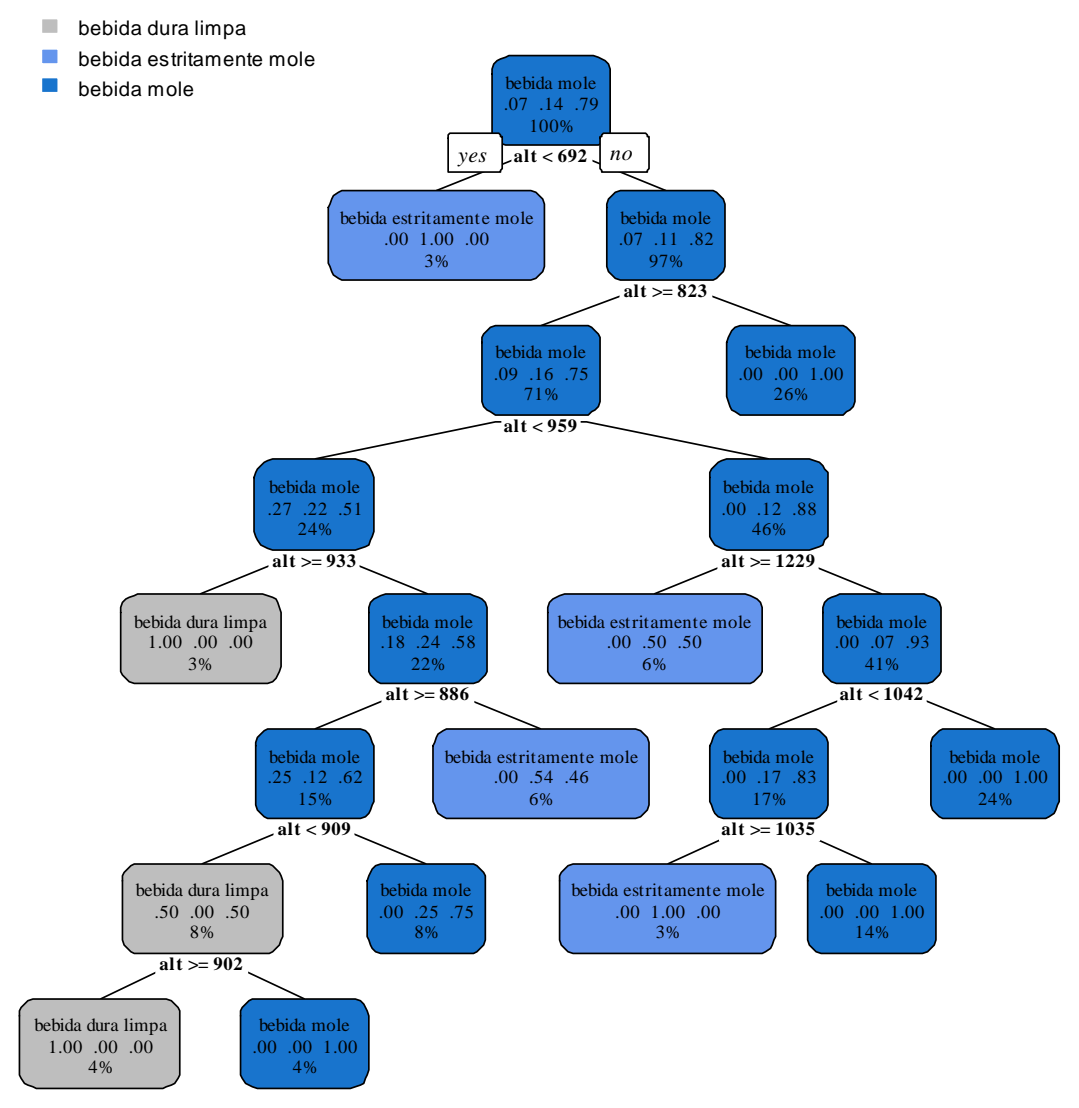

Figura 3.15 - Árvore de decisão considerando as variáveis preditoras: altitude, precipitação e umidade. Bebida estritamente mole - cafés acima de 85 pontos; Bebida mole - cafés de 80 a 84 pontos; e Bebida dura limpa - 75 a 79 pontos. 


\section{REFER̂̂ENCIAS}

ALVARENGA JÚNIOR, W. J. de. Métodos de otimização hiperparamétrica: um estudo comparativo utilizando árvores de decisão e florestas aleatórias na classificação binária. 2018. 82 f. 2018.

ANAND, R. S. et al. Prediction of A12O3/R134a nanorefrigerant based modified thermosyphon performance using random forest algorithm. Materials Today: Proceedings, 12 abr. 2021.

ARABAMERI, A.; PRADHAN, B.; REZAEI, K. Gully erosion zonation mapping using integrated geographically weighted regression with certainty factor and random forest models in GIS. Journal of Environmental Management, v. 232, p. 928-942, 15 fev. 2019.

BIEWEN, M.; KUGLER, P. Two-stage least squares random forests with an application to Angrist and Evans (1998). Economics Letters, v. 204, p. 109893, 1 jul. 2021.

BORGES, F. A. S. Extração de características combinadas com árvore de decisão para detecção e classificação dos distúrbios de qualidade da energia elétrica. 2013. 118 f. Dissertação (Mestrado em Ciências, Programa de Engenharia Elétrica) - Universidade de São Paulo., 2013.

BREIMAN, L.; CUTLER, A. Breiman and Cutler's Random Forests for Classification and Regression. . [S.1.]: CRAN. , 2018

BROWN, S. D.; MYLES, A. J. Decision Tree Modeling. Compr. Chemom. [S.1.]: Elsevier, 2020. p. 625-659.

CALDAS, M. U. de C.; PITOMBO, C. S.; ASSIRATI, L. Strategy to reduce the number of parameters to be estimated in discrete choice models: An approach to large choice sets. Travel Behaviour and Society, v. 25, p. 1-17, 1 out. 2021. Disponível em: <https://linkinghub.elsevier.com/retrieve/pii/S2214367X21000399>. Acesso em: 8 jun. 2021.

CARVALHO, D. R. Árvore de decisão/algoritmo genético para tratar o problema de pequenos disjuntos em classificação de dados. 2005. $173 \mathrm{f}$. Tese (Doutorado em computação de alto desempenho) - Universidade Federal do Rio de Janeiro, 2005.

CHEN, J.; HUANG, G.; CHEN, W. Towards better flood risk management: Assessing flood risk and investigating the potential mechanism based on machine learning models. Journal of Environmental Management, v. 293, p. 112810, 1 set. 2021. Disponível em: <https://linkinghub.elsevier.com/retrieve/pii/S0301479721008720>. Acesso em: 7 jun. 2021. 
Capítulo 03 - Árvore de decisão e random forest: fundamentos teóricos e aplicações

CHEN, W. et al. Flood susceptibility modelling using novel hybrid approach of reduced-error pruning trees with bagging and random subspace ensembles. Journal of Hydrology, v. 575, p. 864-873, 1 ago. 2019.

Modeling flood susceptibility using data-driven approaches of naïve Bayes tree, alternating decision tree, and random forest methods. Science of the Total Environment, v. 701, p. 134979, 20 jan. 2020.

CHENG, B. et al. Influence of genotype and environment on coffee quality. Trends in Food Science and Technology. [S.1.]: Elsevier Ltd. , 1 nov. 2016

COLLINS, A. L. et al. Sediment source fingerprinting as an aid to catchment management: A review of the current state of knowledge and a methodological decision-tree for end-users. Journal of Environmental Management, v. 194, p. 86-108, 1 jun. 2017.

DANTAS, D.; DONADIA, E. A. Comparação entre as técnicas de regressão logística, árvore de decisão, bagging e random forest aplicadas a um estudo de concessão de créditos. 2013. 67 f. Monografia (Trabalho de conclusão de curso em Estatística) Universidade Federal do Paraná, 2013.

DE SOUZA ROLIM, G. et al. Climate and natural quality of Coffea arabica L. drink. Theoretical and Applied Climatology, v. 141, n. 1-2, p. 87-98, 1 jul. 2020. Disponível em: <https://doi.org/10.1007/s00704-020-03117-3>. Acesso em: 5 jun. 2021.

DORGO, G.; PALAZOGLU, A.; ABONYI, J. Decision trees for informative process alarm definition and alarm-based fault classification. Process Safety and Environmental Protection, v. 149, p. 312-324, 1 maio 2021.

DOUNA, V. et al. Towards a remote sensing data based evapotranspiration estimation in Northern Australia using a simple random forest approach. Journal of Arid Environments, v. 191, p. 104513, 1 ago. 2021. Disponível em: <https://linkinghub.elsevier.com/retrieve/pii/S0140196321000793>. Acesso em: 10 jun. 2021.

FARKAS, S.; LOPEZ, O.; THOMAS, M. Cyber claim analysis using Generalized Pareto regression trees with applications to insurance. Insurance: Mathematics and Economics, v. 98, p. 92-105, 1 maio 2021.

FOUEDJIO, F. Exact Conditioning of Regression Random Forest for Spatial Prediction. Artificial Intelligence in Geosciences, v. 1, p. 11-23, 1 dez. 2020. 
FRATELLO, M.; TAGLIAFERRI, R. Decision trees and random forests. Encycl. Bioinforma.

Comput. Biol. ABC Bioinforma. [S.1.]: Elsevier, 2018. v. 1-3. p. 374-383.

GARCIA, S. C. O uso da árvores de decisão na descoberta de conhecimento na área da saúde. 2003. 88 f. Dissertação (Mestrado em Ciência da Computação) - UniversidadeFederal do Rio Grande do Sul, 2003.

HONG, H.; LIU, J.; ZHU, A. X. Modeling landslide susceptibility using LogitBoost alternating decision trees and forest by penalizing attributes with the bagging ensemble. Science of the Total Environment, v. 718, p. 137231, 20 maio 2020.

HU, G. et al. Selection of oil spill response method in Arctic offshore waters: A fuzzy decision tree based framework. Marine Pollution Bulletin, v. 161, p. 111705, 1 dez. 2020.

IBRAHIM, I. A.; KHATIB, T. A novel hybrid model for hourly global solar radiation prediction using random forests technique and firefly algorithm. Energy Conversion and Management, v. 138, p. 413-425, 15 abr. 2017.

ILYAS, H.; MASIH, I.; VAN HULLEBUSCH, E. D. A decision tree framework to support design, operation, and performance assessment of constructed wetlands for the removal of emerging organic contaminants. Science of the Total Environment, v. 760, p. 143334, 15 mar. 2021.

KAMIŃSKA, J. A. The use of random forests in modelling short-term air pollution effects based on traffic and meteorological conditions: A case study in Wrocław. Journal of Environmental Management, v. 217, p. 164-174, 1 jul. 2018.

KAPPELHOF, N. et al. Evolutionary algorithms and decision trees for predicting poor outcome after endovascular treatment for acute ischemic stroke. Computers in Biology and Medicine, v. 133, p. 104414, 1 jun. 2021.

KONG, L. et al. Factors influencing the effectiveness of liming on cadmium reduction in rice: A meta-analysis and decision tree analysis. Science of the Total Environment, v. 779, p. 146477, 20 jul. 2021.

KOURGIALAS, N. N.; KARATZAS, G. P. A flood risk decision making approach for Mediterranean tree crops using GIS; climate change effects and flood-tolerant species. Environmental Science and Policy, v. 63, p. 132-142, 1 set. 2016. 
KULKARNI, V. Y.; SINHA, P. K. Pruning of random forest classifiers: A survey and future directions. jul. 2012, [S.1.]: IEEE, jul. 2012. p. 64-68. Disponível em: <http://ieeexplore.ieee.org/document/6282329/>. Acesso em: 9 jun. 2021.

LAN, T. et al. A comparative study of decision tree, random forest, and convolutional neural network for spread-F identification. Advances in Space Research, v. 65, n. 8, p. 2052-2061, 15 abr. 2020.

LEE, S.; PARK, I. Application of decision tree model for the ground subsidence hazard mapping near abandoned underground coal mines. Journal of Environmental Management, v. 127 , p. 166-176, 30 ago. 2013.

MAKUNGWE, M. et al. Performance of linear mixed models and random forests for spatial prediction of soil pH. Geoderma, v. 397, p. 115079, 1 set. 2021.

MIRANDA, E. E. de;(Coord. ). Brasil em Relevo. Disponível em: <http://www.relevobr.cnpm.embrapa.br>.

MORE, A. S.; RANA, D. P. Review of random forest classification techniques to resolve data imbalance. 27 nov. 2017, [S.1.]: Institute of Electrical and Electronics Engineers Inc., 27 nov. 2017. p. 72-78. Disponível em: <http://ieeexplore.ieee.org/document/8122151/>. Acesso em: 9 jun. 2021.

MOSHKOV, M. On the depth of decision trees over infinite 1-homogeneous binary information systems. Array, v. 10, p. 100060, 1 jul. 2021.

MOSHKOV, M. J. Time complexity of decision trees. Lecture Notes in Computer Science (including subseries Lecture Notes in Artificial Intelligence and Lecture Notes in Bioinformatics), v. 3400 LNCS, p. 244-259, 2005. Disponível em: <https://link.springer.com/chapter/10.1007/11427834_12>. Acesso em: 27 maio 2021.

OSEI-BRYSON, K. M. Post-pruning in decision tree induction using multiple performance measures. Computers and Operations Research, v. 34, n. 11, p. 3331-3345, 1 nov. 2007.

OSMANI, F.; ZIAEE, M. Assessment of the risk factors for vitamin D3 deficiency in chronic hepatitis B patient using the decision tree learning algorithm in Birjand. Informatics in Medicine Unlocked, v. 23, p. 100519, 1 jan. 2021.

OYA, J. K. M. Utilização de árvores de decisão para aprimorar a classificação de 
fragmentos. 2016. 100 f. Dissertação (Mestrado em engenharia elétrica) - Universidade de Brasília, 2016.

PEREIRA, L. L. et al. Propositions on the Optimal Number of Q-Graders and R-Graders. Journal of Food Quality, p. 7, 2018.

RAKHRA, M. et al. Crop Price Prediction Using Random Forest and Decision Tree Regression:-A Review. Materials Today: Proceedings, 2 abr. 2021.

RESENDE, P. A. A.; DRUMMOND, A. C. A survey of random forest based methods for intrusion detection systems. ACM Computing Surveys. [S.1.]: Association for Computing Machinery. Disponível em: <https://doi.org/10.1145/3178582>. Acesso em: 9 jun. 2021. , 1 abr. 2018

SCAA. SCAA Protocols Cupping Specialty Coffee. Specialty Coffee Association of America, p. 1-10, 2015.

TANG, X. et al. A novel optimized repeatedly random undersampling for selecting negative samples: A case study in an SVM-based forest fire susceptibility assessment. Journal of Environmental Management, v. 271, p. 111014, 1 out. 2020.

THERnEAU, T.; ATKINSON, B.; RIPLEY, B. Recursive Partitioning and Regression Trees (rpart). . [S.1.]: CRAN. , 2019

TOOKE, T. R.; COOPS, N. C.; WEBSTER, J. Predicting building ages from LiDAR data with random forests for building energy modeling. Energy and Buildings, v. 68, n. PARTA, p. 603610, 1 jan. 2014.

VIEIRA, R. M. da S. P. et al. Land degradation mapping in the MATOPIBA region (Brazil) using remote sensing data and decision-tree analysis. Science of the Total Environment, v. 782, p. 146900, 15 ago. 2021.

WANG, T. et al. Handling over-fitting in test cost-sensitive decision tree learning by feature selection, smoothing and pruning. Journal of Systems and Software, v. 83, n. 7, p. 11371147, 1 jul. 2010.

WANG, Z. et al. Disentangling the effects of stand and climatic variables on forest productivity of Chinese fir plantations in subtropical China using a random forest algorithm. Agricultural and Forest Meteorology, v. 304-305, p. 108412, 15 jul. 2021. 
Capítulo 03 - Árvore de decisão e random forest: fundamentos teóricos e aplicações

ŻABIŃSKI, G. et al. Multi-classifier majority voting analyses in provenance studies on iron artefacts. Journal of Archaeological Science, v. 113, p. 105055, 1 jan. 2020.

ZOUNEMAT-KERMANI, M. et al. Ensemble data mining modeling in corrosion of concrete sewer: A comparative study of network-based (MLPNN \& RBFNN) and tree-based (RF, CHAID, \& CART) models. Advanced Engineering Informatics, v. 43, p. 101030, 1 jan. 2020. 


\section{CAPÍtulo 04 - DEEP LEARNING PARA A CLASSIFICAÇÃO DE IMAGENS}

\section{Taís Rizzo Moreira e Gilson Fernandes da Silva}

https://doi.org/10.29327/ 552680.1-4

\section{INTRODUÇÃO GERAL}

O cérebro humano é composto por bilhões de células denominadas neurônios, que estão frequentemente interagindo entre si por meio de impulsos chamados de sinapses. A passagem e recebimento dos impulsos sinápticos pelos neurônios faz com que o cérebro humano realiza suas funções (ABRAHAM, 2005).

Como apresentado no Capítulo 01, as Redes Neurais Artificiais (RNAs) são modelos computacionais que utilizam como inspiração as redes neurais biológicas. Essas redes possuem a capacidade de identificar padrões em sons, imagens e vídeos, dentre outros (REESE, 2021). Os neurônios que constituem essa rede artificial são compostos por sinais de entradas e pesos sinápticos (SOUSA, 2018). Os sinais de entrada são multiplicados pelos pesos sinápticos e somados ao bias, após a soma, o resultado é aplicado a uma função não linear, chamada de função de ativação. $\mathrm{O}$ valor de saída dessa função corresponde ao valor de saída do neurônio (KAVIANI; SOHN, 2021).

Em alguns casos, quando os problemas apresentam um grau mais elevado de complexidade as funções de ativação não são suficientes. Estes problemas necessitam de uma aprendizagem mais profunda (Deep learning) com redes com mais neurônios e mais camadas (SOUSA, 2018).

O Deep Learning (DL) é construído sobre as redes neurais, sendo um tipo de modelo de machine learning que se parece com os neurônios cerebrais humanos. Utiliza modelo bioinspirado, como uma rede neural artificial, cujos neurônios artificiais estão organizados em camadas interconectadas (ARROYO-FIGUEROA; SUCAR; VILLAVICENCIO, 2000). O DL propicia a classificação de informações em diferentes formatos como áudio no reconhecimento de fala, imagens no reconhecimento facial, entre outros (ALMEIDA, 2019).

Os algoritmos que compõem o Deep learning extraem os descritores, transformam os dados e analisam os padrões através de classificação ou regressão a partir de várias camadas de informações não lineares. Isso faz com que a extração de descritores seja automatizada, reduzindo o trabalho humano de seleção e amenizando o fator de erro humano que ocorre em alguns casos de aprendizado de máquina. Essa característica somada a alta capacidade preditiva 
torna a técnica de Deep learning muito adaptativa, principalmente, para a classificação de imagens (MARTINS, 2018; SOUSA, 2018).

Uma desvantagem desta técnica é o alto poder computacional exigido que aumenta várias vezes conforme a complexidade do problema a ser resolvido e o tempo gasto para treinar um modelo. Com o uso de placas gráficas e computadores com maior capacidade de processamento este problema pode ser contornado (MARTINS, 2018).

\section{DEEP LEARNING}

Os métodos tradicionais de aprendizado de máquina têm sido importantes para promover avanços nas mais diversas áreas e embora essas ferramentas tenham sido muito eficazes na análise de conjuntos de dados massivos e na identificação de relações entre variáveis de interesse, as técnicas tradicionais de machine learning geralmente exigem engenharia manual de recursos e sofrem sobrecarga que limita sua utilidade em cenários que exigem tomadas de decisão quase em tempo real (VALLIANI; RANTI; OERMANN, 2019).

O deep learning difere do machine learning em como as representações são descobertas automaticamente a partir de dados brutos. Em contraste com as RNAs, que são técnicas rasas de aprendizado de recursos, algoritmos de deep learning empregam múltiplas camadas profundas que capturam representações de dados de baixo e alto nível. Isso elimina a necessidade de engenharia manual de recursos e permite que modelos de deep learning descubram naturalmente padrões anteriormente desconhecidos e generalizem melhor para novos dados (LECUN; BENGIO; HINTON, 2015).

Os avanços no deep learning são em grande parte devido aos avanços nos recursos de computação (hardware) e à natureza de código aberto das pesquisas desenvolvidas neste campo. A aplicação de unidades de processamento gráfico à pesquisa de deep learning acelerou drasticamente o tamanho e a complexidade das arquiteturas de algoritmos e, simultaneamente, reduziu o tempo de treinamento de tais algoritmos de meses para dias. A consequência tem sido uma pesquisa de alto rendimento caracterizada por experimentação rápida, permitindo, em última análise, algoritmos mais eficazes. Além disso, o surgimento de estruturas de deep learning de código aberto, como TensorFlow, Keras, PyTorch, Caffe e outros, aumentou a acessibilidade aos avanços técnicos e facilitou o compartilhamento de ideias e sua aplicação em vários domínios (SHI et al., 2017; VALLIANI; RANTI; OERMANN, 2019).

Um trabalho desenvolvido por Hubel e Wiesel (1962) retratou estudos feitos no córtex da visão de gatos, onde foi descrito que o sistema de visão é dividido em sub-regiões e cada 
uma delas é responsável por uma parte do objeto, como bordas, cores, profundidade, etc. e no final a junção destas partes seria a visão como um todo. Baseado nesta linha de pensamento entende-se que uma simulação artificial da visão necessitaria de um conjunto de camadas e parte delas seriam utilizadas no processo de classificação.

Como podemos ver na Figura 4.1, uma rede neural com várias camadas (deep learning) possui conjuntos de camadas específicas para identificação de cada característica da imagem. Como exemplo, um conjunto pode ser responsável pela identificação das bordas, onde o seu resultado pode ser a entrada para outro conjunto de camadas responsável por combinar os resultados encontrados, buscando uma melhor representação, e assim por diante até que no final, todo o conteúdo seja condensado e identificado na camada de saída, esse processo é denominado transferência de conhecimento (transfer learning) (SILVA, R. L. de F., 2016).

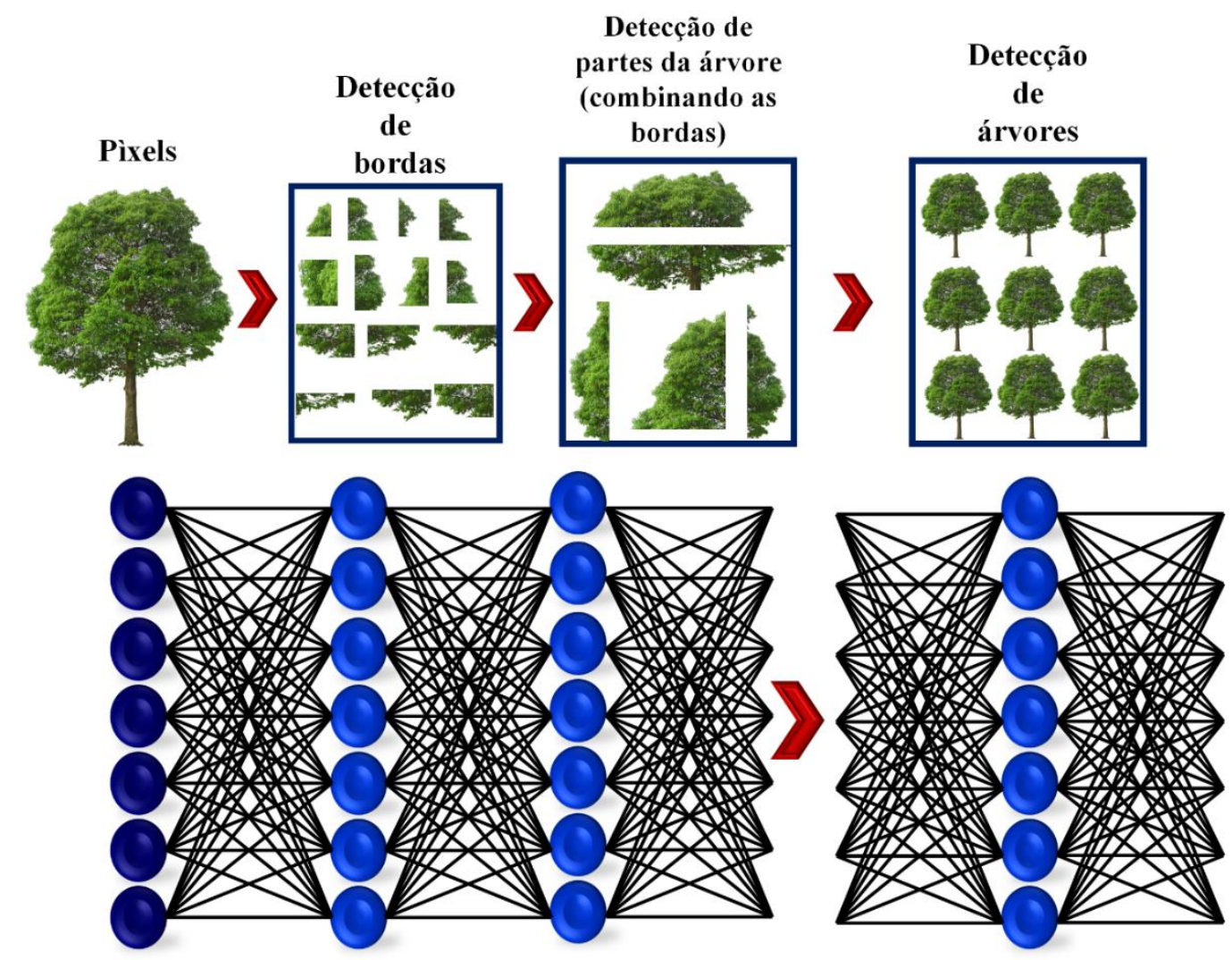

Figura 4.1 - Responsabilidade das camadas de um modelo de deep learning.

\subsection{Rede Neural Convolucionais}

Rede neural convolucional, do inglês Convolutional Neural Networks (CNNs), são um tipo específico de rede neural artificial, proposta pelo pesquisador francês Yann LeCun (LECUN et al., 1998b). As CNNs recebem esse nome pelo tipo de operação linear com matrizes que realizam, as convoluções. Estas redes possuem multicamadas e, além das camadas de convolução, também podem apresentar camadas com outras operações, como cálculos não lineares, por exemplo (ALBAWI; MOHAMMED; AL-ZAWI, 2018). 
O desenvolvimento das CNNs foi embasado no funcionamento do córtex visual (MASSUCATTO, 2018). Com a melhoria do hardware, as redes neurais convolucionais passaram a ser mais viáveis e se tornaram mais populares nas áreas de visão computacional e aprendizado de máquina demonstrando eficiência na solução de problemas de classificação, sendo uma alternativa viável aos métodos tradicionais para esse tipo de problema (MOMENY et al., 2021).

Classificar uma imagem é um processo que consiste, com base em uma imagem de entrada, gerar uma saída com a classe à qual a imagem de entrada pertence ou a probabilidade de pertencer a esta classe. Para humanos, classificar uma imagem é algo feito rotineiramente, e também uma das primeiras habilidades a ser aprendida, e que se desenvolve no decorrer do crescimento, permitindo que se possa identificar e classificar uma imagem ou objeto sem pensar duas vezes (MASSUCATTO, 2018). Entretanto para uma máquina essa tarefa não é tão orgânica (fácil).

Quando uma imagem é inserida no computador, a máquina entende uma matriz de pixels variando seus valores entre 0 a 255, possuindo três camadas quando tratando-se de imagens RGB, uma camada para cada canal de cor e podendo variar o tamanho desta matriz de acordo com o tamanho da imagem de entrada. Para uma CNN, uma imagem com $\mathrm{H}$ linhas, W colunas e três canais ( $R, G$ e $B$, respectivamente) também podem ser descritas como sendo um tensor de ordem 3, ou ordem 2 se a imagem estiver em escala de cinza (LEE, H.; SONG, 2019).

Em uma arquitetura $\mathrm{CNN}$, a imagem de entrada percorre uma série de processamentos (cada um desses processamentos pode ser dito como uma camada) a fim de obter uma saída que possa permitir a classificação da imagem. Existem diversos tipos de camadas em uma CNN, entre elas as camadas mais básicas são: camadas de convolução, camadas de agrupamento (pooling) e camadas totalmente conectadas. Os primeiros estágios presentes em uma rede neural convolucional, ou seja, seus primeiros layers convolucionais e de pooling, são tidos como os mais importantes da rede e são responsáveis pela maior parte do processamento computacional (MASSUCATTO, 2018).

\subsubsection{Camadas convolucionais}

Para compreender plenamente o funcionamento das redes neurais convolucionais (CNN) é necessário primeiro ter uma noção sobre operações de convolução. A camada de convolução é responsável por extrair as chamadas features de entrada. O processo de extração dessas features se dá por meio de filtros convolucionais de tamanhos reduzidos, onde os filtros percorrem os dados de entrada em largura, altura e profundidade (chamada de dimensão) realizando a operação de convolução sobre os dados (RODRIGUES, D. A., 2018). 
As camadas convolucionais são a parte mais importante de um $\mathrm{CNN}$, visto que são nessas camadas que grande parte do processamento é de fato realizado. De maneira similar as camadas das RNAs, as camadas convolucionais também consistem em um conjunto de parâmetros que são ajustados durante o processo de treinamento da rede, porém, ao invés de serem constituídos por pesos de conexão entre neurônios, estas camadas consistem em um conjunto de filtros digitais. Os filtros tipicamente empregados nestas camadas possuem dimensão espacial reduzida (altura e largura), mas se estendem por toda a profundidade do volume de entrada. Por exemplo, na Figura 4.2, um filtro aplicado na camada de entrada pode ser de tamanho 7X7X3, ou seja, 7 pixels de largura e altura, e 3 de profundidade que é o mesmo número de canais presentes na imagem RGB (SANTOS, R. R. dos, 2019).

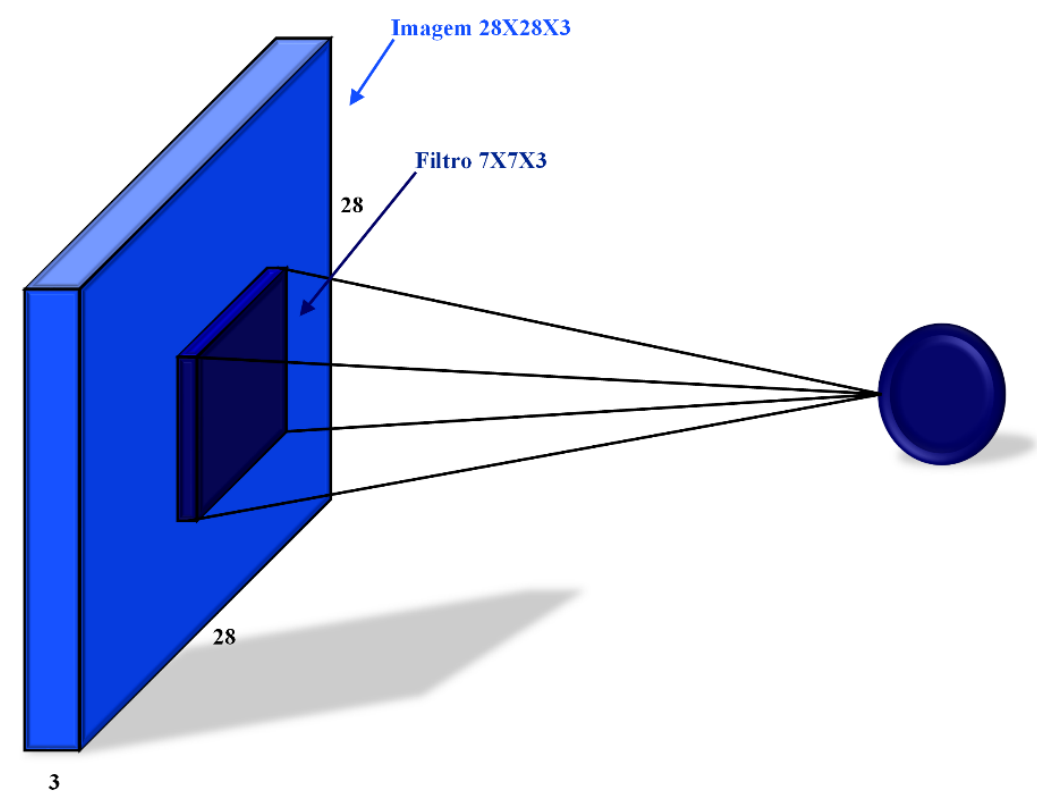

Figura 4.2 - Exemplo do funcionamento de uma camada convolucional.

Deste modo, uma diferença fundamental das redes neurais convolucionais em relação as redes neurais comuns, é que na última os neurônios utilizam uma ligação do tipo "todostodos" de uma camada para outra. $\mathrm{Na} \mathrm{CNN}$, um recurso chamado de campos receptivos locais, ao invés de ligar cada um dos neurônios da primeira camada com todos os neurônios da segunda camada, faz a ligação de um conjunto de neurônios da primeira camada (matriz de convolução) com um neurônio da segunda camada, conforme ilustrado Figura 4.3 (GOMES, 2019). 


\section{Neurônios de entrada}

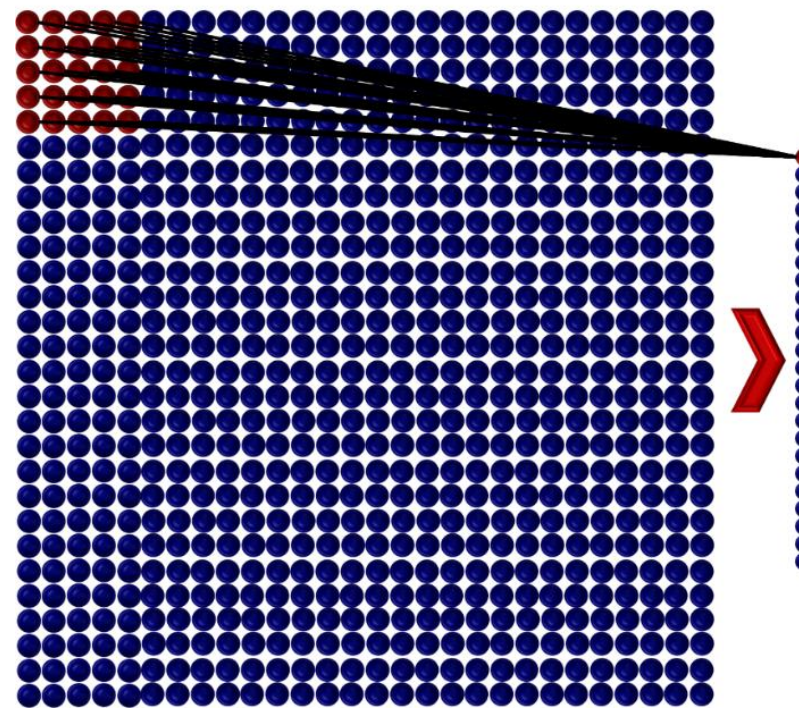

Primeira camada oculta

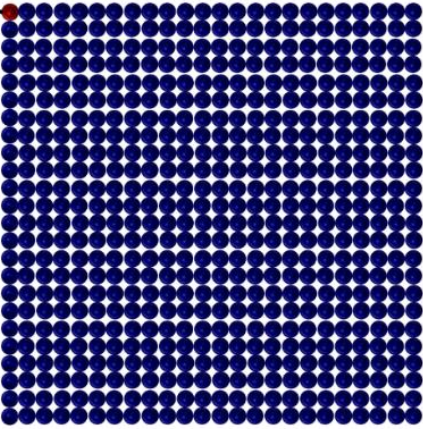

Figura 4.3 - Esquema de rede neural convolucional.

Usando como exemplo a Figura 4.3, composta por 28X28 pixels, a técnica consistiria em selecionar um determinado campo dessa imagem com um tamanho específico, por exemplo um campo de $5 \times 5$, onde esse campo teria seus valores filtrados para um único neurônio da próxima camada. Esse processo de filtragem é chamado de convolução. No momento em que essa imagem é convolucionada são gerados mapas de característica, ou feature maps. No caso da entrada de $28 \times 28$ pixels, tendo um campo de 5x5 e um passo de 1 neurônio, resultariam mapas de características na camada de convolução com o tamanho de 24x24 neurônios. Todos os neurônios de um determinado mapa de características receberão um mesmo peso e valor de passagem, esse é outro conceito importante das redes convolucionais e é chamado de pesos compartilhados. Ele é quem permite que cada mapa corresponda a uma característica específica (NIELSEN, 2015). Neste exemplo, percebe-se que a dimensão 28x28 da imagem na camada de entrada cai para $24 \times 24$ na segunda camada, isso é uma característica da convolução, essa redução pode ser evitada, se necessário, com algumas técnicas.

Ainda na camada de convolução, é comum encontrar uma subcamada de ativação conectada aos mapas de características. Nas literaturas recentes, para CNNs vêm sendo usado três possíveis tipos de função de ativação, sendo do tipo sigmoidal, que transforma valores de entrada em um intervalo de 0 a 1; a função de unidade linear retificada (ReLU), que transforma valores negativos em 0 e mantém os valores positivos sem nenhuma modificação e ReLU parametrizado (PReLU), que mapeia os maiores valores negativos em valores menores reduzindo a inclinação da função de mapeamento (KUO, 2016). Dentre as funções de ativação citadas, a função ReLU é a mais usada nas CNNs.

Ao realizar uma operação matemática como a convolução, aplicando detectores de características para gerar mapas de ativação, arrisca-se criar uma saída linear, portanto a função 
da camada ReLU, conectada à camada de convolução, é evitar que isso aconteça, adicionando uma não linearidade para a saída da convolução (MASSUCATTO, 2018).

A partir do comportamento das camadas convolucionais, é possível concluir que elas trabalham como extratores de características, e não como classificadores, e por isso há a necessidade de adicionar camadas totalmente conectadas ao fim da arquitetura (SANTOS, R. R. dos, 2019). Além disso, os filtros vão gerando estruturas cada vez mais complexas, ou seja, quanto mais filtros convolucionais, mais features extraímos da entrada, porém isso tem um custo de memória e processamento, o que precisa ser balanceado na hora de definir a arquitetura.

\subsubsection{Camadas de agrupamento (pooling)}

A segunda camada em uma CNN é a camada de pooling. A camada de pooling, também conhecida como down sampling, tem como objetivo reduzir o tamanho espacial, com exceção da profundidade, das matrizes resultantes da convolução, reduzindo assim os parâmetros a serem aprendidos na rede (MASSUCATTO, 2018; RODRIGUES, D. A., 2018). Desta forma, ocorre a redução da dimensionalidade da imagem categorizando melhor cada sub-região por meio da generalização.

Essa generalização pode ser feita de várias formas, os dois métodos mais utilizados são o maxpooling e o meanpooling. A função maxpooling parte da análise do maior valor de uma região (WU, J., 2017), pois os valores máximos no mapa de características representam aonde estão localizadas as características, e ao aplicar a camada de pooling uma porcentagem de informação que não é característica é descartada (ALBOY, 2019). A função meanpooling por sua vez é responsável por computar o valor médio de uma determinada região limitada pelo filtro (ALBOY, 2019; MARQUES, 2017; MASSUCATTO, 2018).

Na Figura 4.4 um exemplo simples de maxpooling de tamanho 2x2 é demonstrado. Assim como o filtro de convolução a aplicação desse filtro envolve o seu deslizamento sobre toda a entrada. A cada passo a janela é deslizada na mesma quantidade da sua largura, de forma que não existam pontos de interseção. A ideia é escolher um candidato de cada vizinhança como representante que no caso do maxpooling é sempre o maior valor do grupo. 


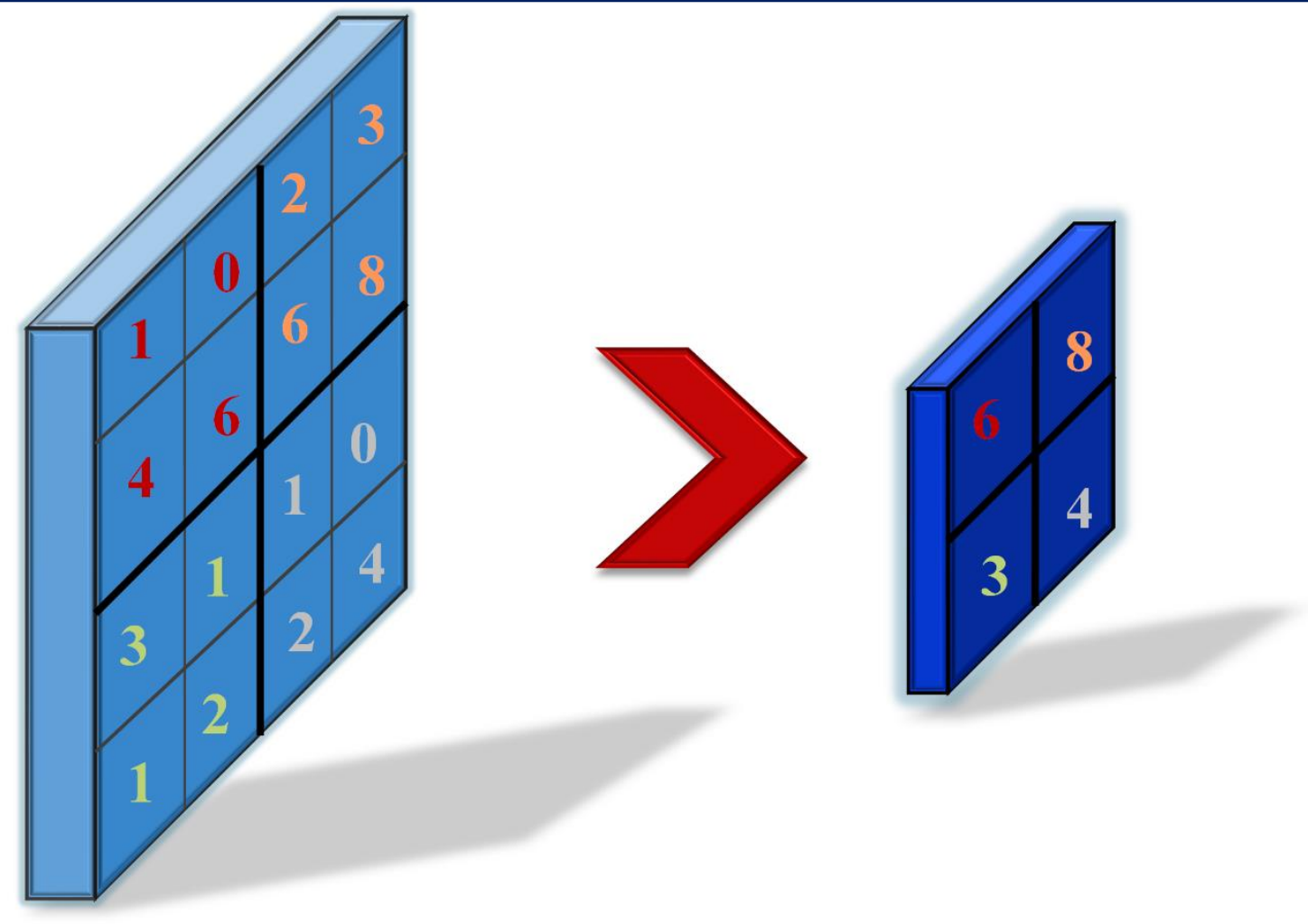

Figura 4.4 - Filtro de maxpooling de tamanho $2 \mathrm{X} 2$.

\subsubsection{Camada completamente conectada}

Inicialmente, antes de chegar até as camadas totalmente conectadas é necessário realizar a conversão das matrizes de características resultantes da camada de pooling em um vetor coluna (flattening)(RODRIGUES, D. A., 2018).

As camadas totalmente conectadas, tipicamente são utilizadas como camadas finais, onde diferente das camadas convolucionais, todos os pesos são totalmente conectados com a camada anterior. Uma rede neural artificial é adicionada ao final de uma rede neural convolucional, na qual cada elemento do vetor coluna criado pela camada de flattening se comporta como uma entrada para uma RNA clássica, para em seguida serem ligados às camadas escondidas totalmente conectadas até a camada final (MARQUES, 2017; RODRIGUES, D. A., 2018).

O propósito de uma RNA após a uma operação de flattening é combinar as características em mais atributos, para melhorar o desempenho de previsão das classes. O erro é calculado e propagado de volta como em uma RNA comum e alguns parâmetros como: os pesos da RNA (sinapses) e os filtros (detectores de características) são ajustados para ajudar a otimizar o desempenho. Inicialmente, os filtros procuram por determinadas características, mas tais características podem não estar corretas, então os filtros são ajustados para procurarem por novas características (ALBOY, 2019; MASSUCATTO, 2018). 
Para finalizar, na Figura 4.5 pode-se observar uma Rede Neural Convolucional completa desde sua imagem de entrada como a classe de saída, que no exemplo mostrado possui somente 2 classes.

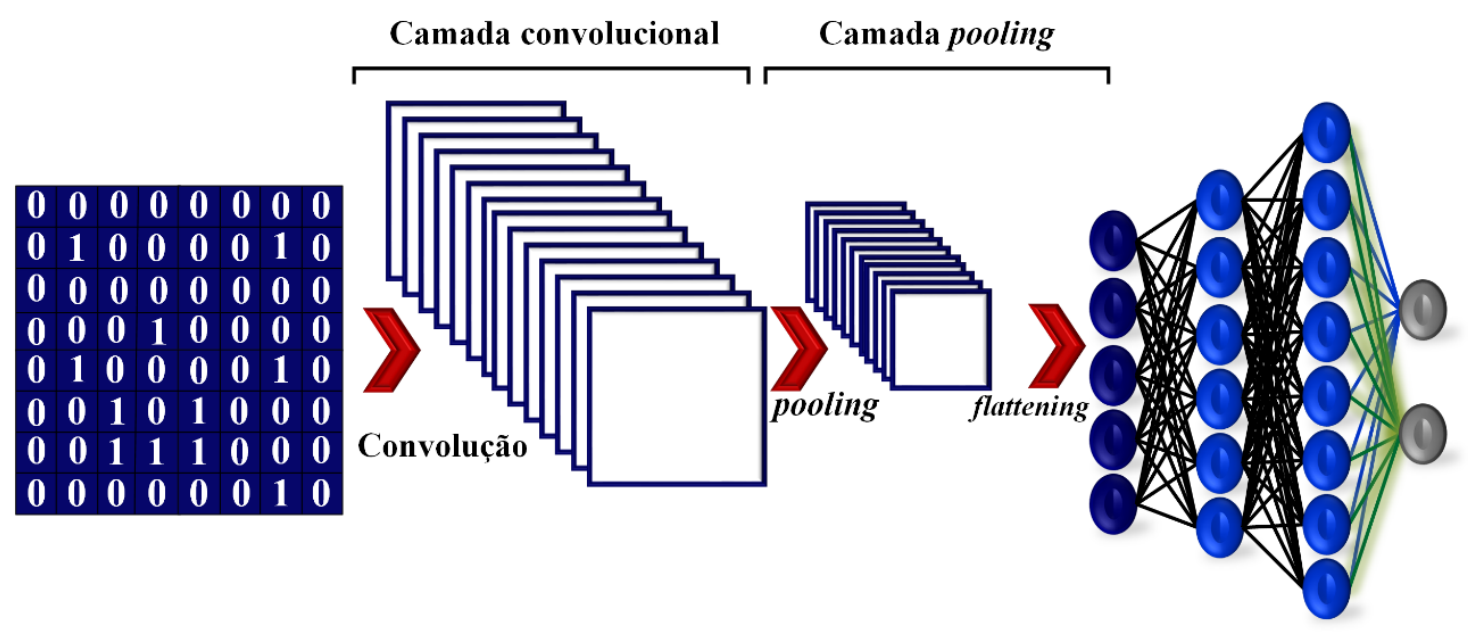

Figura 4.5 - Arquitetura simplificada de uma Rede Neural Convolucional.

\section{FERRAMENTAS E BIBLIOTECAS}

Os termos ferramenta e biblioteca são comuns em computação e tem significados específicos na área. Uma ferramenta é um programa de computador construído especificamente para auxiliar no desenvolvimento e manutenção de outros softwares e aplicativos. A maioria dessas ferramentas podem ser complementadas com funções adicionais, integrando-as ao próprio código do programa. Existem também conjuntos de funções disponíveis nos repositórios na web, desenvolvidos para resolver problemas recorrentes, que podem ser agregados a ferramenta para aumentar sua capacidade e seu potencial de aplicação. Os conjuntos de funções, que são geralmente desenvolvidos e disponibilizados por colaboradores ou organizações, são denominados bibliotecas. Muitas são as bibliotecas disponibilizadas gratuitamente na web e tais bibliotecas possuem diferentes linguagens (Python, $\mathrm{R}, \mathrm{C}++$, dentre outros) que facilitam estudos e a criação de modelos de redes neurais, machine learning e inteligência artificial de modo geral (GOMES, 2019).

Normalmente, uma ferramenta necessita de componentes adicionais para aplicações específicas, portanto é muito importante atentar-se a estas dependências, pois disso depende, na maioria das vezes, a eficiência da ferramenta. Entre os frameworks (ferramentas e bibliotecas) para implementação de redes neurais convolucionais apresentaremos a Theano, TensorFlow e Keras (ALBOY, 2019; GOMES, 2019). 


\subsection{Theano}

O Theano foi desenvolvido pelo grupo LISA da Universidade de Montreal, Canadá. Este framework não é específico para deep learning, mas sim uma biblioteca para a computação de expressões matemáticas complexas e pode ser executada tanto em CPU como em GPU (graphics processing unit). Mesmo não sendo específica para deep learning, possui módulos para facilitar o desenvolvimento de diferentes redes. Também pode utilizar vetores multidimensionais de forma a aumentar o desempenho do hardware na construção de grafos para que os dados sejam mais bem explorados (ALBOY, 2019).

\subsection{Tensorflow}

Tensorflow é uma ferramenta de interface desenvolvimento que tem como objetivo a elaboração e implementação de algoritmos de aprendizado de máquina. É um sistema bastante flexível e que pode ser usado para expressar vários tipos de algoritmos, incluindo algoritmos de deep learning. Esta ferramenta é amplamente utilizada para pesquisa e melhoramento de algoritmos de voz, visão computacional, robótica, processamento de linguagem natural, extração de informações geográficas, imagens, entre outras aplicações. É uma ferramenta em constante desenvolvimento e de código aberto que também realiza a computação numérica de mapas de fluxo de dados trabalhando com matrizes multidimensionais dinâmicas que interagem com os nós do mapa, que em geral implementam modelos de operações matemáticas (GOMES, 2019; TENSORFLOW, 2016).

\subsection{Keras}

A Keras é uma biblioteca de código aberto para aplicação de redes neurais, possui um conjunto de funções de alto nível podendo trabalhar tanto com recursos do Theano quanto TensorFlow. O Theano é uma biblioteca com recursos parecidos com os Tensorflow, porém não é muito utilizada nos estudos mais recentes, devido a algumas limitações superadas pelo seu sucessor, o Tensorflow. A biblioteca Keras foi desenvolvida com foco na experimentação rápida, fazendo com que seja relativamente rápido produzir resultados a partir do momento da geração da ideia, imprimindo mais agilidade em pesquisas onde a biblioteca possa ser aplicada (GOMES, 2019). 


\section{APLICAÇÕES DE DEEP LEARNING EM CLASSIFICAÇÃO DE IMAGENS}

Dado todos os conceitos e definições, citados anteriormente, nota-se que modelos de deep learning, de descoberta e uso recente, podem ser utilizados numa diversidade de problemas, com destaque para problemas onde a classificação de imagem é necessária. Em razão das propriedades citadas e da capacidade de realizar inferências, os modelos de deep learning tem encontrado grandes aplicações em várias áreas das ciências florestais e da agricultura, a seguir citaremos alguma dessas aplicações, que embora tenham se iniciado em um período relativamente recente tem demostrado todo o seu potencial.

Os modelos de deep learning para classificação de imagens tem potencial de utilização na obtenção de informações sobre a distribuição espacial de determinada espécie florestal que são cruciais para a exploração e manejo comercial (FERREIRA, M. P. et al., 2020), no diagnóstico precoce de doença em árvores detectadas por meio de imagens de VANT que possibilitem um manejo e combate mais adequado (WU, B. et al., 2021), na classificação de imagens hiperespectrais que viabilizem dentre outros usos a identificação do uso e ocupação da terra para o planejamento (FANG et al., 2020; PAN; SHI; XU, 2018), na classificação de cenas de imagens de sensoriamento remoto de alta resolução (HAN et al., 2018), na detecção de incêndios ativos por meio de imagens de satélite (DE ALMEIDA PEREIRA et al., 2021), no mapeamento de zonas climáticas por meio de classificação de cenas de sensoriamento remoto (LIU, S.; SHI, 2020), na gestão ambiental por meio da identificação de poluentes visuais (AHMED et al., 2019), na identificação de áreas de suscetibilidade e risco (CHEN, W. et al., 2021), dentre outros.

Além das utilizações citadas anteriormente a aplicação dos modelos de deep learning na classificação de imagens demonstra potencial para classificar e identificar os objetos que compõem uma imagem, tais objetos podem ser: frutos em uma determinada árvore, que permitem cálculos de produtividade; madeira em uma pilha, permitindo cálculos volumétricos; números de árvores em área urbana, permitindo um maior planejamento paisagístico, discrepâncias em áreas de produção agrícola e florestal, que podem ser fruto de doenças, déficits nutricionais e/ou déficit hídricos, dentre outras. Neste tópico apresentaremos dois diferentes exemplos de aplicação de modelos de deep learning na classificação de imagens.

\subsection{Classificação de área ocupada por uma espécie de gramínea}

Neste tópico apresentamos um script ajustado do tutorial e do banco de dados criado por Knoth (2020). Neste script, pretendemos obter uma compreensão básica das principais etapas práticas para aplicar o aprendizado profundo na detecção de objetos em imagens de 
sensoriamento remoto e como fazê-los em R. O exemplo objetiva mapear a extensão do crescimento do silvestre (Elymus athericus) no norte da Alemanha. A Elymus athericus é uma espécie de grama comum nas salinas da Europa Central. Ao se tornar dominante, pode impactar negativamente a biodiversidade de um ecossistema, requirindo monitoramento e gerenciamento.

Muitas partes do que é explicado aqui são baseadas no livro Deep Learning with $\mathrm{R}$ (CHOLLET; ALLAIRE, 2018), que é um ótimo recurso para obter uma introdução (completa) no campo junto com conselhos práticos (exemplos de código R).

O modelo será construído para classificação de imagens com uma quantidade relativamente pequena de dados. O desenvolvimento do modelo de classificação pixel a pixel será realizado aplicando uma arquitetura chamada U-net (RONNEBERGER; FISCHER; BROX, 2015) conforme script descrito no Apêndice D.

A Figura 4.6 mostra a área em estudo e as regiões cobertas pela espécie Elymus athericus, a gramínea que objetivamos identificar.

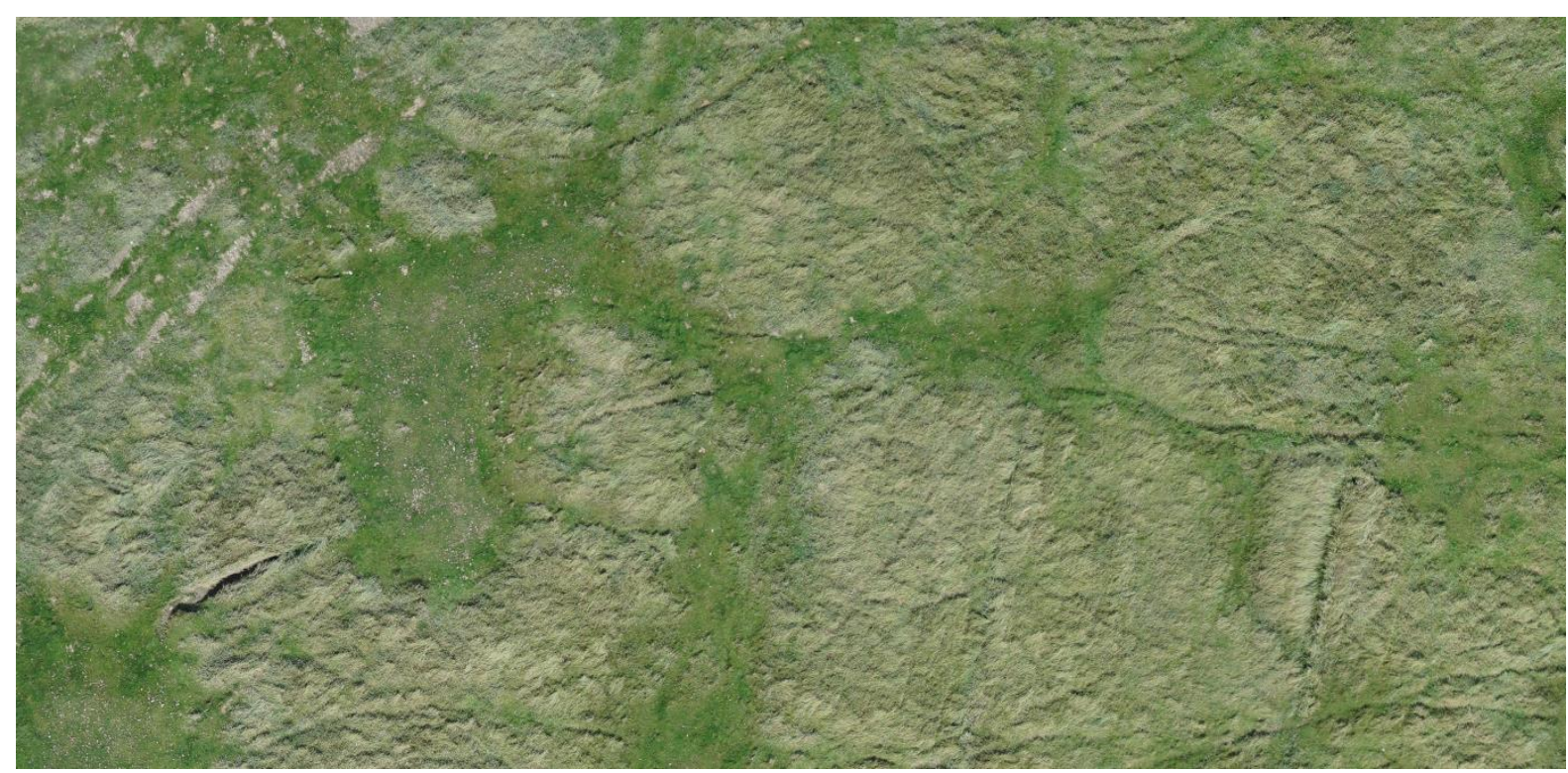

Fonte: Ronneberger; Fischer e Brox (2015).

Figura 4.6 - Imagem da área em estudo (áreas mais claras são áreas com Elymus athericus).

\section{Modelo 1 - Sequencial}

Com o uso de modelo sequencial objetivamos identificar as imagens como: 0 -imagens sem a gramínea em estudo e 1 -imagens com a gramínea em estudo.

Podemos observar na Figura 4.7 o gráfico de perda (A) que específica a medida da diferença entre a previsão e o rótulo. Consideramos este problema como do tipo de classificação binário, para este tipo de problema é comumente usado como função de perda a entropia cruzada binária para avaliação da acurácia do modelo. Nesta mesma figura observamos o gráfico de acurácia (B) que calcula a fração de amostras que são classificadas corretamente em 
0 para áreas onde a gramínea não está presente, e 1 para áreas onde a gramínea está presente (aplicando automaticamente um limite de 0,5 para a decisão entre 0 e 1).

A)

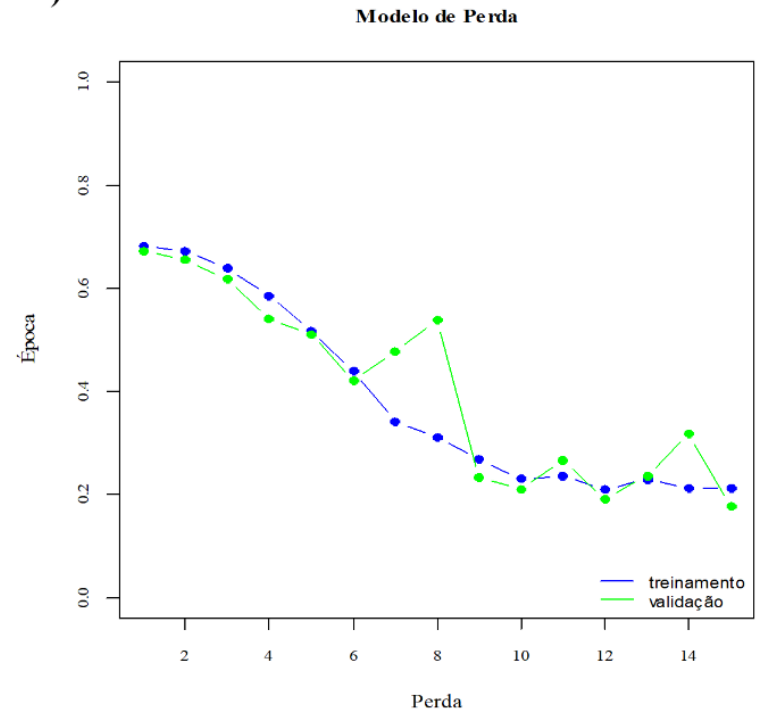

B)

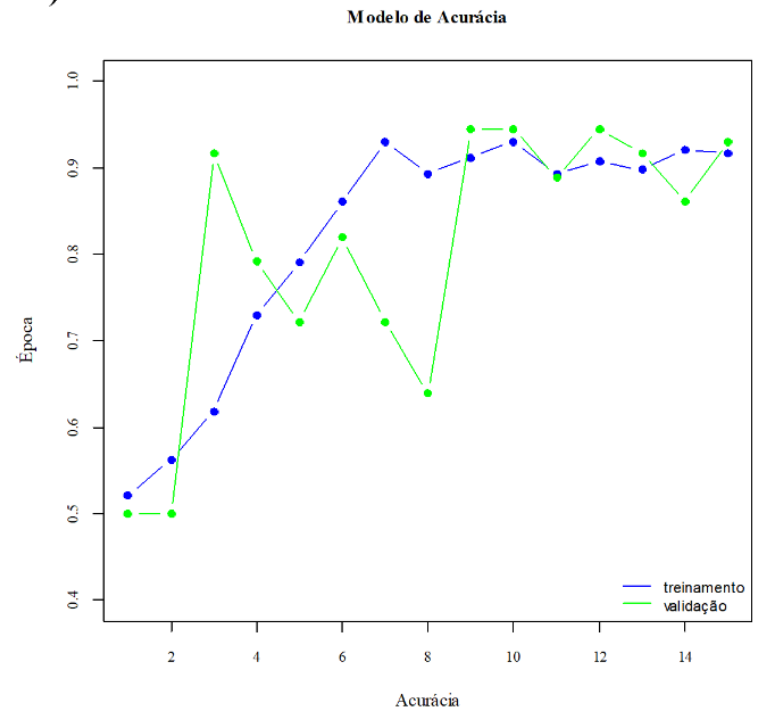

Figura 4.7 - Gráficos de Perda (A) e de Acurácia (B) calculadas com base nas projeções do primeiro modelo.

Podemos observar que a acurácia de classificação da imagem dos dados de treinamento e de validação indicam quão boa é a estimativa do valor real (classificação das imagens fragmentadas de áreas com e sem a gramínea) (Figura 4.7). Formalmente, ela é a correlação entre o valor estimado e o verdadeiro, no caso deste exemplo o modelo proposto obteve uma acurácia de 0,91 para os dados de treinamento e 0,92 para os dados de validação.

Na Figura 4.8 podemos observar um resultado aleatório dos dados de validação. O valor predito é o gerado para o modelo, valores menores que 0,5 são classificados como 0 e valores maiores que 0,5 são classificados como 1 . O valor de rótulo é o real criado pelo observador. Deste modo, notamos que o modelo classificaria de forma correta todas as imagens contidas na Figura 4.8, a primeira imagem que apresentou valor predito de 0,112 foi classificada como 0 por aproximação, sendo condizente com o rótulo, indicando a ausência do target (Elymus athericus). Cabe ressaltar que a variação destes valores entre 0 e 1 é devido a função de ativação utilizada (neste caso a função logística), poderíamos obter valores discretos 0 e 1 com a função softmax; no entanto, a acurácia entre as duas funções para este modelo não diferiu. 


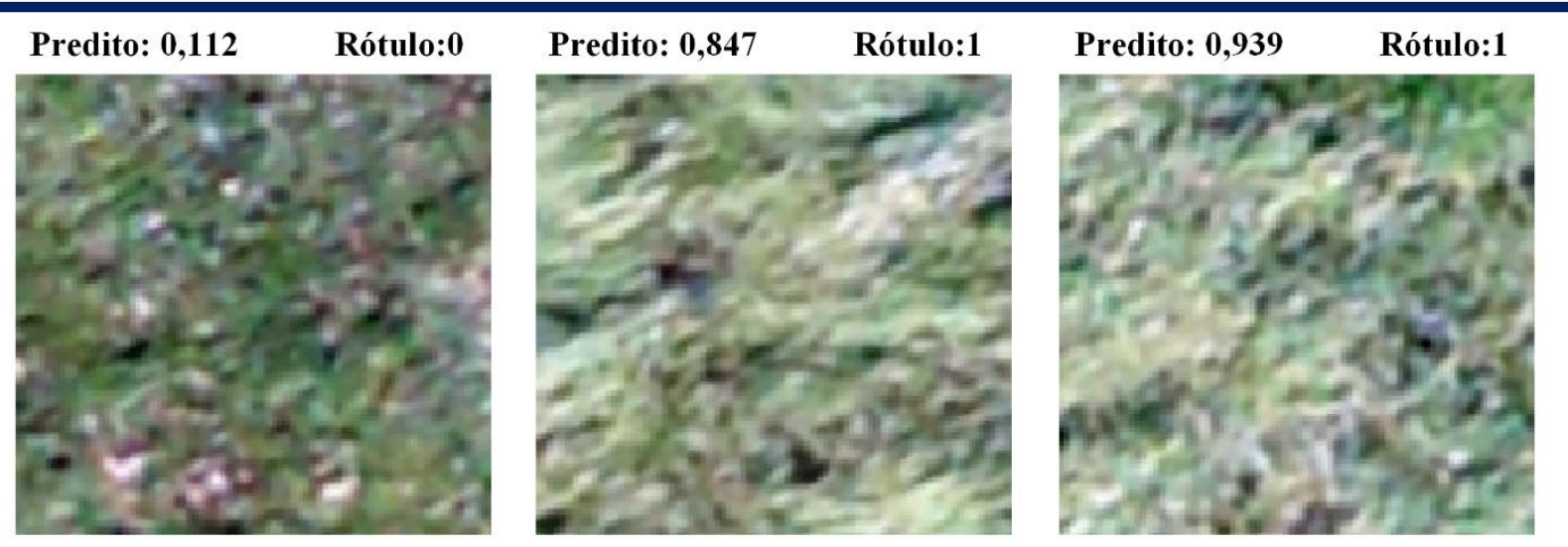

Fonte: Ronneberger; Fischer e Brox (2015).

Figura 4.8 - Resultado de predição sobre os dados de validação com base no primeiro modelo.

\section{Modelo 2 - Convolucional}

No modelo Convolucional objetivamos identificar em uma única imagem as áreas referentes a gramínea e a não gramínea por meio da classificação pixel a pixel. Em vez de nos dizer se há um objeto-alvo presente em um subconjunto de imagem, como no modelo 1 deste exemplo, este modelo (modelo 2) nos dirá onde o alvo está presente na imagem.

Na Figura 4.9 podemos observar o gráfico de perda (A) que específica a medida da diferença entre a previsão (estimado) e o rótulo (observado). Nesta mesma figura observamos o gráfico de acurácia (B) que calcula a fração de amostras que são classificadas corretamente em 0 para áreas onde a gramínea não está presente, e 1 para áreas onde a gramínea está presente.

A)

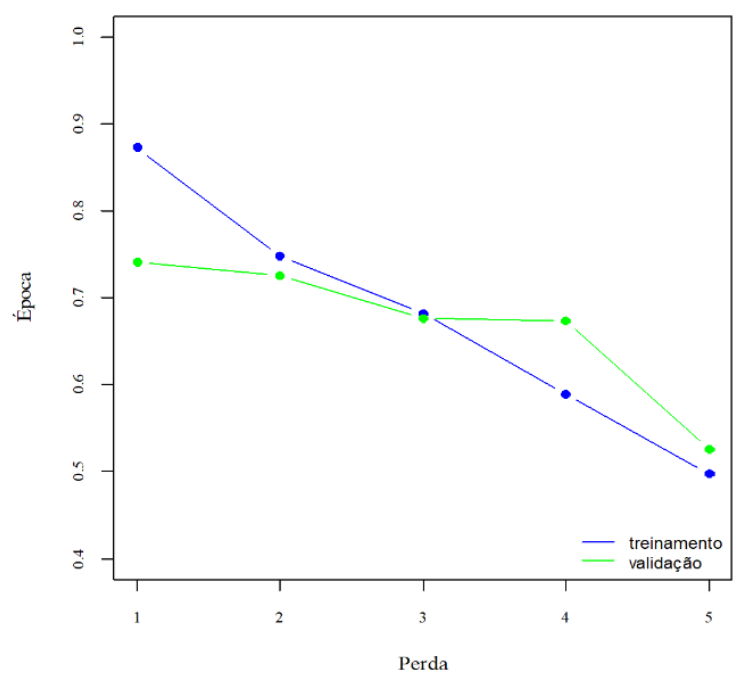

B)

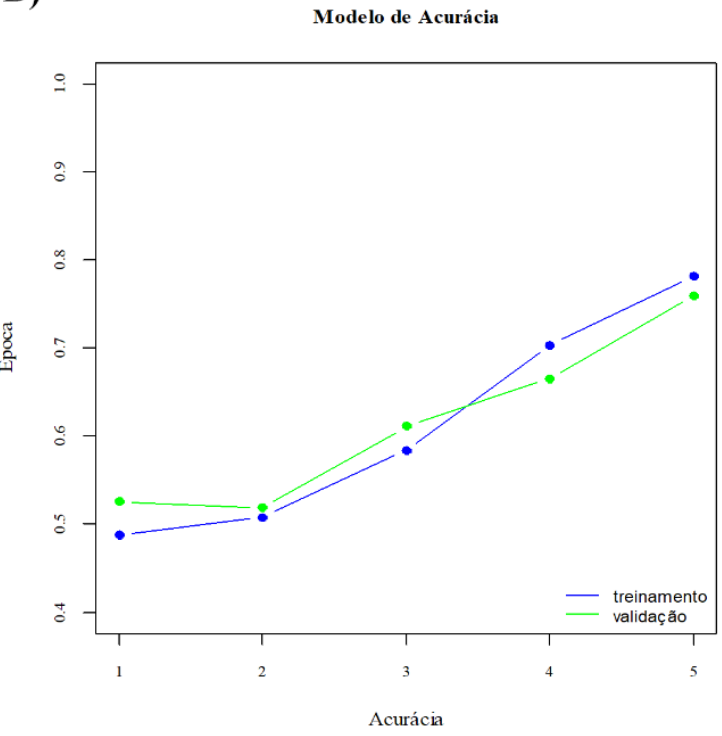

Figura 4.9 - Gráficos de Perda (A) e de Acurácia (B) calculadas com base nas projeções do segundo modelo.

Podemos observar que a acurácia de classificação da imagem dos dados de treinamento e de validação indicam quão boa é a estimativa do valor real (classificação das áreas de uma 
mesma imagem em áreas com (1) e sem a gramínea (0)) (Figura 4.9). Obtivemos com esse modelo uma acurácia de 0,79 para os dados de treinamento e 0,75 para os dados de validação.

Na Figura 4.10 podemos observar um resultado aleatório dos dados gerados. A primeira imagem refere-se a máscara tida como o real, feita manualmente sobre a imagem RGB, a segunda refere-se a Imagem RGB e a terceira refere-se à predição de áreas com e sem o objeto target (Elymus athericus) feita pelo modelo.

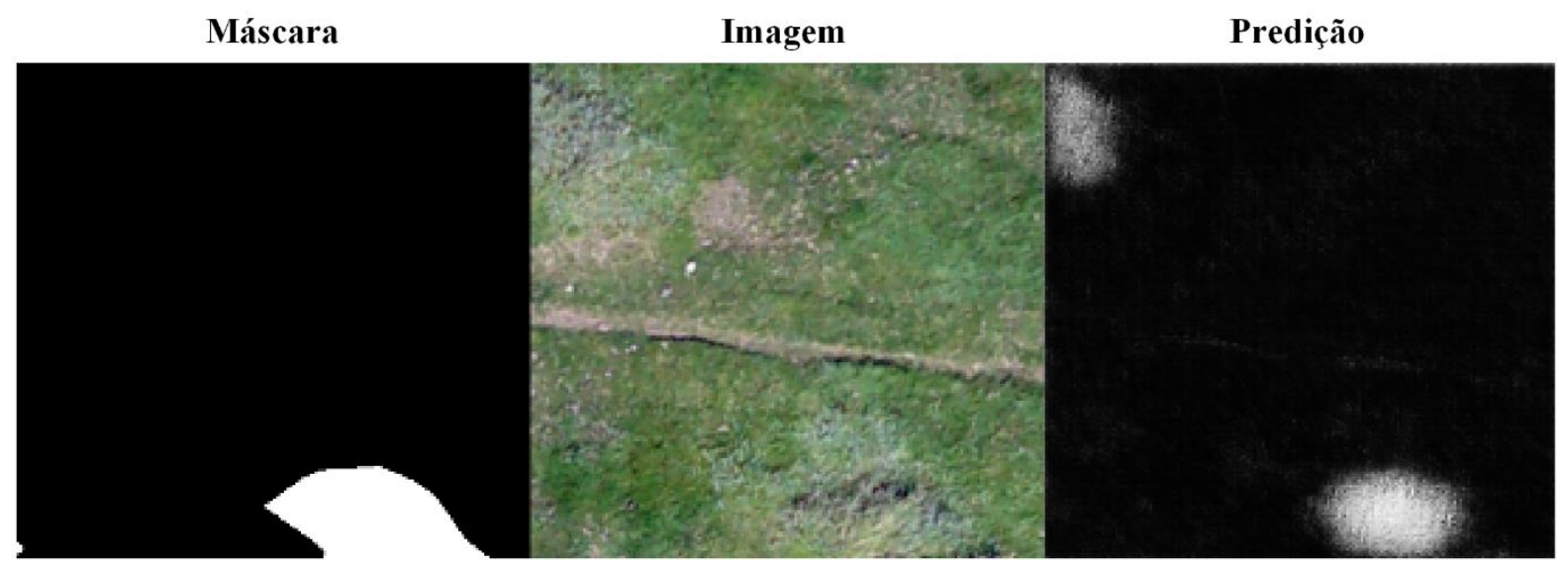

Fonte: Adaptado de Ronneberger; Fischer e Brox (2015).

Figura 4.10 - Resultado de predição com base no segundo modelo e comparação com a máscara.

\subsection{Classificação de pilhas de madeira}

Para execução deste exemplo utilizamos o banco de dados de imagens de Lobato (2021). No trabalho, desenvolvido por de Lobato (2021) e seus colaboradores, ele estimou o volume de pilhas de madeira em pátios de estocagem. Devido à dificuldade de execução dos métodos tradicionais e alto custo de aquisição das novas tecnologias, o objetivo da pesquisa foi desenvolver uma metodologia precisa e com baixo custo para estimar o volume de madeira empilhada em pátio de estocagem por meio do processamento de imagens digitais obtidas com o auxílio de smartphone.

Lobato (2021) fez uso das métricas de textura das amostras de madeira e espaços vazios retirados da foto original para treinamento da ramdon forest. Foi utilizado na ramdon forest 500 árvores, cinco observações por folha e uma variável para divisão. Após o treinamento, a foto de cada face foi classificada, sendo atribuído o número 1 para madeira e 0 para espaço vazio. $\mathrm{Na}$ execução de nosso exemplo utilizaremos modelos de deep learning para classificar os pixels relativos à madeira e a espaços vazios, visa-se com isso uma automatização de todo o processo, fazendo com que tenhamos acurácia assentáveis na estimativa do volume de madeira em pátio de estocagem por meio de técnicas de Inteligência Artificial.

Vale ressaltar que os modelos de deep learning necessitam de dois atributos tidos como básicos para apresentarem uma acurácia elevada: grande conjunto de dados e grande poder 
computacional. O script utilizado nesta etapa pode ser visualizado no Apêndice E e se assemelha ao apresentado no Apêndice D.

\section{Modelo 1 - Sequencial}

Assim como no exemplo anterior, referente a classificação de gramínea, objetivamos com este modelo identificar as imagens como: 0 - imagens sem madeira e 1 -imagens com madeira.

Podemos observar na Figura 4.11 o gráfico de perda (A) que específica a medida da diferença entre a estimado e o observado. Nesta mesma figura observamos o gráfico de acurácia (B) que calcula a fração de amostras que são classificadas corretamente em 0 para imagens sem madeira, e 1 para imagens com madeira (aplicando automaticamente um limite de 0,5 para a decisão entre 0 e 1$)$.

A)

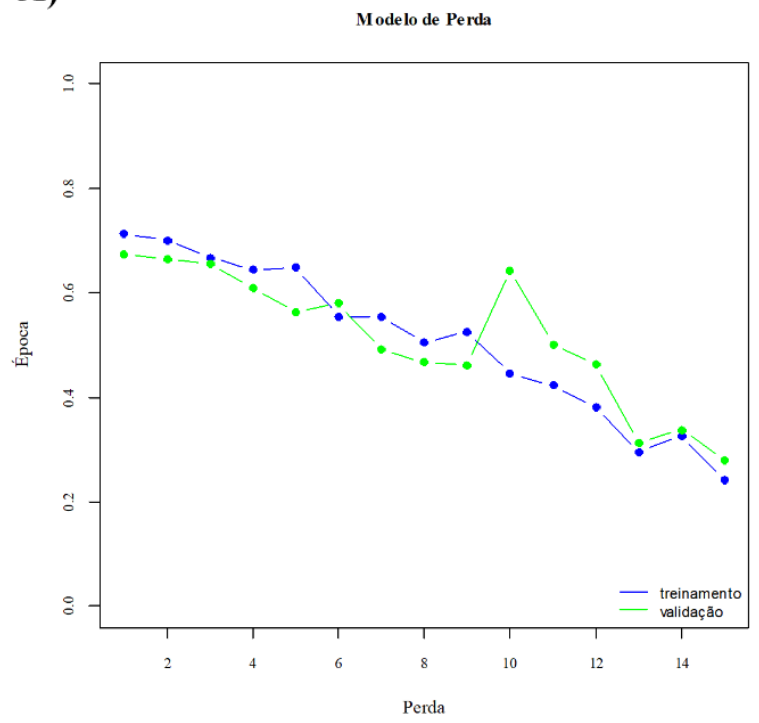

B)

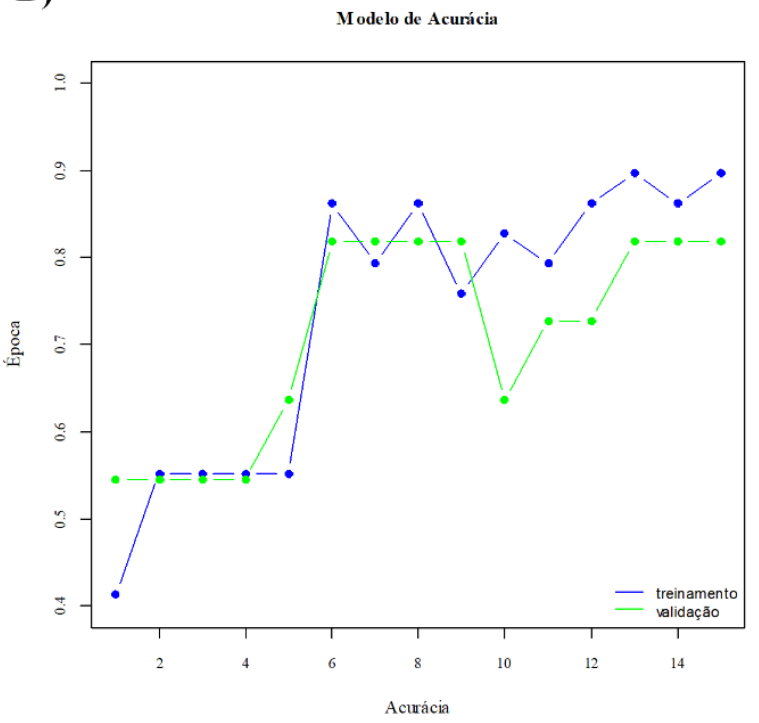

Figura 4.11 - Gráficos de Perda (A) e de Acurácia (B) calculadas com base nas projeções do primeiro modelo.

Podemos observar que a acurácia de classificação da imagem dos dados de treinamento e de validação indicam quão boa é a estimativa do valor real (classificação das imagens em com e sem madeira) (Figura 4.12). Formalmente, ela é a correlação entre o valor estimado e o verdadeiro, no caso deste exemplo o modelo proposto obteve uma acurácia de 0,90 para os dados de treinamento e 0,82 para os dados de validação.

Na Figura 4.12 podemos observar 12 imagens classificadas pelo modelo com base no banco de dados de validação. Deste modo, notamos que o modelo classificaria de forma correta (valores em verde) quase todas as imagens contidas na Figura 4.12, exceto a imagem com legenda em vermelho. Tal imagem é referente a madeira (classe 1), no entanto, o valor obtido pelo modelo foi de 0,290, classificando a como 0 (não madeira). Aparentemente o erro ocorre devido a porcentagem de óleo da corrente do motosserra sobre a madeira que gerou certo grau 
de dificuldade no processo de classificação. Somado a isso, temos o baixo número de amostras, uma vez que os modelos de deep learning necessitam de um número mais elevado de amostras para melhores resultados.
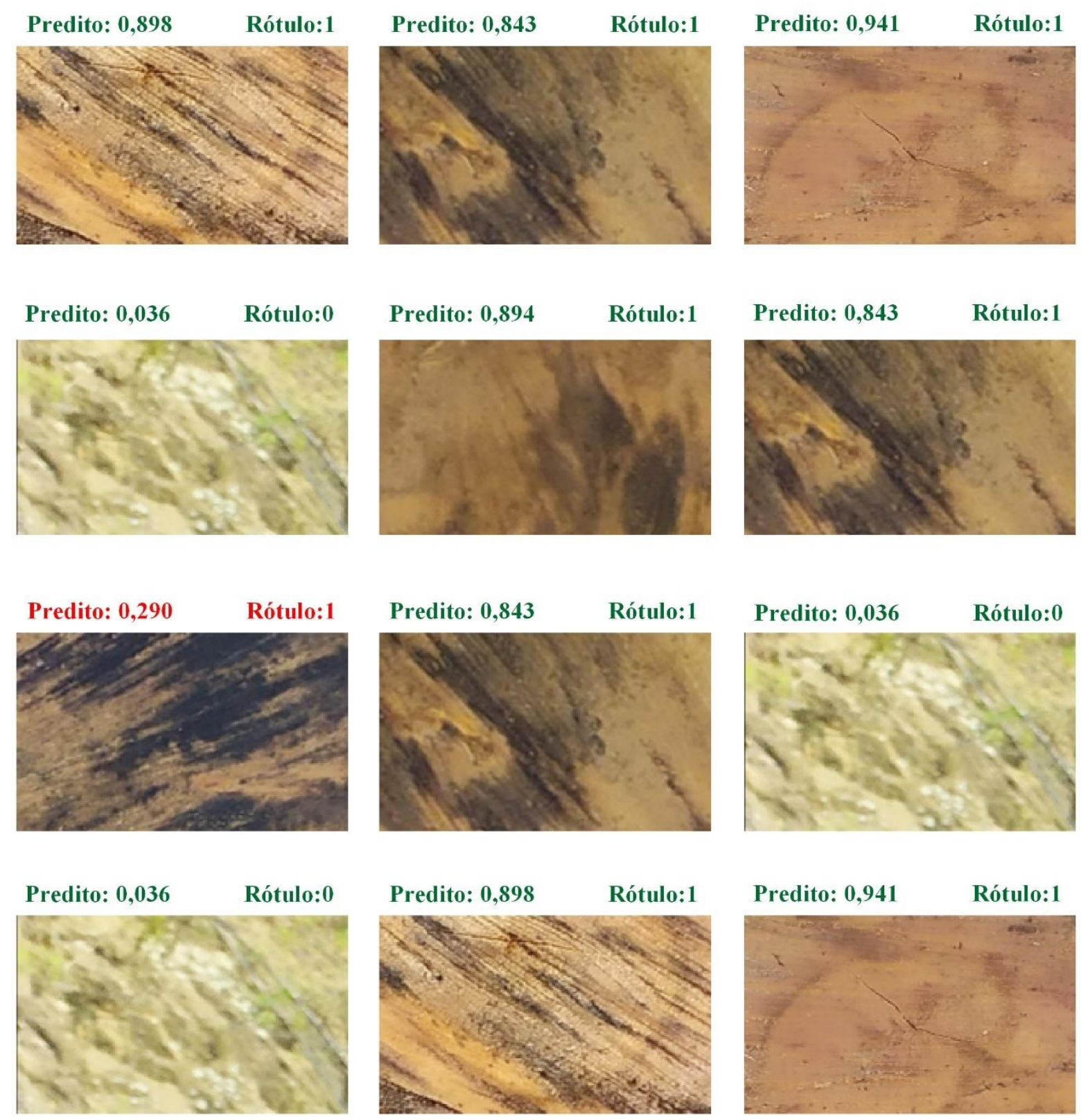

Figura 4.12 - Resultado de predição sobre os dados de validação com base no primeiro modelo.

\section{Modelo 2 - Convolucional}

No modelo Convolucional objetivamos identificar em uma única imagem as áreas referentes a madeira e a não madeira por meio da classificação pixel a pixel.

Na Figura 4.13 podemos observar o gráfico de perda (A) que específica a medida da diferença entre a estimado e o observado. Nesta mesma figura observamos o gráfico de acurácia (B) que calcula a fração de amostras que são classificadas corretamente em 0 para áreas onde a madeira não está presente, e 1 para áreas onde a madeira está presente. 
A)

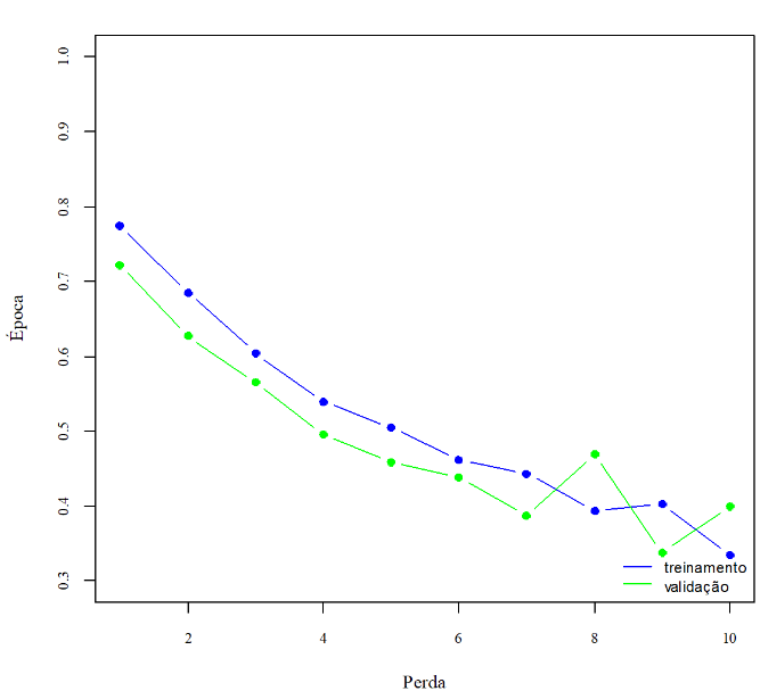

B)

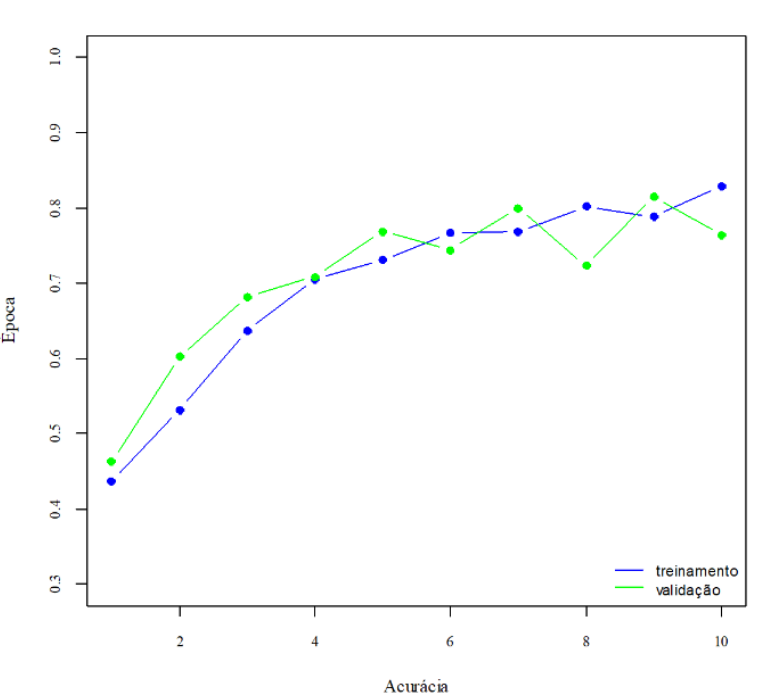

Figura 4.13 - Gráficos de Perda (A) e de Acurácia (B) calculadas com base nas projeções do primeiro modelo.

Podemos observar que a acurácia de classificação da imagem dos dados de treinamento e de validação indicam quão boa é a estimativa do valor real (classificação das áreas de uma mesma imagem em áreas com (1) e sem a madeira (0)) (Figura 4.13). Obtivemos com esse modelo uma acurácia de 0,76 para os dados de treinamento e 0,81 para os dados de validação.

Na Figura 4.14 podemos observar um resultado aleatório dos dados gerados. A primeira imagem refere-se a máscara tida como o real, feita manualmente sobre a imagem RGB, a segunda refere-se a Imagem RGB e a terceira refere-se à predição de áreas com e sem o objeto target (madeira) feita pelo modelo.
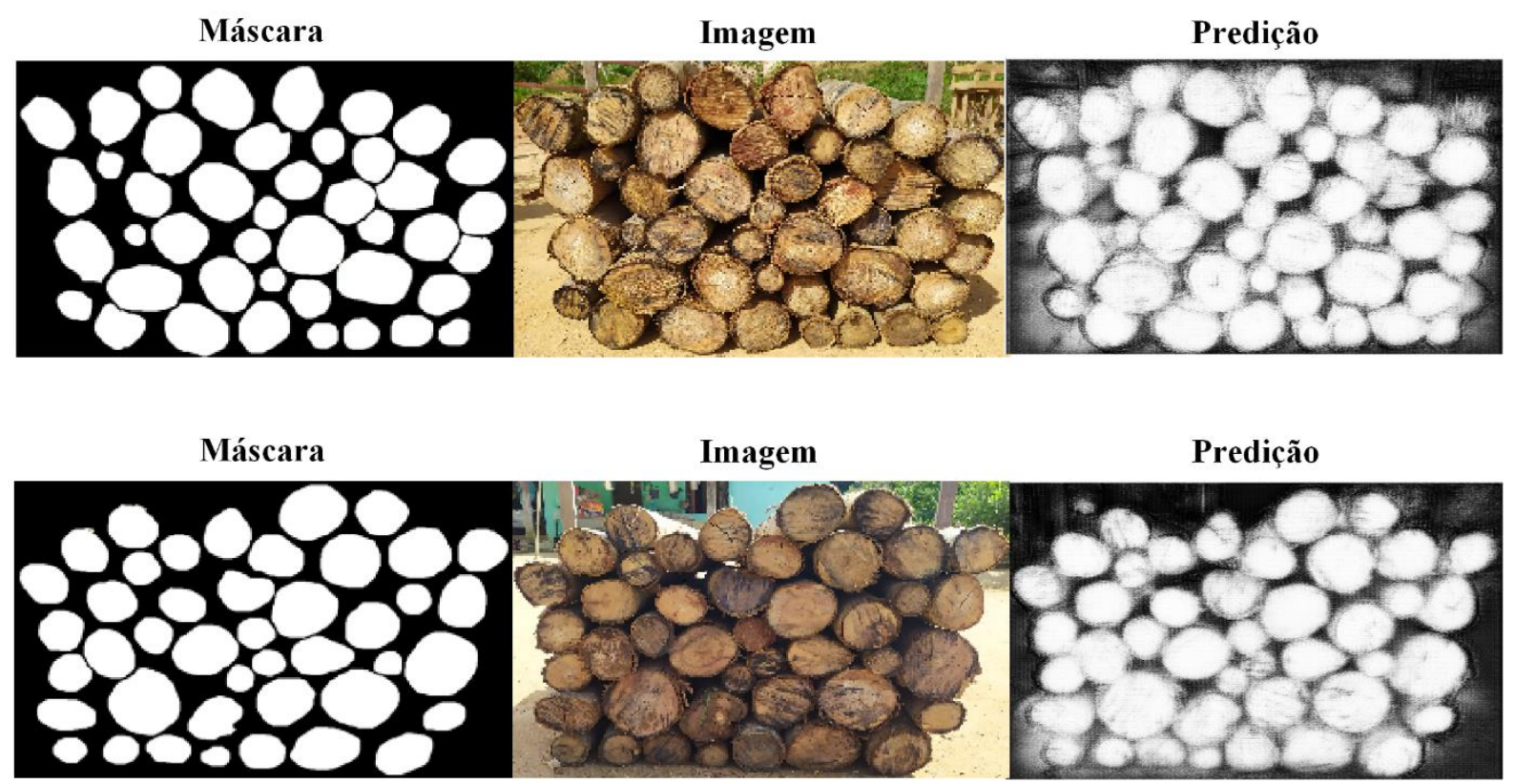

Figura 4.14 - Resultado de predição com base no segundo modelo e comparação com a máscara. 
De posso da identificação dos pixels referentes a madeira poderíamos calcular a área das faces que juntamente com o comprimento da tora (padronizado) nos forneceriam o volume de madeira por meio da equação de Smallian. Esse seria uma das possíveis utilizações da classificação de imagens no setor florestal.

\section{CONSIDERAÇÕES FINAIS}

A utilização da técnica Deep Learning apresenta resultados interessantes, tanto para modelo de redes sequenciais, quanto convolucionais. Isso viabiliza a continuidade do estudo para um modelo mais otimizado e que categorize, por exemplo, defeito das madeiras, ou que identifique os pixels de madeira e estime o volume.

O sucesso do modelo utilizado foi possível devido às características das redes convolucionais, como os campos receptivos locais, o agrupamento, o compartilhamento de pesos entre um mesmo mapa de característica, além da organização dos neurônios em formato bidimensional (ou não linear). Tais características e a correta aplicação das mesmas possibilitaram, de acordo com os resultados, um bom processamento das imagens.

Outro ponto a se destacar é que os modelos apresentam tempos de processamento diferentes e, dependendo do caso, um modelo pode apresentar um resultado significativamente bom e consistente, porém, o tempo necessário para o processamento pode inviabilizar sua aplicação. Outra característica relevante da Deep Learning foi que essa técnica possibilita que estudiosos do aprendizado de máquina possam contribuir com pesquisas de outras áreas de atuação, sem ter, necessariamente, que especializarem-se naquela área, viabilizando a formação de equipes multidisciplinares. 


\section{REFERÊNCIAS}

ABRAHAM, A. Artificial Neural Networks. Handb. Meas. Syst. Des. Chichester, UK: John Wiley \& Sons, Ltd, $2005 . \quad$. Disponível em: <http://doi.wiley.com/10.1002/0471497398.mm421>. Acesso em: 15 jun. 2021.

AHMED, N. et al. Solving visual pollution with deep learning: A new nexus in environmental management. Journal of Environmental Management, v. 248, p. 109253, 15 out. 2019.

ALBAWI, S.; MOHAMMED, T. A.; AL-ZAWI, S. Understanding of a convolutional neural network. 7 mar. 2018, [S.1.]: Institute of Electrical and Electronics Engineers Inc., 7 mar. 2018. p. $1-6$.

ALBOY, R. G. Técnicas de reconhecimento de imagem para incorporação em ferramentas de auxílio a deficientes visuais. 2019. 83 f. Dissertação (Mestrado em Ciência da Computação) - Universidade Federal de São Carlos, 2019.

ALMEIDA, C. C. de. Identificação e classificação de imagens usando rede neural convolucional e Machine learning: implementação em sistema embarcado. 2019. 202 f. Tese (Doutorado em Engenharia Mecânica) - Universidade Estadual de Campinas, 2019.

ARROYO-FIGUEROA, G.; SUCAR, L. E.; VILLAVICENCIO, A. Fuzzy intelligent system for the operation of fossil power plants. Engineering Applications of Artificial Intelligence, v. 13, n. 4, p. 431-439, 1 ago. 2000.

CHEN, W. et al. Evaluation of different boosting ensemble machine learning models and novel deep learning and boosting framework for head-cut gully erosion susceptibility. Journal of Environmental Management, v. 284, p. 112015, 15 abr. 2021.

CHOllet, F.; Allaire, J. J. Deep Learning with R. New York, EUA: Manning Publications, 2018.

DE ALMEIDA PEREIRA, G. H. et al. Active fire detection in Landsat-8 imagery: A largescale dataset and a deep-learning study. ISPRS Journal of Photogrammetry and Remote Sensing, v. 178, p. 171-186, 1 ago. 2021. Disponível em: <https://linkinghub.elsevier.com/retrieve/pii/S092427162100160X>. Acesso em: 27 jun. 2021.

FANG, B. et al. Collaborative learning of lightweight convolutional neural network and deep clustering for hyperspectral image semi-supervised classification with limited training samples. ISPRS Journal of Photogrammetry and Remote Sensing. [S.1.]: Elsevier 
B.V., 1 mar. 2020

FERREIRA, M. P. et al. Individual tree detection and species classification of Amazonian palms using UAV images and deep learning. Forest Ecology and Management, v. 475, p. 118397, 1 nov. 2020.

GOMES, R. C. Aplicação de deep learning na classificação de tábuas de madeira por meio de análise de imagens digitais. 2019. 98 f. Tese (Doutorado em agronomia) - Universidade Estadual Paulista, 2019.

HAN, W. et al. A semi-supervised generative framework with deep learning features for highresolution remote sensing image scene classification. ISPRS Journal of Photogrammetry and Remote Sensing, v. 145, p. 23-43, 1 nov. 2018.

HUBEL, D. H.; WIESEL, T. N. Receptive fields, binocular interaction and functional architecture in the cat's visual cortex. The Journal of Physiology, v. 160, n. 1, p. 106-154, 1 jan. $1962 . \quad$ Disponível em: <https://physoc.onlinelibrary.wiley.com/doi/full/10.1113/jphysiol.1962.sp006837>. Acesso em: 18 jun. 2021.

KAVIANI, S.; SOHN, I. Application of complex systems topologies in artificial neural networks optimization: An overview. Expert Systems with Applications. [S.1.]: Elsevier Ltd. , 15 out. 2021

KNOTH, C. Introduction to Deep Learning in R for the Analysisof UAV-based Remote Sensing Data. Disponível em: <https://dachro.github.io/ogh_summer_school_2020/Tutorial_DL_UAV.html\#references_and _further_reading>. Acesso em: 20 jun. 2021.

KUO, C. C. J. Understanding convolutional neural networks with a mathematical model. Journal of Visual Communication and Image Representation, v. 41, p. 406-413, 1 nov. 2016. Disponível em: <http://yann.lecun.com/exdb/mnist/>. Acesso em: 20 jun. 2021.

LECUN, Y. et al. Gradient-based learning applied to document recognition. Proceedings of the IEEE, v. 86, n. 11, p. 2278-2323, 1998. Disponível em: <http://ieeexplore.ieee.org/document/726791/>. Acesso em: 18 jun. 2021.

LECUN, Y.; BENGIO, Y.; HINTON, G. Deep learning. Nature. [S.1.]: Nature Publishing Group. Disponível em: <http://colah.github.io/>. Acesso em: 16 jun. 2021. , 27 maio 2015 
LEE, H.; SONG, J. Introduction to convolutional neural network using Keras; An understanding from a statistician. Communications for Statistical Applications and Methods, v. 26, n. 6, p. 591-610, 2019. Disponível em: <https://doi.org/10.29220/CSAM.2019.26.6.591>. Acesso em: 19 jun. 2021.

LIU, S.; SHI, Q. Local climate zone mapping as remote sensing scene classification using deep learning: A case study of metropolitan China. ISPRS Journal of Photogrammetry and Remote Sensing, v. 164, p. 229-242, 1 jun. 2020.

LOBATO, L. J. T. Estimativa do volume de madeira empilhada utilizando processamento de imagens digitais. 2021. 33 f. Monografia (Graduação em Engenharia Florestal) Universidade Federal do Espírito Santo, 2021.

MARQUES, V. G. O. Avaliação do desempenho das redes neurais convolucionais na detecção de ovos de esquistossomose. 2017. 49 f. Monografia (Graduação em Engenharia da Computação) - Universidade Federal de Pernambuco., 2017.

MARTINS, V. E. Deep learning para classificação de imagens. 2018. 25 f. Dissertação (Mestrado em Ciência da Computação) - Universidade Estadual de Londrina, 2018.

MASSUCATTO, J. D. P. Aplicação de conceitos de redes neurais convolucionais na classificação de imagem. 2018. 70 f. Monografia (Graduação em Engenharia de Computação) - Universidade Tecnológica federal do Paraná., 2018.

MOMENY, M. et al. A noise robust convolutional neural network for image classification. Results in Engineering, v. 10, p. 100225, 1 jun. 2021.

NIELSEN, M. A. Using neural nets to recognize handwrritten digits. Neural Networks Deep Learn. Determ. Press. [S.1: s.n.], 2015. .

PAN, B.; SHI, Z.; XU, X. MugNet: Deep learning for hyperspectral image classification using limited samples. ISPRS Journal of Photogrammetry and Remote Sensing, v. 145, p. 108119, 1 nov. 2018.

REESE, K. M. Deep learning artificial neural networks for non-destructive archaeological site dating. Journal of Archaeological Science, v. 132, p. 105413, 1 ago. 2021. Disponível em: 
<https://linkinghub.elsevier.com/retrieve/pii/S0305440321000832>. Acesso em: 16 jun. 2021.

RODRIGUES, D. A. Deep learning e redes neurais convolucionais: reconhecimento automático de caracteres em placas de licenciamento automotivo. 2018. 37 f. Monografia (Graduação em Ciência da Computação) - Universidade Federal da Paraíba, 2018.

RONNEBERGER, O.; FISCHER, P.; BROX, T. U-net: Convolutional networks for biomedical image segmentation. 2015, [S.1.]: Springer Verlag, 2015. p. 234-241. Disponível em: $<$ http://lmb.informatik.uni-freiburg.de/http://lmb.informatik.unifreiburg.de/people/ronneber/u-net.>. Acesso em: 28 jun. 2021.

SANTOS, R. R. dos. Detecção de ataques de apresentação facial utilizando redes neurais convolucionais e informações de contexto. 2019. 67 f. Dissertação (Mestrado em Engenharia Elétrica) - Universidade Federal do Rio Grande do Sul, 2019.

SHI, S. et al. Benchmarking state-of-the-art deep learning software tools. 13 jul. 2017, [S.1.]: Institute of Electrical and Electronics Engineers Inc., 13 jul. 2017. p. 99-104. Disponível em: <www.comp.hkbu.edu.hk/>. Acesso em: 16 jun. 2021.

SILVA, R. L. de F. Reconhecimento de ambientes em fotos do Instagram com deep learning. 2016. 50 f. Monografia (Graduação em ciência da computação) - Universidade Federal de Pernambuco, 2016.

SOUSA, G. G. B. Deep learning para detecção e classificação de pneumonia por radiografias do tórax. 2018. 43 f. Monografia (Mongrafia em Ciência da Computação) Universidade Federal do Maranhão, 2018.

TENSORFLOW. TensorFlow is an Open Source Software Library for Machine Intelligence. . [S.1: s.n.]. , 2016

VALliani, A. A. A.; RANTI, D.; OERMANN, E. K. Deep Learning and Neurology: A Systematic Review. Neurology and Therapy. [S.1.]: Adis. Disponível em: <https://doi.org/10.6084/>. Acesso em: 16 jun. 2021., 1 dez. 2019

WU, B. et al. Application of conventional UAV-based high-throughput object detection to the early diagnosis of pine wilt disease by deep learning. Forest Ecology and Management, v. 
486, p. 118986, 15 abr. 2021.

WU, J. Introduction to convolutional neural networks. National Key Lab for Novel Software

Technology, v. 23, n. 5, 2017. 


\section{APÊNDICES}

\section{APÊNDICE A - Script Fuzzy C-Means (Cap. 02)}

Script para agrupar as regiões de acordo com as variáveis climáticas e altitude por meio da técnica de Fuzzy C-Means.

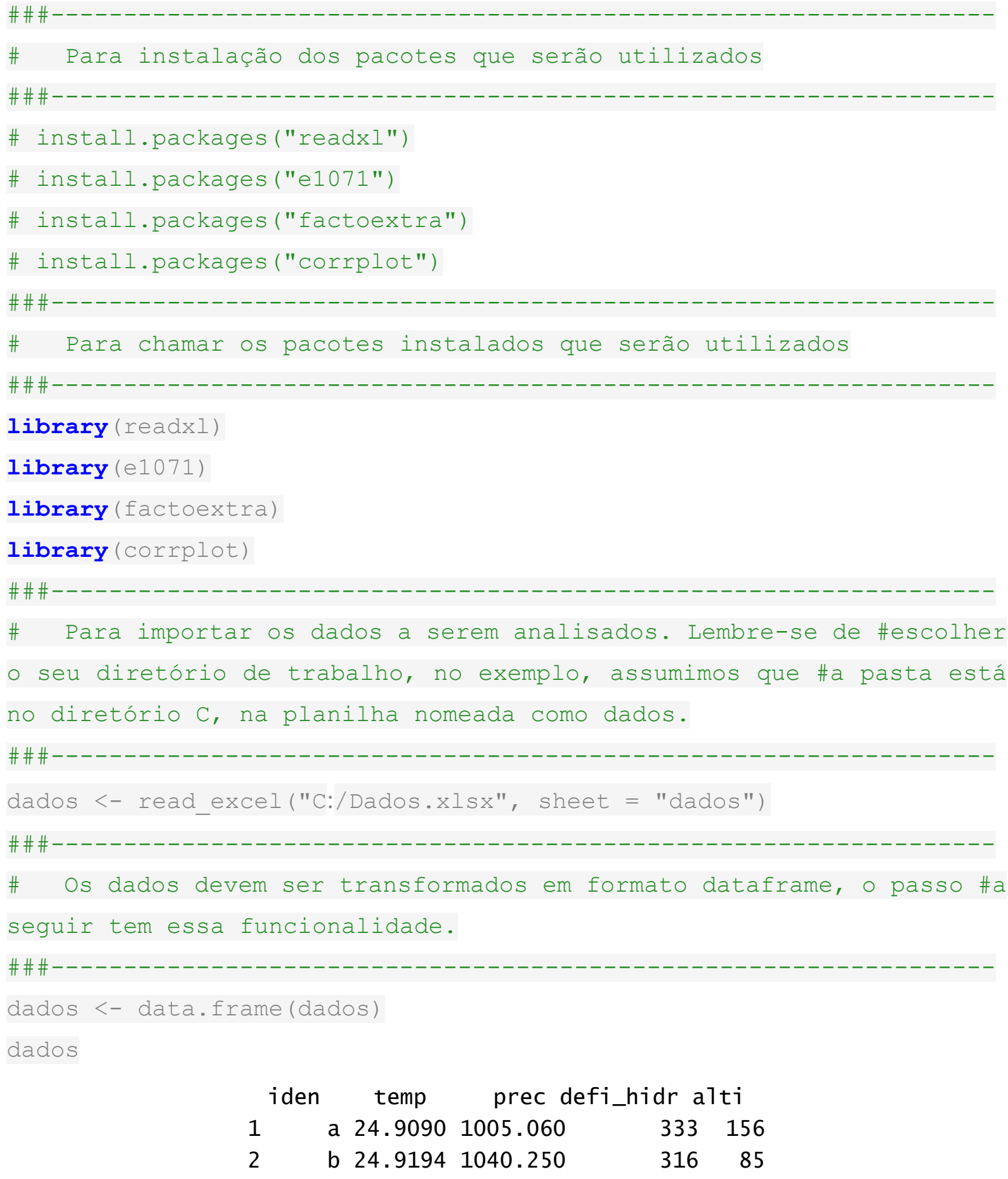

\begin{tabular}{llccrr}
\multicolumn{2}{c}{ iden } & temp & prec defi_hidr a7ti \\
1 & a 24.9090 & 1005.060 & 333 & 156 \\
2 & b 24.9194 & 1040.250 & 316 & 85
\end{tabular}




$\begin{array}{rrrrrr}3 & \text { c } 22.5079 & 1111.590 & 59 & 598 \\ 4 & \text { d } 24.5391 & 1089.150 & 228 & 176 \\ 5 & \text { e } 24.6922 & 1124.870 & 176 & 92 \\ 6 & \text { f } 24.6178 & 1171.460 & 120 & 57 \\ 7 & \text { g } 24.7680 & 1205.650 & 138 & 12 \\ 8 & \text { h } 23.8574 & 945.215 & 282 & 240 \\ 9 & \text { i } 23.3732 & 1017.030 & 175 & 308 \\ 10 & \text { j } 20.3695 & 1396.110 & 2 & 719 \\ 11 & \text { k } 22.5009 & 1387.740 & 3 & 395 \\ 12 & \text { T } 20.8000 & 1284.800 & 14 & 640 \\ 13 & \text { m } 19.7357 & 1354.650 & 27 & 977 \\ 14 & \text { n } 20.3561 & 1403.360 & 11 & 755 \\ 15 & \text { o } 22.0641 & 1456.550 & 8 & 514 \\ 16 & \text { p } 24.6296 & 1412.780 & 66 & 168 \\ 17 & \text { q } 20.2569 & 1433.670 & 14 & 844 \\ 18 & \text { r } 22.4871 & 1354.510 & 29 & 435 \\ 19 & \text { s } 20.1598 & 1281.620 & 8 & 715 \\ 20 & \text { t } 24.7638 & 1150.870 & 244 & 46 \\ \# \# \#-----------------------------------------------------------\end{array}$

\# A coluna "iden" deve ser transformada em rótulos de linhas, \#para tanto utilizaremos o seguinte comando.

\section{rownames (dados) $<-$ dados $[, 1]$}

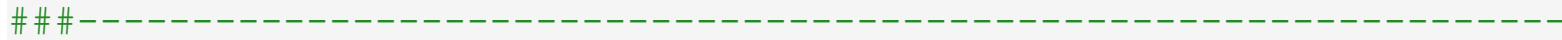

\# Após este comando os dados ficaram a da seguinte forma.

\begin{tabular}{|c|c|c|c|c|c|}
\hline$\Delta$ & iden & temp & prec & defi_hidr $\hat{=}$ & alti \\
\hline a & a & 24.9090 & 1005.060 & 333 & 156 \\
\hline b & $b$ & 24.9194 & 1040.250 & 316 & 85 \\
\hline c & $c$ & 22.5079 & 1111.590 & 59 & 598 \\
\hline d & d & 24.5391 & 1089.150 & 228 & 176 \\
\hline e & e & 24.6922 & 1124.870 & 176 & 92 \\
\hline f & $f$ & 24.6178 & 1171.460 & 120 & 57 \\
\hline g & $g$ & 24.7680 & 1205.650 & 138 & 12 \\
\hline h & $h$ & 23.8574 & 945.215 & 282 & 240 \\
\hline $\mathrm{i}$ & $i$ & 23.3732 & 1017.030 & 175 & 308 \\
\hline j & $\mathrm{j}$ & 20.3695 & 1396.110 & 2 & 719 \\
\hline$k$ & $k$ & 22.5009 & 1387.740 & 3 & 395 \\
\hline I & 1 & 20.8000 & 1284.800 & 14 & 640 \\
\hline m & $\mathrm{m}$ & 19.7357 & 1354.650 & 27 & 977 \\
\hline n & $n$ & 20.3561 & 1403.360 & 11 & 755 \\
\hline o & 0 & 22.0641 & 1456.550 & 8 & 514 \\
\hline p & $p$ & 24.6296 & 1412.780 & 66 & 168 \\
\hline$q$ & 9 & 20.2569 & 1433.670 & 14 & 844 \\
\hline r & $r$ & 22.4871 & 1354.510 & 29 & 435 \\
\hline s & 5 & 20.1598 & 1281.620 & 8 & 715 \\
\hline$t$ & $t$ & 24.7638 & 1150.870 & 244 & 46 \\
\hline
\end{tabular}


\# Perceba que embora os dados estejam com rótulo "iden" em \#linha, ainda encontra-se no dataframe como coluna, para retira-\#lo de tal formato utilizaremos o seguinte comando.

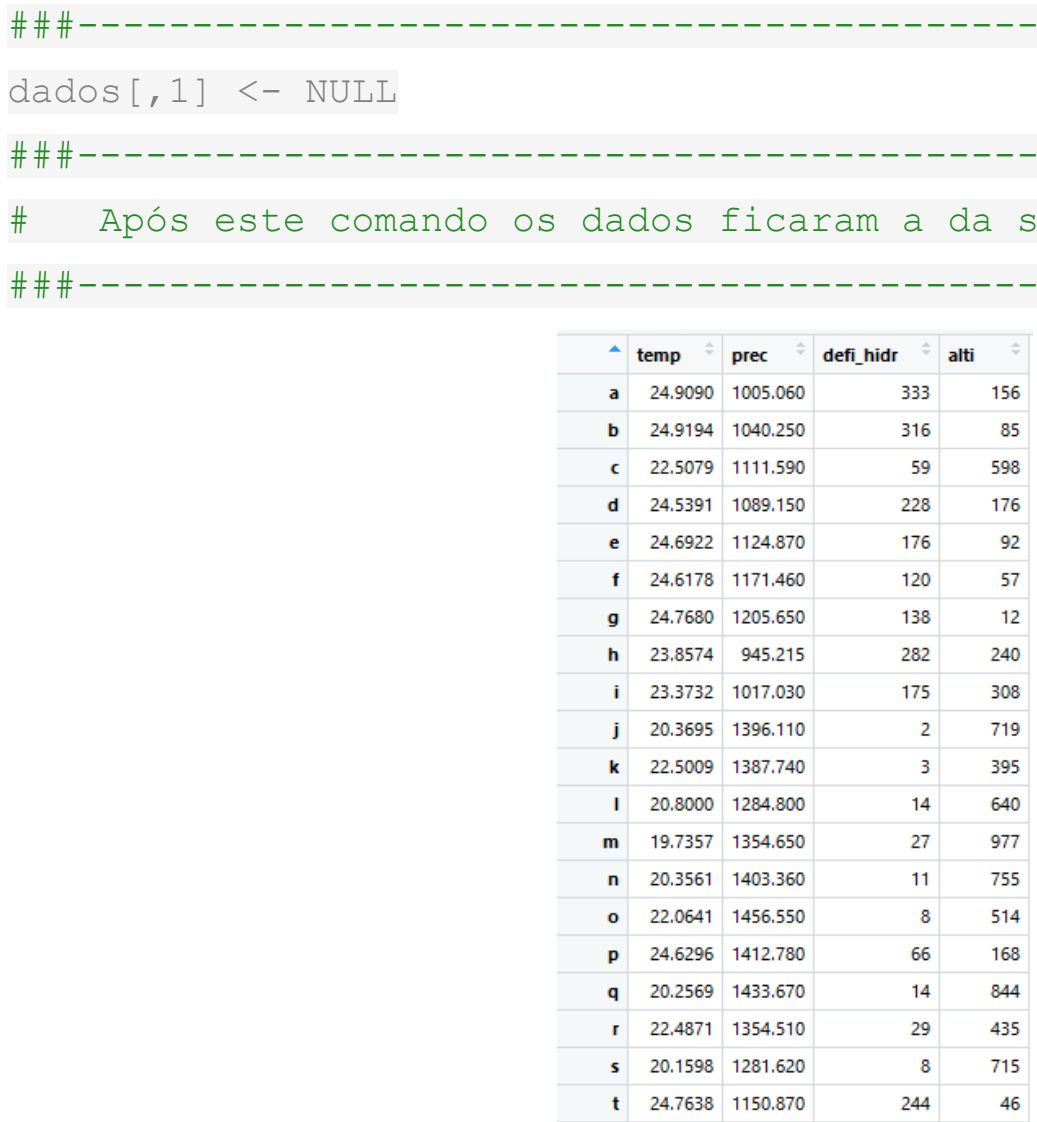

\#\#\#\#------------------------- - - - - - - - - - - - - - - - - - - - - - - - - - - - - - - - - - - \# Para cálculo do agrupamento fuzzy.

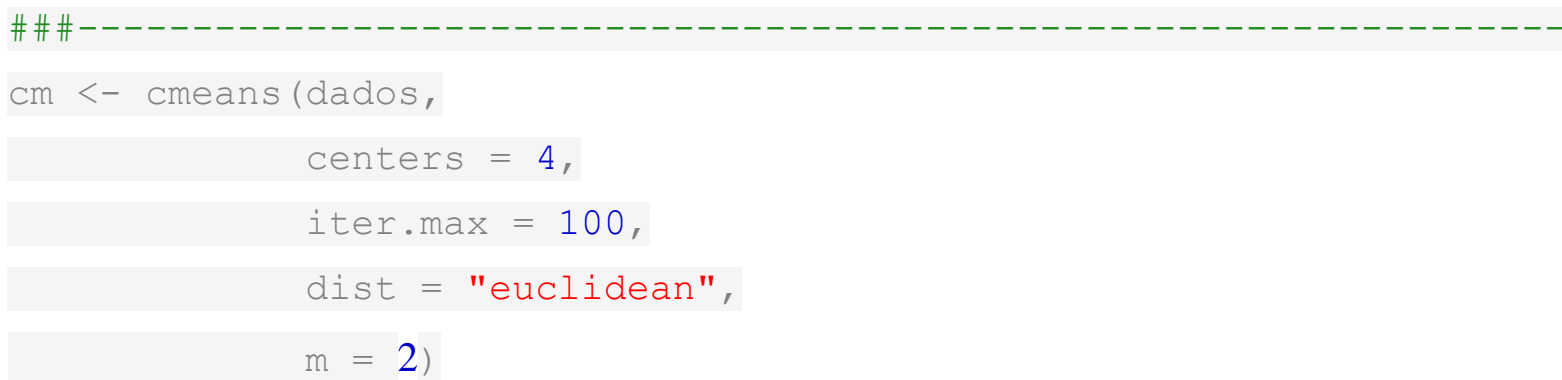

\#\#\#------------------------ - - - - - - - - - - - - - - - - - - - - - - - - - - - - - - - - - - - - - - - \# Para visualização usando corrplot.

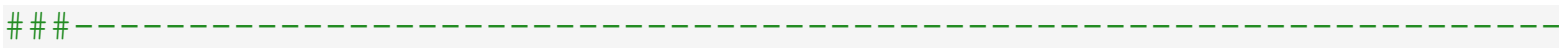
corrplot (cm\$membership, is.corr = FALSE)

\#\#\#---------------------- - - - - - - - - - - - - - - - - - - - - - - - - - - - - - - - - - - - - \# Para visualização dos grupos/clusters.

\#\#\#---------------------------------------------------------------cm\$cluster

fviz cluster(list(data = dados, cluster $=\mathrm{cm} \$ \mathrm{cluster)}$, 
ellipse.type = "norm",

ellipse.level $=0.75$,

palette = "jco",

ggtheme = theme minimal ())

\section{APÊNDICE B - Script para obtenção da árvore de regressão (Cap. 03)}

O script utilizado para obtenção da árvore de regressão pode ser visualizado a seguir:

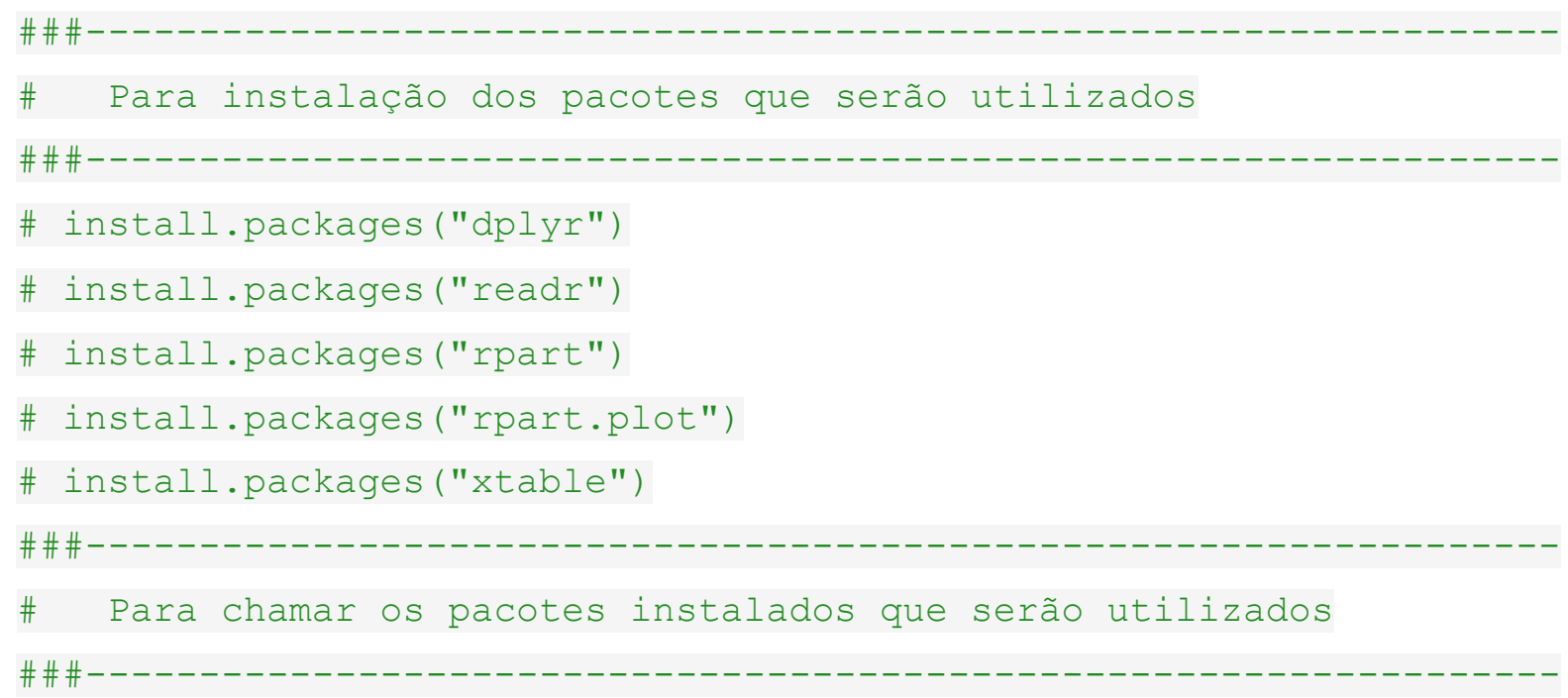

library (dplyr)

library (readr)

library (rpart)

library (rpart.plot)

library (xtable)

library (readxl)

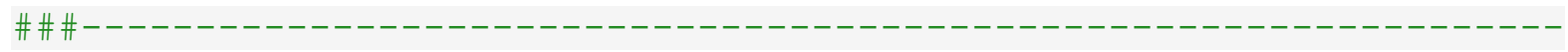

\# Para importar os dados a serem analisados. Lembre-se de \#escolher - seu diretório de trabalho, no exemplo, assumimos que \#a pasta está no diretório C, na planilha nomeada como dados.

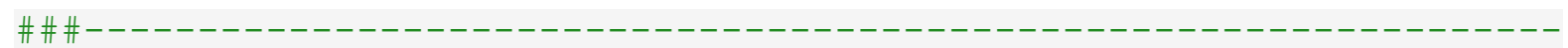

dados <- read_excel ("C:/Dados.xlsx", sheet = "dados")

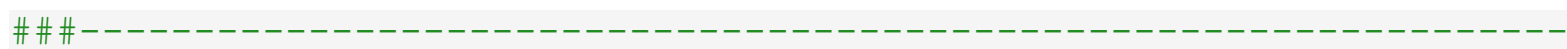

\# Os dados foram separados em treinamento e teste.

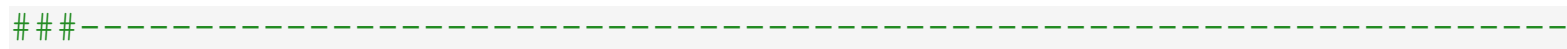

set. seed (123)

data <- c("training", "test") 응

sample (nrow (dados), replace $=\mathrm{T}) \div$

split (dados, .) 


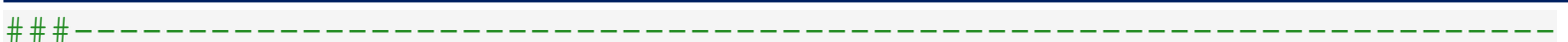

\# Para criação da árvore de decisão. Note que testamos diferentes variáveis independentes, neste script utilizamos as variáveis altitude (alt); precipitação (prec), Temperatura (temp) e umidade. Para calibração utilizamos a função rpart.control.

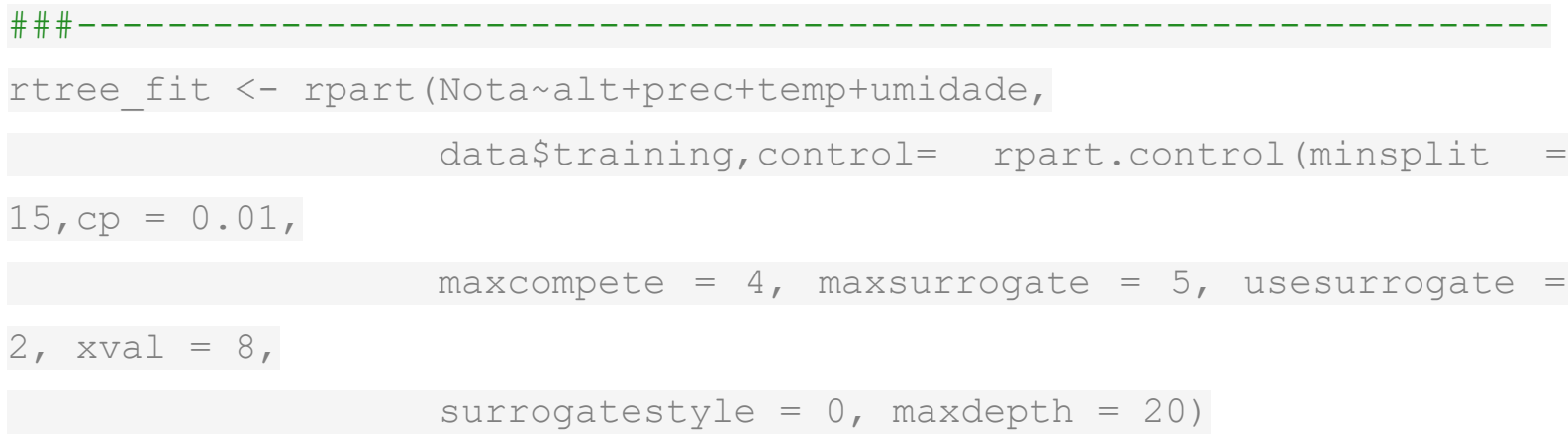
adicionado de forma manual o valor encontrado através da formula do passo anterior.

\#\#\#

plot(predict(rtree_fit, data\$training), data\$training\$Nota, lwd=1, main="Treinamento", family="serif",

$\mathrm{xlab}=$ "Nota Observada", ylab="Nota Estimada", cex.axis=0.8, cex.lab=1, cex.main=1,pch $=8, x \lim =c(79,88), y \lim =c(79,88))$

abline $(0,1, \operatorname{col}=$ "blue", lwd=2)

text $(x=80, y=86$,

labels $=" r=0,909 "$ )

\#\#\#\#-----------------------------------------------------------------

\# Para plotagem do gráfico de dados de teste, note que foi adicionado de forma manual o valor encontrado através da formula do passo de cálculo de correlação. 
plot(predict(rtree_fit, data\$test), data\$test\$Nota, lwd=1,

main="Teste", family="serif",

xlab="Nota Observada", ylab="Nota Estimada", cex.axis=0.8, cex.lab=1, cex.main=1, $\mathrm{pch}=8, \mathrm{x} \lim =\mathrm{c}(79,88), \mathrm{ylim}=\mathrm{c}(79,88))$

abline $(0,1$, col = "blue", lwd=2)

text $(x=80, y=86$,

labels $=" r=0,769 "$ )

\section{APÊNDICE C - Script para cálculo da random forest (Cap. 03)}

O script a seguir foi utilizado para cálculo da random forest:

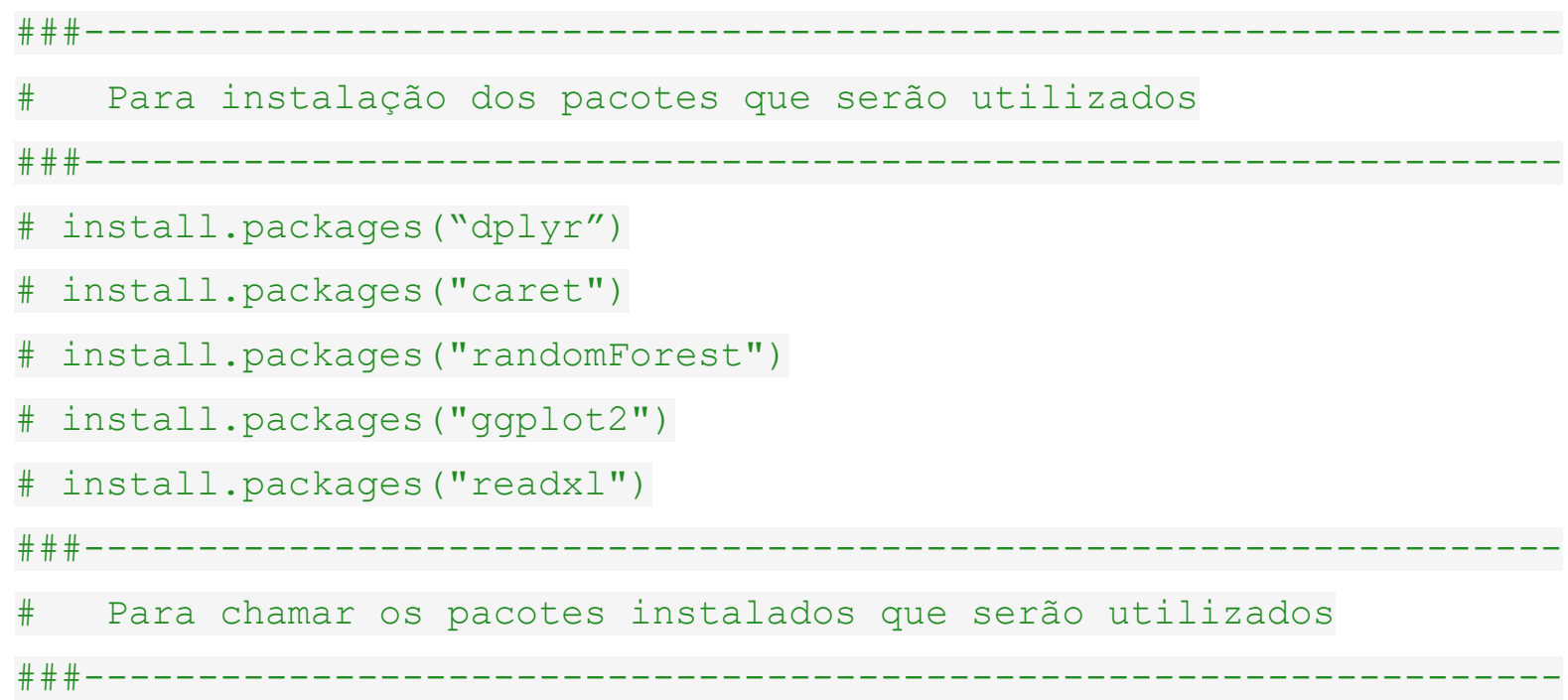

library ( dplyr)

library (caret)

library (randomForest)

library (ggplot2)

library (readxl)

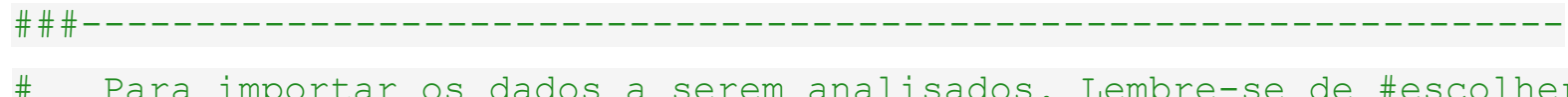
- seu diretório de trabalho, no exemplo, assumimos que \#a pasta está no diretório $C$, na planilha nomeada como dados.

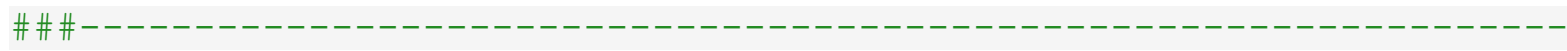
dados <- read_excel ("C:/Dados.xlsx", sheet = "dados")

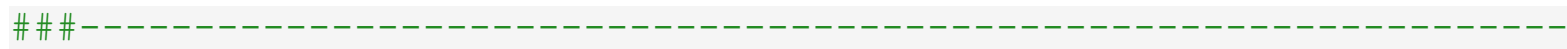

\# Os dados foram separados em treinamento e teste.

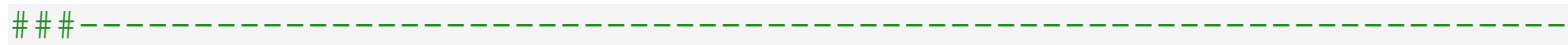

set.seed(123) \#Para reprodutibilidade 
data <-c("training", "test") \%>\%

sample (nrow (dados), replace $=\mathrm{T}) \%$

split(dados, .)

\#\#\#-

\# Para criação do modelo através da Random Forest. Note que testamos

diferentes variáveis independentes, neste script utilizamos as variáveis altitude (alt); precipitação (prec), Temperatura (temp) e umidade.

\#\#\#--------------------

random_forest_model <- randomForest (Nota alt+prec+temp+umidade,

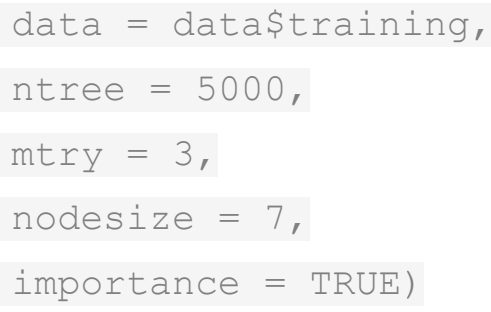

\#\#\#--

\# Para plotar o grau de importância das variáveis em análise.

\#\#\#----------------------------------------------------------------

important=importance (random_forest_model)

barplot (important [, 1], horiz=TRUE, col="navyblue", las=1, lwd=1, main="Grau

de Importância das Variáveis", family="serif", cex.axis=0.8, cex.main=1,xlim $=c(0,250))$

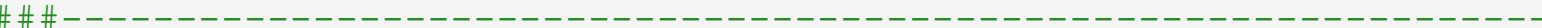

\# Para cálculo da correlação com os dados de treinamento e teste.

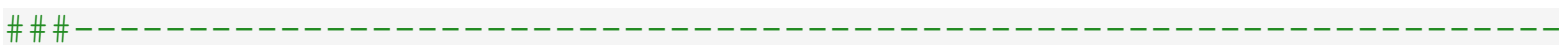
cor (predict (random_forest_model, data\$training), data\$training\$Nota) cor (predict (random_forest_model, data\$test), data\$test\$Nota)

\#\#\#--

\# Para plotagem do gráfico de dados de treinamento, note que foi adicionado de forma manual o valor encontrado através da formula do passo anterior.

\#\#\#-

plot (predict (random_forest_model, data\$training), data\$training\$Nota, 1 $\mathrm{wd}=1$, main="Treinamento", family="serif", xlab="Nota Observada", ylab="Nota Estimada", cex.axis=0.8, cex.lab=1, cex.main=1,pch = 8, xlim $=\mathrm{c}(79,88), \mathrm{ylim}=\mathrm{c}(79,88))$

abline $(0,1, \operatorname{col}=$ "blue", lwd=2)

text $(\mathrm{x}=80, \mathrm{y}=86$,

labels $=" r=0,951 "$ ) 


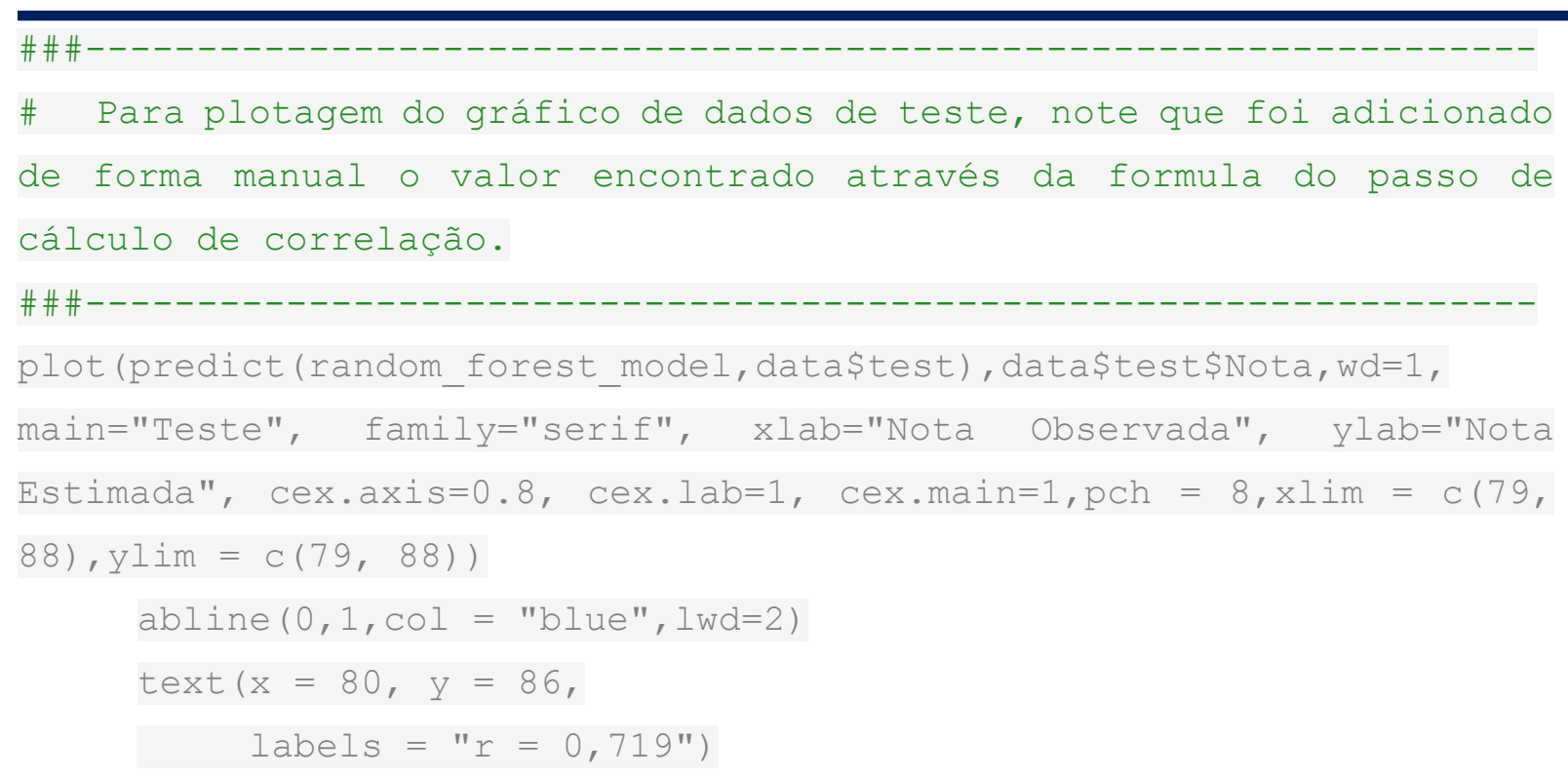

\section{APÊNDICE D - Script de classificação de área ocupada por gramínea (Cap. 04)}

O modelo será construído para classificação de imagens com uma quantidade relativamente pequena de dados. O desenvolvimento do modelo de classificação pixel a pixel será realizado aplicando uma arquitetura chamada U-net. Segue abaixo o script utilizado:

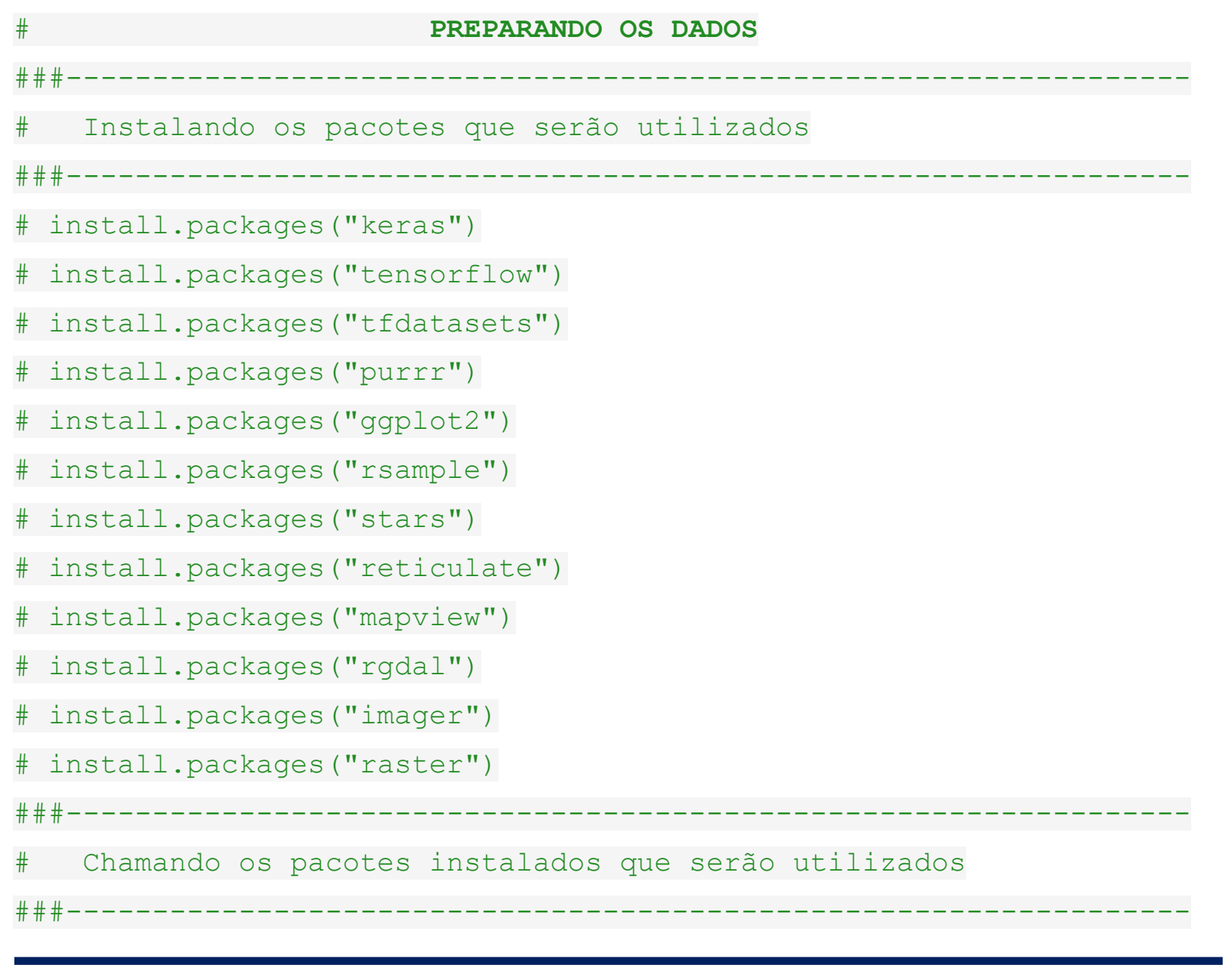




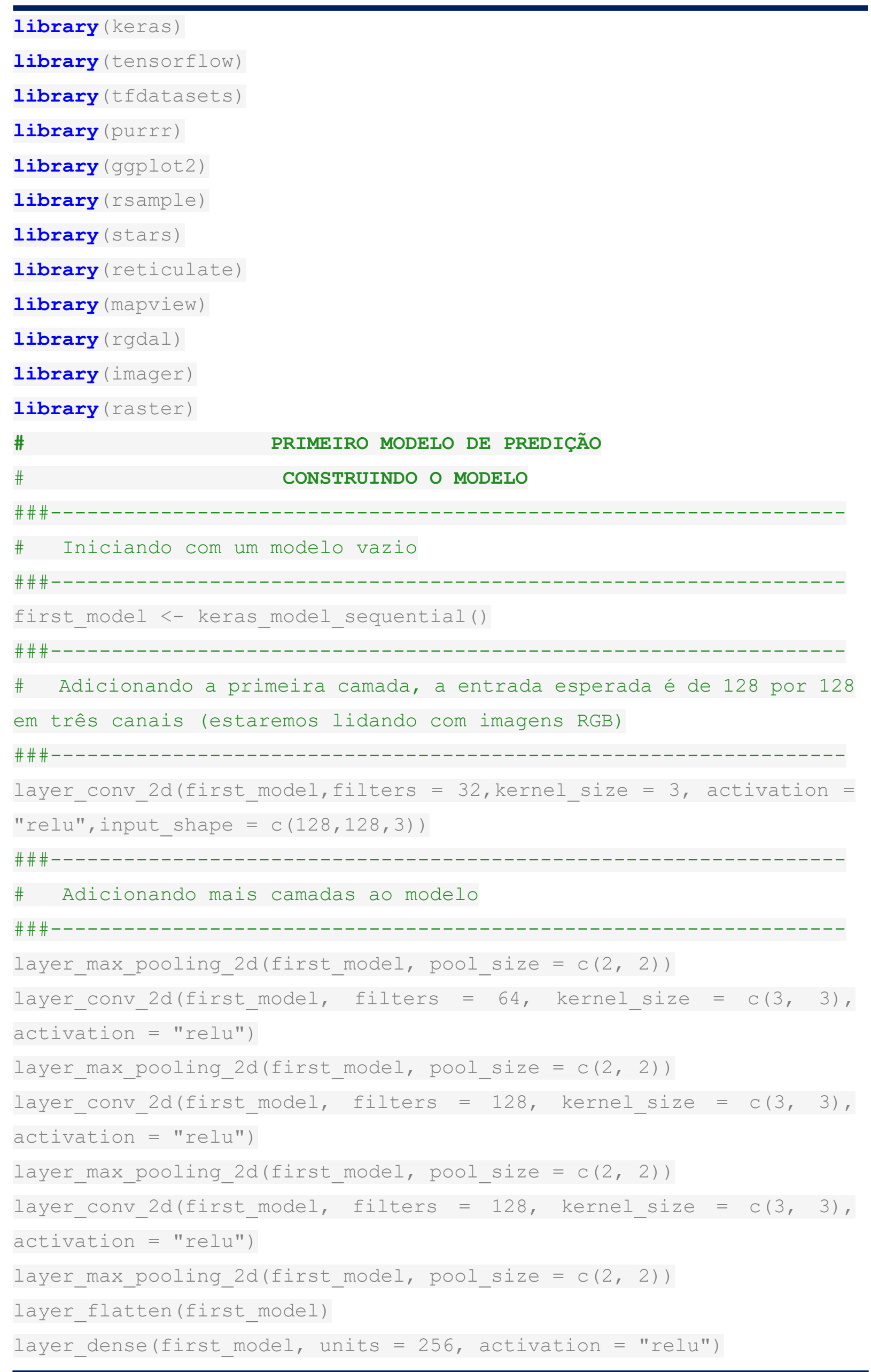




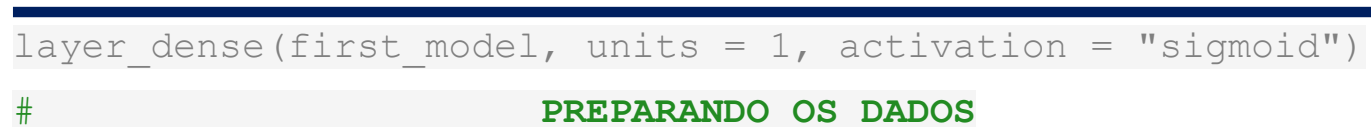

\#

PREPARANDO OS DADOS

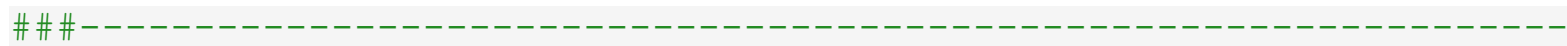

\# Obtenção dos arquivos de imagem que contêm os alvos a serem estudados

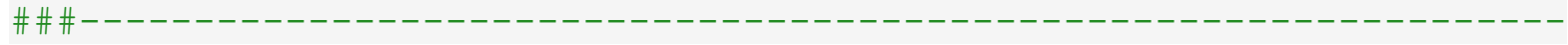

subset_list $<-\quad$ list.files("G:/tutorial_data/training_part1/true", full. names $=\mathrm{T}$ )

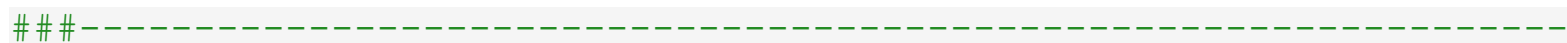

\# Criação de um data-frame com duas colunas: caminho de arquivos e rótulos

\#\#\#-----1
data_true
data.frame (img=subset_list, lbl=rep (1L, length(subset_list)))

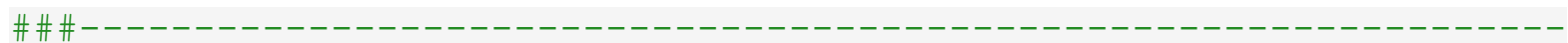

\# Obtenção dos caminhos de arquivos das imagens contendo os nãoalvos

\#\#\#-----------------------------------------------------------------

subset_list <- list.files("G:/tutorial_data/training_part1/false", full. names $=\mathrm{T}$ )

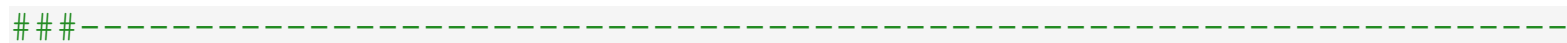

\# Criação de um data-frame com duas colunas: caminho de arquivo e os rótulos

\#\#\#-----------------------------------------------------------------

data_false $<-$ data.frame (img=subset_list, lbl=rep (OL, length (subset_list)) )

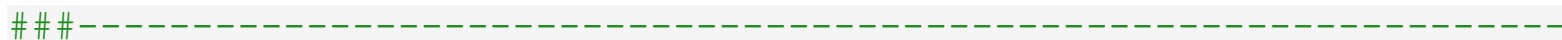

\# Mesclando os dois data-frames

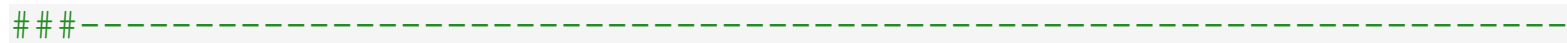

data $<-$ rbind (data_true, data_false)

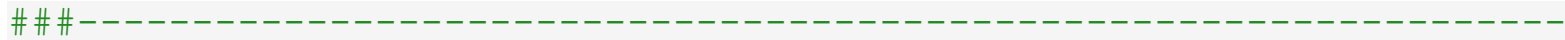

\# Dividindo aleatoriamente o conjunto de dados em treinamento (75\%)

e dados de validação (25\%). Usamos 'lbl' como estrato, para que a visão seja feita proporcionalmente para alvo e não alvos.

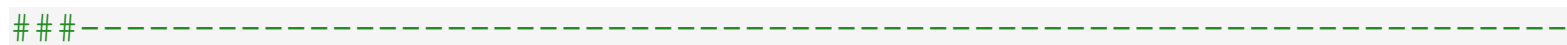

set. $\operatorname{seed}(2020)$

data $<-$ initial_split(data,prop $=0.75$, strata $=$ "lbl")

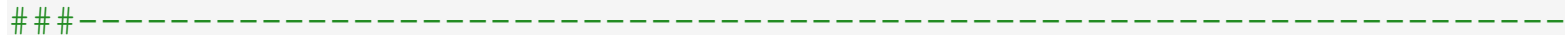




\# Para retornar algumas das primeiras entradas em data-frame de
treinamento

\#\#\# \# head (training (data))

\# \# \# \# validação

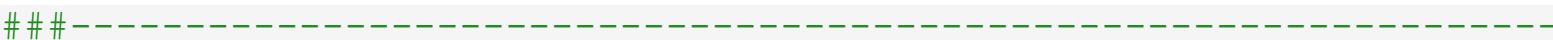
head (testing (data))

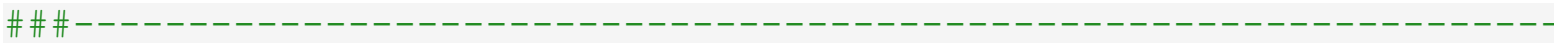

\# Comparação do número de arquivos nos dados de treinamento, que mostram não alvos versus aqueles que mostram alvos (devem ser semelhantes)

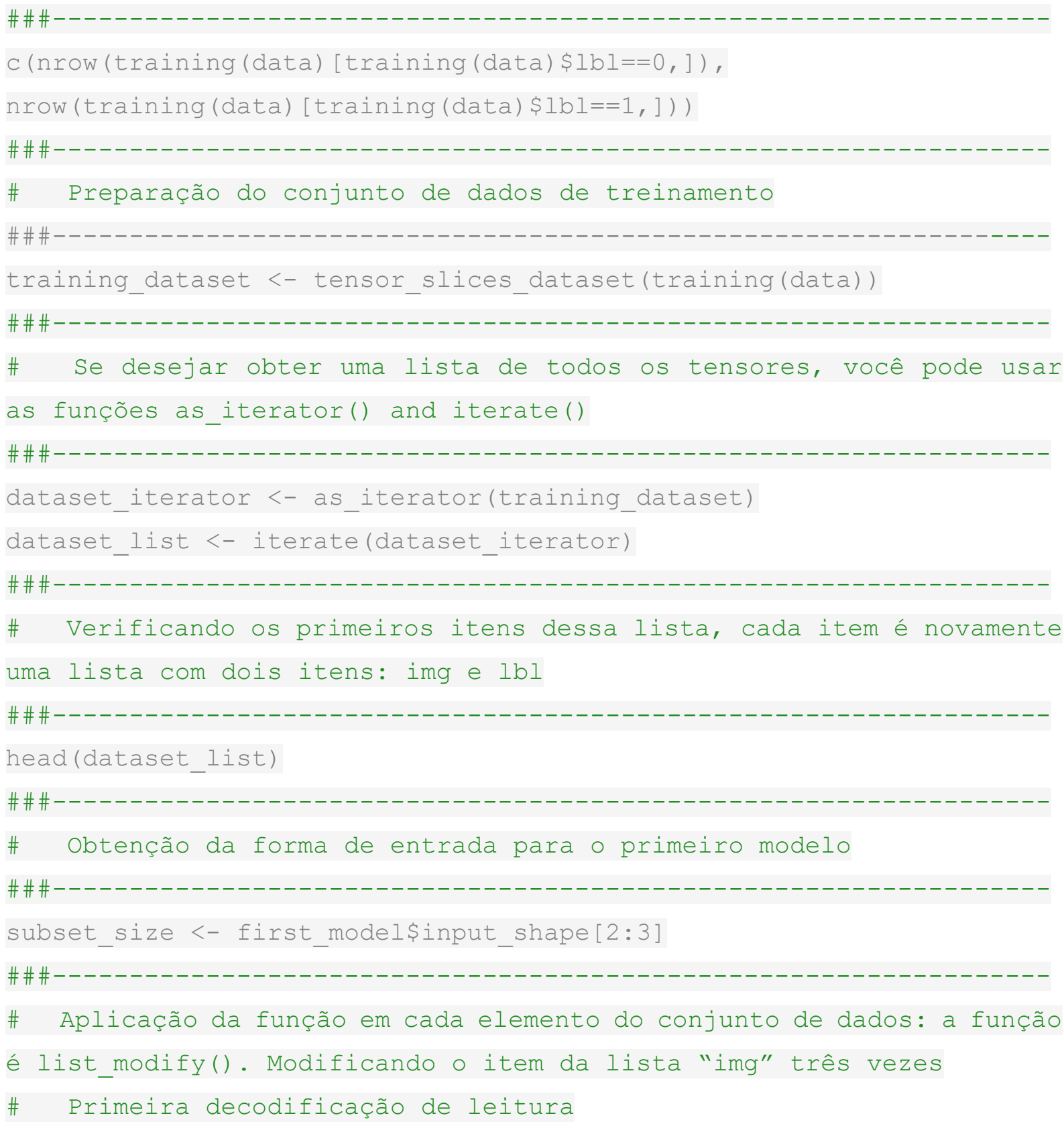




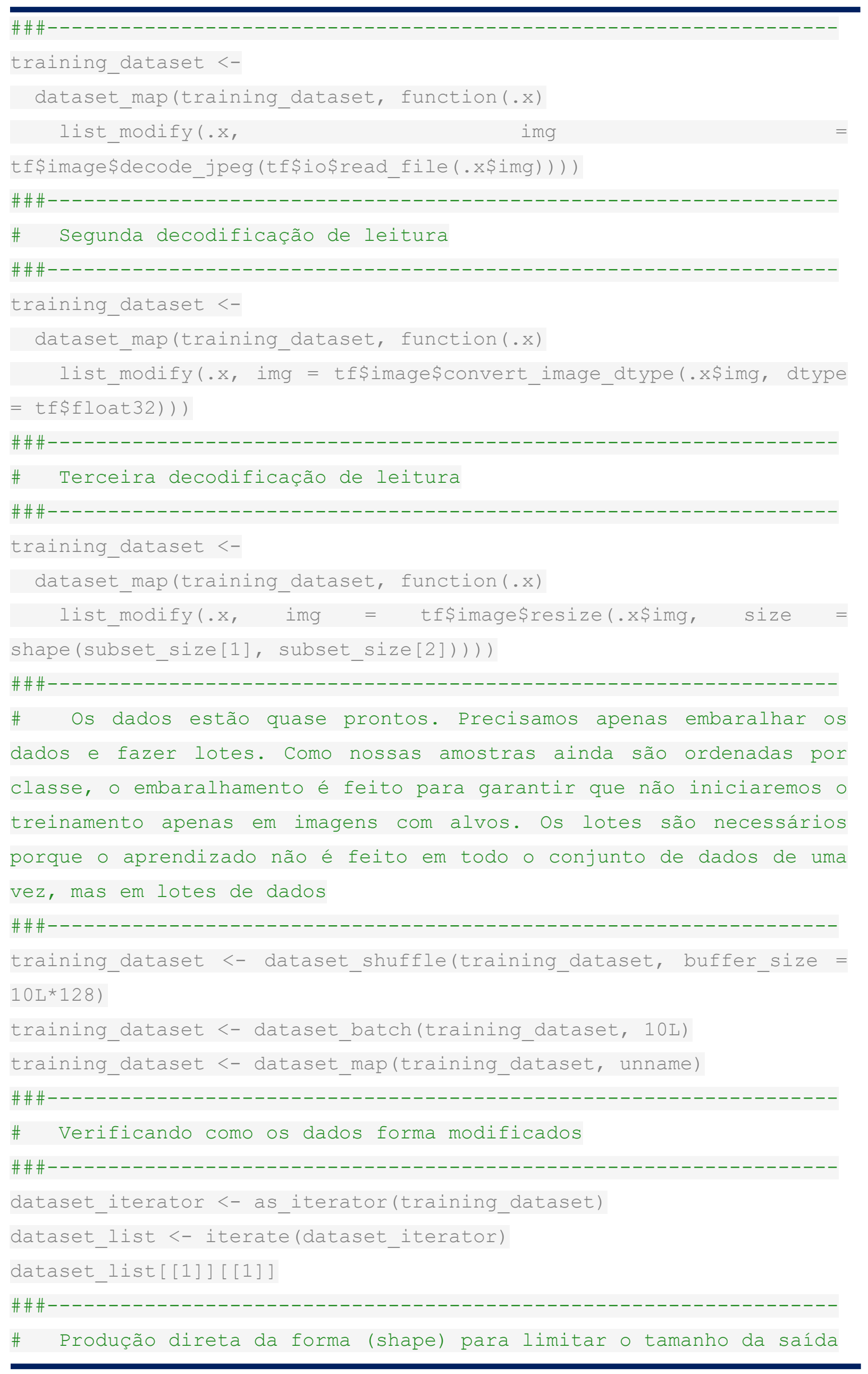




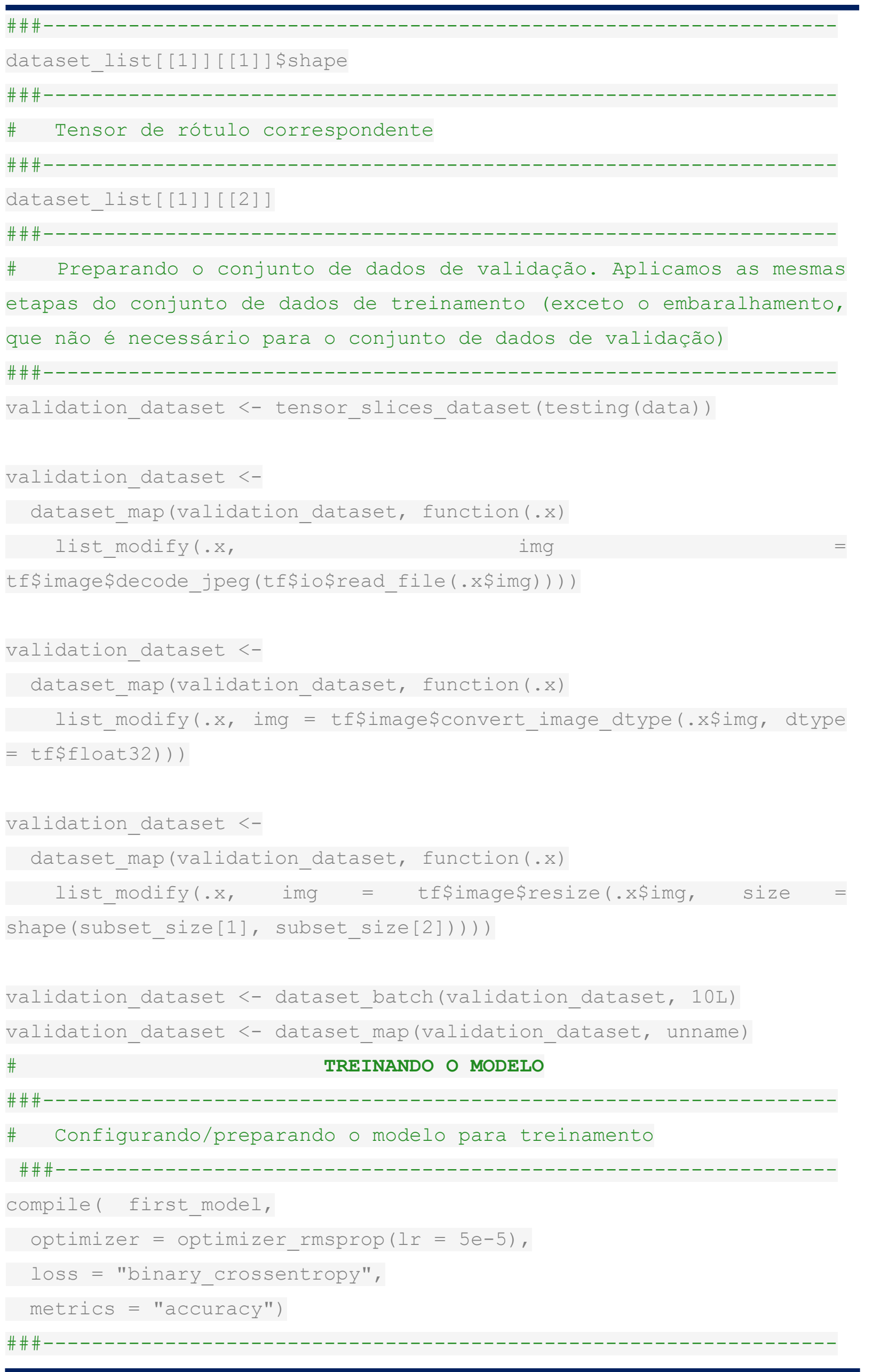


\# Iniciando o treinamento

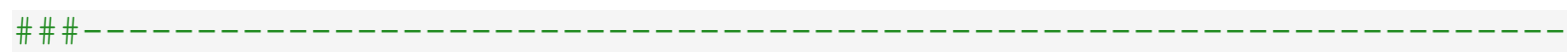

diagnostics <- fit (first model,

training_dataset,

epochs $=15$,

validation_data = validation_dataset)

plot (diagnostics)

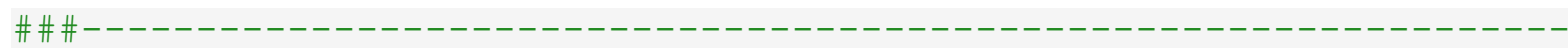

\# Plotando os gráficos

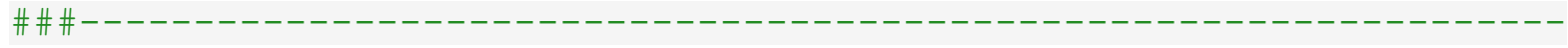

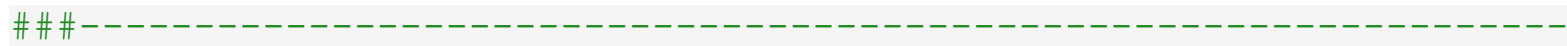

\# Gráficos de perda

df $=$ data.frame(loss = diagnostics\$metrics\$loss, val loss

=diagnostics\$metrics\$val_loss, epocas = 1:15)

plot(df\$epocas, df\$loss, main="Modelo de Perda", family="serif", $\mathrm{xlab}="$ Perda", ylab="Época", cex.axis=0.8, cex.lab=1, cex.main=1, xlim $=\mathrm{c}(1,15), \mathrm{ylim}=\mathrm{c}(0,1))$

plot(df\$epocas, df\$val_loss, main="Modelo de Perda", family="serif", xlab="Perda", ylab="Época", cex.axis=0.8, cex.lab=1, cex.main=1, xlim $=\mathrm{c}(1,15), \mathrm{ylim}=\mathrm{c}(0,1))$

lines (df\$loss, col="blue", type="b", pch=19)

lines (df\$val_loss, col="green", type="b", pch=19)

legend("bottomright", c c("treinamento", "validação"), c col=c("blue", "green"), $1 t_{y}=c(1,1)$, bty $\left.=" n ", \quad c e x=0.8\right)$

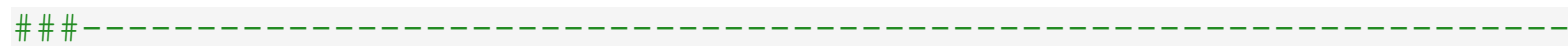

\# Gráficos de Acurácia

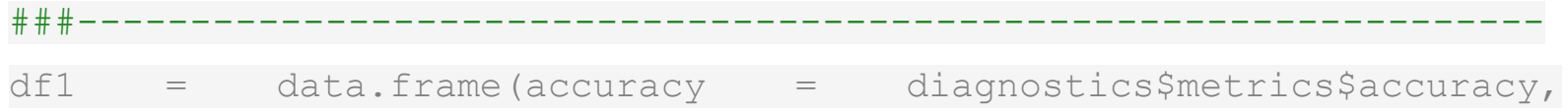
val_accuracy =diagnostics\$metrics\$val_accuracy, epocas = 1:15)
plot (df1\$epocas,
df1\$accuracy,
main="Modelo
de Acurácia",
family="serif",
xlab="Acurácia",
ylab="Época",
cex. axis=0.8,
cex.lab=1, cex.main=1, $x \lim =c(1,15), y \lim =c(0.4,1))$ 


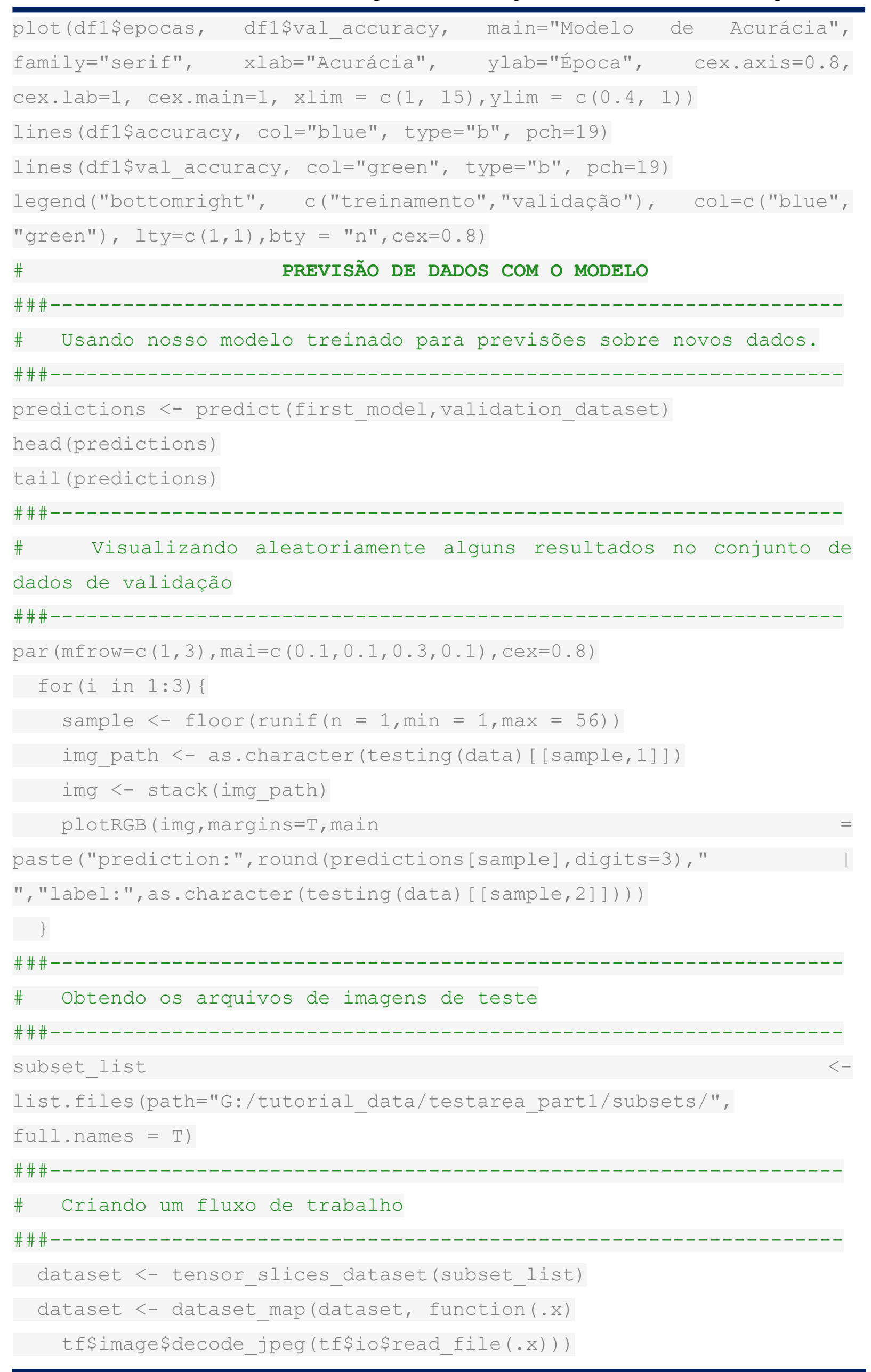




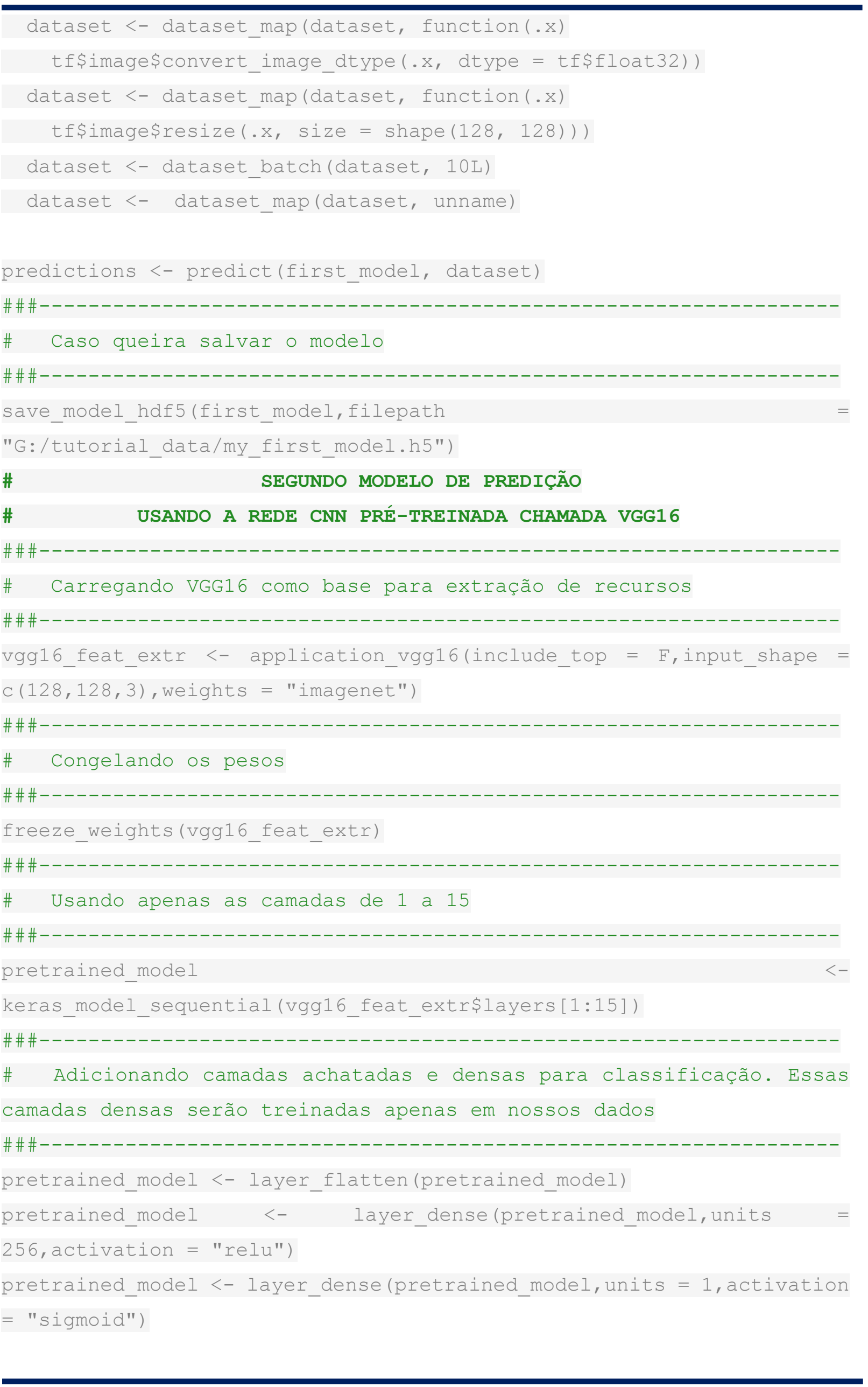


pretrained_model

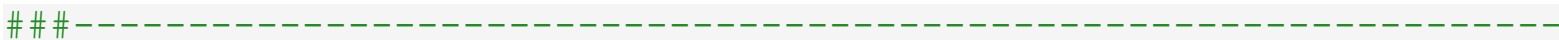

\# Este modelo é mais complexo, mas como vamos treinar apenas as camadas densas em nossos dados, não precisamos aprender todos os parâmetros do modelo. Vamos ver como funciona o treinamento congelando os parâmetros de parte do modelo

\#\#\#--

compile(

pretrained_model,

optimizer $=$ optimizer rmsprop (Ir $=1 e-5)$,

loss = "binary_crossentropy",

metrics $=\mathrm{c}($ (accuracy")

)

diagnostics <- fit(pretrained_model,

training_dataset,

epochs $=6$,

validation_data = validation_dataset)

plot (diagnostics)

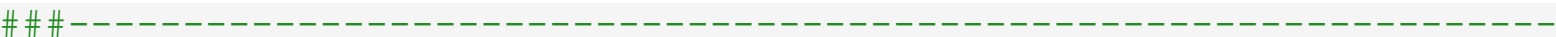

\# Visualizando as métricas

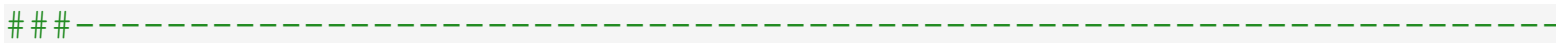

diagnostics\$metrics

\# CLASSIFICAÇÃO DA IMAGEM DE PIXEL A PIXEL

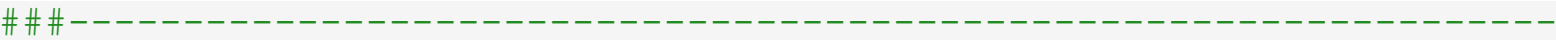

\# Dados de entrada, iniciando com 'caminho de contração'

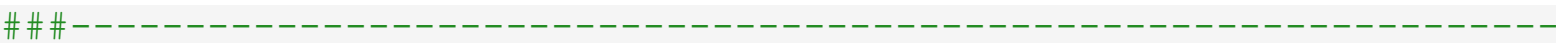

input_tensor $<-$ layer_input $($ shape $=c(448,448,3))$

\#\#\#-------------------- - - - - - - - - - - - - - - - - - - - - - - - - - - - - - - - - - - - - - -

\# Bloco convolucional 1

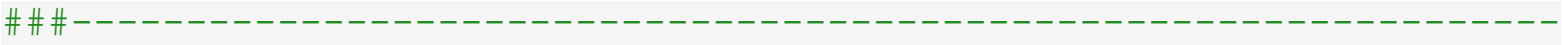

unet_tensor <- layer_conv_2d(input_tensor,filters $=64$, kernel_size = c $(3,3)$, padding = "same", activation = "relu")

conc_tensor2 <- layer_conv_2d(unet_tensor,filters = 64, kernel_size =

c $(3,3)$, padding = "same", activation = "relu")

unet_tensor <- layer_max_pooling_2d(conc_tensor2)

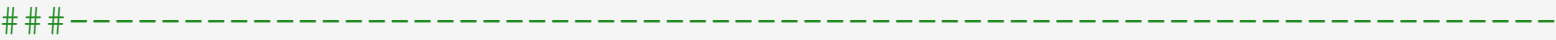

\# Bloco convolucional 2

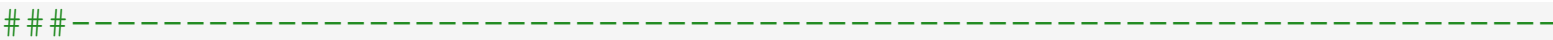




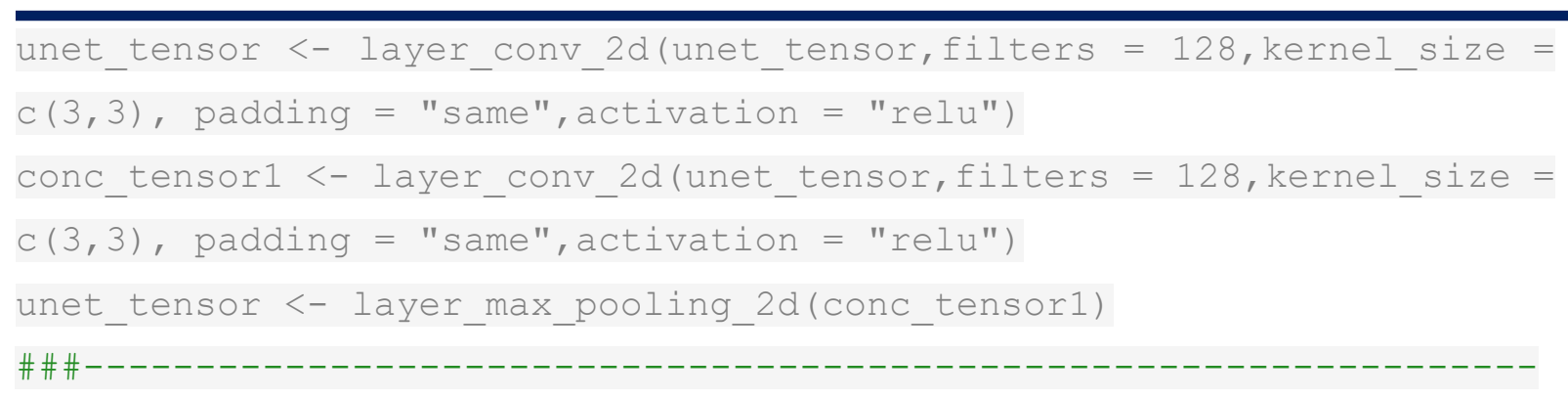

\# Curva inferior de unet

\#\#\#----------------------------------------------------------------unet_tensor <- layer_conv_2d(unet_tensor,filters = 256, kernel_size = c $(3,3)$, padding = "same", activation = "relu")

unet_tensor <- layer_conv_2d(unet_tensor,filters = 256, kernel_size = c $(3,3)$, padding = "same",activation = "relu")

\#\#\#----------------------------------------------------------------

\# Iniciando o caminho de expansão

\# Aumentando as amostras do bloco 1

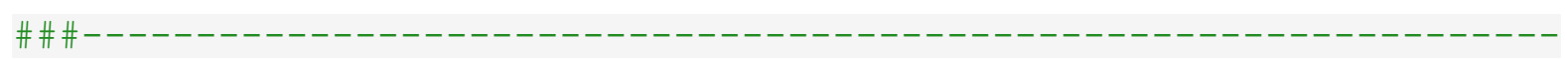

unet_tensor $\quad<-\quad$ layer_conv_2d_transpose(unet_tensor,filters= = 128, kernel_size $=\mathrm{c}(2,2)$, strides $=2$,padding = "same")

unet_tensor <- layer_concatenate (list (conc_tensor1, unet_tensor))

unet_tensor <- layer_conv_2d(unet_tensor, filters = 128, kernel_size $=\mathrm{c}(3,3)$, padding = "same", activation = "relu")

unet_tensor <- layer_conv_2d(unet_tensor, filters $=128$, kernel_size $=c(3,3)$, padding $=$ "same", activation = "relu")

\#\#\#---------------------------------------------------------------

\# Aumentando as amostras do bloco 2

\#\#\#----------------------------------------------------------------unet_tensor $\quad<-\quad$ layer_conv_2d_transpose(unet_tensor,filters = 64 , kernel_size $=c(2,2)$, strides $=2$, padding $=$ "same")

unet_tensor <- layer_concatenate (list (conc_tensor2, unet_tensor))

unet_tensor <- layer_conv_2d(unet_tensor, filters $=64$, kernel_size $=$ c $(3,3)$,padding = "same", activation = "relu")

unet_tensor <- layer_conv_2d (unet_tensor, filters $=64$, kernel_size $=$ $c(3,3)$,padding = "same", activation = "relu")

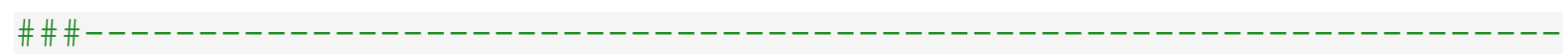

\# Resultados

\#\#\#---------------------------------------------------------------------unet_tensor <- layer_conv_2d (unet_tensor,filters $=1$, kernel_size = 1, activation = "sigmoid")

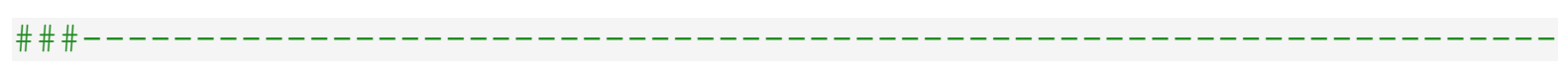


\# Combinando unet_tensor final (carregando todas as transformações através das camadas) com imput tensor para criar o modelo

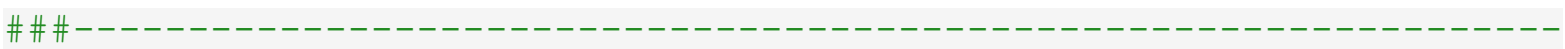
unet_model <- keras_model(inputs = input_tensor, outputs = unet_tensor)

USANDO CAMADAS PRÉ-TREINADAS EM UMA REDE U

\# Carregando VGG16 pré-treinado e usar parte dele como cominho de contratação (extração de recursos)

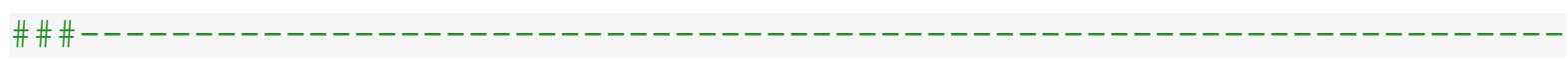
vgg16_feat_extr <- application_vgg16(weights = "imagenet", include_top $=$ FALSE, input_shape $=c(448,448,3))$

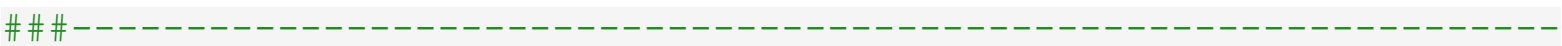

\# Opcionalmente, pode-se congelar as primeiras camadas para evitar a alteração de seus pesos, seja convbase inteira ou apenas certas camadas. Não usaremos todo o modelo, mas apenas até a camada 15

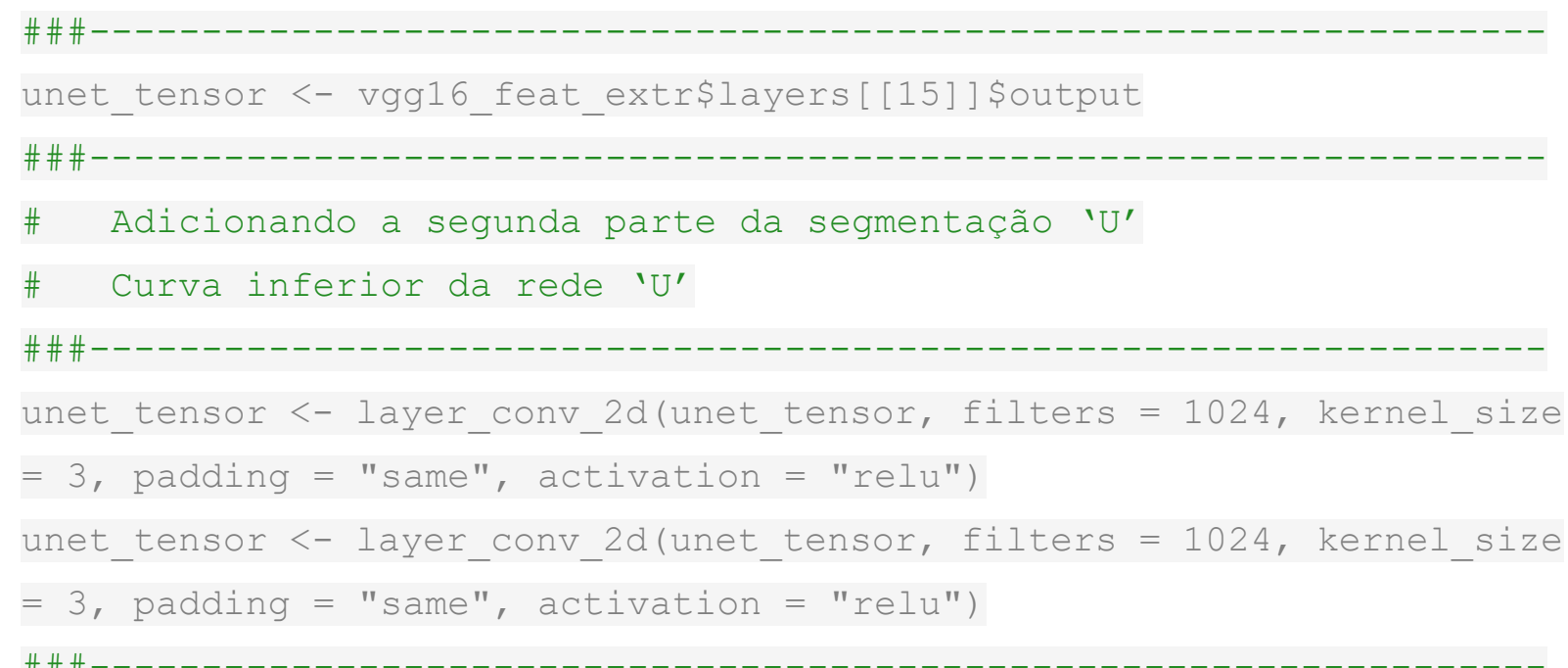

\# Aumentando as amostras do bloco 1

\#\#\#----------------------------------------------------------------unet_tensor <- layer_conv_2d_transpose(unet_tensor, filters = 512, kernel_size $=2$, strides $=2$, padding $=$ "same")

unet_tensor

layer_concatenate (list (vgg16_feat_extr\$layers [ [14] ] \$output, unet_tensor))

unet_tensor <- layer_conv_2d(unet_tensor, filters = 512, kernel_size = 3, padding = "same", activation = "relu")

unet_tensor <- layer_conv_2d(unet_tensor, filters = 512, kernel_size $=3$, padding = "same", activation = "relu")

\#\#\#---------------------------------------------------------------- 


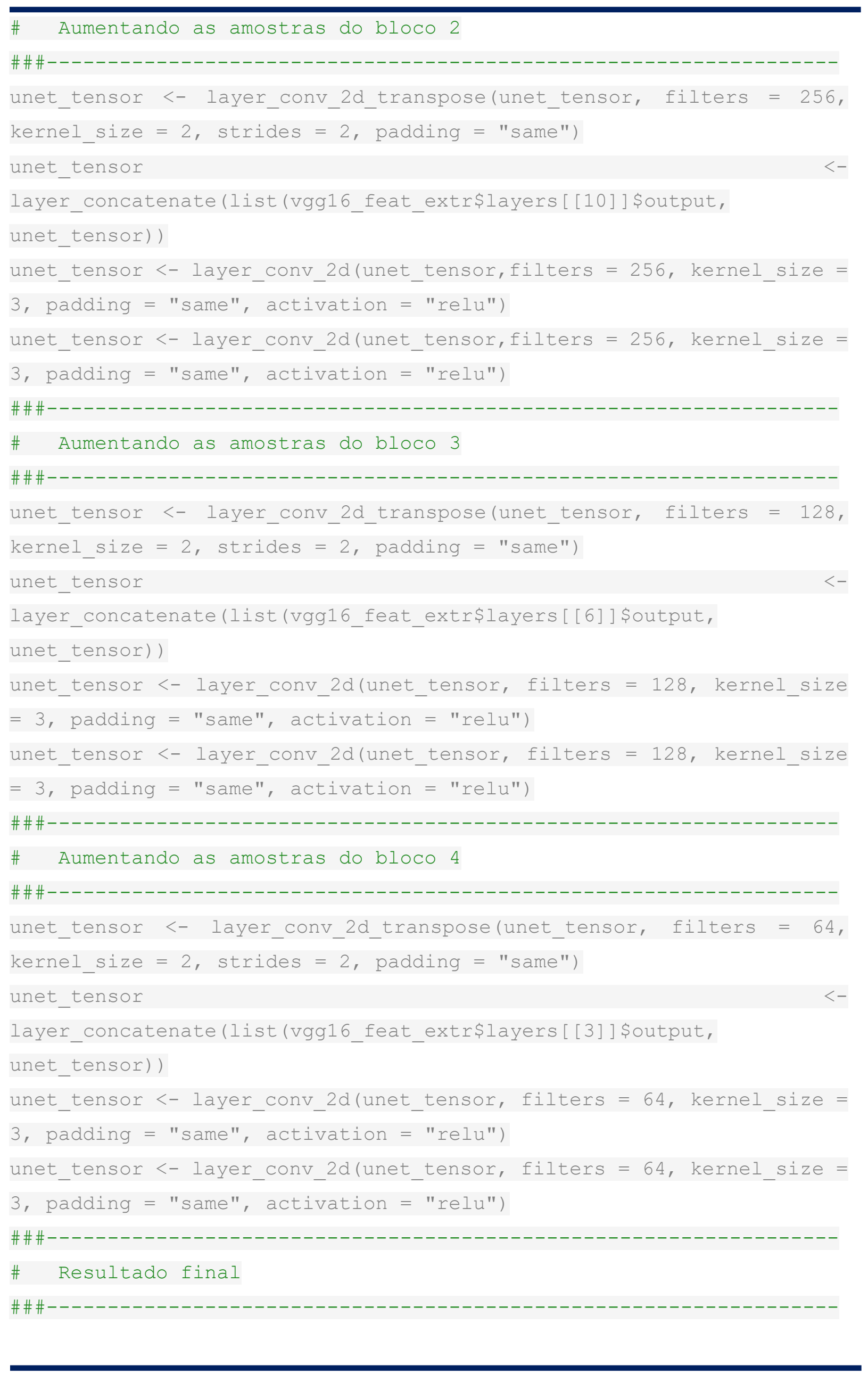




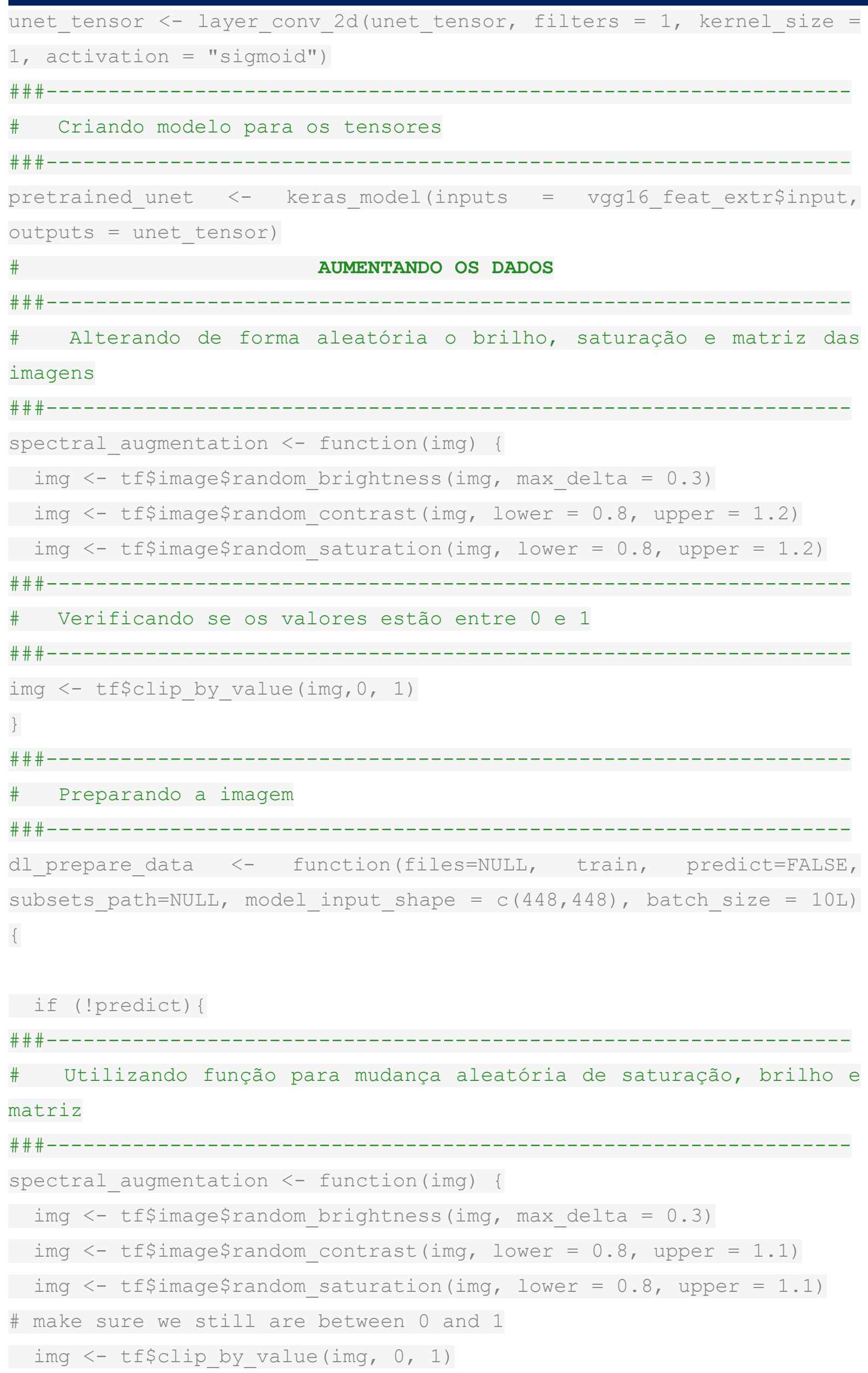




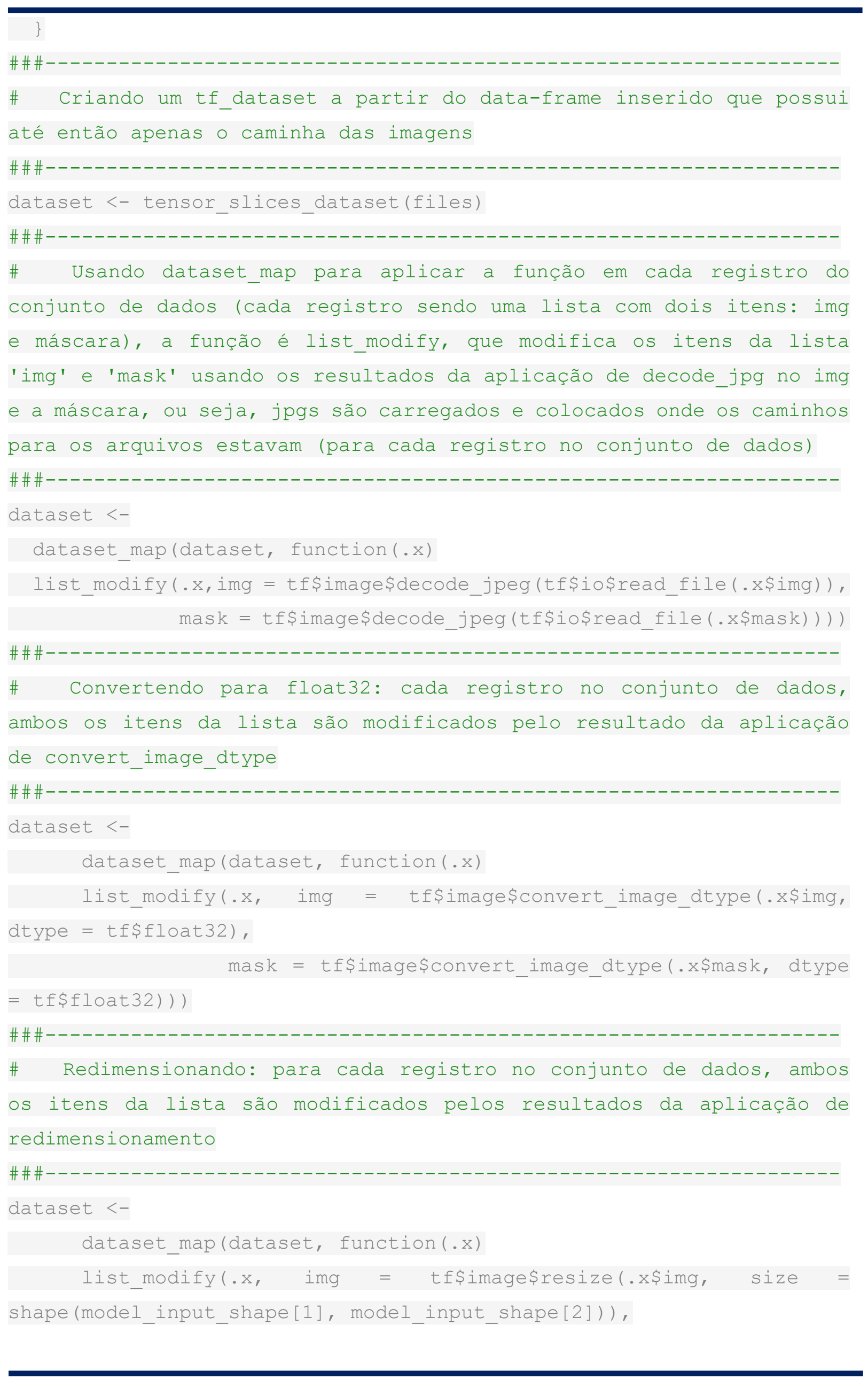


shape (model_input_shape [1], model_input_shape[2]))))

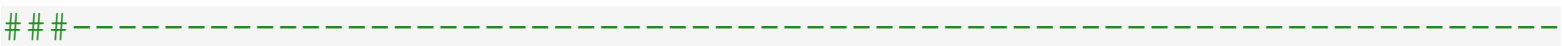

\# Aumentando os dados no conjunto de treinamento

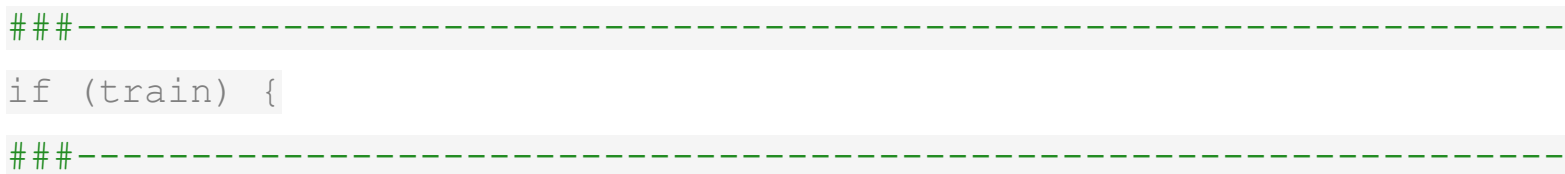

\# Augmentation 1: virando para a esquerda para a direita, incluindo mudança aleatória de saturação, brilho e contraste para cada registro no conjunto de dados, apenas o item img é modificado pelo resultado da aplicação de aumento_espectral

\#\# \#----------------------------------------------------------------augmentation $<-$

dataset_map (dataset, function(.x)

list_modify(.x, img = spectral_augmentation(.x\$img)))

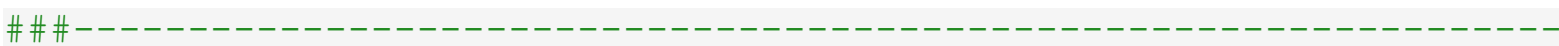

\# Aplicando a inversão ao img e à máscara de cada registro

\#\#\#-----------------------------------------------------------------

augmentation $<-$

dataset_map (augmentation, function(.x)

list_modify(.x, img = tf\$image\$flip_left_right(.x\$img), mask = tf\$image\$flip left right(.x\$mask)))

dataset_augmented <- dataset_concatenate (dataset, augmentation)

\#\#\#-----------------------------------------------------------------

\# Augmentation 2: virando para cima e para baixo, incluindo mudança aleatória de saturação, brilho e contraste

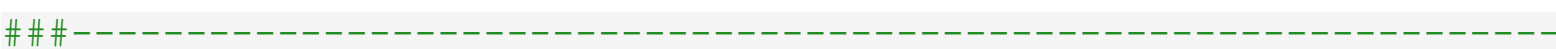

augmentation $<-$

dataset_map (dataset, function(.x)

list_modify(.x, img = spectral_augmentation(.x\$img)))

augmentation <-

dataset_map (augmentation, function(.x)

list_modify (.x, img = tf\$image\$flip_up_down(.x\$img), mask = tf\$image\$flip_up_down (.x\$mask)) ) 


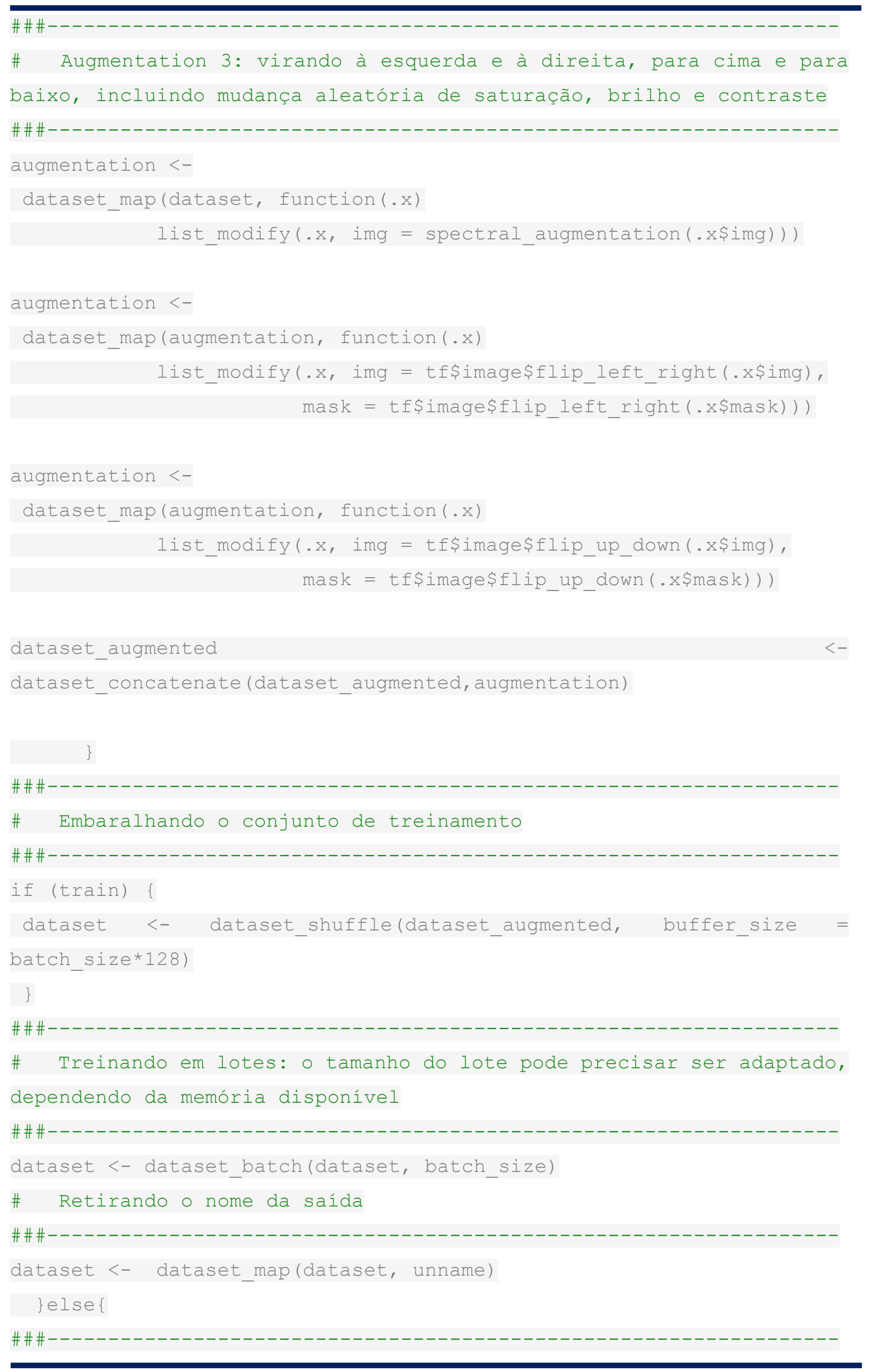




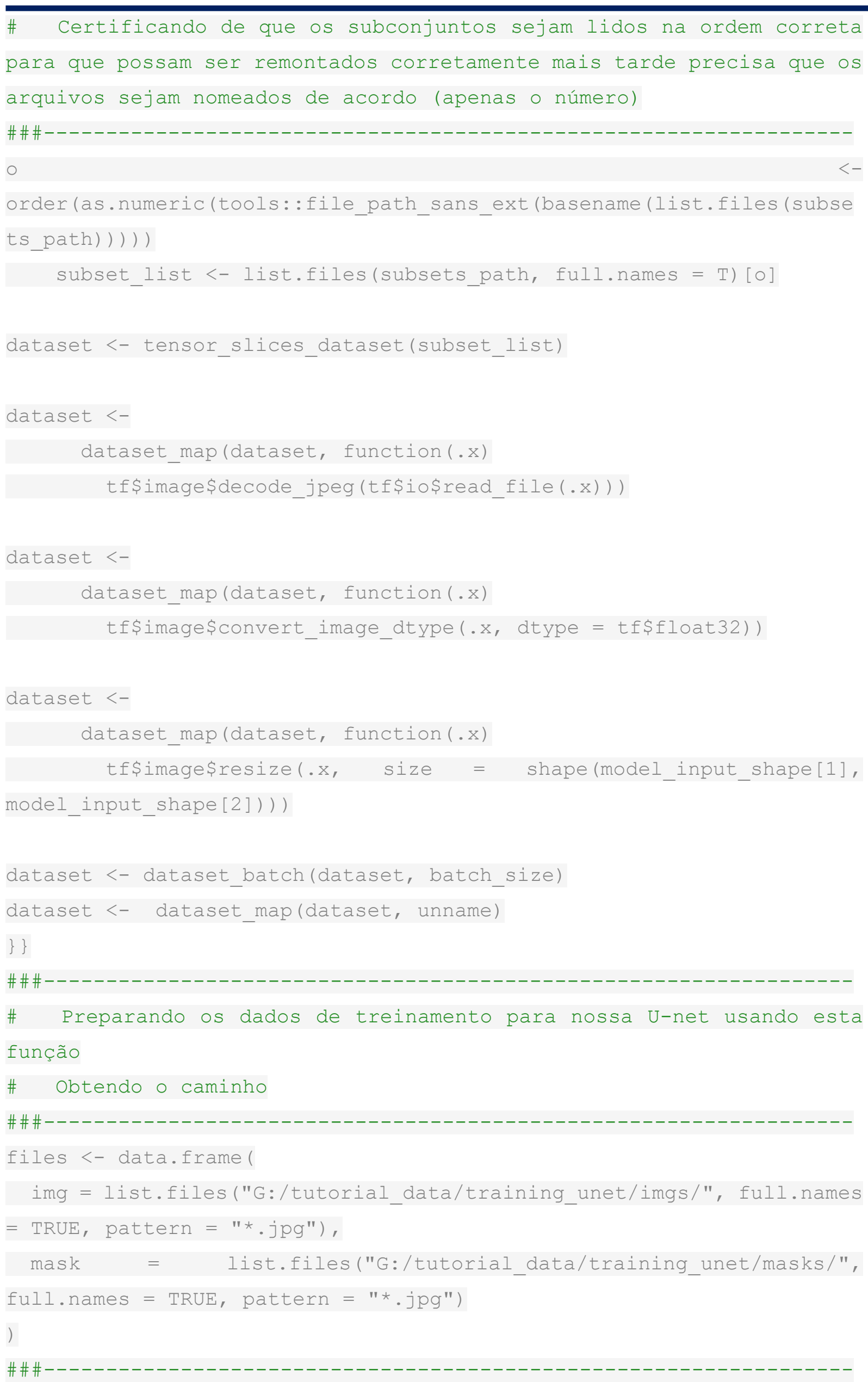




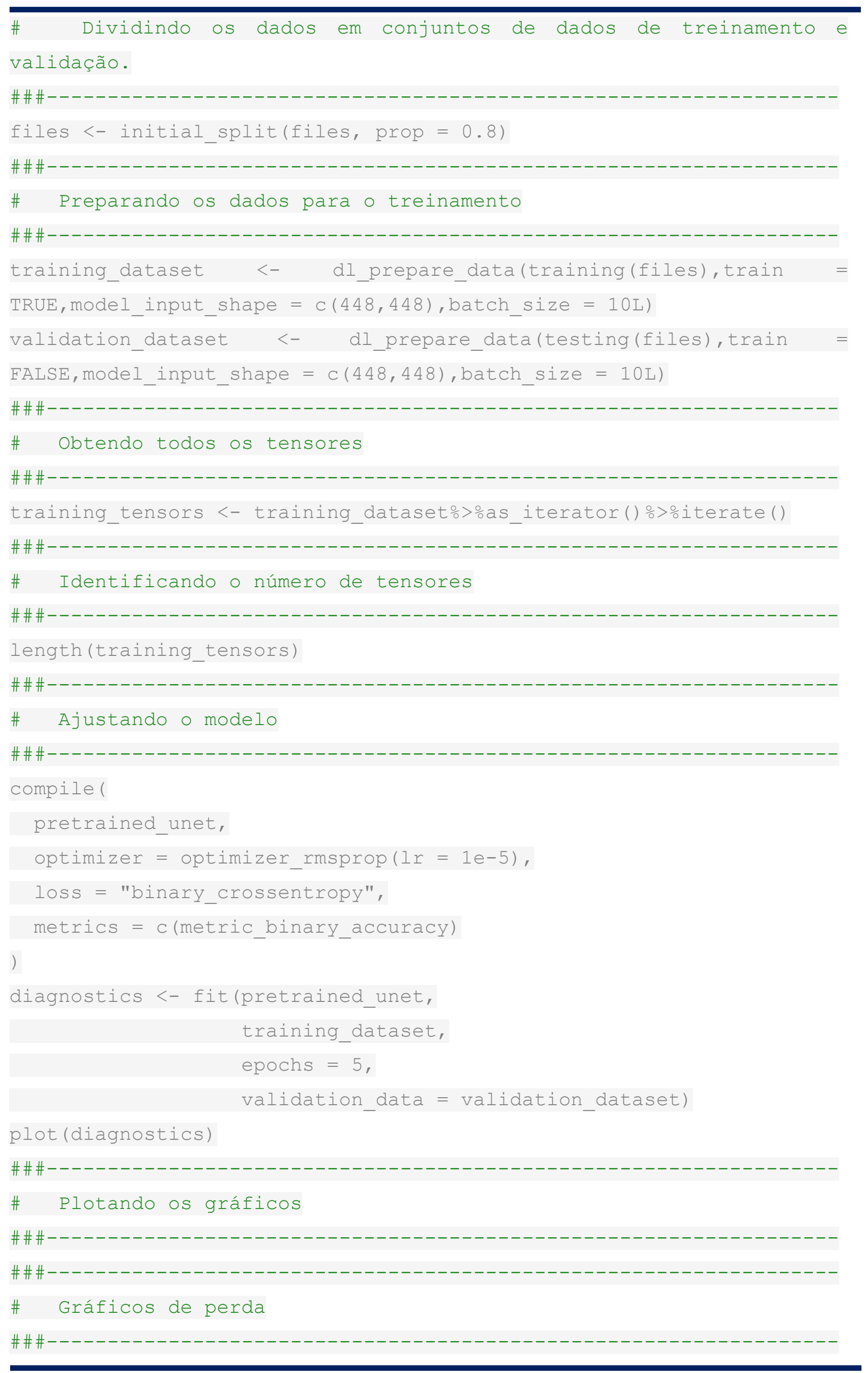


=diagnostics\$metrics\$val_loss, epocas = 1:5)

plot(df\$epocas, df\$loss, main="Modelo de Perda", family="serif", xlab="Perda", ylab="Época", cex.axis=0.8, cex.lab=1, cex.main=1, xlim $=c(1,5), y \lim =c(0.4,1))$

plot(df\$epocas, df\$val_loss, main="Modelo de Perda", family="serif", xlab="Perda", ylab="Época", cex.axis=0.8, cex.lab=1, cex.main=1, xlim $=\mathrm{c}(1,5), \mathrm{ylim}=\mathrm{c}(0.4,1))$

lines(df\$loss, col="blue", type="b", pch=19)

lines(df\$val_loss, col="green", type="b", pch=19)

legend("bottomright", c("treinamento","validação"), col=c("blue", "green"), 1 ty=c(1,1), bty $=$ "n", $c e x=0.8)$

\#\#\#-10

\#\#\#-

\# Gráficos de Acurácia

\#\#\#-1-10

$\mathrm{df1}$

data.frame (binary_accuracy

diagnostics\$metrics\$binary_accuracy,

val_binary_accuracy

=diagnostics\$metrics\$val_binary_accuracy, epocas = 1:5)

plot(df1\$epocas, df1\$binary_accuracy, main="Modelo de Acurácia", family="serif", $\quad$ xlab="Acurácia", ylab="Época", cex.axis=0.8, cex.lab=1, cex.main=1, xlim $=c(1,5), y l i m=c(0,1))$

plot(df1\$epocas, df1\$val_binary_accuracy, main="Modelo de Acurácia", family="serif", $\quad$ xlab="Acurácia", ylab="Época", $\quad$ cex.axis=0.8, cex.lab=1, cex.main=1, $x \lim =c(1,5), \operatorname{ylim}=c(0.4,1))$

lines(df1\$binary accuracy, col="blue", type="b", pch=19)

lines (df1\$val_binary_accuracy, col="green", type="b", pch=19)

legend("bottomright", c("treinamento","validação"), col=c("blue", "green"), 1 ty $=c(1,1)$, bty $=" n ", c e x=0.8)$

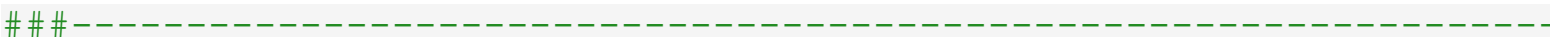

\# Carregando o U-net, que foi treinado

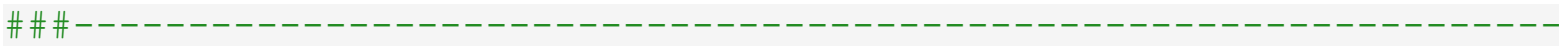

pretrained unet

load_model_hdf5 ("G:/tutorial_data/pretreino_unet.h5")

\#\#\# - 


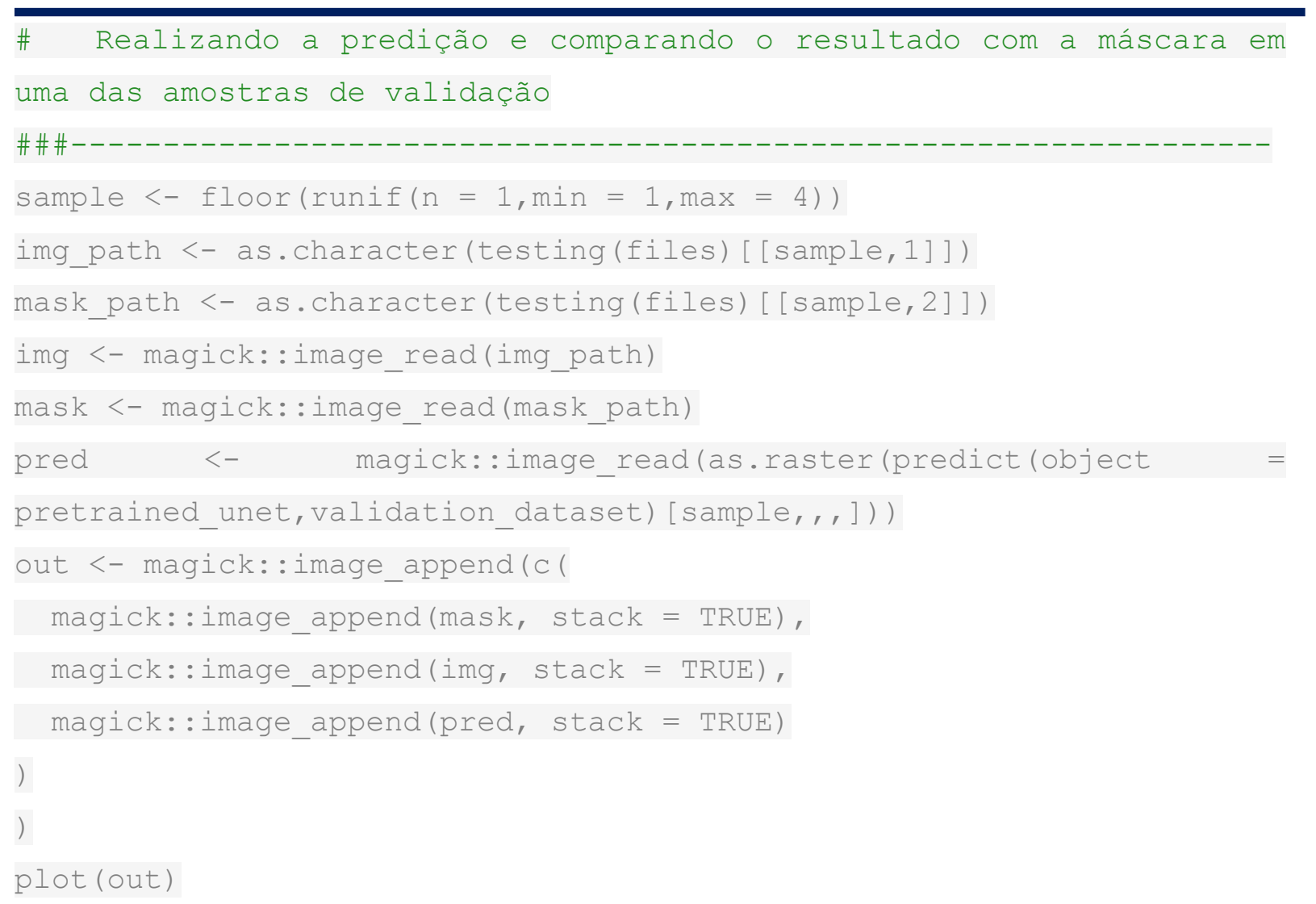

\section{APÊNDICE E - Script de classificação de pilhas de madeira (Cap. 04)}

O script a seguir foi utilizado para classificar os pixels, referentes a madeira, presentes nas imagens:

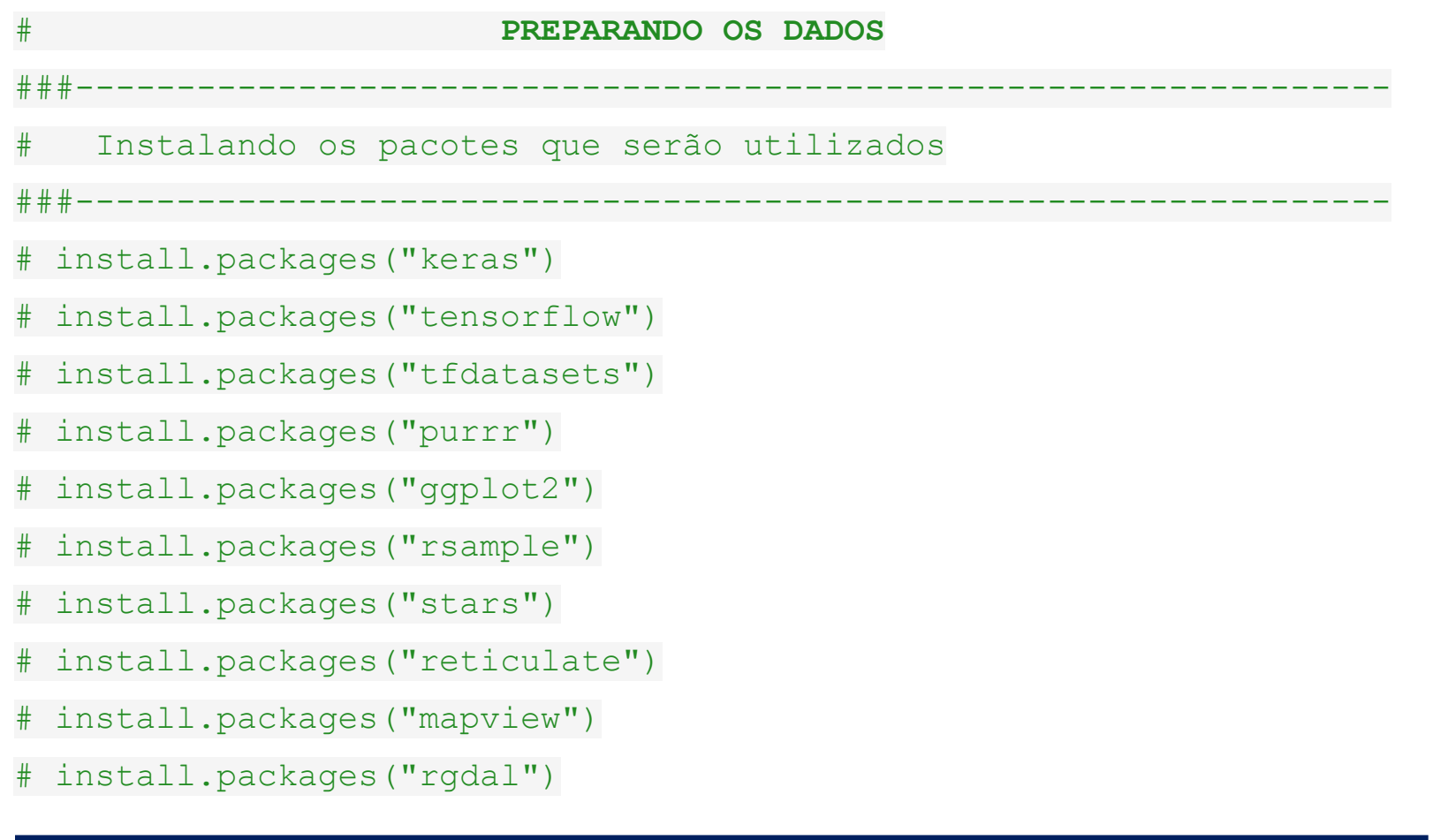




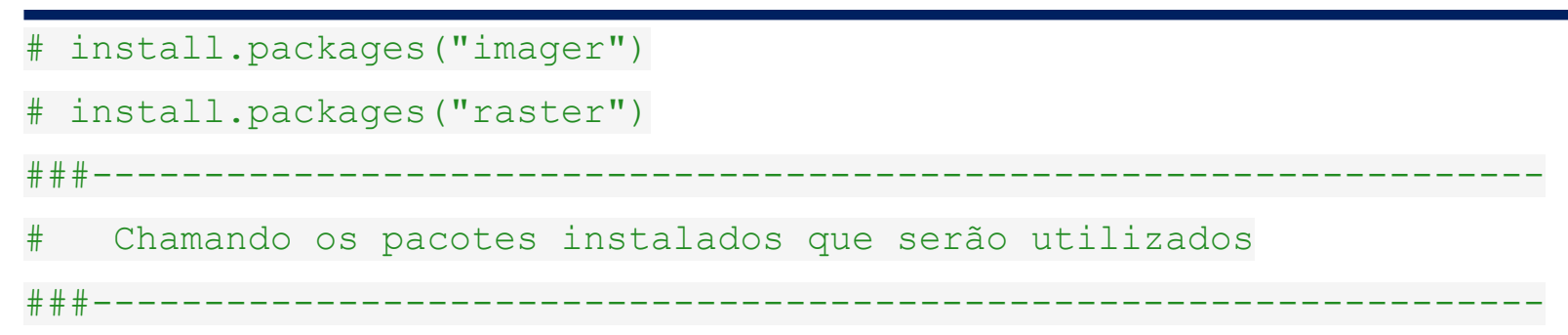

\section{library (keras)}

library (tensorflow)

library (tfdatasets)

library (purre)

library (ggplot2)

library (rsample)

library (stars)

library (reticulate)

library (mapview)

library (rgdal)

library (imager)

library (raster)

\#

\#

$\#$

\# Iniciando com um modelo vazio

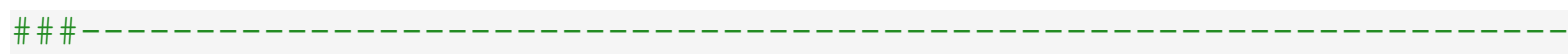
first_model <- keras_model_sequential()

\#\#\#----------------------------------------------------------------\# Adicionando a primeira camada, a entrada esperada é de 128 por 128 em três canais (estaremos lidando com imagens RGB)

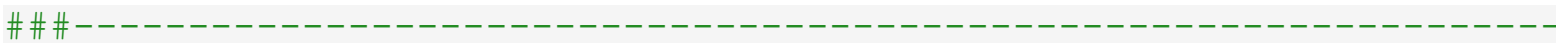
layer_conv_2d(first_model,filters $=32$, kernel_size $=3$, activation $=$ "relu", input_shape $=c(128,128,3))$

\#\#\#----------------------------------------------------------------\# Adicionando mais camadas ao modelo

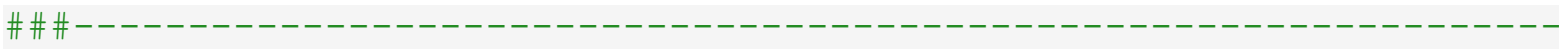
layer_max_pooling_2d(first_model, pool_size $=c(2,2)$ ) layer_conv_2d(first_model, filters $=64$, kernel_size $=\mathrm{c}(3,3)$, activation = "relu")

layer_max_pooling_2d(first_model, pool_size $=\mathrm{c}(2,2)$ ) layer_conv_2d(first_model, filters $=128$, kernel_size $=\mathrm{c}(3,3)$, activation = "relu")

layer_max_pooling_2d(first_model, pool_size $=\mathrm{c}(2,2)$ ) 


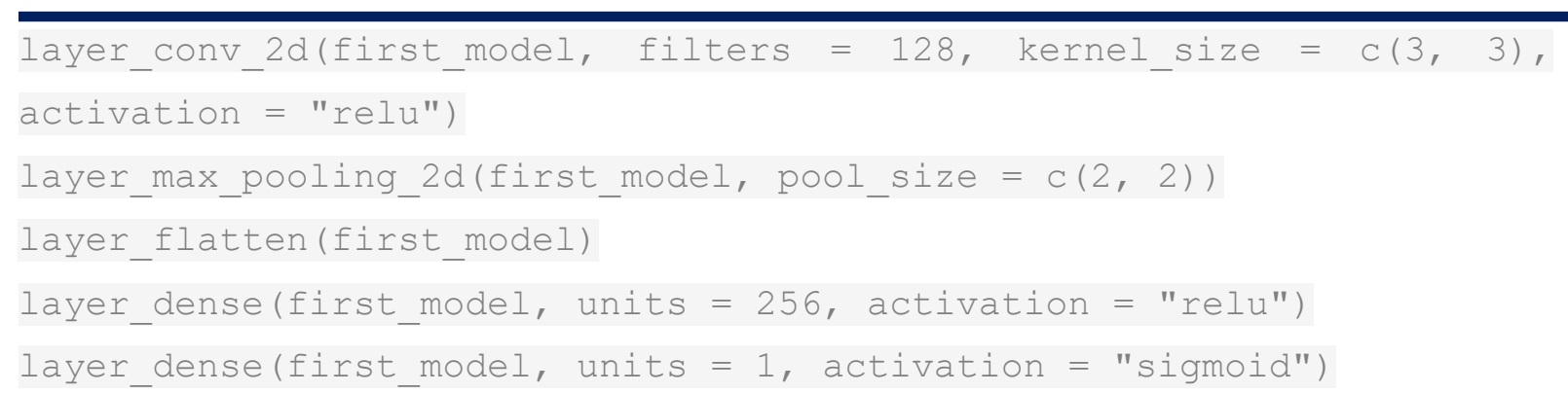

\section{PREPARANDO OS DADOS}

\#\#\#--

\# Obtenção dos arquivos de imagem que contêm os alvos a serem estudados

\#\#\#-----------------------------------------------------------------

subset_list <- list.files("G:/madeira/training_part1//true", full. names $=\mathrm{T}$ )

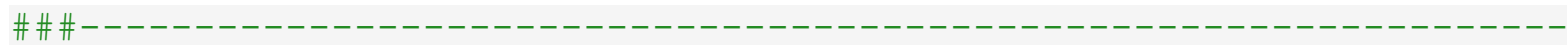

\# Criação de um data-frame com duas colunas: caminho de arquivos e rótulos

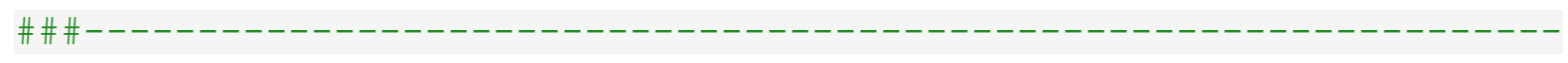

data_true $\quad<-$ data.frame (img=subset_list, lbl=rep (1L, length (subset_list)) )

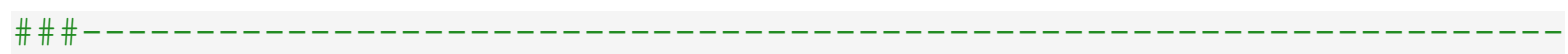
\# Obtenção dos caminhos de arquivos das imagens contendo os nãoalvos

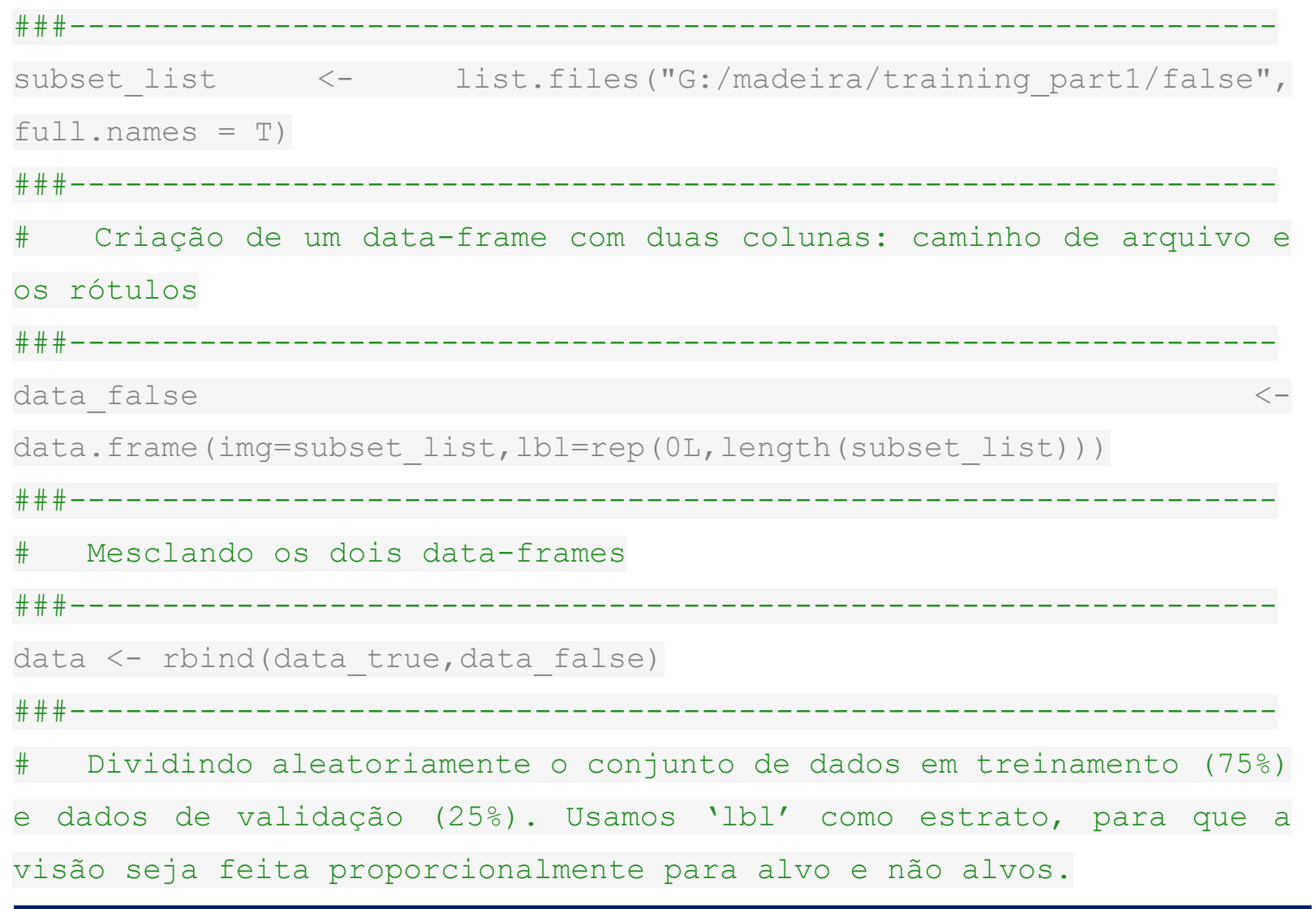




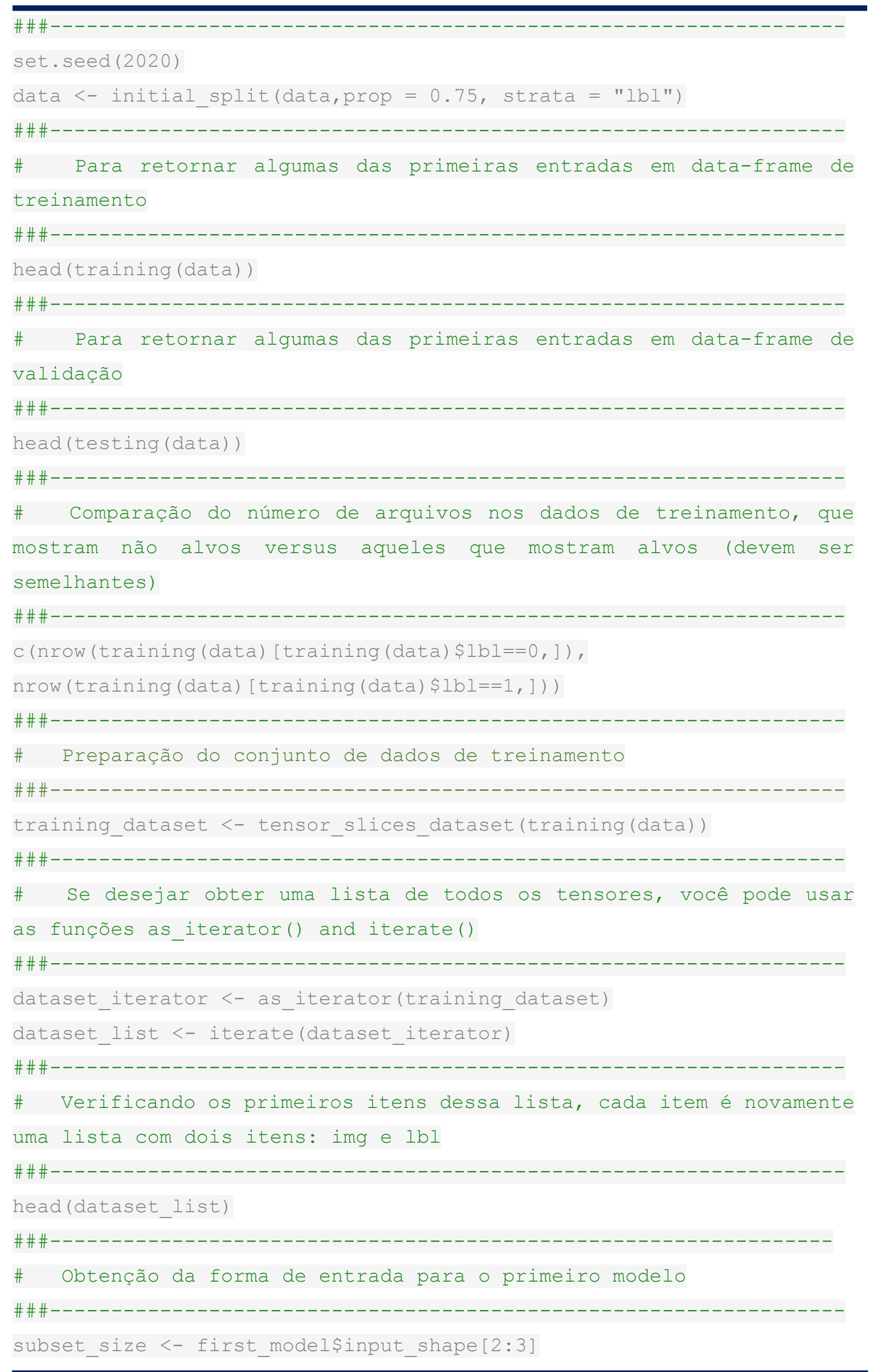




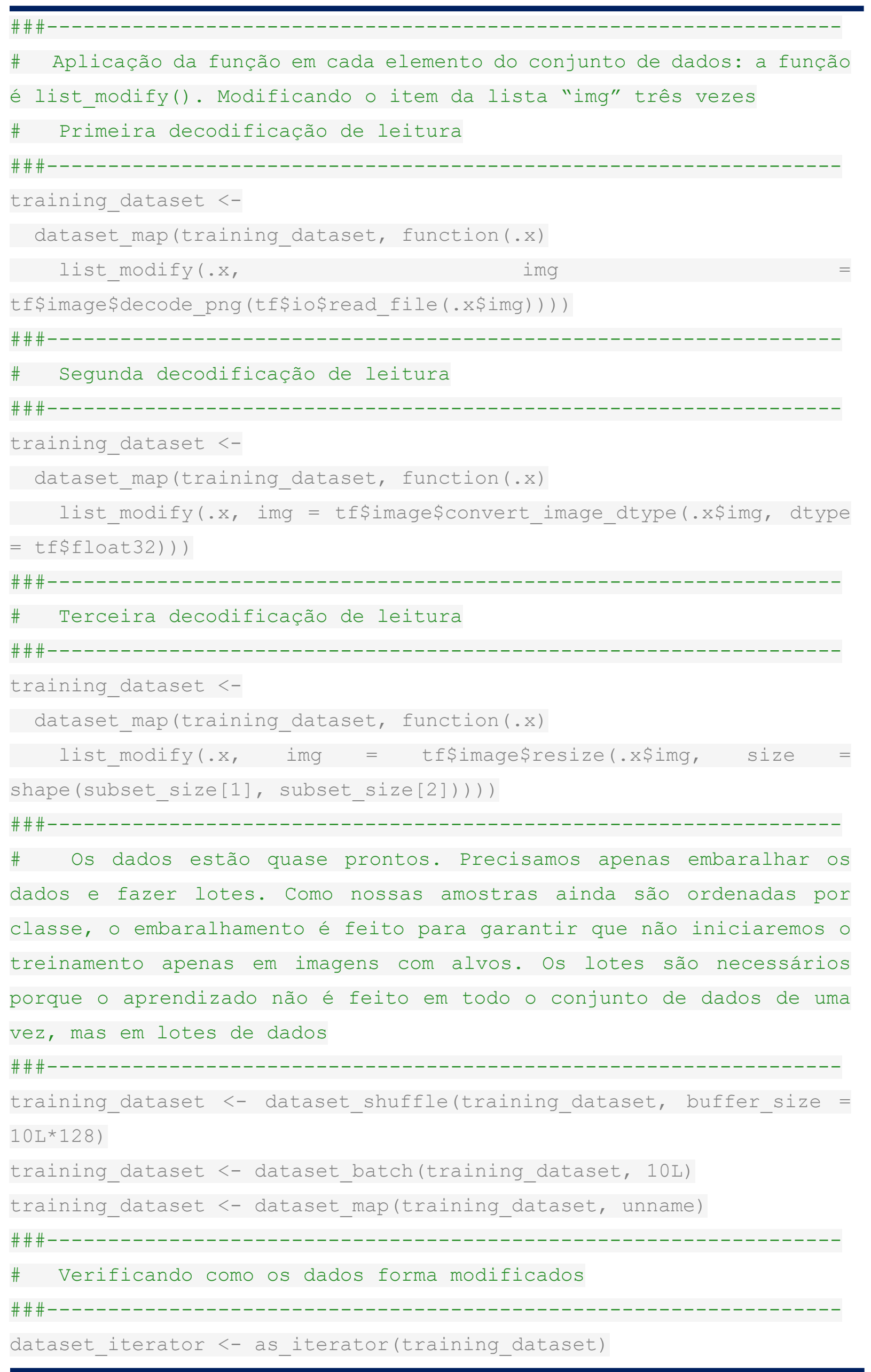




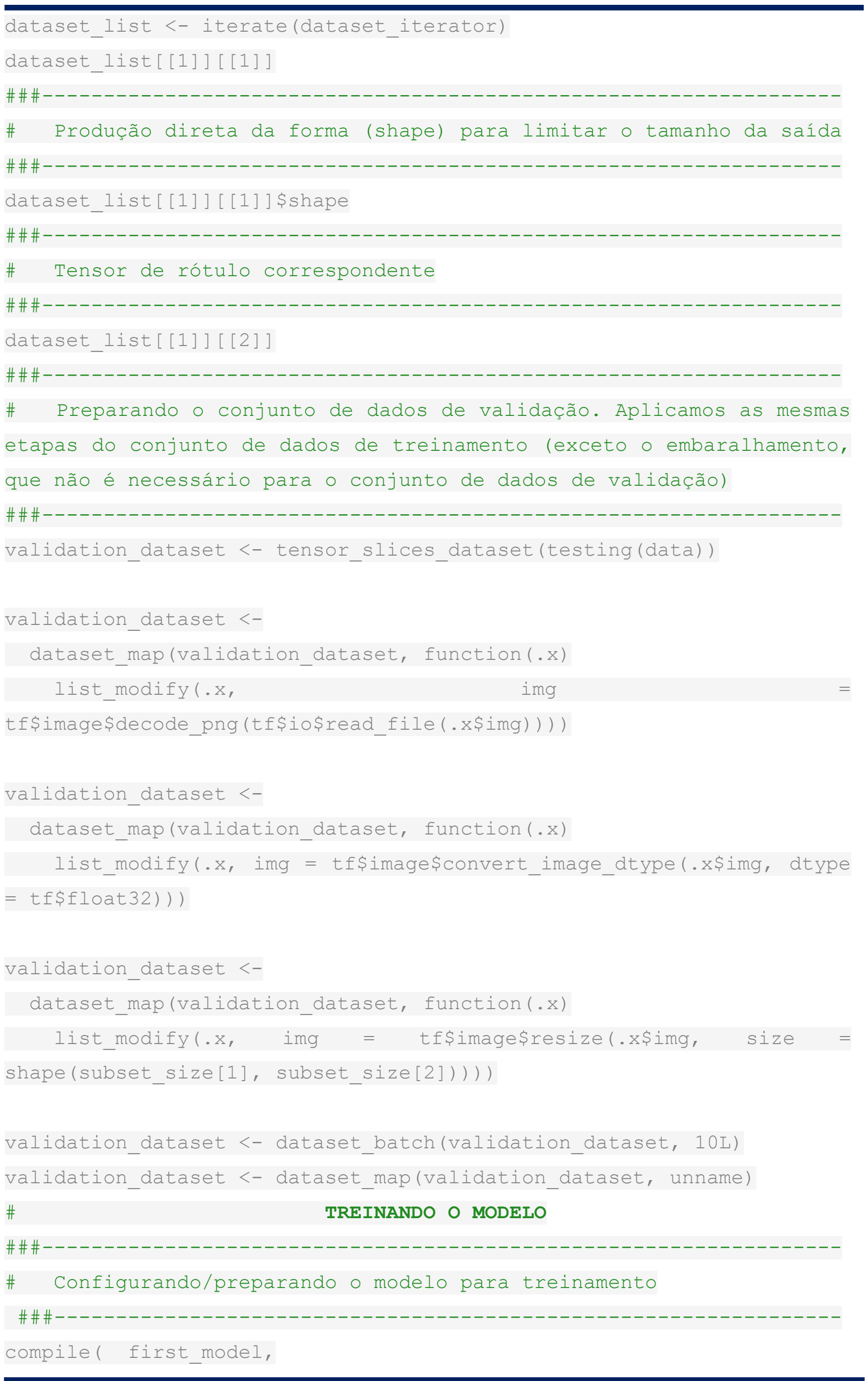




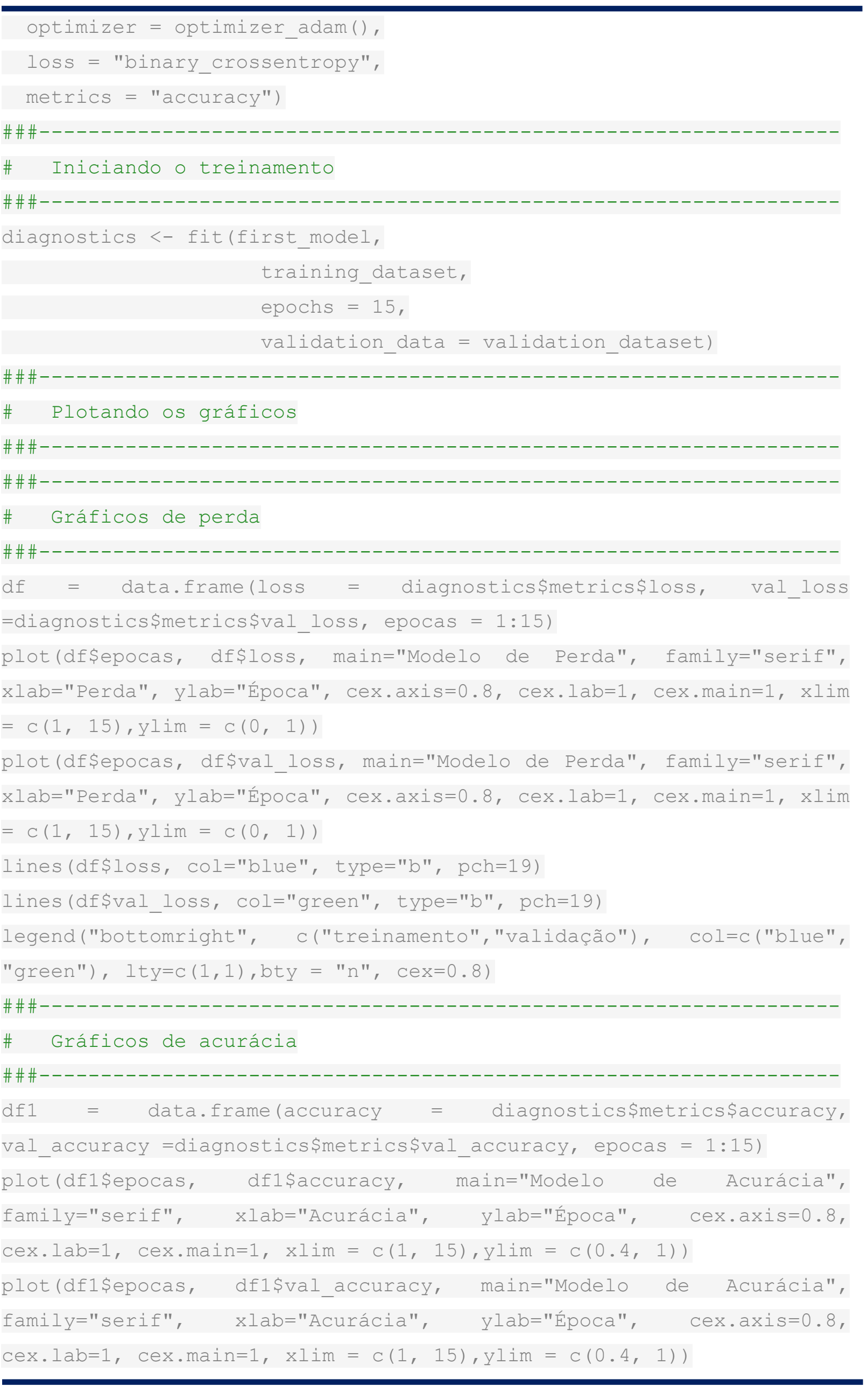




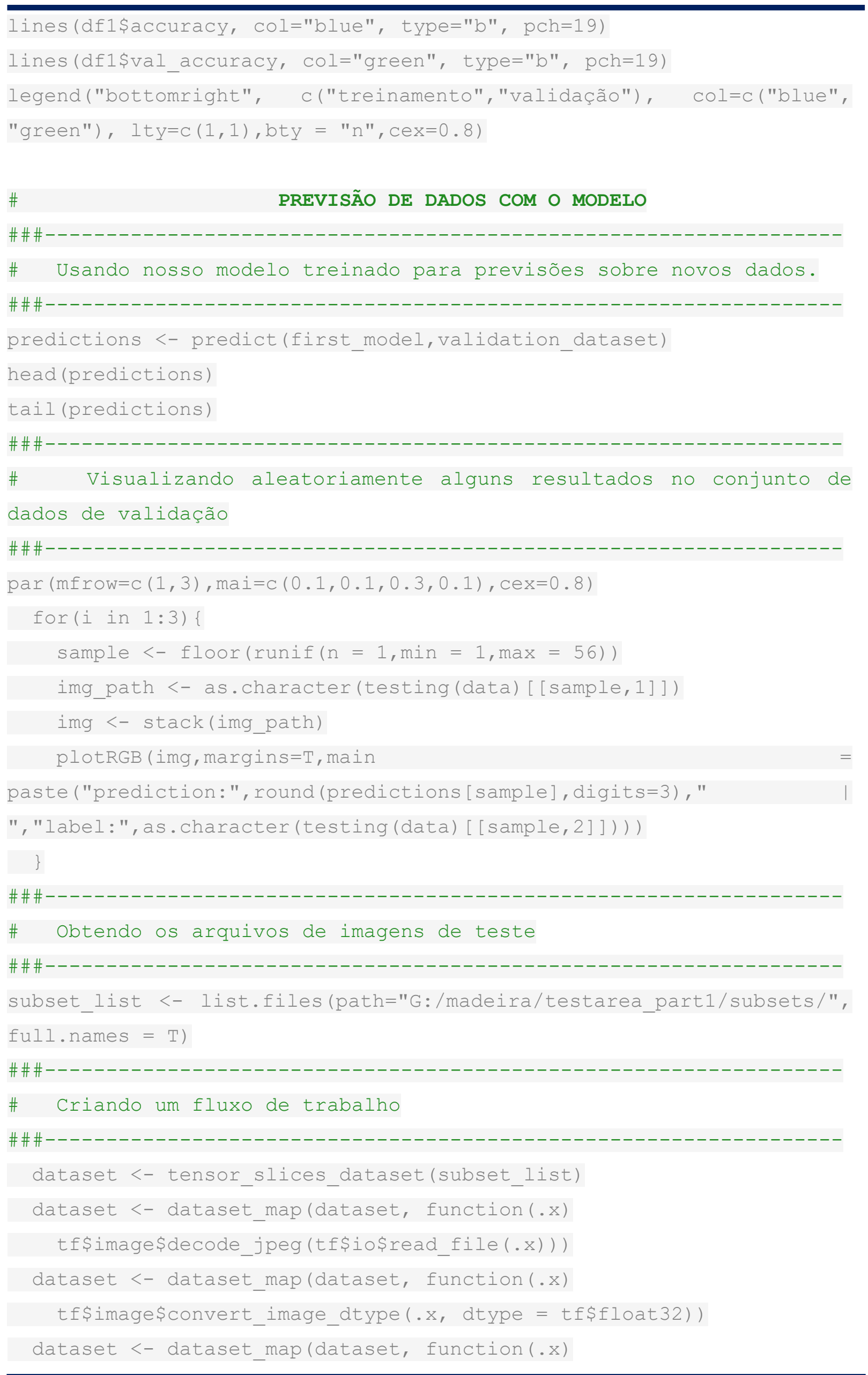




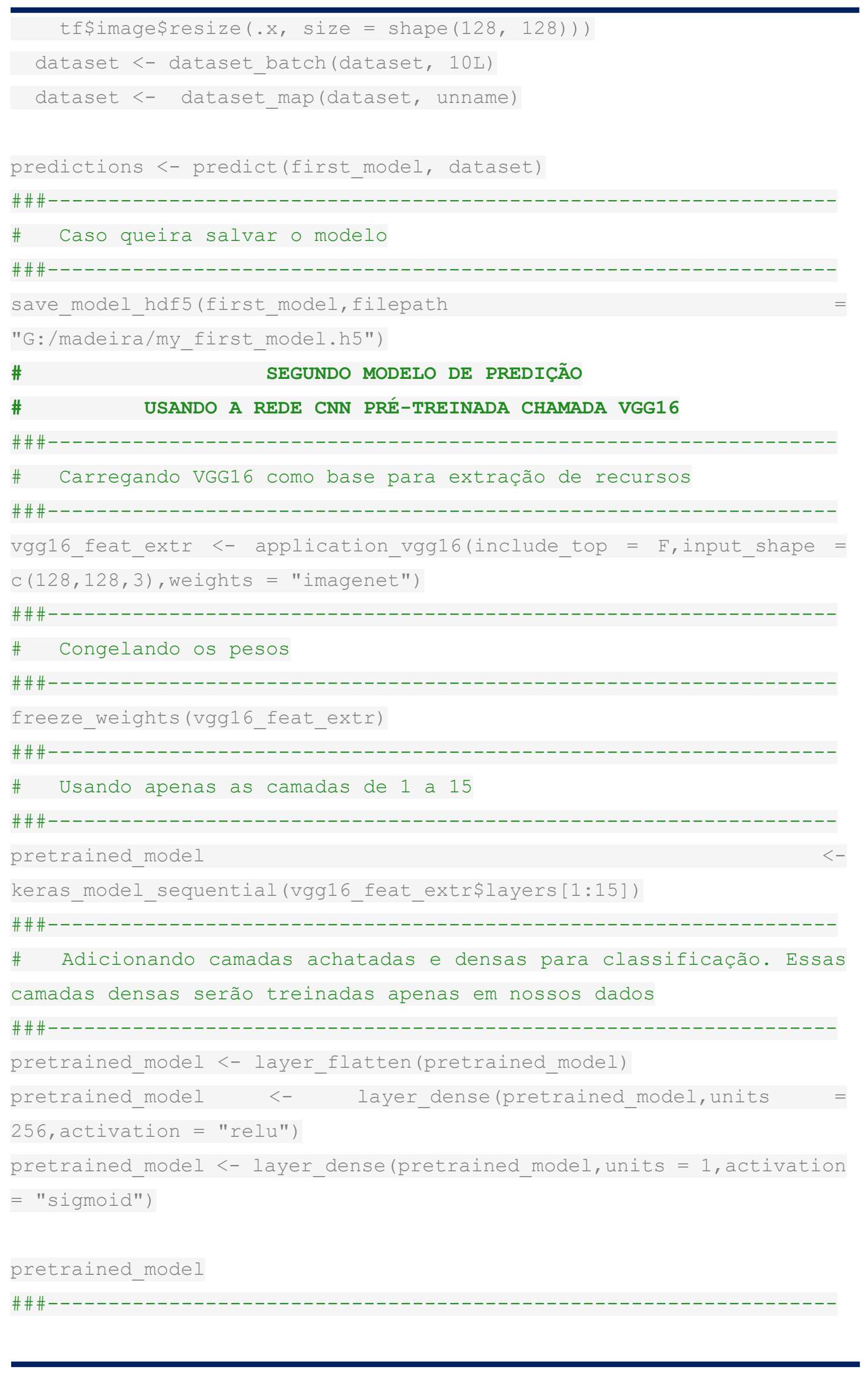


\# Este modelo é mais complexo, mas como vamos treinar apenas as camadas densas em nossos dados, não precisamos aprender todos os parâmetros do modelo. Vamos ver como funciona o treinamento congelando os parâmetros de parte do modelo

\#\#\#-

compile(

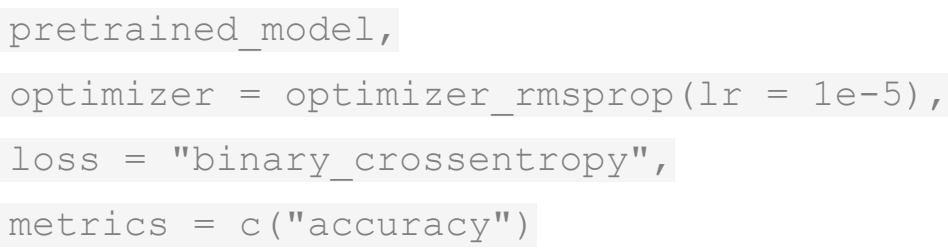

CLASSIFICAÇÃO DA IMAGEM DE PIXEL A PIXEL

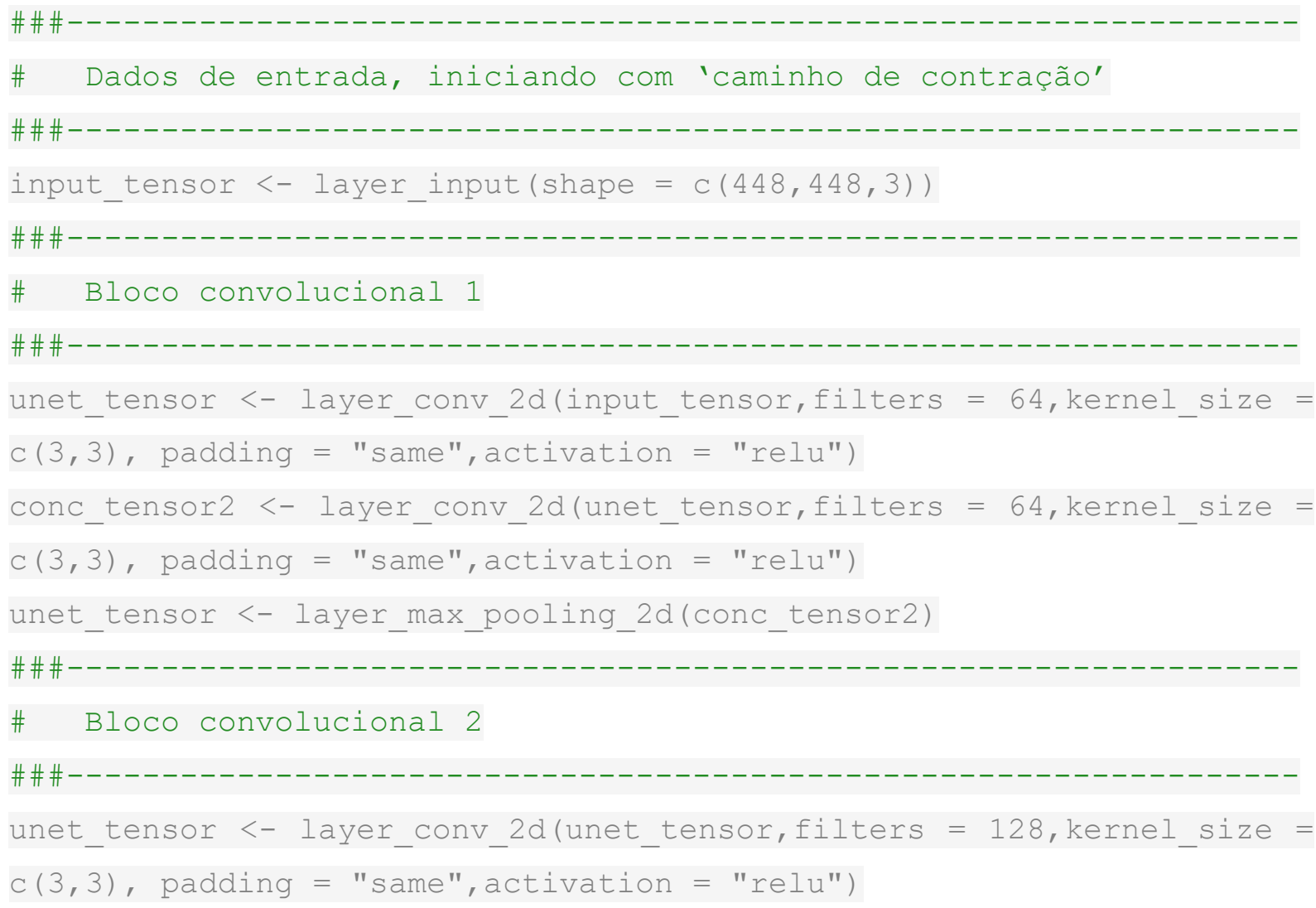




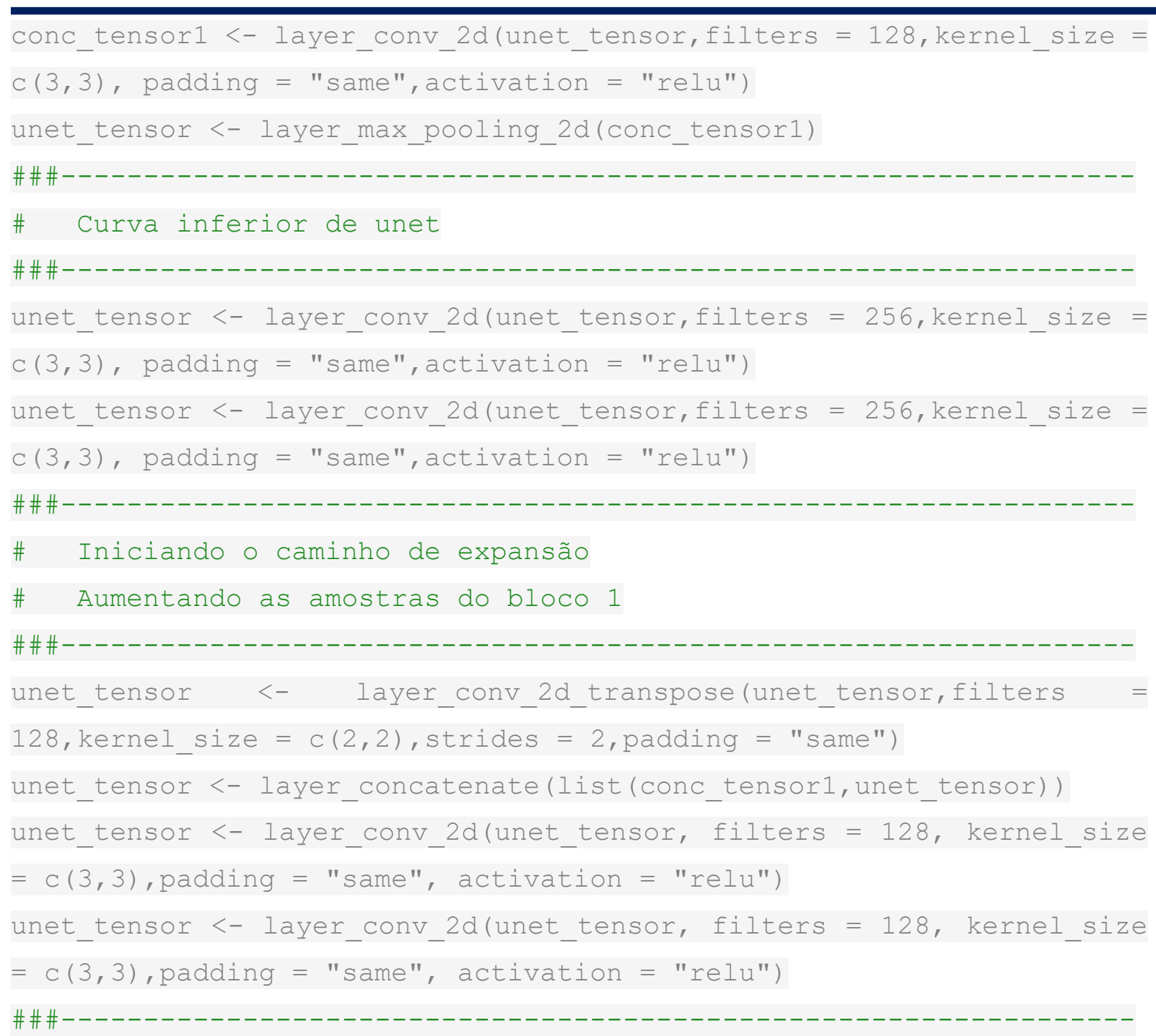

\# Aumentando as amostras do bloco 2

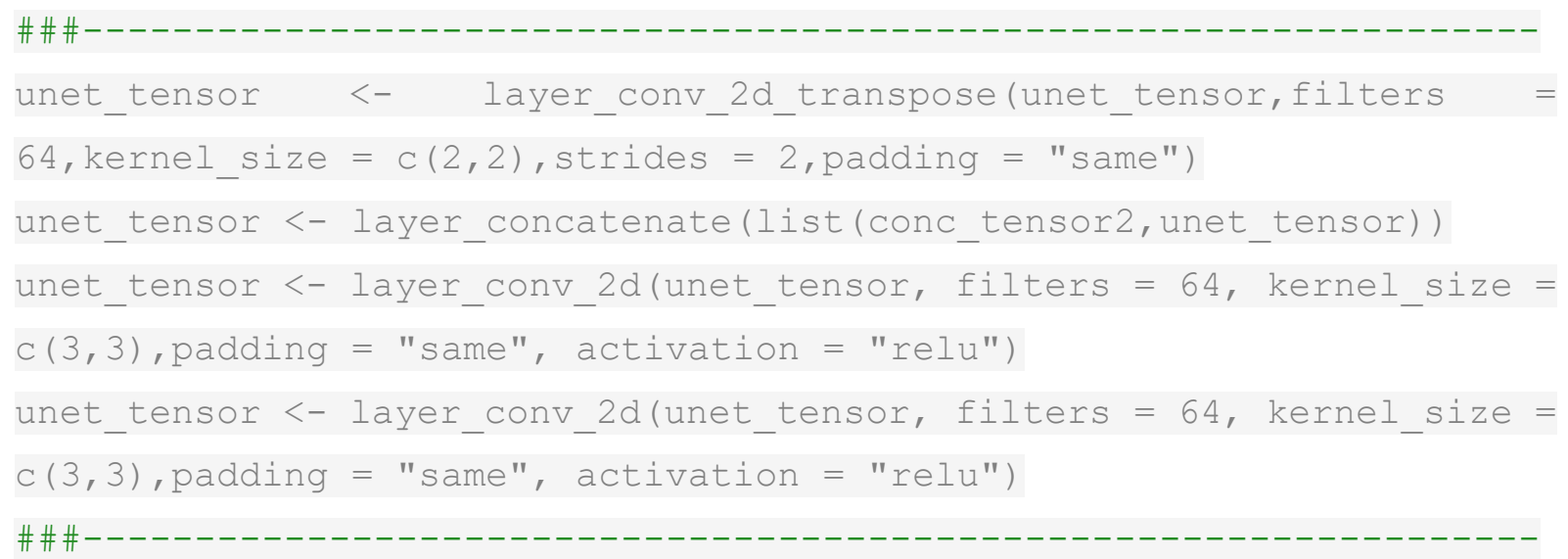

\# Resultados

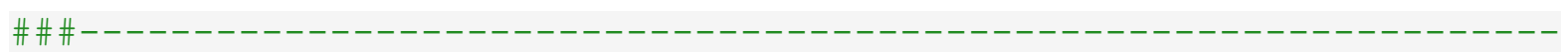

unet_tensor <- layer_conv_2d(unet_tensor,filters $=1$, kernel_size $=1$, activation = "sigmoid")

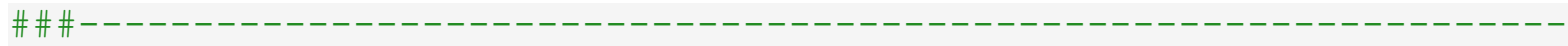

\# Combinando unet_tensor final (carregando todas as transformações através das camadas) com imput_tensor para criar o modelo 


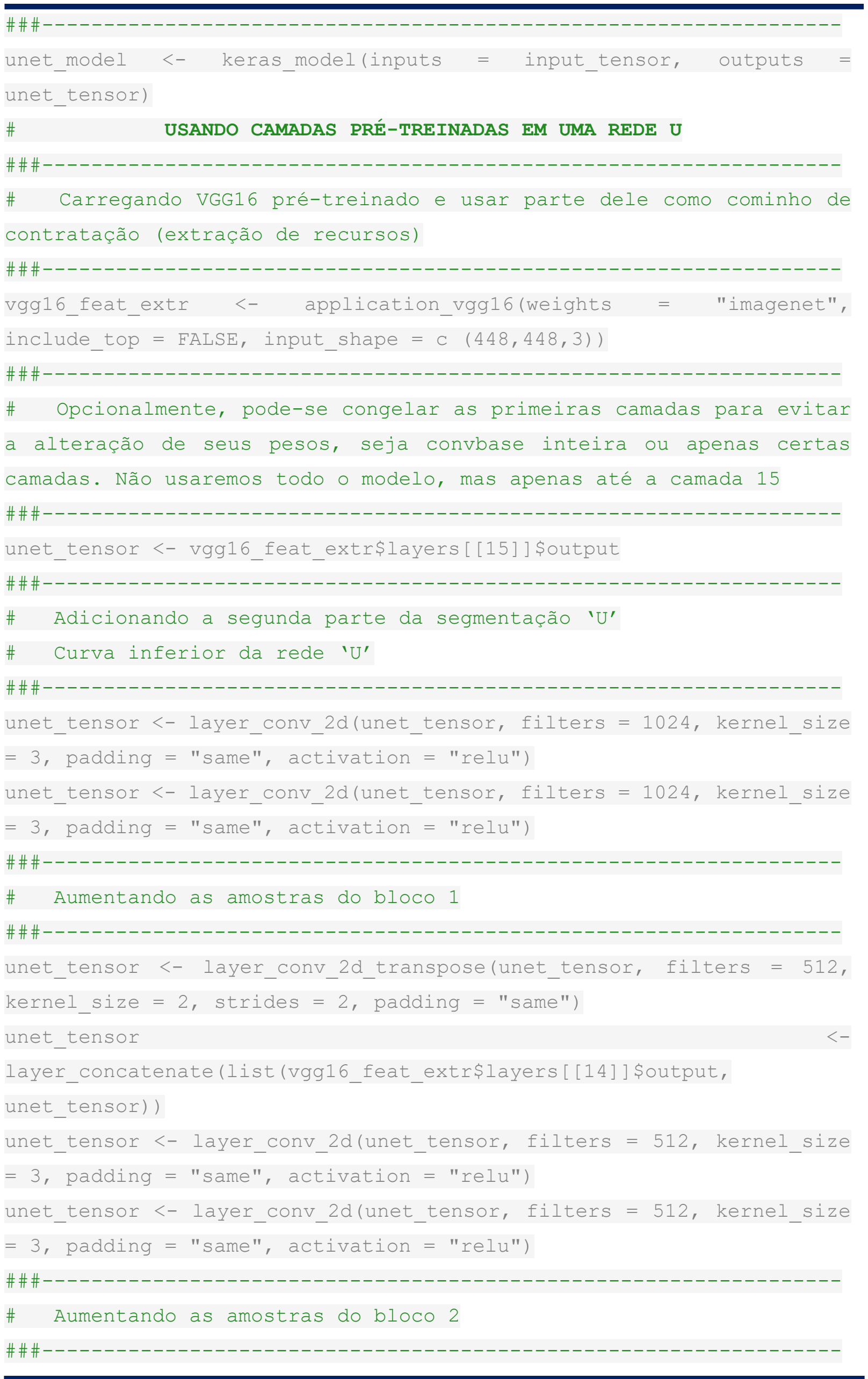




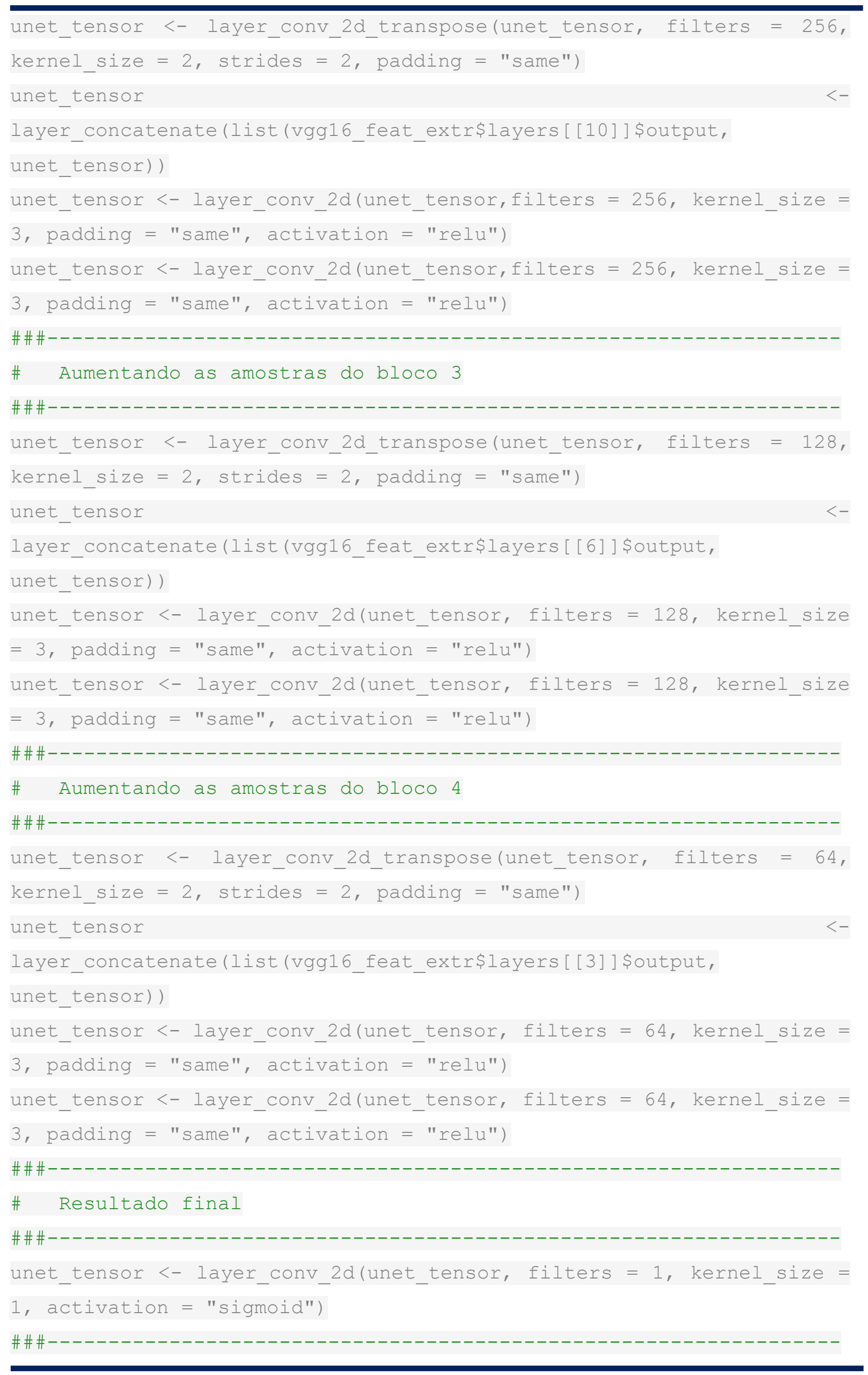



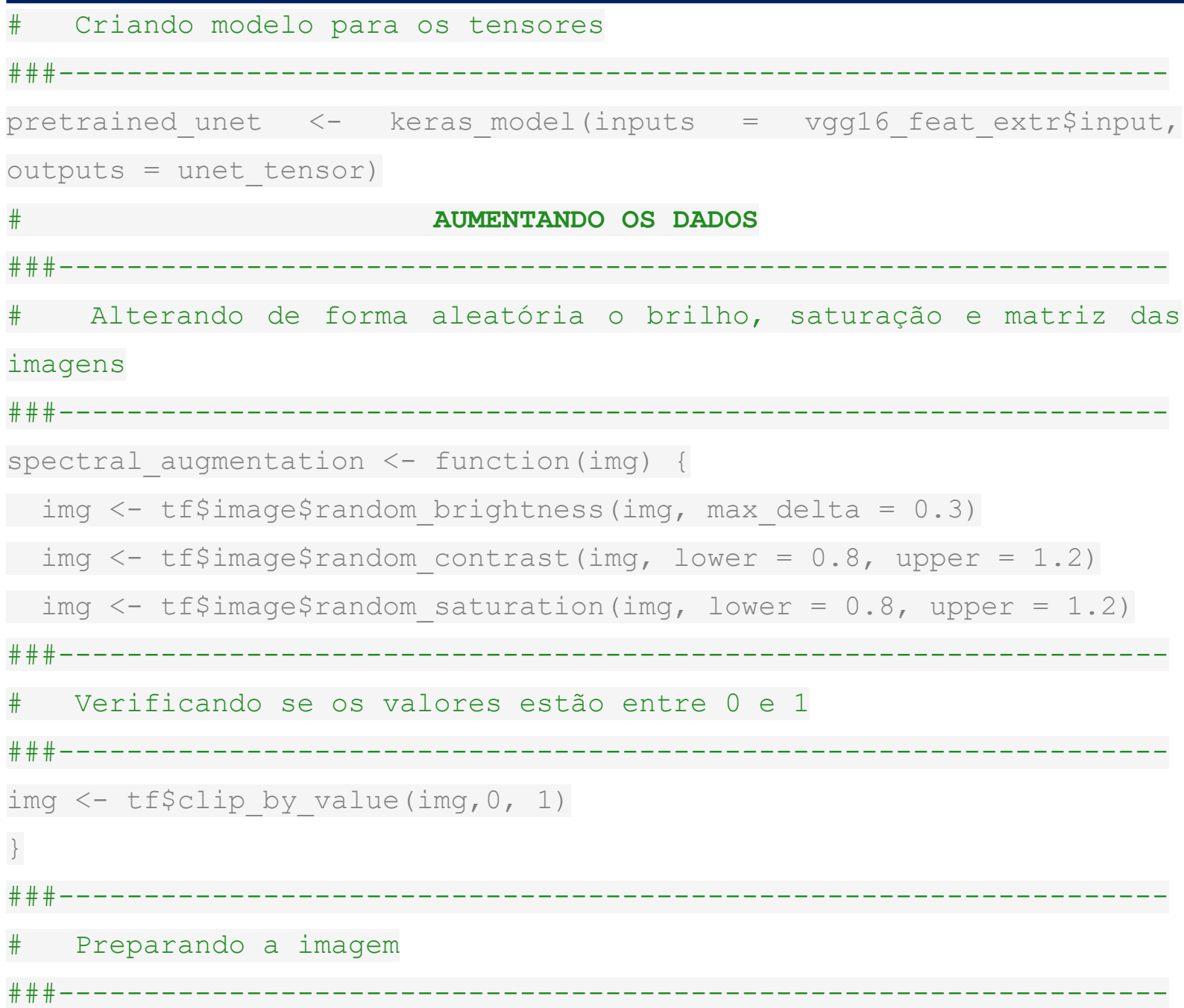


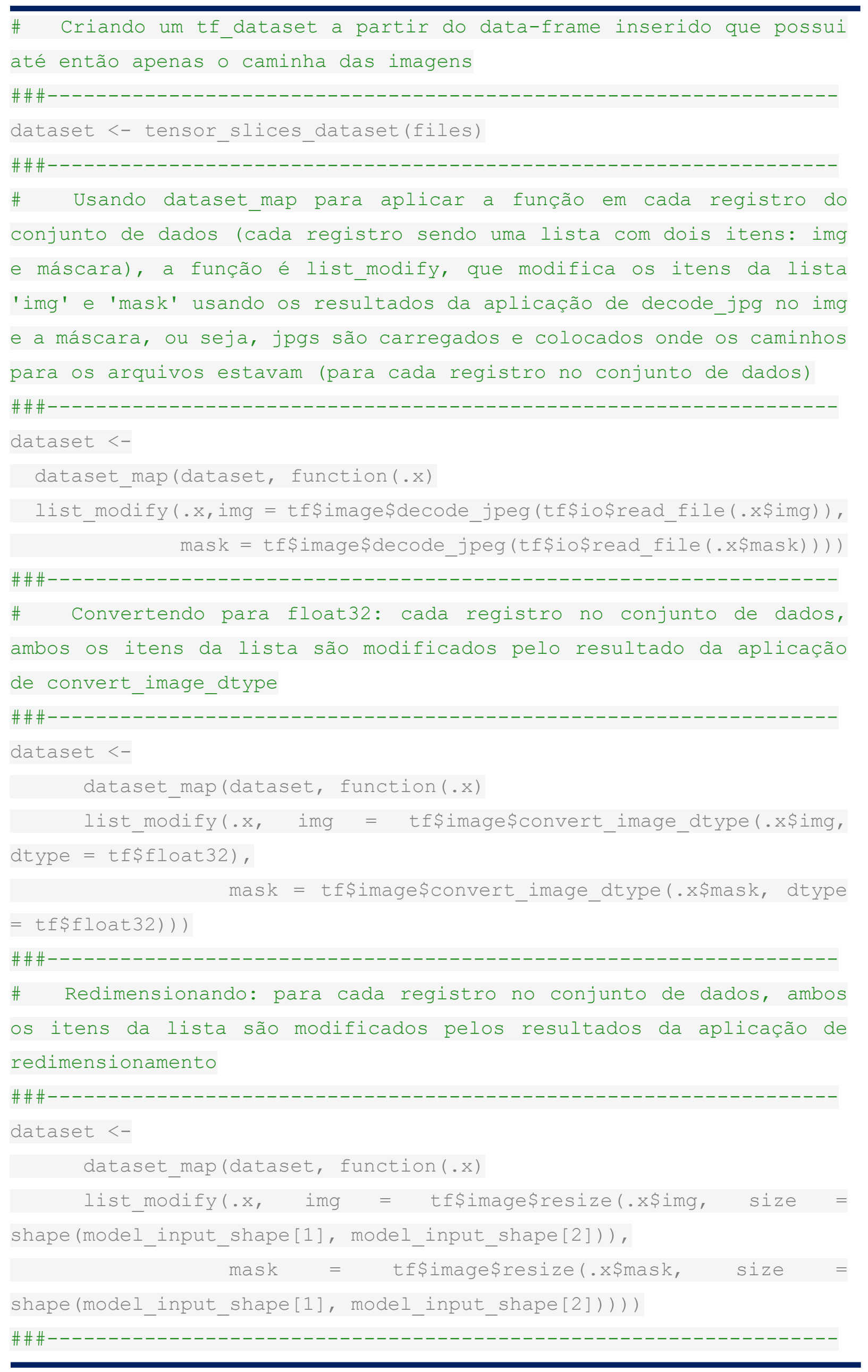




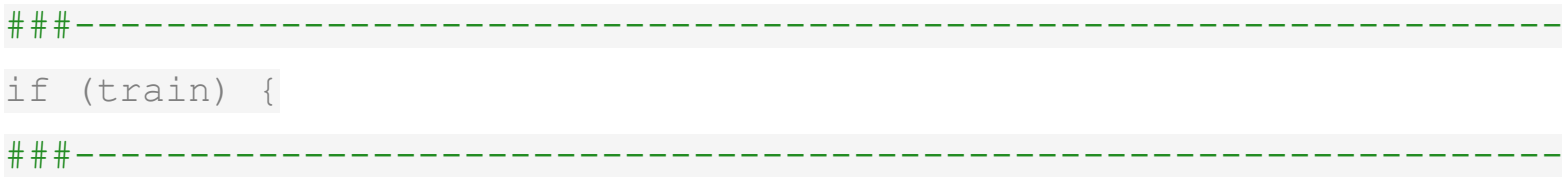

\# Augmentation 1: virando para a esquerda para a direita, incluindo mudança aleatória de saturação, brilho e contraste para cada registro no conjunto de dados, apenas o item img é modificado pelo resultado da aplicação de aumento_espectral

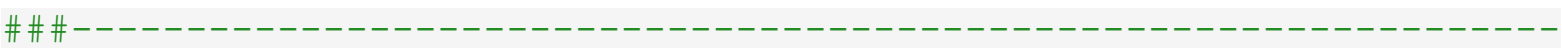

augmentation $<-$

dataset_map (dataset, function(.x)

list_modify(.x, img = spectral_augmentation(.x\$img)))

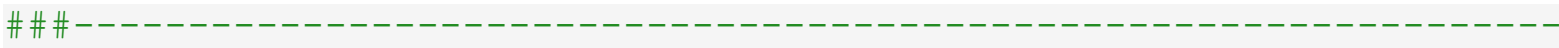

\# Aplicando a inversão ao img e à máscara de cada registro

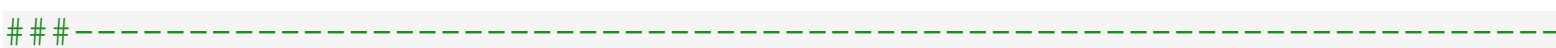

augmentation $<-$

dataset_map (augmentation, function(.x)

list_modify(.x, img = tf\$image\$flip_left_right(.x\$img), mask = tf\$image\$flip_left_right(.x\$mask)))

dataset_augmented <- dataset_concatenate(dataset, augmentation)

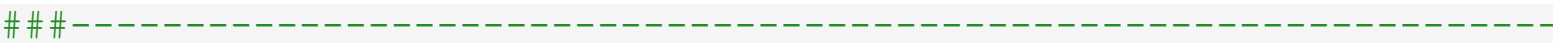

\# Augmentation 2: virando para cima e para baixo, incluindo mudança aleatória de saturação, brilho e contraste

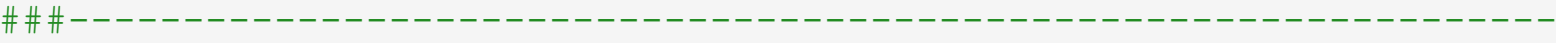

augmentation $<-$

dataset_map (dataset, function(.x)

list_modify(.x, img = spectral_augmentation(.x\$img)))

augmentation $<-$

dataset_map (augmentation, function(.x)

list_modify(.x, img = tf\$image\$flip_up_down(.x\$img), mask = tf\$image\$flip_up_down (.x\$mask)))

dataset_augmented

dataset_concatenate (dataset_augmented, augmentation)

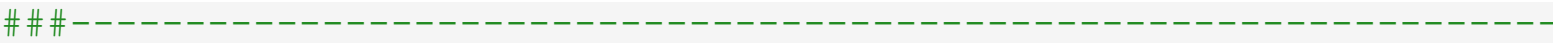

\# Augmentation 3: virando à esquerda e à direita, para cima e para baixo, incluindo mudança aleatória de saturação, brilho e contraste 


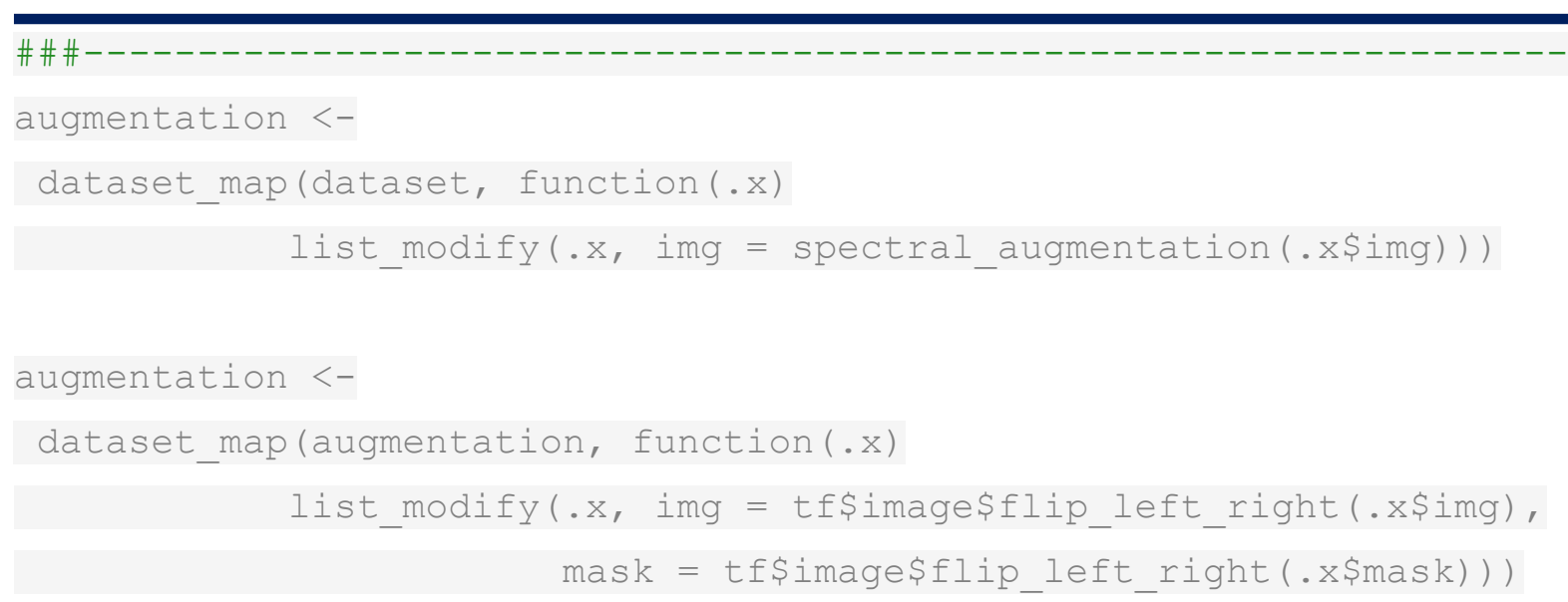




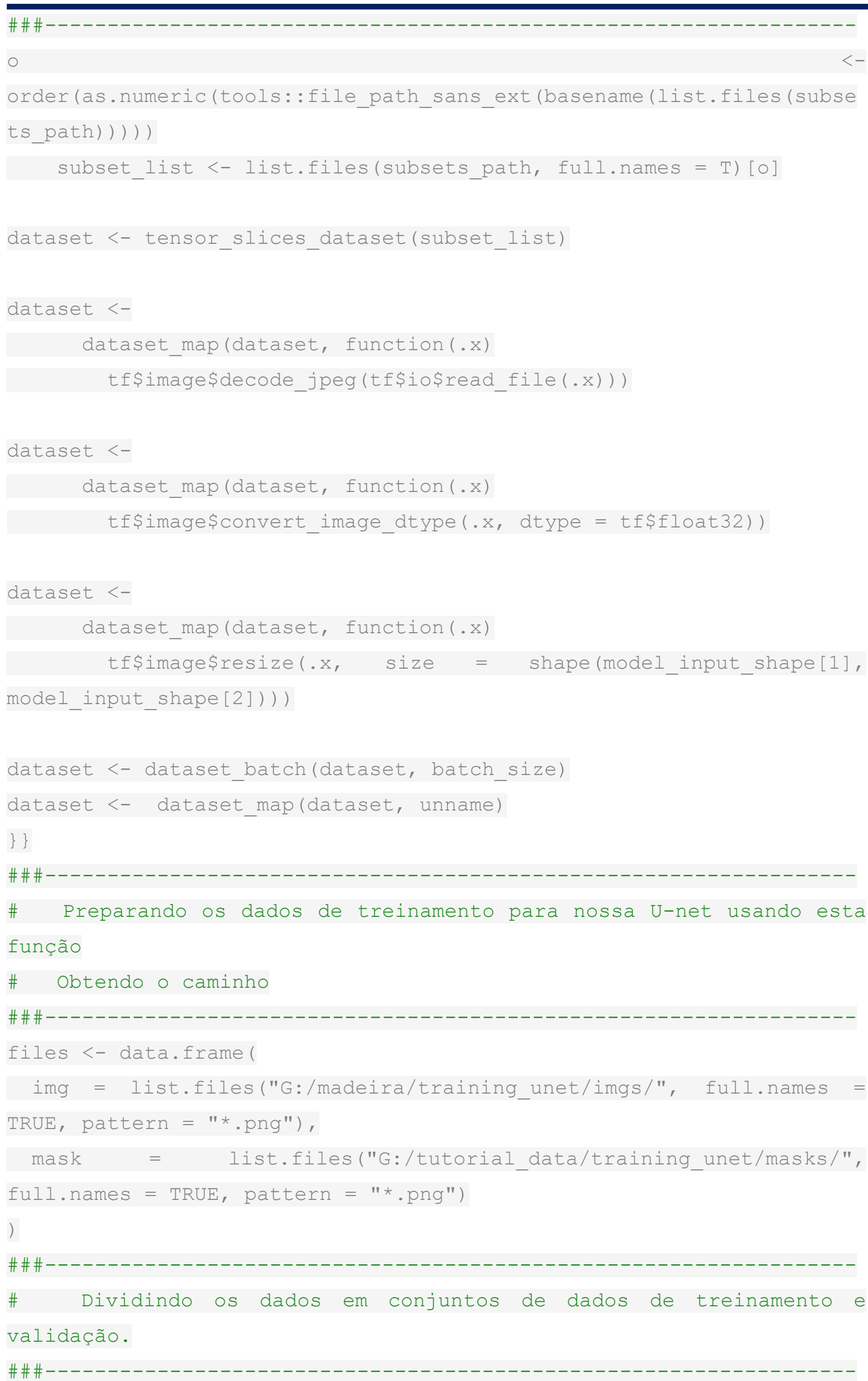




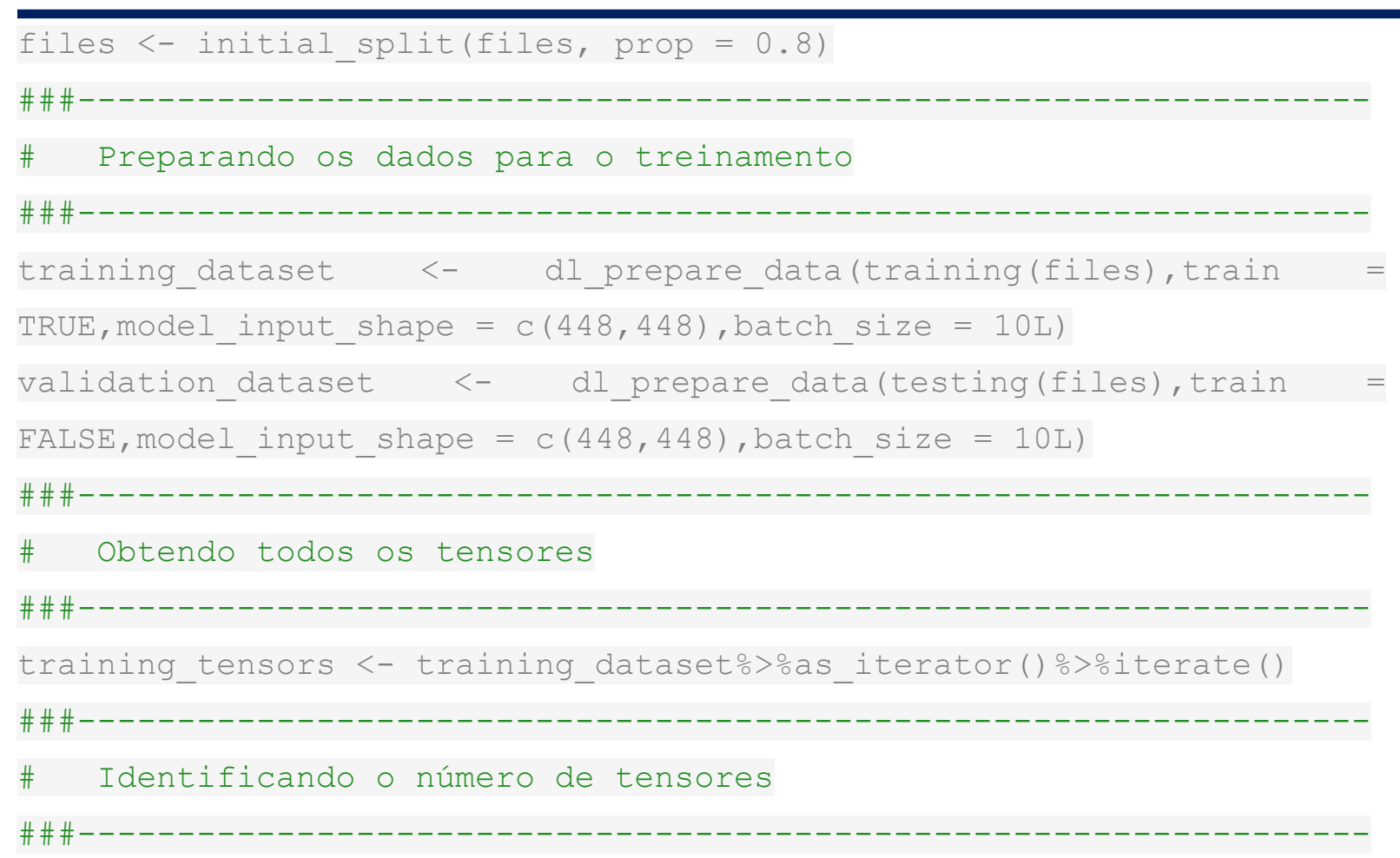

length (training_tensors)

\#\#\#-------------------------------------------------------------------

\# Ajustando o modelo

\#\#\#-----------------------------------------------------------------

compile(

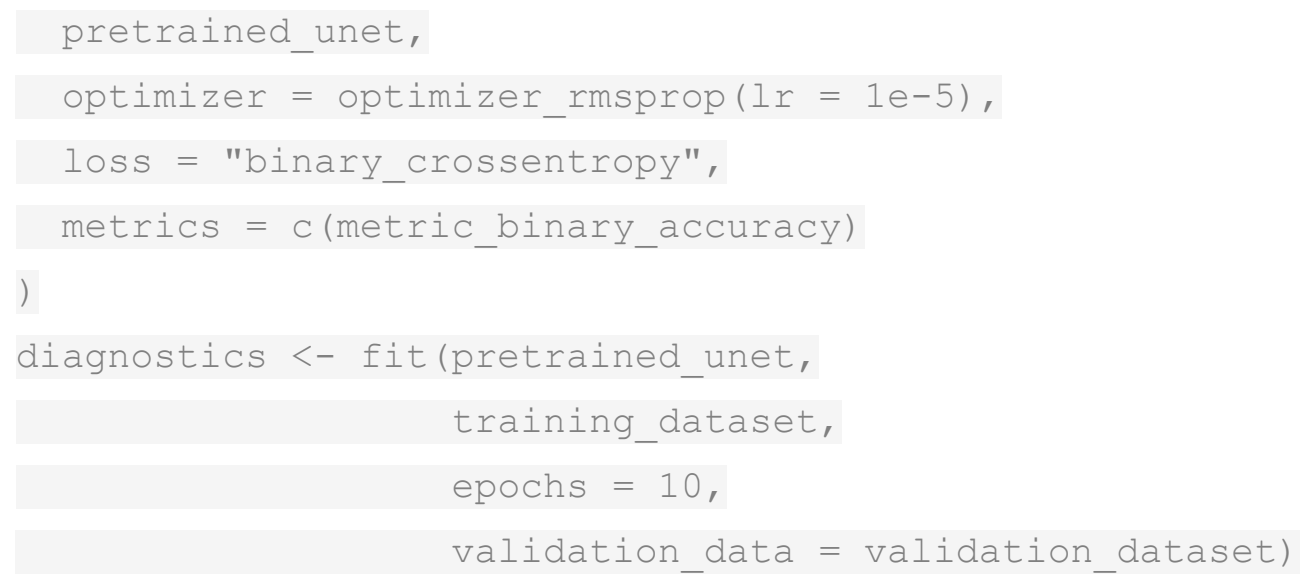


plot(df\$epocas, df\$loss, main="Modelo de Perda", family="serif", xlab="Perda", ylab="Época", cex.axis=0.8, cex.lab=1, cex.main=1, xlim $=\mathrm{c}(1,10), \mathrm{ylim}=\mathrm{C}(0,1))$

plot(df\$epocas, df\$val_loss, main="Modelo de Perda", family="serif", xlab="Perda", ylab="Época", cex.axis=0.8, cex.lab=1, cex.main=1, xlim $=\mathrm{c}(1,10), \mathrm{ylim}=\mathrm{c}(0,1))$

lines(df\$loss, col="blue", type="b", pch=19)

lines (df\$val_loss, col="green", type="b", pch=19)

legend("bottomright", c("treinamento","validação"), col=c("blue", "green"), $\left.1 t_{y}=c(1,1), b t y=" n ", c e x=0.8\right)$

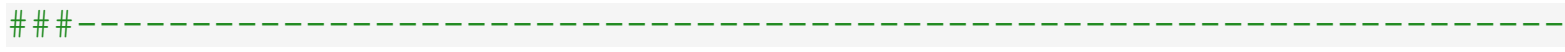
\# Gráficos de acurácia

$\mathrm{df} 1=$ data.frame (accuracy = diagnostics\$metrics\$accuracy, val_accuracy =diagnostics\$metrics\$val_accuracy, epocas = 1:10)

plot(df1\$epocas, dfl\$accuracy, main="Modelo de Acurácia", family="serif", xlab="Acurácia", ylab="Época", $\quad$ cex.axis=0.8, cex.lab=1, cex.main=1, xlim =c(1, 10), ylim $=c(0.4,1))$

plot(df1\$epocas, dfl\$val_accuracy, main="Modelo de Acurácia", family="serif", xlab="Acurácia", ylab="Época", cex.axis=0.8, cex.lab=1, cex.main=1, $x \lim =c(1,10), y l i m=c(0.4,1))$

lines(dfl\$accuracy, col="blue", type="b", pch=19)

lines(df1\$val_accuracy, col="green", type="b", pch=19)

legend("bottomright", c("treinamento","validação"), col=c("blue", "green"), 1 ty $=c(1,1), b t y=" n ", c e x=0.8)$

\# realizando a predição e comparando o resultado com a máscara em

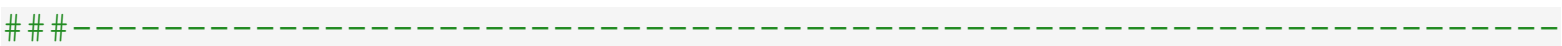

sample $<-$ floor (runif $(\mathrm{n}=1$, $\min =1$, $\max =4)$ )

img_path <- as.character(testing(files) [ [sample,1]])

mask_path <- as.character(testing(files) [ [sample,2] ])

img <- magick: :image_read(img_path)

mask <- magick: :image_read(mask_path)

pred $\quad<-\quad$ magick: :image_read(as.raster(predict(object

pretrained_unet, validation_dataset) [sample, , ] ))

out <- magick: :image_append(c) (

magick::image_append(mask, stack = TRUE),

magick: :image_append(img, stack = TRUE), 
magick: : image_append (pred, stack = TRUE)

plot (out) 
Inteligência artificial (IA) está relacionado à capacidade de máquinas realizarem atividades de um modo considerado inteligente. IAs também podem "aprender por si mesmas" graças a sistemas de aprendizado que analisam grandes volumes de dados, possibilitando a elas ampliarem seus conhecimentos. O modo como um computador representa um problema, as variáveis que ele usa e os operadores aplicados a essas variáveis podem fazer a diferença entre um algoritmo eficiente e um algoritmo que não funciona. Desta forma, uma técnica de IA deve representar eficientemente 0 conhecimento, ser concisa, facilmente armazenável e recuperável, legível pelo especialista e passível de representação de restrições, de forma a facilitar o trabalho de inferência. Neste livro apresentamos algumas técnicas de IA e aplicações no campo das Ciências Florestais e da Agricultura. 